ORNL/TM-2002/55

\title{
An Assessment of Future Demands for and Benefits of Public Transit Services in Tennessee
}

\section{March 2002}

\section{Prepared by}

Frank Southworth

David P. Vogt

T. Randall Curlee

Center for Transportation Analysis

Oak Ridge National Laboratory

P.O. Box 2008

Oak Ridge, TN 37831

Managed By UT-Battelle, Llc

For The U. S. Department Of Energy

Under Contract No. DE-AC05-00OR-22725

and

Arun Chatterjee

Frederick J. Wegmann

Civil and Environmental Engineering Department

The University of Tennessee

Knoxville, TN 37996-2010

Prepared for

Office of Public Transportation

Tennessee Department of Transportation

Nashville, TN 37243 


\section{Contents}

Executive Summary vi

1. Introduction $\quad 1.1$

1.1 Study Purpose $\quad 1.1$

1.2 Report Organization and Content $\quad 1.2$

$\begin{array}{ll}1.3 \text { Glossary of Terms Used } & 1.3\end{array}$

2. Transit Benefits Analysis Process $\quad 2.1$

2.1 Introduction $\quad 2.1$

2.2 Literature Review $\quad 2.2$

2.3 The Benefits Framework $\quad 2.4$

2.4 Mobility-Based Accessibility Impacts From Transit Use 2.5

$\begin{array}{ll}2.4 .1 \text { Benefits Categories Analyzed } & 2.5\end{array}$

2.4.2 Transit User Trip Benefits $\quad 2.7$

$\begin{array}{ll}\text { 2.4.3 Non-Transit User Trip Benefits } & 2.20\end{array}$

2.5 Environmental Impacts From Transit Use $\quad 2.21$

2.6 Safety and Security Impacts From Transit Use 2.28

2.7 Economic Benefits of Transit Supply 2.32

2.7.1 Economic Benefits From Transit System Expenditures $\quad 2.34$

2.7.2 Transit System Impacts on Economic Growth 2.36

$\begin{array}{ll}2.8 \text { Societal and Community Benefits } & 2.38\end{array}$

$\begin{array}{ll}\text { 2.9 Summary of Benefits Estimated } & 2.38\end{array}$

3. Transit Ridership Forecasting Models $\quad 3.1$

3.1 Introduction $\quad 3.1$

3.2 Forecasting Urban Transit Ridership $\quad 3.2$

3.2.1 Introduction $\quad 3.2$

3.2.2 Fixed Route Transit Service Models $\quad 3.2$

3.2.3 Demand-Responsive Service Model $\quad 3.7$

3.2.4 Small Urban Tourist-Oriented Transit Model 3.8

$\begin{array}{ll}\text { 3.3 Forecasting Rural Transit Ridership } & 3.12\end{array}$

$\begin{array}{ll}3.3 .1 \text { Introduction } & 3.12\end{array}$

3.3.2 Rural Transit Forecasting Model $\quad 3.13$

$\begin{array}{ll}\text { 3.3.3 Rural Ridership Forecasts } & 3.18\end{array}$

4. Urban Transit Systems $\quad 4.1$

4.1 Introduction 4.1

4.2 Urban Transit Services in the State 4.1

4.3 Base Year Urban Transit Benefits Estimation 4.9

4.3.1 Mobility-Based Accessibility Benefits $\quad 4.10$

4.3.2 Environmental and Energy Consumption Impacts $\quad 4.17$

$\begin{array}{ll}\text { 4.3.3 Travel Safety Benefits } & 4.18\end{array}$

4.3.4 Economic Benefits From Transit Supply $\quad 4.24$ 
4.4 Summary of Base Year Benefits

Page

4.5 Urban Transit Ridership and Benefits Forecasts

5. Rural Transit Systems

5.1 Introduction

5.2 Urban Transit Services in the State

5.3 Base Year Rural Transit Benefits Estimation

5.3.1 Mobility-Based Accessibility Benefits

5.3.2 Air Quality and Safety Benefits

5.3.3 Economic Benefits From Transit Supply

5.4 Summary of Base Year Benefits

5.5 Rural Transit Ridership and Benefits Forecasts

5.18

6. Recommendations for Future Analysis

6.1

6.1 Introduction

6.1

6.2 Some Data Elements Needing Additional Attention

6.1

7. Bibliography.

7.1

Appendix : List of Tennessee Counties in Each Rural Transit District 


\section{List of Tables}

Table 2.1 Common Alternatives to Public Transit and Their Estimated Costs.

Table 2.2 Estimated Annual Costs of Owning and Operating A Private Automobile in 1998.

Table 2.3 Default Vehicle Operating Cost Assumptions Used in This Study. 2.10

Table 2.4 Estimated Rural and Urban Transit Trips by Trip Purpose. 2.14

Table 2.5 Costs Per Medical Visit by Transit District (Ranges), in 1998 Dollars. 2.17

Table 2.6 Baseline Per Mile Air Quality Damage Costs by Mode (in 1998 \$). 2.25

Table 2.7 Baseline Safety Costs by Mode of Transportation. 2.31

Table 2.8 Quantitative Treatment of Transit Benefits. 2.39

Table 3.1 Urban Transit Related Data and Sources. 3.3

Table 3.2 Factors Affecting Fixed Route Ridership Forecasts. 3.6

Table 3.3 Sensitivity of Fixed Route Ridership Model to Population. 3.6

Table 3.4 Sensitivity of Fixed Route Ridership Model to Transit Investment. 3.6

Table 3.5 Rural Transportation Operations in Tennessee (1986-1998) - Annual Trips 3.14 and Annual Vehicle-Miles.

Table 3.6 Rural Transportation Operations in Tennessee (1986-1998) - Vehicle-Miles 3.15 per Trip, Use by Elderly, and Fleet Size.

Table 3.7 Calibrated NCHR3 Rural Public Transportation Ridership Model 3.19

Table 3.8. Rural Public Transportation District Demographic Forecasts. 3.20

Table 3.9 Changes in Rural Ridership for Changes in Service Levels. 3.21

Table 3.10 Rural Transportation Forecasting - 1999 Vehicle Miles of Service 3.21

Table 3.11 Rural Transportation Forecasting - Vehicle Miles Change in Proportion 3.22 to Growth in Elderly Population.

Table 4.1 Types of Urban Transit Service in Tennessee.

Table 4.2 Urban Transit Demand and Supply Variables, Calendar Year 1998

(All Services).

4.8

Table 4.3 Urban Transit District Specific Service Characteristics. 4.9

Table 4.4 Estimated Percentage of Urban Transit Trips by Trip Purpose. 4.11

Table 4.5 Representative Costs Per Medical Visit by Urban Transit District. 4.12

Table 4.6 Urban Mobility-Based Accessibility Benefits: 10\% Foregone Trips Scenario. 4.14

Table 4.7 Urban Mobility-Based Accessibility Benefits: Zero Percent Foregone

Trips Scenario.

Table 4.8 Sensitivity of Transit Mobility Benefits to Various Parameter Values. 4.16

Table 4.9 Baseline Per Mile Air Quality Damage Costs by Mode (in 1998 \$). 4.18

Table 4.10 Alternative Air Quality Impact Estimates (in 1998 \$). 4.18

Table 4.11 Urban Transit Fuel Use Statistics by District, Fuel and Service Types, 1998. 4.20

Table 4.12 Estimated Automobile Equivalent VMT and Fuel Consumption, 1998. 4.21

Table 4.13. Estimated Noise Impacts.

Page 
Table 4.14 Baseline Safety Costs by Mode of Transportation. $\quad 4.23$

Table 4.15 Estimated Urban Transit Safety Benefits. 4.24

Table 4.16 Urban Public Transit System Expenditures in 1998.

Table 4.17 1998 Employment and Economic Impacts of Urban Transit Supply. $\quad 4.27$

Table 4.18 Local Area Impacts of Federal and State Urban Transit Expenditures in 1998. 4.28

Table 4.19 Net Statewide Impacts of Federal and State Urban Transit Expenditures

in $1998 . \quad 4.28$

Table 4.20 Estimated Direct Plus Indirect and Induced Employment Impacts

of Transit Expenditures in $1998 . \quad 4.29$

Table 4.21 Urban Public Transit Benefits Summary Table. 4.30

Table 4.22 Urban Transit Benefits Statistics for CY 1998. 4.31

Table 4.23 Urban Transit Baseline Ridership (Unlinked Trip) Forecasts:

All Services Combined. $\quad 4.36$

Table 4.24 Baseline Urban Fixed Route Transit Ridership (Unlinked Trip) Forecasts. $\quad 4.37$

Table 4.25 Baseline Urban Demand Responsive Transit Ridership (Unlinked Trip)

Forecasts. $\quad 4.38$

Table 4.26 Baseline Urban Transit Ridership Benefits Forecasts. 4.39

Table 4.27. Alternative Congestion Growth and Air Quality Improvement Scenarios. $\quad 4.40$

Table 5.1 Rural Transit Demand and Supply Variables in FY 1998-99. 5.2

Table 5.2 Rural Transit District Specific Service Characteristics. Fiscal Year 1998-99. 5.3

Table 5.3 Approximate Distribution of Trip Purposes by Rural Transit District. $\quad 5.4$

Table 5.4 Wheelchair Trips and Riders with Disabilities Trips by Rural Transit District.

Fiscal Year 1998-99. 5.6

Table 5.5 Rural Transit Trips by Elderly Patrons. Fiscal Year 1998-99. 5.6

Table 5.6 Mode of Adult Transport to Work, School or Training in the Families

First Program. $\quad 5.8$

Table 5.7 Rural Transit Trips Operated on Contract in Fiscal Year 1998-99. 5.9

Table 5.8 Average Revenue Dollars Per Transit Trip by Transit District. 5.9

Table 5.9 Representative Costs Per Medical Visit by Rural Transit District. $\quad 5.11$

Table 5.10 Rural Mobility-Based Accessibility Benefits: 25\% Foregone Trips Scenario. 5.12

Table 5.11 Rural Mobility-Based Accessibility Benefits: Zero \% Foregone Trips Scenario.5.12

Table 5.12 Baseline and Alternative Transit Use Benefit Scenarios.

Table 5.13 Rural Public Transit Expenditures in FY 1998-99.

Table 5.14 Economic and Employment Impacts of Rural Transit Supply. 5.16

Table 5.15 Economic Impacts of Rural Transit: Three Perspectives. 5.16

Table 5.16 Rural Transit Benefits Summary Table. $\quad 5.17$

Table 5.17. Base Year, Baseline Rural Transit Benefits Statistics.

Table 5.18 Baseline and An Additional Rural Ridership \& Benefits Forecast. $\quad 5.20$ 


\section{List of Figures}

Figure 1.1 Major Project Tasks.

Page

1.1

Figure 2.1 Principal Public Transit Benefit Categories. 2.5

Figure 2.2 Potential Mobility-Based Accessibility Benefits. 2.6

Figure 2.3 Potential Environmental Benefits. $\quad 2.22$

Figure 2.4 Potential Safety and Security Benefits. $\quad 2.29$

Figure 2.5 Potential Economic Benefits. 2.33

Figure 3.1 Historic Trolley Ridership for Pigeon Forge, Tennessee. 3.9

Figure 3.2 Historical Trolley Ridership for Gatlinburg, Tennessee. 3.9

Figure 3.3 Gatlinburg vs Pigeon Forge, TN Annual Gross Business Receipts. $\quad 3.10$

Figure 3.4 Constant 1990 Dollars Gross Business Receipts vs. Trolley Ridership

for Pigeon Forge, Tennessee (1986-1999). 3.11

Figure 3.5 Trolley Ridership for Gatlinburg, Tennessee (1990-1999).

(Linear Relationship).

Figure 3.6 Forecast Unit Annual Gross Business Receipts for Gatlinburg, TN (1990 \$). 3.12

Figure 3.7 Forecast Unit Annual Gross Business Receipts for Pigeon Forge, TN (1990 \$). 3.13

Figure 4.1. Location of Urban Transit Systems in Tennessee. 4.2

Figure 4.2. Knoxville-Oak Ridge-Gatlinburg-Pigeon Forge Region of East Tennessee. 4.3

Figure 4.3 Nashville \& Clarksville Bus Systems and Regional Context. 4.4

Figure 4.4 Memphis Bus System and Regional Context. 4.5

Figure 4.5 Jackson Bus Transit System and Regional Context. 4.6

Figure 4.6 Fixed Bus Routes: Tri-Cities Region, North-East Tennessee. 4.7

Figure 4.7 Urban Mobility Benefits: Sensitivity to Foregone Trip Percentages. 4.14

Figure 4.8 Total Urban Public Transit Ridership in the 1990's. 4.32

Figure 4.9 Urban Public Transit Ridership in Small Urban Areas in the 1990's. 4.32

Figure 4.10. Fixed Route Bus Ridership in the 1990's. 4.33

Figure 4.11. Fixed Route Bus Ridership in Small Urban Areas in the 1990's. 4.33

Figure 4.12. Demand Responsive Ridership in the 1990's. 4.34

Figure 4.13. Demand Responsive Ridership in Small Urban Areas in the 1990's. $\quad 4.34$

Figure 4. 14. Urban Transit Ridership (Unlinked Trip) Forecasts: All Services Combined. 4.36

Figure 4.15 Baseline Urban Fixed Route Transit Ridership (Unlinked Trip) Forecasts. 4.37

Figure 4.16 Baseline Urban Demand Responsive Ridership (Unlinked Trip) Forecasts. 4.38

Figure 4.17 Traffic Congestion and Air Quality Impacting Future Benefits Scenarios. $\quad 4.40$

Figure 5.1 Tennessee Rural Public Transit District Service Areas.

Figure 5.2 Significance of Medical Trips by Rural Transit District.

Figure 5.3 Car Ownership in Families First Assistance Groups by Rural Transit District. 5.7

Figure 5.4 Rural Transit Ridership in the 1990's. $\quad 5.18$

Figure 5.5 Baseline and An Additional Rural Ridership Forecast. 


\section{Public Transit in Tennessee}

\section{Executive Summary.}

Study Objectives. This report documents results from a study carried out by Oak Ridge National Laboratory and the University of Tennessee at Knoxville for the Office of Public Transportation, Tennessee Department of Transportation. The study team was tasked with developing a process and a supporting methodology for estimating the benefits accruing to the State from the operation of state supported public transit services. The team was also tasked with developing forecasts of the future demands for these State supported transit services at five year intervals through the year 2020, broken down where possible to the local transit system level. Separate ridership benefits and forecasts were also requested for the State's urban and rural transit operations.

Tennessee's public transit systems are subsidized to a degree by taxpayers. It is therefore in the public interest that assessments of the benefits of such systems be carried out at intervals, to determine how they are contributing to the well-being of the state's population. For some population groups within the State of Tennessee these transit services have become essential as a means of gaining access to workplaces and job training centers, to educational and health care facilities, as well as to shops, social functions and recreational sites.

\section{Major Findings : Urban Transit Systems in Tennessee.}

Current Public Transit Services. Urban transit services are provided in each of the state's nine metropolitan areas of Bristol, Chattanooga, Clarksville, Jackson, Johnson City, Kingsport, Knoxville, Memphis and Nashville. Services are also provided in the cities of Oak Ridge, Gatlinburg and Pigeon Forge. Transit ridership within these urbanized areas constituted over $95 \%$ of all one-way, unlinked transit trips in the state in 1998. Table 1 breaks down these revenue earning passenger trips by type of service provided, along with the annual revenue vehicle miles of service provided in calendar year 1998, summed over all twelve urban transit operating systems.

Table 1. Urban Public Transit Trips in Tennessee by Type of Service.

\begin{tabular}{|c|c|c|c|c|}
\hline Service Type & $\begin{array}{c}\text { Revenue Passenger } \\
\text { Trips (Millions) }\end{array}$ & $\%$ & $\begin{array}{l}\text { Revenue Vehicle } \\
\text { Miles (Millions) } \\
\end{array}$ & $\%$ \\
\hline Fixed Route Bus: & 21.97 & 84.9 & 15.08 & 77.2 \\
\hline $\begin{array}{l}\text { Demand Responsive: } \\
\text { (ADA Vanpool) }\end{array}$ & 1.14 & 2.0 & 2.98 & 15.2 \\
\hline Downtown Shuttle: & 1.35 & 5.2 & 0.46 & 2.4 \\
\hline Commuter Van & 0.21 & 0.8 & 0.75 & 3.8 \\
\hline Light Rail: & 1.36 & 5.3 & 0.24 & 1.2 \\
\hline Incline: & 0.48 & 1.8 & 0.02 & 0.1 \\
\hline
\end{tabular}




\section{Public Transit in Tennessee}

The dominant service type in the State is fixed route bus transit. There is currently only one Light Rail Transit line in Tennessee, a 4.3 mile long loop serving downtown Memphis. Nashville also operates a long distance Commuter Van service. Two of the 12 urbanized area providers, the Gatlinburg and Pigeon Forge systems, operate bus/trolley systems in support of tourists visiting attractions within and close to the Smoky Mountains National Park. Eleven of the twelve urban systems also provide some level of demand responsive van service. A popular incline (funicular) is also operated in Chattanooga, and most of its riders are tourists. Statewide, over half of all fixed route (bus, light rail, trolley) trips are estimated to be employment based. In contrast, some $62 \%$ of State supported demand responsive transit van trips are for medical purposes. Much of this van service is provided to support the Americans with Disabilities Act (ADA).

Urban Transit Benefits. A major part of the study effort went into developing a comprehensive approach to transit benefits estimation. Based on a review of the literature, two principal types of public transit benefit were identified: benefits accruing directly from travelers' use of the transit system, termed Transit Use Benefits; and benefits that accrue to local areas from the presence of, including expenditures on, public transit services within their region, termed Transit Supply Benefits. Transit Use benefits were subdivided into:

1. Mobility-Based Accessibility Benefits From Transit Use;

2. Environmental Benefits From Transit Use; and

3. Safety and Security Benefits From Transit Use

Similarly, under the heading of Transit Supply, potential benefits were divided into:

4. Economic Benefits From Transit System Supply; and

5. Other Societal and Community Benefits Associated With Transit Supply.

Each of these benefits categories have a number of specific sub-benefits associated with them. To avoid double counting, these benefits were arranged into an inverted "benefits tree". While the emphasis was placed on computing net statewide and regional (urban and rural districtbased) benefits, gross economic impacts were also computed and are presented in the report.

Accessibility-supporting mobility benefits were found to dominate the study's findings, as shown in Table 2 below for a representative benefits scenario. These are net mobility benefits. That is, they are net estimated economic gains from public transit, after subtracting the cost of transit fares and the costs to State and local governments of funding transit operations. Most urban transit riders are currently traveling to and from work. Depending on the urban area, between $70 \%$ and $90 \%$ of current riders found public transit to be essential for gaining access to workplaces and job training centers, to educational and health care facilities, and to shops, social functions and recreational sites. Especially dependent on public transit for their mobility needs are many elderly and low income Tennesseans, as well as many residents with medical 


\section{Public Transit in Tennessee}

problems. The US Census Bureau ${ }^{1}$ estimated that some 820,000 Tennesseans were living in poverty at the turn of the century. Many of these low income residents are among the over 99,700 households in Tennessee that this present study estimates did not own a vehicle in year 2000. Elderly patrons form another important public transit market in the State. Again, according to the US Census Bureau ${ }^{2}, 700,000$ people in Tennessee were 65 years of age or older at the turn of the century. Many of these elderly persons also have mobility problems and reside in low income households. This present study estimates that this over-65 age group will grow by $70 \%$ by year 2020 . If a large percentage of riders are forced to give up their travel activities due to a loss or reduction in current transit service, these lost trip benefits can be very costly in terms of income lost, health care not received, and education or job training foregone. With this in mind the study devoted a good deal of attention to recent literature documenting transit impacts on other, non-transportation public service costs.

Table 2. Example Base Year (1998) Urban Public Transit Benefits Scenario.

\begin{tabular}{|c|c|c|c|c|}
\hline $\begin{array}{l}\text { Net Statewide Urban Public Transit } \\
\text { Systems Benefits: }\end{array}$ & $\begin{array}{l}\text { Total \$ Benefits } \\
\text { (in } 1998 \text { \$'s) }\end{array}$ & $\begin{array}{l}\text { \$ Per Trip } \\
\text { Benefits }\end{array}$ & $\begin{array}{l}\text { \$ Per Vehicle } \\
\text { Mile Benefits } \\
\end{array}$ & $\begin{array}{l}\text { \$ Per Passenger } \\
\text { Mile Benefits } \\
\end{array}$ \\
\hline User Mobility Benefits & $\$ 137,451,823$ & $\$ 5.41$ & $\$ 6.68$ & $\$ 1.13$ \\
\hline Congestion Mitigation & $\$ 8,756,426$ & $\$ 0.34$ & $\$ 0.43$ & $\$ 0.07$ \\
\hline Safety Benefits & $\$ 4,938,336$ & $\$ 0.19$ & $\$ 0.24$ & $\$ 0.04$ \\
\hline Air Quality Benefits & $\$ 2,072,253$ & $\$ 0.08$ & $\$ 0.10$ & $\$ 0.02$ \\
\hline Expenditure Multiplier Benefits & $\$ 11,663,145$ & $\$ 0.46$ & $\$ 0.57$ & $\$ 0.10$ \\
\hline Transportation Efficiency Benefits & $\$ 5,435,593$ & $\$ 0.21$ & $\$ 0.26$ & $\$ 0.04$ \\
\hline Total Estimated Benefits: & $\$ 170,317,576$ & $\$ 6.70$ & $\$ 8.28$ & $\$ 1.40$ \\
\hline Total Transit Trips: & $25,418,580$ & & & \\
\hline Total Transit Vehicle Miles: & $20,574,622$ & & & \\
\hline Total Estimated Passenger Miles: & $121,337,257$ & & & \\
\hline Total Expenditures $(\mathrm{F}+\mathrm{S}+\mathrm{L}):^{*}$ & $\$ 77,818,558$ & & & \\
\hline Total Expenditures (S+L): & $\$ 47,178,387$ & & & \\
\hline
\end{tabular}

*F+S $+\mathrm{L}=$ expenditures based on federal + state + local contributions. Note: Benefits within the specific categories shown were found to vary a good deal across the State's urban transit districts. Ten percent of current trips are assumed foregone in this scenario.

\footnotetext{
${ }^{1}$ US Census Bureau, Annual Demographic Survey, March 2001, Table 25.

${ }^{2}$ US Census Bureau, Census 2000 Summary File SF-1,Table DP-1, Profile of General Demographic Characteristics.
} 


\section{Public Transit in Tennessee}

Even where current riders have a choice between transit and the private automobile, or other means of transport (friends/relatives, taxi, walk/bike) cost savings can also result from the use of urban transit, especially if the full cost of driving an automobile is taken into account. Detailed computation of these alternative mode costs are provided in this report, along with estimates of safety, air quality and traffic congestion externalities. A small benefit also probably accrues from travel time savings from congestion reduction in the State's two large metropolitan areas (Memphis and Nashville). While not large currently, this type of savings is likely to increase as both of these urbanized areas continue to grow in population over the next two decades. The environmental (air quality, noise) and safety impacts of urban public transit were also found to be small currently, although positive on a statewide basis. All of these benefits are termed Transit Use Benefits in this report.

Also computed are the statewide and local district economic benefits associated with both expenditures on, and availability of, regional public transit systems. Most of these economic benefits (see Table 2) result from the direct, indirect and induced multiplier effects of local, state and federal monies spent on public transit (termed Expenditure Multiplier Benefits in Table 2). To support this assessment a set of district specific input-output analyses were carried out, using economic data aggregated up from the county level. The economic benefits of transit supply were also found to be positive at both the statewide and (particularly so) at the individual transit district level. Gross economic impacts from urban transit expenditures in the State were estimated to be on the order of $\$ 80$ million in 1998 , which translated into some 2,600 jobs. Deducting benefits associated with transfer payments between the State and its regions, urban transit systems are still found to generate significant net economic benefits: on the order of $\$ 11.7$ million in net value added to the economy. In addition, and also shown in Table 2, are a set of Transportation Efficiency Benefits, worth an additional \$5.4 million. These represent an estimate of the regional economic growth benefits likely to result from the presence of low cost public transit within a region. Combining these Expenditure Multiplier and Transportation Efficiency Benefits produces net economic benefits of just over \$17 million, or roughly 538 jobs.

Not all of these benefits/impacts could be easily quantified, given available data sources. In particular, the results of the study approach are most susceptible to the assumptions governing the alternative response of current, typically lower income, "captive" transit riders to lost transit service. Given a good deal of uncertainty in a number of the data elements required to compute benefits, and using transit district specific data wherever possible, an extensive sensitivity analysis was carried out. This analysis suggests that the benefits from urban transit in the State are likely to range from $\$ 6$ to approximately $\$ 7.25$ per one-way revenue generating transit trip, based on 1998 data, and expressed in 1998 dollars. In terms of the 1998 capital plus operating expenditures spent on urban transit in Tennessee this provides approximate statewide benefit to cost ratios in the range of 2 to 2.5 to 1 in favor of urban transit operations. In some of the State's urban transit systems this ratio may be higher. These are benefits derived on the basis of 1998 operating, financial and ridership practices. 


\section{Public Transit in Tennessee}

Urban Ridership Forecasts. Using data from 125 urban transit systems across the United States a cross-sectional, demographic and socio-economically based regression model was developed for ridership forecasting, at 5 year intervals out to 2020. This approach, supplemented by simple trend analysis for the State's smaller and tourist oriented transit systems, predicts a gradual recovery of transit patronage within the State over the next two decades.

Dominated by fixed bus ridership, these forecasts (see Figure 1) imply getting back to the level experienced in 1990 and the late 1980's, when 29 million plus transit trips were taken over the course of a year. A net increase of 3.27 million one way trips is projected between 2000 and 2020. This is equivalent to a $12.6 \%$ increase in ridership over the full two decades. This forecast, termed the Baseline forecast, assumes a constant level of transit service (in terms of transit revenue vehicle miles of service operated) over the time period.

Figure 1. Urban Transit Ridership Forecasts: All Services Combined.

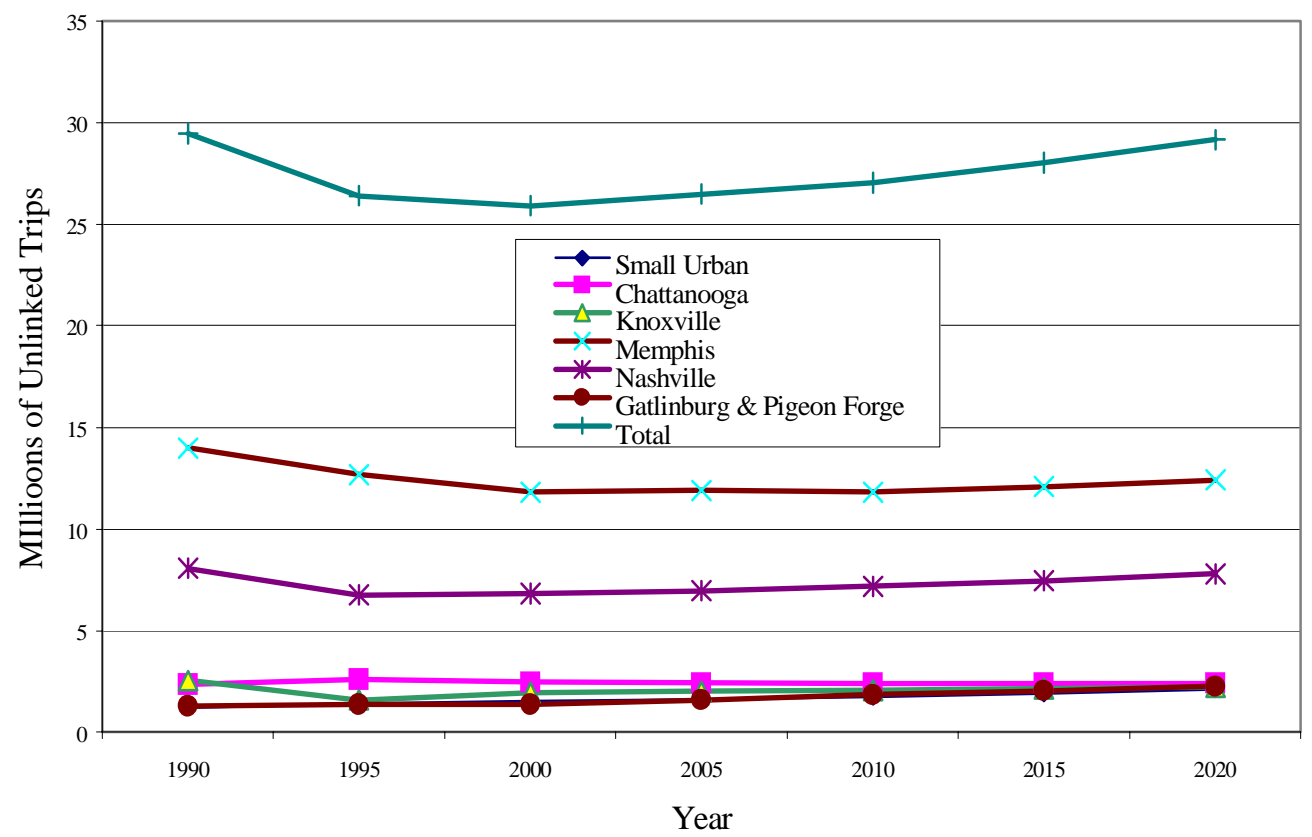

Among the State's small urban systems, the tourist transit oriented systems of Pigeon Forge and Gatlinburg are expected to see the most significant growth, on the assumption that their recent and quite rapid economic expansion will continue. However, as Figure 2 shows, from a Statewide perspective the fastest growing sector of the urban transit market over the past decade has been the demand responsive (ADA assisting) ridership. While this rate of growth is projected to slacken now that all of these systems have been operating within the State for a number of years, some additional growth is expected as a result of increases in the size of the elderly populations within the State's urban areas. While not large by comparison to fixed route patronage, these demand responsive trips typically bear greater than average expenses in order to 
Public Transit in Tennessee

move special needs riders longer than average distances

\section{Figure 2. Recent Historical and Forecast Demand Responsive (DR) Ridership Growth in Tennessee Urban Areas.}

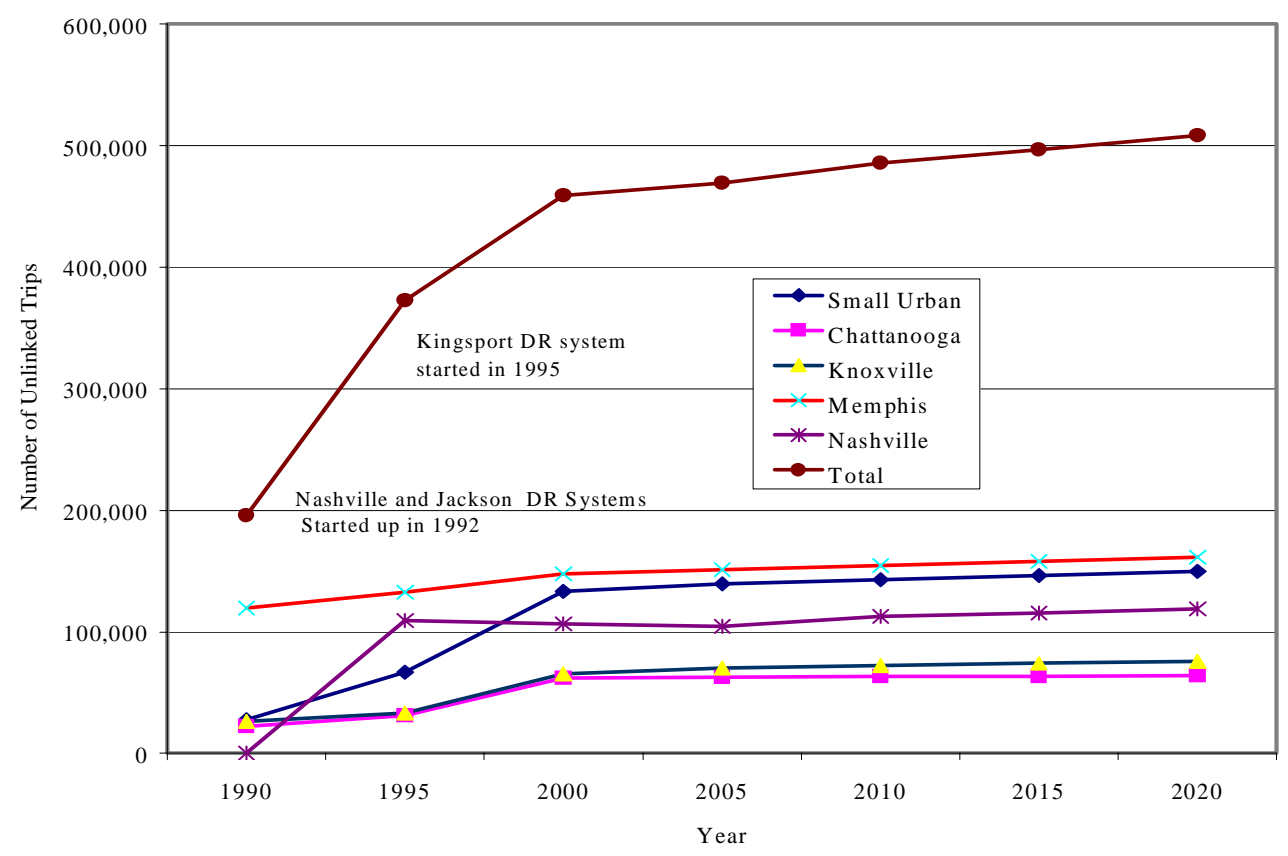

\section{Major Findings: Rural Transit Systems in Tennessee.}

Current Transit Services. All 95 of Tennessee's counties receive some form of public transit service. Rural transit operations in Tennessee consist of demand responsive van service, a large percentage of which involves contract rides such as pick-up and drop at hospitals or other public service facilities. Almost half of the trips made in FY 1998-99 were for medical or nutrition purposes, while just over half were made by citizens over 60 years of age. During this same twelve month period some $31.6 \%$ of all rides were taken by Tennesseans with some form of disability, including some $8 \%$ in wheelchairs. A significant number of these rides now occur as part of Tennessee's TennCare (Medicaid replacement) program. An additional estimated 17.4\% of all rural trips occurred for employment or daycare purposes, as part of the State's Families First job-training and related Welfare-to-Work program.

Rural Transit Benefits. The same benefits framework used on the State's urban transit systems was applied to the State's rural transit operating districts. The demand for rural transit services in Tennessee over the decade of the 1990's was found to have changed a good deal in terms of the miles required to satisfy the average trip. While average miles per trip increased by more that $72 \%$ ( 6.7 miles to 11.5 miles per trip) over the decade, the ridership statewide remained 


\section{Public Transit in Tennessee}

reasonably stable. Despite having to serve these additional miles, the State's rural transit systems still managed to generate benefits in excess of their operating costs in fiscal year 199899. As with their urban counterparts, benefits came largely through improved mobility, notably for the State's rural elderly, poor and transportation disadvantaged. With as much as $90 \%$ transit dependency for such trip making, the potential social as well as medical costs of lost trips in these circumstances can be quite high. To estimate such costs, detailed data on the costs of both at home and within health care facility medical visits was collected and compared to the costs of current rural transit services in each rural transit district. Similar computations were done for lost work and job training trips, as well as lost shopping and other general purpose trips.

Table 3 below shows an example rural transit benefits scenario, based on an assumed 25\% foregone trips ratio (i.e. 1 in every 4 trips currently taken would no longer be continued).

At $\$ 14.65$, the per trip benefits are estimated to be noticeably higher on average than their urban counterparts. However these, typically longer, trips are also obtained at greater expense. After mobility benefits, economic benefits, notably the Expenditure Multiplier Benefits that represent the effects of monies spent in these rural areas on public transit services (jobs, equipment, materials) form the second and only other significant benefits category. As a percentage of all benefits, these economic benefits, taken as the sum of the Expenditure Multiplier and Transportation Efficiency Benefits in Table 3, are noticeably higher for rural than urban systems, as might be expected on an intuitive basis.

Table 3. Example Base Year (1998) Rural Transit Benefits Scenario.

\begin{tabular}{l|rrrr}
$\begin{array}{l}\text { Net Statewide Rural Transit } \\
\text { Benefits: }\end{array}$ & $\begin{array}{l}\text { Total Benefits } \\
\text { (in 1998 \$'s) }\end{array}$ & $\begin{array}{l}\text { \$ Per Trip } \\
\text { Benefits }\end{array}$ & $\begin{array}{l}\text { \$ Per Vehicle } \\
\text { Mile Benefits }\end{array}$ & $\begin{array}{l}\text { \$ Per Passenger } \\
\text { Mile Benefits }\end{array}$ \\
\hline User Mobility Benefits & $\$ 11,688,382$ & $\$ 10.21$ & $\$ 1.04$ & $\$ 0.86$ \\
Congestion Mitigation & $\$ 339,403$ & $\$ 0.30$ & $\$ 0.03$ & $\$ 0.03$ \\
Safety Benefits & $\$ 69,165$ & $\$ 0.06$ & $\$ 0.01$ & $\$ 0.01$ \\
Air Quality Benefits & $\$ 2,789,726$ & $\$ 2.44$ & $\$ 0.25$ & $\$ 0.21$ \\
Expenditure Multiplier Benefits & $\$ 1,879,861$ & $\$ 1.64$ & $\$ 0.17$ & $\$ 0.14$ \\
Transportation Efficiency Benefits & & & & $\$ 1.24$ \\
& & & & \\
\hline Total Estimated Benefits: & $\$ 16,766,535$ & $\$ 14.65$ & & \\
Total Transit Trips: & $1,144,694$ & & & \\
Total Transit Vehicle Miles: & $11,250,606$ & & & \\
Total Estimated Passenger Miles: & $13,549,485$ & & & \\
Total Expenditures (F+S+L):* & $14,485,452$ & & & \\
Total Expenditures (S+L): & $10,414,224$ & & & \\
\hline
\end{tabular}

$* \mathrm{~F}+\mathrm{S}+\mathrm{L}=$ expenditures based on federal + state + local contributions. Note: Benefits within the specific categories shown were found to vary a good deal across the State's rural transit districts. 


\section{Public Transit in Tennessee}

Under the rural baseline scenario shown in Table 3, for example, these two types of economic benefit represent $27.8 \%$ of all benefits, with transit user mobility benefits accounting for almost all of the remainder. The $\$ 4.67$ million (i.e. $\$ 2.79$ million plus $\$ 1.88$ million) in combined Expenditure Multiplier plus Transportation Efficiency benefits shown in Table 3 represent net to the State economic benefits, less any transfer payments based on internal state provided funding to local transit districts. Gross economic value added benefits from these transactions between federal, State and local rural transit agencies were estimated under this scenario to be just over $\$ 13.5$ million. This translated into 598 jobs statewide. Subtracting pure transfer payments from the State to its local transit districts yields the $\$ 2.89$ million of net estimated Expenditure Multiplier benefits shown in Table 3, which translates into185 jobs that can be considered to be net gains from rural transit service supply.

Rural Transit Ridership Forecasts. As with the urban systems a baseline rural transit ridership forecast was developed by assuming that there will be no change in the level of rural transit vehicle miles of service offered per trip during the forecast period. Under this baseline forecast ridership is predicted to remain roughly level until around 2005, when it is expected to increase at an average rate of around 1.7\% per year, reaching 1.38 million one-way trips by 2020 . Applying these statewide rural transit forecasts to the baseline per trip benefit figure of $\$ 14.65$ shown in Table 3, transit benefits are estimated to increase from some $\$ 16.7$ million in 1998 to \$20.3 million dollars, in constant 1998 dollars, by 2020. Under a more aggressive scenario, in which the revenue miles of transit service offered to the public increases in proportion to the growth in Tennessee's elderly rural population, rural ridership is forecast to grow more rapidly, as the number of elderly patrons grows, reaching nearly 2.1 million trips by year 2020 . Under this scenario, public transit benefits are forecast to grow to $\$ 20.4$ million by 2010 , increasing to $\$ 30.6$ million by 2020 . 
Public Transit in Tennessee

\section{Introduction.}

\subsection{Study Purpose.}

Tennessee's regional and statewide economies rely heavily on their transportation systems. Where passenger travel is concerned, movements between places are dominated by the private automobile. Supplementing this automobile travel, the State supports a number of public transit systems. Currently these public transit systems, within the state as within the nation as a whole, are subsidized to a greater or lesser degree by taxpayers. It is therefore in the public interest that assessments of the benefits of such transit systems be carried out at intervals to determine how they are contributing to the well-being of the state's population. For some population groups within the State of Tennessee these transit services have become essential as a means of gaining access to workplaces and job training centers, to educational and health care facilities, as well as to shops, social functions and recreational sites.

The purpose of this report is to document the results of a study carried out by Oak Ridge National Laboratory and the University of Tennessee at Knoxville for the Office of Public Transportation, Tennessee Department of Transportation (TDOT). The study team was tasked with developing a methodology for estimating the benefits accruing to the State and its local regions from the operation of state supported public transit services. The team was also tasked with developing forecasts of future demands for these transit services. Figure 1 shows the major tasks undertaken by the study and their relationships to one another.

\section{Figure 1.1 Major Project Tasks.}

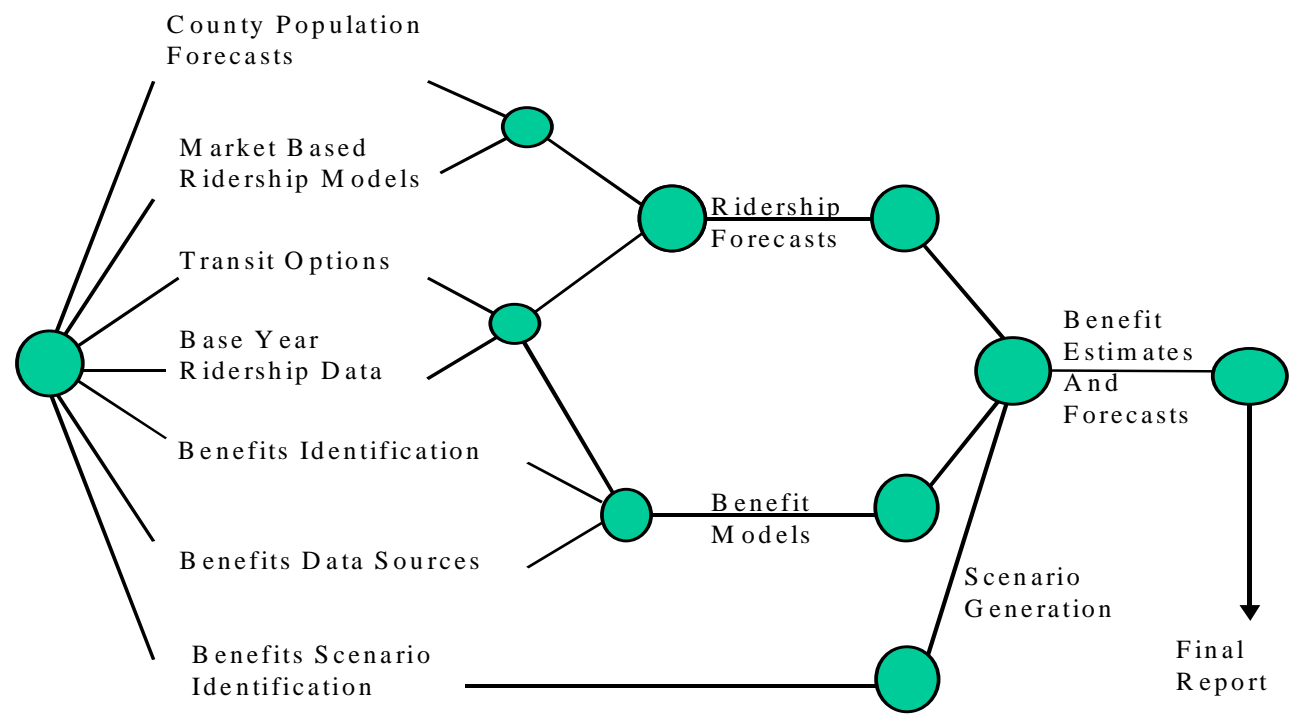




\section{Public Transit in Tennessee}

Literature reviews were carried out covering the latest information on transit ridership forecasting methods and on methods for estimating transit benefits. The Bibliography at the end of this report contains a listing of the studies reviewed. To carry out the benefits analysis, data was collected from the State of Tennessee's Department of Transportation and from other sources, including interviews with transit agency and planning agency staffs in each of the State's nine Metropolitan Planning Agencies. At the outset a distinction was made between the state's urban and rural transit systems and the different service options relevant to each. The next step was to generate a set of urban and rural transit ridership estimation models for the state by type of transit service (effectively, fixed route and demand responsive services) (see Chapter 3 ).

To generate ridership forecasts at 5 year intervals for years 2005, 2010, and 2015 and 2020, these models were combined with a set of county population forecasts, broken down for the purpose of supporting these ridership estimation equations by urban and rural locations and by household types. This was done using already prepared projections of county populations by five-year intervals, to 2020, as derived by the Center for Business Economics (CBER) at the University of Tennessee prior to the start of the present study. ${ }^{3}$

Concurrently, a transit benefits estimation framework was developed, and applied initially to 1998 data. These two lines of effort were then merged to develop a baseline forecast of transit ridership and benefits for the State, projected out to year 2020. Finally, the ridership forecasting equations were used to develop additional urban and rural transit ridership and benefits scenarios. The initial idea for at least the short range urban ridership scenarios was a simple "what-if" analysis of benefits if this ridership could be increased by $5 \%$ or $10 \%$ over the next few years. By developing a statistical relationship between transit demand and transit supply this initial idea was extended to include scenarios based on increasing ridership by improving levels of transit service.

At each step in the study an effort was made to incorporate the latest techniques and data, as identified by reviews of both the ridership and benefits literature. The result of this approach is a methodology that uses a variety of market specific forecasting techniques and benefits computations, drawn from a number of recent transit studies, as well as from more broadly based travel forecasting and public service assessment publications.

\subsection{Report Organization and Content.}

This report is organized into six chapters, as follows. Chapter 2 reviews the transit benefits literature and describes the use of this literature in the development of a benefits analysis framework based loosely on the concept of an inverted benefits analysis tree. Chapter 3 then

\footnotetext{
${ }^{3}$ Murray, M. N. (1999) Population Projections for Tennessee Counties and Municipalities. 2000-2020. Center for Business and Economic Research, University of Tennessee, Knoxville, TN 37996. March 1999.
} 


\section{Public Transit in Tennessee}

describes the approach taken to ridership forecasting and provides the details of the different transit service-specific ridership equations used to generate these forecasts. With these chapters as technical background, Chapter 4 provides the details behind our base year (1998) benefits estimates and what we term the baseline benefits ridership forecasts for the state's urban public transit operations. Chapter 5 provides the same details for the state's rural transit operations. Both of these chapters also describe the results of carrying out a sensitivity analysis on the benefits computations. Chapter 6 provides a summary of the study's major findings as well as a short list of recommendations for future data collection exercises in support of the analysis framework that has been developed. Not quantified in this study are the potential effects and likely benefits of introducing light rail or commuter rail systems. Nor does the study consider the operation of express bus transit-supporting High Occupancy Vehicle (HOV) lanes within the State's largest metropolitan areas. While recent studies of such options have been conducted for the cities of Memphis and Nashville, these options were considered beyond the scope of this present study: although the benefits analysis framework that has been developed is readily extensible to these and other types of transit service in future applications.

\subsection{Glossary of Terms Used.}

Alternative Mode (AM) -- A mode such as the private automobile, taxi, walk or cycle, that offers an alternative means of transportation to public transit.

Americans with Disabilities Act (ADA). This act, signed into law July 26, 1990, bans discrimination based on disability and guarantees equal opportunity for individuals with disabilities in employment, public accommodations, transportation, state and local government services and telecommunication relay services. ${ }^{4}$

Commuter Rail (CR) Transit ---- Rail passenger service operating between metropolitan and suburban areas

Demand Responsive (DR) Transit - A form of public transit service involving pre-arranged passenger pickup and drop-off. This report refers to DR transit vans used in both urban and rural settings. Also often termed "paratransit" in urban systems.

Families First -- $\quad$ Enacted September $1^{\text {st }}, 1996$, this is the State of Tennessee's replacement for the federal government's Aid to Families and Dependent Children (AFDC) Program, which, under current federal welfare reform, is now

\footnotetext{
${ }^{4}$ See www.sctgaa.org/ct/july97/medicaid.htm.
} 


\section{Public Transit in Tennessee}

termed the Temporary Aid to Needy Families (TANF) Program. ${ }^{5}$ Along with the State's Welfare to Work program, Families First helps to provide access to education, job training and employment, subsidized in part through the federal government's Job Access and Reverse Commute Program. ${ }^{6}$

Fixed Bus (FB) Transit - public transit on fixed bus routes with pre-defined routes and schedules. This is the major form of public transit in Tennessee.

Foregone Trips (Travel) ---- Trips not taken because of lost or altered (reduced) transit service.

Generative Benefits - Indirect transit benefits that result from economic growth within a region, as a result of the economic efficiencies afforded by public transit services.

Light Rail (LR) Transit -- Lightweight passenger rail cars operating in short, usually one- or two-car, trains, on fixed rails in right-of-way.

Metropolitan Planning Organization (MPO) — The public agency responsible for planning, usually including long range transportation planning, within each of the State's urbanized areas.

Rural Transit District --- A Tennessee DOT defined single or multi-county geographic area served by a single, State supported transit service agency. (There are 11 such non-overlapping districts which together include all 95 Tennessee counties ).

TennCare ---------- Enacted on January $1^{\text {st }}, 1994$, this is the State of Tennessee's replacement of the federal government's Medicaid Program, aimed at providing medical insurance to those on welfare, plus the uninsured or uninsurable. Services include outpatient hospital care and transportation access to these medical services.

Transfer Benefits - Economic benefits accruing to a region as a result of monies originating outside of that region but spent on transit services within the region. In this study, local area transfer benefits result from transfer payments from the

\footnotetext{
${ }^{5}$ See www.state.tn.us/humanserv/fmfirst.htm

${ }^{6}$ See www.CTAA.ORG/ntrc/atj/pubs/staates-move/welfare-tn.shml
} 


\section{Public Transit in Tennessee}

State and federal governments into either a specific urban transit system or into a local rural transit service district. Transfer payments in support of public transit from the federal government to the State of Tennessee also qualify to generate transfer benefits at the Statewide level.

Transfer Payments - See transfer benefits.

Transit Dependent Riders ---- People who rely on public transit as their only current means of making specific trips (i.e. no alternative modes considered useable).

Urbanized Area----- A geographic area of 50,000 or more population so designated by the U.S. Bureau of the Census.

Unlinked Trips--The number of passengers who board public transportation vehicles to make a trip. One trip is counted each time a rider boards a transit vehicle even though more than one boarding may be needed for same journey/destination. A Linked Trip, in contrast, may include more than one boarding, and refers instead to the number of one-way origin-to-destination journeys.

Urban Transit System ---An urbanized area served by a single, State supported urban public transit system. (There are 12 such systems). 
Public Transit in Tennessee

\section{Transit Benefits Analysis Process}

\subsection{Introduction.}

The purpose of this chapter is to describe the methods used to quantify the benefits provided by the State's public transit systems. Where possible, benefits have been put in 1998 dollar terms, using 1998 transit ridership and expenditure data to create a set of base year estimates. These 1998 benefits are then combined with a set of trip based transit ridership forecasts to generate a set of benefit forecasts to year 2020. Not all benefits could be translated into dollar figures. Some benefits of public transit, while they clearly exist, are difficult to quantify. We provide discussions of these additional benefits and where possible relate them to specific instances where Tennesseans have and can in the future continue to profit from public transportation.

Annually collected data on ridership and on transit system expenditures for each of the State's twenty-three transit systems formed the basis of the benefits computations presented in this report, supplemented by other sources from the available literature. An early project task involved putting this data into spreadsheets. Two spreadsheets were created, one for the State's urban and one for the State's rural transit systems, with each spreadsheet containing data for a single system on a separate page or worksheet. Additional information was obtained from telephone requests to regional planning agencies, with on-site interviews with Urban Transit System and local Metropolitan Planning Organization staffs during September-October of 2000. In addition, short written surveys of the State's urban and rural transit operators also provided important trip purpose information to the study. Even so, a number of data limitations were encountered, and in the discussions that follow it is noted where data from transit ridership surveys ought to be used to improve on our estimates of benefits. Where the value of a specific statistic was considered questionable, a sensitivity analysis was carried out to determine how important it was to the results. In an effort to bound the most likely set of values, this report contains a range of results for the major benefits computed.

This chapter proceeds from a discussion of the transit benefits literature to an in-depth description of the benefits framework developed and applied as part of this study. Details from specific studies covered by the literature review are brought into the discussions of each type of benefit analyzed. The same basic benefits assessment framework was applied to both urban and rural transit systems within the State, but with different emphasis placed on specific benefits categories. This present chapter is focused on methodology. Chapters 4 and 5 provide a detailed description of how this analytic framework was applied to the State's urban and rural transit operations respectively. 


\section{Public Transit in Tennessee}

\subsection{Literature Review.}

The past decade has seen a growth in the literature on public transit benefits, as transportation planners and policy makers struggle to get the most out of their multimodal transportation systems. This includes analyses carried out at various geographic scales, including studies of transit service within small towns or rural districts (Peng and Nelson, 1998; Skolnik and Schneider, 1998), studies of transit service within a single urban corridor (Cervero, 1999), within an entire metropolitan area (see Cambridge Systematics, 1998), as well as studies assessing the national picture (Camph, 1997; Cambridge Systematics and Glen Weisbrod Associates, 1999; Lewis and Williams, 1999). It also includes a small number of recent statewide studies of urban or rural transit systems (RM Plan Group, 1994 and CGA Consulting Services, 1998 for Tennessee; Leigh, Scott and Cleary, Inc. et al, 1999 for Colorado; Meyer, Nelson and Peng, 1999 for rural Georgia). Tennessee specific studies include an assessment of public transit's economic impacts on the cities of Memphis (MATA, 1982) and Jackson (Hearn, 1985); a study of fixed route bus and taxicab-based demand responsive transit services in Bristol, Johnson City, Kingsport and Oak Ridge (Wegmann, Chatterjee and Volpe ,1992); a 1996-based evaluation of the economic impacts of the Upper Cumberland Human Resource Agency, based in Cookeville (one of the many case studies reported in Burkhardt et al, 1998, pages 133-136); Newsome and Wegmann (1992) on the benefits of long distance vanpool commutes; an assessment of fixed route bus transit service introduction in Johnson City in 1979 (Chatterjee and Wegmann, 1983); and a study by Wegmann, et al (1979) on the impacts of the 1977 Knoxville transit strike.

Complementing these regional and service specific studies are a number of studies devoted to methodological improvements in the way benefits are identified and, data permitting, measured (Beimborn et al, 1993; Horowitz and Beimborn, 1995 ; Burkhardt, et al, 1998; Cambridge Systematics et al, 1996, 1998, 1999; Louis Berger and Associates, 1998; Crain \& Associates, 1999; Litman, 1994, 1999). This present study sought to make the most use of this, for the most part quite recent literature. This was done by first defining the scope of public transit benefits reported in previous studies, and second by identifying possible sources of data with which to compute these benefits. References were often made to this previous work to derive specific assumptions or to inform the selection of parameter values.

The most common approach to quantifying public transit benefits is to consider the effects of increasing or decreasing the current level of public transit service, by comparing the costs (positive or negative) associated with transit use against the costs of other travel, and in some cases non-travel, alternatives. Implicit in such considerations is the desire to at least keep conditions for the traveling public from getting worse, and where possible to make them better. A significant part of the technical challenge facing such an analysis is to define the appropriate set of alternatives against which current transit services are to be compared. In doing so not all of the benefits reviewed above are readily translated into monetary terms; while among those benefits that can be quantified there is a range of uncertainty associated with their estimation, 


\section{Public Transit in Tennessee}

often in terms of assigning a dollar value to an otherwise measurable impact.

Based on a review of the public transit literature two principal types of public transit benefit were identified. The first type are benefits accruing directly from travelers' use of the transit system, termed Transit Use Benefits. The second type are benefits that accrue to local areas from the presence of public transit services within their region, termed Transit Supply Benefits. Transit Use Benefits are usefully subdivided into:

1. Mobility-Based Accessibility Benefits From Transit Use;

2. Environmental Benefits From Transit Use; and

3. Safety and Security Benefits From Transit Use

Similarly, under the heading of Transit Supply, potential benefits are usefully divided into:

4. Economic Benefits From Transit System Supply; and

5. Societal and Community Benefits Associated With Transit Supply.

The principal purpose of any transportation system is to provide people with access to other persons and locations. The more mobile a population the more accessible it is. Greater accessibility to jobs, shops, medical, recreational and social activities creates a higher standard of living. Benefits from transit accrue where it offers the least cost alternative means of transportation, by saving travelers time, money, or avoiding inconvenience. In many instances public transit is still today the only cost effective means of getting from place to place for some elderly, disabled or poor residents. Among other things, a significant increase or decrease in transit service can impact the cost and provision of public services outside the transportation sector per se: notably health care and employment services (see GAO, 1999; Lewis and Williams, 1999). As noted in the summary to Transit Cooperative Research Program Report 20 (Cambridge Systematics, Inc et al, 1996): "With the exception of requirements under the Americans with Disabilities Act, the value and/or cost to society of ensuring that disadvantaged and dependent citizens have access to employment opportunities, job training opportunities, social services, health care, etc., is not being assessed or factored into transportation decision making at the present time." We make an attempt to do so in this study.

Where well patronized transit services are provided in sufficient quantity, notably fixed route metropolitan rush-hour bus and rail transit services, they can also impact non-transit travelers by keeping large numbers of automobiles off the highways, reducing traffic congestion that results in travel time savings. Where these savings are large enough (i.e. where ridership is high enough) this situation also holds the potential to reduce the need for additional highway lanemiles in response to current and anticipated traffic growth.

Besides these "mobility benefits", a number of additional benefits are often attributed to the operation of public transit systems. These include both environmental (air and groundwater quality, noise, land use) and safety/security benefits, each of which are often termed externality 


\section{Public Transit in Tennessee}

benefits in the transport economics literature. Positive benefits accrue to transit systems where vehicle occupancy and route circuity are sufficiently high and low respectively to offer significant vehicle miles of travel reductions over private automobile use. As with mobility benefits it is now popular to quantify both of these types of benefits in dollar terms, since each can be responsible, in particular, for reduced health care costs.

Additional economic benefits are also often associated with the presence of transit systems. First, there are the benefits accruing from the public expenditures devoted to transit services. This includes expenditures on staff, vehicles, operations and facilities, all of which either directly or indirectly create local jobs and the demand for local materials and services. Second, there are the less readily observed benefits of regional economic growth that may be created when transit services provide a more efficient regional and multimodal transportation system. The former, expenditure based benefits, are what economists often term transfer benefits in that they devolve from funds brought into the state and local economies from other sources. In contrast, economic growth benefits are considered to represent newly created wealth, and as such are termed generative benefits in the transit literature. Both types of benefit are important to the local districts in which transit services are offered, as they generate both jobs and income within a region.

Finally, a number of less tangible societal and community benefits have also been claimed for transit systems. One of the more measurable benefits under this category is the ability of public transit systems to fill a "mobility gap" (Leigh, Scott and Cleary, Inc. et al, 1999) between those with and without private vehicle transportation available to them on a regular basis. This category of benefits also includes the feelings of improved quality of life that many citizens express when asked how they feel about public transit systems in their areas. While difficult to quantify, these are nonetheless real benefits to a society that prides itself on providing access to opportunities for all members of its population.

\subsection{The Benefits Analysis Framework.}

Where possible, an effort was made in this study to assign dollar values to each type of benefit for which data could be obtained. In doing so an effort was also made to avoid double counting benefits by developing a transit "benefits tree" that helps to separate benefits into nonoverlapping categories (see Horowitz and Beimborn, 1995; Beimborn et al, 1993). This is not always an easy thing to do. Nor is there necessarily a single best way to categorize these benefits. The potential exists for concepts to overlap, leading to quite complex benefits analysis frameworks (see Cambridge Systematics, 1996). This present study made use of this benefits tree idea while trying to retain a reasonably straight-forward view of the problem that will allow state planners to collect, at reasonable expense, the data needed for future study updates. This was considered important because, in reviewing the various benefit assessment studies referenced in the bibliography to this report, it became clear that data limitations as well as study purpose have played a significant role in determining not just how, but also which, benefits 


\section{Public Transit in Tennessee}

were computed. This includes how such benefits are standardized: across types of benefits, across types of transit services, and across types of transit riders.

Figure 2.1 shows the five major benefit categories identified above in the form of such a benefits tree. This study's benefits analysis framework consisted of identifying and applying specific subcategories of benefits under each of these five principal benefit categories. Where possible, an estimate of benefits was based on applying this benefits tree concept using local data, or by combining local data with recent estimates from the broader transit and travel behavior literature. Without funding to cover extensive ridership surveys, methods had to be developed to make the most of existing data sources. Where data have been taken from previous studies these data sources are noted in the text, and a full set of references to these studies, is provided at the end of this report.

Figure 2.1 Principal Public Transit Benefit Categories.

\section{Public Transit Services}

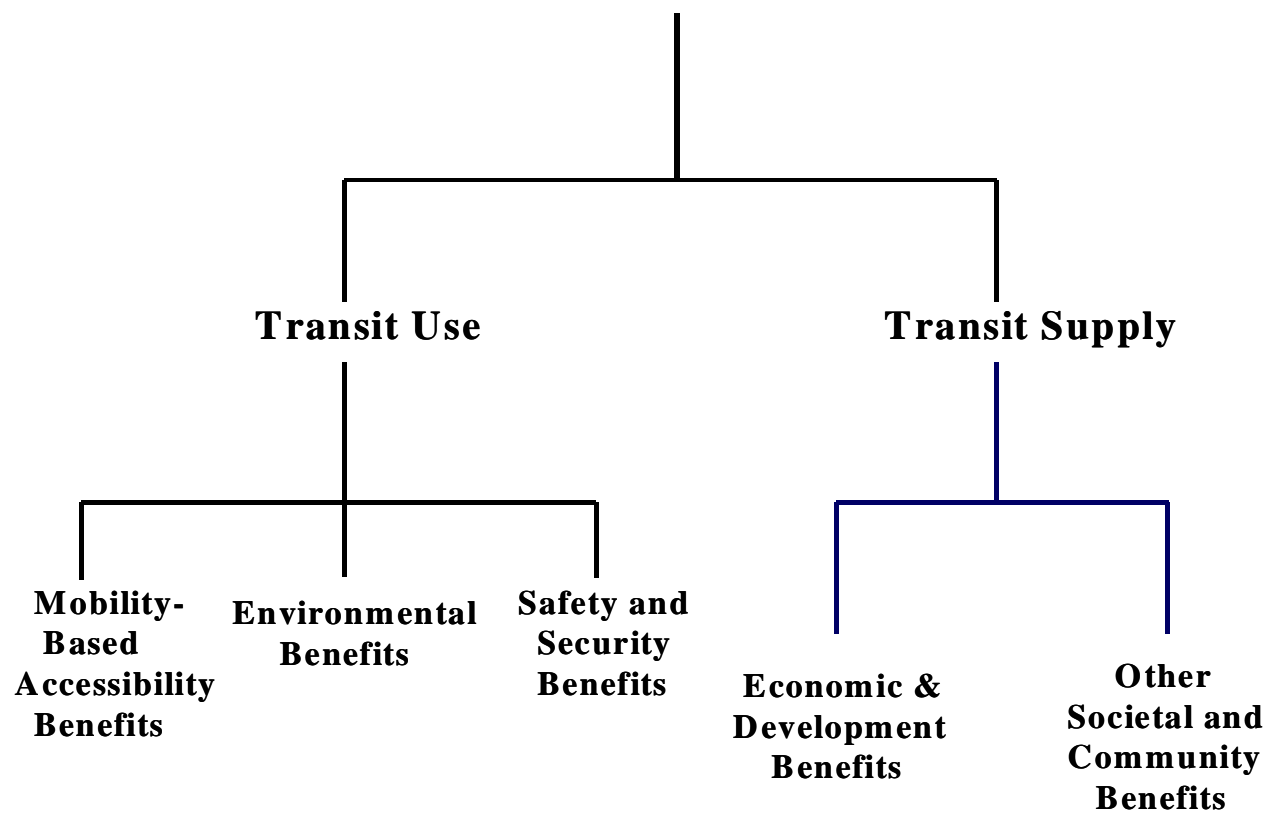

\subsection{Mobility-Based Accessibility Impacts From Transit Use.}

\subsubsection{Benefits Categories Analyzed.}

Figure 2.2 shows the benefits of transit under the mobility and accessibility branch of the benefits tree. Accessibility is taken to be the major goal of any transportation service, including public transit service: accessibility to places, to people, to services and goods. The more mobile 


\section{Public Transit in Tennessee}

a person is, the greater his or her potential for access. This branch of the benefits tree begins by identifying both Transit User and Non-Transit User Trip Benefits. Transit User benefits

produced by far the largest percentage of the benefits found in this study, taken over all five of the major benefits categories shown in Figure 2.1. In general, a loss of transit service will lead to one of three responses from individual travelers: 1) use of another mode of transportation, 2) cancellation of trips, or 3) relocation to be nearer to one or more commonly visited travel destinations. Similarly, an increase in transit service may cause individuals to change from one of these current options to riding the bus, van or train. In all three cases a cost is usually incurred as a result of lost transit service: while improved transit service might in some instances lead to a less costly form of access. Cancellation of trips is referred to in this report as foregone travel, and savings are computed as the value of the trip saved less the cost of the transit trip currently taken. Relocation cost savings result when current transit service forestalls the need for a patron to relocate in order to access the services (e.g. medical services) that may be required on a regular basis.

Figure 2.2 Potential Mobility-Based Accessibility Benefits.

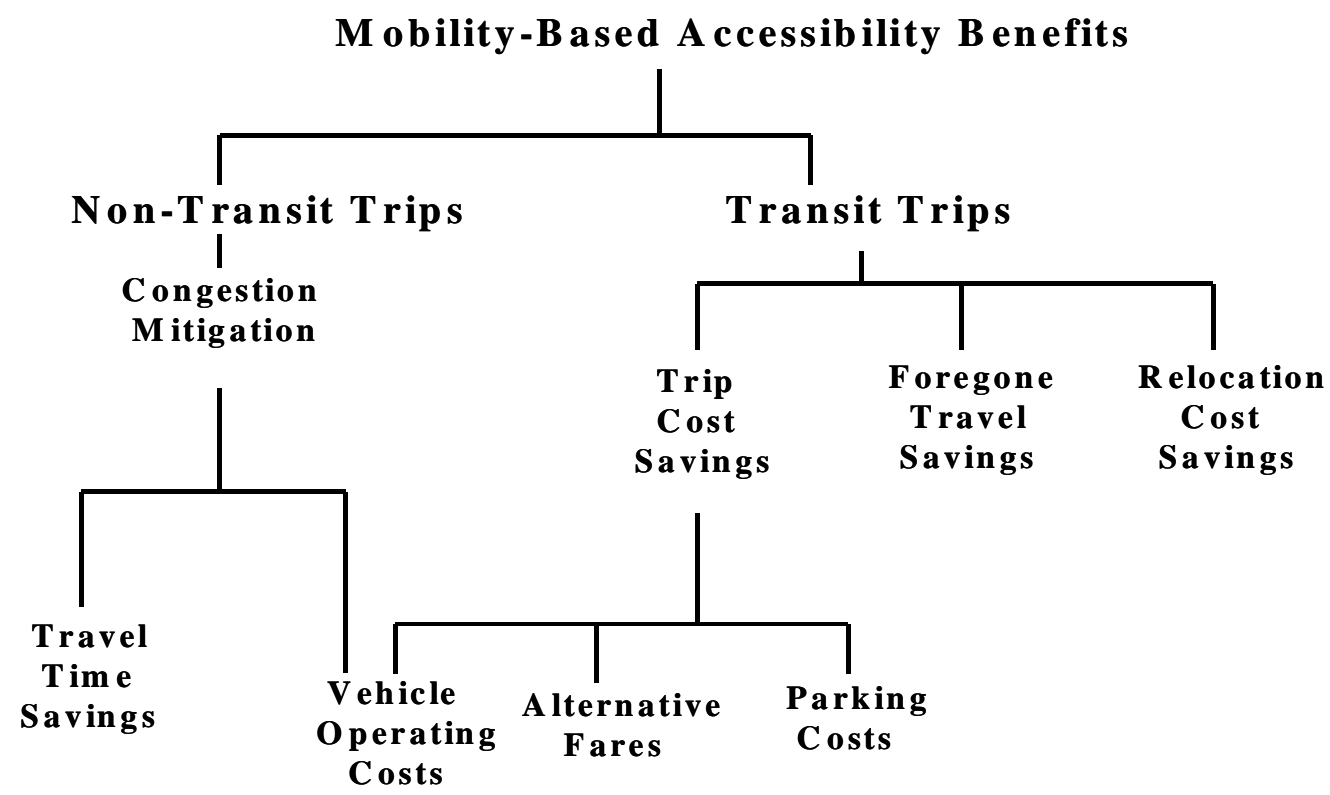

Persons who use transit services because they don't have a private vehicle available for travel are referred to as being "transit dependent", i.e. they rely on transit to move around. ${ }^{1}$ A high percentage of current transit riders in Tennessee fall into this category, in urban as well as rural districts.

\footnotetext{
"also referred to as "transit captive" in the literature
} 


\section{Public Transit in Tennessee}

Non-Transit User Trip benefits are typically much smaller. They refer in this study to the indirect impacts on the drivers and passengers in automobiles and other vehicles (e.g. trucks) that result from public transit ridership. That is, they occur as a result of fewer vehicles on the State's highways. In this study these are measured as the benefits of reduced traffic congestion, and hence in terms of traveler time saved.

\subsubsection{Transit User Trip Benefits.}

Trip Cost Savings: Where an alternative mode of transportation would be used to satisfy a current transit trip the benefit of transit service to transit riders is computed as the difference that riders have to pay in order to make these same trips by this other mode. The major challenge in getting quantitative estimates for this type of benefit rests in 1) defining the nature of the available alternatives to transit ridership, 2) determining their respective probabilities of use, and 3) acquiring data on the costs of using each of these alternatives. Step 2 is usually the most difficult to accomplish, since it requires transit rider survey data. In this study it was decided to compare the different modal operating costs in terms of the person miles of travel involved. Using this approach positive benefits accrue to public transit in cases where the aggregate number of vehicle miles traveled by an alternative mode is significantly higher than it is with transit service in place. This need not always be the case, and depends on transit vehicle occupancy. Where such occupancy is low, as in the case of some demand responsive operations, positive benefits depend on the route circuity involved in transit vehicle pick-up and drop-off services.

\section{Table 2.1 Common Alternatives to Public Transit and Their Estimated Costs.}

\section{Alternative Mode:}

Private Vehicle (automobile, small truck or van)

Taxi

Ride with Friend/Relative

Private Carpool/Vanpool

Walk/Cycle

Forego Trip (i.e. don't travel)
Per Mile Trip Cost:

$\$ 0.445$ per mile

$\$ 1.50$ per mile

$\$ 0.445$ per mile

not used in this study (requires survey data)

cost of a transit trip

varies between approx \$20/trip and \$102/trip

Table 2.1 shows the most common alternatives to a public transit trip along with the per mile travel costs. How these costs were arrived at is discussed in detail below. "Private vehicle" refers here principally to automobiles. The two major costs of travel are travel time and vehicle operating costs. In theory, when a transit rider moves to the automobile there may be time cost savings (or losses). These travel time differences are difficult to measure as they depend on route specific trip times and these in turn depend on time of day and level of highway congestion. Other factors, such as time spent having to park the car and walk to the work site or other destination, also impact such time savings where urban travel is concerned. Since a large proportion of Tennessee's transit users do not have access to a private vehicle anyway these time 


\section{Public Transit in Tennessee}

cost differences were not computed. The emphasis was instead placed on monetary cost savings. The two major monetary cost components associated with use of the private automobile are the vehicle's purchase price and its operating and maintenance costs. Where applicable, these also include parking costs. For example, for a 10 mile one-way trip the loss of transit service to a transit rider who must now use the automobile as his or her next best available option might be computed as:

Trip length $(1$-way $)=10$ miles, automobile cost per mile $=44.5$ cents.

Auto cost per trip $=\$ 4.45$

Bus transit trip cost $=\$ 1.50$ one-way fare.

Savings to transit rider per one-way trip $=\$ 2.95$, plus any parking costs saved.

This figure of 44.5 cents per vehicle mile was derived from a review of the recent literature. Table 2.2 shows the estimated annual costs of owning and operating an average automobile in Tennessee in 1998. This includes the costs of fuel and oil, maintenance and tires, insurance, depreciation, license, registration, taxes and a finance charge. Two sets of figures are provided, both based on the breakdown of 1998 costs reported by the American Automobile Association and Runzheimer International ${ }^{2}$, adapted to reflect the mix of vehicle types purchased in Tennessee over the period 1992-1998 ${ }^{3}$, and further factored to reflect the annual vehicle miles of travel reported for different vehicle types in Tennessee in 1995 (the latest date for which these data were readily available). ${ }^{4}$ Both of these 53.1 and 44.5 cents per mile figures fall within the values reported in recent literature (see Berk and Associates, et al, 1998; Litman,1999).

The first column of figures shows the estimated costs associated with operating an average vehicle in Tennessee in 1998, for a vehicle traveling 12,000 miles per year ${ }^{5}$ and with ownership costs based on six years and 60,000 miles of use before replacement. The resulting estimate of 53.1 cents per vehicle mile is a little below the estimate of 54.8 cents per vehicle mile reported in Table 5.11 of the US Department of Energy's Transportation Energy Data Book (Davis, 2000; Edition 20), which uses the same data source (the American Automobile Association's "Your Driving Costs") ${ }^{3}$ to estimate 1998 automobile use costs.

2 Source: American Automobile Association and Runzheimer International, Your Driving Costs, 1999 Edition. http://www.apta.com/stats/trvsauto/drivcost.htm.

${ }^{3}$ Source: Registration and Vehicle Miles of Travel of Light-Duty Vehicles, 1985-1995. ORNL-6936 (P.S. Hu, S.C. Davis and R.L. Schmoyer. Feb. 1998 .

${ }^{4}$ Source: Table 7.3 in Davis S.C. (1999) Transportation Energy Data Book 19, Oak Ridge National Laboratory, ORNL-6958. Oak Ridge, TN 37831.

5 An average mileage of 11,914 was estimated for the entire US in 1998, according to the Federal Highway Administration's 1998 Highway Statistics Series. Table VM-

1.http://www.fhwa.dot.gov/ohim/hs98/hs98page.htm. 


\section{Public Transit in Tennessee}

The second column of costs shown in Table 2.2 represents the Baseline costs used in this study. The value of 44.5 cents per vehicle mile results from a significant reduction in depreciation costs, compensated somewhat by an increase in vehicle maintenance costs and a reduction in estimated annual miles of travel (from 12,000 to 11,200, the latter just under the national average of 11,400). These changes are based on the assumption that current transit riders are more likely to operate lower cost and older vehicles that the average driver. As a rationality check, the annual Baseline cost of operating a private vehicle less any depreciation costs, estimated in Table 2.2 as just over $\$ 3,209$, is quite close to the estimate of $\$ 3,185$ one obtains by taking the 1998 average annual expenditures on transportation for all US households with incomes under $\$ 20,000$ (based on data in Davis, 2000, Table 11.2), suggesting a reasonable value for this present study.

Table 2.2 Estimated Annual Costs of Owning and Operating A Private Automobile in 1998.

\begin{tabular}{|c|c|c|}
\hline \multirow[b]{2}{*}{ Cost Category } & \multicolumn{2}{|c|}{ \$/Year } \\
\hline & $\begin{array}{l}\text { Tennessee } \\
\text { Average } \\
\text { (Estimated) }\end{array}$ & $\begin{array}{c}\text { Values } \\
\text { Used in } \\
\text { This Study } \\
\end{array}$ \\
\hline Gasoline \& Oil & 715.0 & 667.4 \\
\hline Maintenance & 366.3 & 461.6 \\
\hline Tires & 163.1 & 152.1 \\
\hline Insurance & 936.1 & 936.1 \\
\hline License, registration, taxes & 2355 & 235.5 \\
\hline Depreciation & $3,196.3$ & $1,775.0$ \\
\hline $\begin{array}{l}\text { Finance charge } \\
\text { Miles traveled per year }\end{array}$ & $\begin{array}{r}756.6 \\
12,000 \\
\end{array}$ & $\begin{array}{r}756.6 \\
11,200 \\
\end{array}$ \\
\hline $\begin{array}{l}\text { Costs minus depreciation } \\
\text { Total cost in } \$ \text { year }\end{array}$ & $\begin{array}{l}3,172.5 \\
6,368.9\end{array}$ & $\begin{array}{l}3,209.2 \\
4,984.2\end{array}$ \\
\hline Total cost in cents/mile: & 0.531 & 0.445 \\
\hline
\end{tabular}

Table 2.3 Default Vehicle Operating Cost Assumptions Used in This Study.

Costs per Vehicle Mile: $\quad$ Costs per Passenger Mile:

$$
\text { Occupancy }=1.1 \quad \text { Occupancy }=1.4
$$

\begin{tabular}{lll}
44.5 cents & 40.5 cents & 31.8 cents \\
53.1 cents & 48.3 cents & 38.9 cents \\
\hline
\end{tabular}




\section{Public Transit in Tennessee}

Finally, to allow for some level of ridesharing when estimating aggregate vehicle operating costs, private vehicle occupancy was assumed to be approximately that of the national average, at 1.1 persons per vehicle for commute trips, and 1.4 for non-work related trips. Applying these values to the estimated average cost per passenger mile produces the figures shown in Table 2.3 above. The table heading refers to these as default cost assumptions because some sensitivity analysis was carried out around these numbers based on the above discussion (see Chapters 4 and $5)$.

As an additional yardstick, these figures compare with the cost of reimbursing a government employee for the use of his or her own vehicle for business travel at a rate of 32.5 cents per mile. ${ }^{6}$ Most of the State's 11 urban transit supporting areas have an average vehicle occupancy rate between 1.2 and 1.3 persons per vehicle. For rural trips the default average vehicle occupancy was assumed to be 1.1 persons per vehicle.

The above estimates were also generated, it is worth noting, before the significant at the pump fuel price increases in year 2000. Under the full 53.1 cents per mile cost figure, fuel (actually, gasoline and oil) costs are just over $11.2 \%$ of annual vehicle costs. The increase of around $30 \%$ in the price of gasoline at the pump during the past year would increase this percentage to approximately $14.1 \%$ of the total private vehicle costs: an almost $3.4 \%$ overall increase in private vehicle operating costs.

Parking Cost Savings: While some 95\% of workers in large US cities currently park for free when at work (Mildner, Strathman and Bianco, 1996; Shoup and Breinholt, 1997) there is nevertheless a real cost imposed on the employers, or on the city, for providing this parking. As Burkhardt, et al (1998) point out, the true cost of providing parking depends on the type of parking, the cost of land and construction, and the nature of the local real estate market. Where land used for parking could be put to more profitable use we have what economists call an "opportunity cost" associated with supplying the parking space. In higher density and high land rent areas, such as the downtown commercial areas of Memphis, Nashville, and Knoxville, empty parking spaces are often hard to find. Adding additional spaces would require land that would otherwise be put to other productive use. The savings in the cost of supplying these extra parking spaces to automobile commuters is therefore a legitimate transit benefit. This includes the additional taxes the city or municipality might receive as a result of receiving higher taxes on the land from uses more profitable than parking.

One way to get at these parking cost savings is to estimate the annualized land, construction, financing, design and operating/maintenance costs involved in supplying these spaces.

According to Burkhardt, et al (1998) these costs vary considerably by type of parking structure: from a nationally averaged low of about $\$ 5,100$ per surface space or stall, to as much as $\$ 53,300$ for a space in an above-ground, multi-level parking structure, up to as much as $\$ 99,300$ per

\footnotetext{
${ }^{6}$ For details: http://policyworks.gov/org/main/mt/homepage/mtt/mtthp.htm
} 


\section{Public Transit in Tennessee}

space in an underground structure (in 1997 dollars). These costs then need to be apportioned over the lifetime of the parking structure. ${ }^{7}$ Litman (1999) uses a number of different data sources and estimates typical monthly urban parking facility (construction, land, annualized capital plus operating) costs to be around $\$ 50$ for a surface parking space, $\$ 125$ for structured parking space, and \$200 for an underground parking space, in 1996 dollars: noting that most parking structures also impose environmental (e.g. groundwater runoff) and aesthetic costs. ${ }^{8}$

A second, and much simpler approach to the problem of estimating parking cost savings was taken in this study. Based on an informal summer 2000 telephone survey of a small number of (1 to 4) parking companies operating privately owned parking lots within each of the State's metropolitan areas, monthly parking charges in the range \$20 - \$100 were reported, depending on city, type of parking space and location. Based on this information a default parking cost of $\$ 1.50$ per one way trip was used in this study (i.e. an average of approximately $\$ 3$ in parking costs per day). Assuming that these costs are capturing the value of the structures and spaces they are using over a reasonable period of operation, the following formula was used to compute annual parking cost savings in each metropolitan area, where available parking was found to be a scarce resource:

parking cost savings $=\$$ parking cost savings per one way trip $\mathbf{x}$ (number of one way non-transit trips caused by loss of transit service $\mathbf{x}$ percentage of these trips taken to downtown) / non-transit vehicle occupancy ratio.

Walk and Cycle Trips are assumed to occur only when the distance traveled is quite short. The cost difference between transit and this option should include the value of lost travel time caused by having to walk rather than ride. In this project the lost value of a transit ride to those who walk or cycle is conservatively assumed to be equal to at least the transit fare they were willing to pay to make the trip. Few such trips entered the analysis.

Rides with Friends or Relatives. A common solution to loss of transit service for transit dependent riders, especially of a temporary nature, is to rely on rides from friends or relatives. Leinbach, Watkins and Stamatiadis (1994), for example, found that $63 \%$ of the 155 elderly persons they surveyed in non-urban Kentucky sometimes received rides from neighbors, $49 \%$ received rides from friends, $69 \%$ from nearby relatives, and 51\% from more distant relatives. Estimating the cost difference between transit and transport by a friend or relative requires

\footnotetext{
${ }^{7}$ Note here that while an increase in public transit ridership may reduce the demand for such high cost downtown parking spaces it may also create a demand for less expensive parking in suburban or ex-urban locations around transit stops.

${ }^{8}$ Litman (1999) also points out that there is an additional cost to residential parking, estimating that just one parking space per housing unit increases construction costs by $18 \%$. We did not consider such costs in the present study.
} 


\section{Public Transit in Tennessee}

knowledge of per mile vehicle operating costs as well as the additional travel time involved for all occupants of the vehicle. The operating-only cost of a private automobile trip includes the costs of fuel, tires, maintenance and taxes associated with them: since the costs of vehicle ownership, licensing, other taxes and finance charges have already been borne by the vehicle owner (Skolnik and Schreider, 1998). Based on the figures presented in Table 2.2 above, this leaves a per mile vehicle operating cost of 10.4 cents per mile not including any additional parking costs that might result from the altered trip. Added miles, however, also impact vehicle depreciation to a small extent.

The associated travel time gains or losses are more difficult to compute. Especially within an urban environment, the transit rider may or may not arrive sooner than he or she would by using transit, while the driver (and any other passenger) is likely to take longer to reach his or her destination. If the friend or relative has no other reason for taking the trip then significant additional travel time costs are also involved. In rural areas where workplaces are more widely dispersed there may be significant additional travel time penalties involved in specific trips. For example, allowing for an additional 15 minutes of one way travel time for the vehicle's occupants at a value of time of $\$ 10$ per hour gives an additional time use cost, per occupant, of $\$ 2.50$ per trip. At an average speed of $30 \mathrm{mph}$ this would also imply an additional 7.5 miles of operation. At 10.4 cents per mile this yields an additional 78 cents in vehicle operating cost per trip. Additional return trip costs may not be symmetric, depending on the driver's location prior to pickup for (typically) the journey home. Given the wide range of possibilities, and since the value of time also depends on trip purpose, among other things, a somewhat conservative default value equivalent to the cost of automobile travel was used in this study.

The next best or "least-cost" alternative may not always be a private automobile. If the next best alternative to riding a bus is to take a taxi cab then the value of transit service to that user is calculated as the difference in the taxi one way trip fare minus the transit one-way trip fare. Ideally, survey data is required from which to estimate the percentage of transit patrons who would choose each of the above travel alternatives. Selecting the most likely modal alternative to transit can be especially challenging in the case of transit riders in households with no automobiles, or in households where there are more workers than available automobiles. How such benefits have been handled in the past has been very much determined by the data available to each study. Where a survey of transit riders has been possible, riders have been asked what they would most likely do if transit service was discontinued or scaled back. Where such surveys can obtain information on either the trip distances or on the actual origins and destinations of transit trips, it is also possible to compute the alternative travel costs of using a private automobile, taking a taxi, or using some other means of travel. For Tennessee, limited survey data were available from a handful of past studies, requiring the use of other data sources to develop some of the Statewide estimates (see Chapters 4 and 5 of this report for details). Since the benefits of transit to individuals have a great deal to do with why and to where they are traveling, data is required on both the number of trips taken and on the trip lengths involved, by trip purpose. The total revenue miles of transit vehicle operations as well as the total cost of providing these services is reported annually for each Tennessee transit district. These data were 


\section{Public Transit in Tennessee}

obtained from the Tennessee DOT and put into spreadsheets. The major data collection effort involved obtaining trip length and operating characteristics data for the alternative modes. In the case of trip length statistics this presented a non-trivial problem for rural and small urban transit service districts, where there is no readily available source of information. These are not in general easy data to come by and can be expected to vary in content and currency across transit districts. The State's twelve urban transit systems all provide annual estimates of the total number of passenger trips and the total transit vehicle revenue miles operated. With the exception of the three smallest urban transit systems (Bristol, Oak Ridge and Pigeon Forge) they also provide an estimate (reported to the Federal Transit Administration) of the annual number of passenger miles of travel supported by each system. ${ }^{9}$ Unfortunately, the number of different riders using these various services is not estimated. The State's rural systems also report annual transit vehicle miles of operation. They also provide an estimate of the number of clients using the service in addition to the number of trips these clients make. ${ }^{10}$ The nature of this trip purpose data is discussed in greater detail below and in Chapters 4 and 5 of this report, notably under the heading of foregone travel benefits.

Foregone Travel Cost Savings. In many instances the loss of public transit service can lead to trips being canceled. In Figure 2.2 and throughout this report we refer to trips not taken due to the loss of transit service as foregone travel. The nature of these costs is likely to be highly dependent on trip purpose. Where work trips are lost it can lead to loss of wages and eventually to loss of the job itself. Where the trip is a medical one it can lead to major health consequences for the individual concerned. This foregone travel can also have a social as well as an economic cost, creating an increased sense of isolation for some non-drivers. This is often the case where sick, elderly or disabled persons are involved in travel. Ideally, the percent of foregone trips by trip purpose and type of service is needed to establish the foregone travel costs of lost transit service (or the benefits of adding new or improved transit services) with great confidence.

Trip Purpose Data: To assist our understanding of the value of lost trips, a Fall 1999 poll of the State's eleven rural transit providers, requested on the study's behalf by the Tennessee DOT, obtained their best estimates of the breakdown in their annual ridership by trip purpose. ${ }^{11}$ This process is described in detail in Chapter 5 of this report. Data on the trip purposes of urban transit riders were less easy to come by and had to be estimated for a number of systems. Table 2.4 summarizes the results of this survey aggregated across all 11 rural and across all 12 urban transit districts.

9 on annual on-board or vehicle following ridership surveys.

${ }^{10}$ Data on number of trips appears to be more reliable than the data on number of clients for these systems.

${ }^{11}$ While not a true sample, these ought to be reasonably good data given that the majority of trips these providers handle are contract rides, including a significant percentage of elderly and persons with disabilities whose reason for traveling is known. 
Public Transit in Tennessee

Table 2.4 Estimated Rural and Urban Transit Trips by Trip Purpose.

\begin{tabular}{l|cc}
\multicolumn{1}{c|}{ Trip Purpose: } & $\begin{array}{c}\text { Percent of Total Annual Trips: } \\
\text { Urban } \\
\end{array}$ & \multicolumn{2}{|c}{ Rural } \\
\hline Medical & 7.8 & 35.8 \\
General (Shopping, etc.) & & 25.4 \\
Families First/ & 12.4 \\
Job Training & & \\
Nutrition Sites & & 10 \\
Day Care Adult & & 3.2 \\
Headstart & & 1.2 \\
Employment & 50.1 & 1.7 \\
Foster Grandparents & & 0.3 \\
Non-Work, Non-Medical & 42.1 & 0 \\
\hline
\end{tabular}

More details on the urban trip purpose breakdown are found in Chapter 4 of this report. However, in using the available data to place a value on foregone trips within the urban benefits spreadsheet, trip purposes were aggregated in this present study to the three trip purpose categories shown in Table 2.4: employment, medical and other. Where no data were available for a particular urban system, the number of trips taken in each of the reporting urban transit districts was used to produce a weighted statewide averaged percentage for each of these three broad trip purpose categories. Adjustments for district specific services were needed however: notably where a specific group of riders is well know to use a particular transit district's services (e.g. University of Tennessee students in Knoxville; tourists and shoppers in Gatlinburg and Pigeon Forge). Given the considerable variability evident in the distribution of trip purposes by transit district, these estimates need to be replaced with more concrete trip purpose data from specific urban transit districts. ${ }^{12}$

Foregone Trip Percentages: Default estimates of foregone travel percentages were used in this study to generate best guess benefits estimates in this project. These estimates were set at $10 \%$ of urban and $25 \%$ of rural transit trips. Given the significant impact this percentage can have on the benefits generated, however, a range of values was experimented with, as reported on extensively in Chapters 4 and 5 of this report. Data on the likely extent of foregone travel for Tennessee include an early 1980's survey for the City of Jackson (Hearn, 1985) that puts foregone trips at 14\%, and a 1985 survey of fixed bus ridership in Johnson City that reported almost $35 \%$ of 230 interviewees indicating that they would not be able to make the trip without a

\footnotetext{
12 At least one survey is currently planned by Knoxville Area Transit
} 


\section{Public Transit in Tennessee}

bus (Smith and Rieken, 1985). A 1992 sample of some 90 Kingsport taxicab subsidized riders, by Wegman, Chatterjee and Volpe (1993), indicated that $25 \%$ of respondents didn't have anyone to provide them with an alternative means of riding to their destination. Moving outside Tennessee, a recent 9 city study of US bus riders reported between $14 \%$ and $25 \%$ of trips not being taken with loss of bus service (see Pratt, 2001). Recent data reported for the city of San Diego, California (Wegmann and Chatterjee, 2000) found that out of an $82 \%$ transit captive bus ridership some $15.3 \%$ of weekday and $18.7 \%$ of weekend trips would be lost if bus service ceased to operate. For Light Rail Transit riders (56\% of whom are transit captive) these foregone trip percentages were $11.0 \%$ on weekdays and $19.3 \%$ on weekends. ${ }^{13}$ A May, 1996 survey of Houstonic Regional Transit District (HART) riders based in Danbury, Connecticut, reported by Skolnik and Schreiner (1998) had 450 respondents report that they would forego $10.7 \%$ of the sampled weekday trips, and 5.2\% of weekend trips on the fixed bus route system; while $29.1 \%$ of sampled trips would be dropped with loss of paratransit services. Some 53\% of HART's fixed route ridership were estimated to be transit dependent. Based on discussions held with urban transit district personnel in Tennessee during September-October 2000, the percentage of transit dependent riders appears to be a good deal higher in Tennessee than for any of the studies reported above: on the order of $90 \%$.

The recent literature on foregone travel (Burkhardt et al 1998; Skolnik and Schneider, 1998; Lewis and Williams, 1999) includes a number of approaches to the benefits estimation problem. In keeping with the development of a spreadsheet that contains data on the number of transit trips taken annually, these foregone travel benefits were placed on a per trip basis. While not ideal, there is precedent for this approach (see, for example, Skolnik and Schneider, 1998). A preferable approach would be to identify the number of riders using the various transit services, and compute the effects on these people in terms of lost wages, lost medical attention, etc (see Burkhardt et al 1998, for example). With the only reliable data available to the study in the form of number of trips made annually by each system and service type, this would have meant assuming values for the annual number of trips per rider. Given that not all riders are as regular as others, and often don't use the system each day of the week, a trip based estimate of foregone benefits was adopted. Future surveys might benefit from obtaining data on the frequency with which riders use the state's transit services to allow an estimate of number of patrons to be computed. ${ }^{14}$ Based on the above literature, the following trip purpose specific approach was chosen for valuing such lost trips:

13 Foregone travel during the Knoxville transit strike of 1977 was estimated by Wegmann et al (1979), but this is for a temporary condition, allowing little time for further trips to be lost as the short run options to transit become more burdensome over time.

${ }^{14}$ Wegmann, Chatterjee and Volpe (1992) do provide some data on this for the Johnson City Transit system: with significant differences in daily rides per day between choice versus transit dependent riders, and across age groups, for example. 


\section{Public Transit in Tennessee}

Medical and Nutrition Site Trips: An analysis of access to health services in the state, based on the 1997 Tennessee Health Care Risk Survey (Scheb, 1997), found that $11.8 \%$ of the sample survey's over 19,000 respondents had a problem with availability of transportation to health care facilities. ${ }^{15}$ This included $12.2 \%$ of respondents from low income households (under $\$ 20,000$ per year), $11.0 \%$ of respondents from rural areas and $9.5 \%$ of urban residents who said they had a "definite problem" with transportation availability. Given the importance of medical trips to many, notably demand responsive transit patrons, some effort was put into obtaining reasonable estimates of their costs. This includes the over $31 \%$ of rural transit trips involving either wheelchairs or travel by persons with other disabilities.

If a person cannot or will not travel due to loss of transit service, and assuming that medical services need to be provided, two options are open. One is to have that person visited by a qualified medical professional. The other is for the patient to move into, or near to, a health care facility. Data was obtained from the Tennessee State Department of Health in order to compute representative costs per visit for both at home visits and for visits to health care facilities. ${ }^{16}$ For at- home visits, Home Health Agency Data for fiscal year 1998-99 (Tennessee Department of Health, 2000) were used to compute average at home visit costs in each urban and rural transit district, data that had to be aggregated from the individual health care agency level, as well as averaged across a number of different visit categories ${ }^{17}$.

Table 2.5 summarizes the range of per visit values used in this study. In computing the estimated savings per one way transit trip, district specific per visit health care costs were divided by 2 to capture the need for a return trip. It was also assumed that the costs of providing the at-home medical service includes the cost (and also the mileage involved) in a round trip visit by the medical staff persons involved. ${ }^{18}$

15 Based on telephone interviews of at least 200 residents per county using random digit dialing to select respondents between the Summer of 1996 through the Spring of 1997.

http://web.utk.edu/ chrg/hit/main/tables/ssri/report2.htm

${ }^{16}$ For the case of visits to facilities these costs may not be exactly the ones we want if we are trying to reproduce relocation costs on a cost per trip basis. However, they would appear to be of the right order of magnitude.

17 The available categories of care are skilled nursing, home health aids, speech therapy, occ. therapy, physical therapy, medical social service, home-maker and other. Averaging was based on annual number of visits by each type.

${ }^{18}$ Note that in recognizing these at-home medical visit requirements, the two-way automobile trips involved need to be accounted for when computing transit's environmental and safety benefits. 
Public Transit in Tennessee

Table 2.5 Costs Per Medical Visit by Transit District (Ranges), in 1998 Dollars.

\begin{tabular}{lll} 
& $\begin{array}{l}\text { Nursing Home } \\
\text { Costs/Day }\end{array}$ & $\begin{array}{c}\text { At Home } \\
\text { Visit Costs }\end{array}$ \\
\hline Urban Transit Districts: & 113 to $210\left(157^{*}\right)$ & 48 to $188\left(88^{*}\right)$ \\
Rural Transit Districts: & 87 to $171\left(135^{*}\right)$ & 38 to $76\left(65^{*}\right)$
\end{tabular}

* Numbers in brackets are the unweighted average costs across all (urban or rural) districts.

Clearly, these health care costs represent significant costs on a per trip basis to a society that determines that it must look after its ailing citizens.

To bring these nursing home costs most effectively into the analysis, an estimate is also needed of how many current riders would need to relocate to such homes in the event of a loss or significant reduction of their current transit service. Such relocation costs can be significant while the need to relocate from one county or municipality to another can lead to lost revenues in the community vacated. A recent study of transit service benefits in rural Georgia counties (Meyer, Nelson and Peng, 1999) computes very high economic costs associated with such relocations. Some sense of the number of riders who would need to relocate can be obtained from the number of elderly, wheelchair assisted patient riding vans in rural areas. Without definitive data a sensitivity analysis was carried out to assess the impact of assuming different percentages of at home verus at facility treated patients.

Employment and Job Training Trips: The value of lost work (commute) trips is estimated as the average value of a lost work day divided by two (i.e. by the to-work and from-work trips). For example, a value of lost annual wages of $\$ 20,000$, divided by 230 working days per year would give a value of $\$ 100$ a day in lost wages, or $\$ 50$ per one way trip. For residents who are taking part in the Tennessee Families First or another job training program these costs are reduced to equal the current minimum wage $(\$ 5.15$ hour $* 8$ hours $=\$ 41.20)$ again divided by two trips, giving a value of $\$ 20.60$ per trip. Ideally, to obtain the value of a work day the average wage of a transit rider is required within each district. Since we did not have any statistically reliable data on the average income of transit riders within the majority of transit districts in the state, an estimated average income from wages and salaries was made for riders in each transit district. Average county wage and salary income per job varies a good deal across counties, with Department of Commerce data ${ }^{19}$ showing an average in 1998 of $\$ 27,840$, a high of over $\$ 32,000$ (Anderson County) and a low of just \$16,200 (Hancock County). Based on recent transit survey data for the State, these values were adjusted downwards to reflect the lower than average wage rate of current transit riders. Where the State provides public assistance to people who have lost

\footnotetext{
${ }^{19}$ Regional Economic Information System (REIS). Bureau of Economic Analysis data found at http://fisher.lib.virginia.edu/reis/
} 


\section{Public Transit in Tennessee}

their employment this assistance can be subtracted from the figures above to yield the approximate local area impact of lost income. However, in this study the full (e.g. \$20,000) cost was assigned to lost Statewide benefits.

Day Care, Headstart and Foster Grandparent Trips. Loss of access to day care services, to Headstart services and to the foster grandparent program in rural Tennessee can lead to lost time at work or at job training sites, for those families who need this time away from their children in order to earn a living. While it is difficult to assign a cost per lost trip to these benefits, a reasonable estimate would appear to be the cost of lost work time. This approach was taken in the present study. (An alternative might be to value them at the cost of lost day care. According to the Tennessee Commission on Children and Youth (1999) the average cost per week for quality child care in the state ranged from $\$ 70$ for a four year old to $\$ 150$ for an infant, based on a 1996 task force report. We can expect such numbers to vary a good deal by geographic location, however. ${ }^{20}$ At $\$ 70$ per week this implies a lost value $\$ 14$ per day, or $\$ 7$ per one way trip, which seemed low for such a disruption to a family's daily routine.

Shopping and other trips: It is difficult to assign a value to a lost opportunity such as a shopping trip, since many trips of this nature might be considered "discretionary." Nevertheless, shopping at some level of trip-making is necessary, and there is obviously value in trips that allow social interaction and recreation. As a minimum, these trips are worth the cost of the transit fare spent on them. They will typically be worth a good deal more. Lacking data on the subject, in this study we made the conservative estimate of a \$25 loss of utility per shopping or other purpose (mainly social, recreational, or personal business) trip. Skolnik and Schreiner (1998), for example, report a value of $\$ 24.63$ cents per one-way shopping trip in what appear to by 1996 dollars. More definitive data is needed here.

Less Tangible Mobility Benefits: A topic of growing interest within the transit and related human services communities is the issue of equity in access, and the clear evidence for a "mobility gap" (Leigh, Scott and Cleary, Inc, 1999) between those with and those without everyday use of a private vehicle. Statistics from the latest (1995) National Personal Transportation Survey ${ }^{21}$ indicate that persons in households with no vehicles tend to travel a good deal less than those who do own at least one vehicle. Significantly fewer trips on average are taken by the elderly, especially the elderly in rural households where such households do not own a vehicle.

${ }^{20}$ In 1997 the average amount paid per week for child care by participants in the Families first program was \$33.17, with urban participants paying a little more (\$35.96) than rural ones (\$28.07). These are subsidized costs since the Tennessee Department of Human Services pays a significant percentage of the true costs of this child day care in many cases. http://cber.bus.utk.edu/tdhs/ccs1997/ccs1997.htm

${ }^{21}$ NPTS data can be accessed on line via the Oak Ridge National Laboratory/ Federal Highway Administation website at ttp://www-cta.ornl.gov/npts/1995/Doc/index.shtml . 


\section{Public Transit in Tennessee}

Leigh, Scott and Cleary's analysis of this NPTS data, for example, found that person trip rates for age 65+ residents living outside Metropolitan Statistical Areas (MSAs) averaged only 1.47 trips per day, versus 4.41 trips by this same age group in households with vehicles. For "NonUrban" residents living within MSAs, daily trip rates for the elderly without and with vehicle groups were 1.95 vs 3.96 trips per day, respectively. The equivalent "MSA Urban" trip rate comparisons yielded a closer, but still significant percentage drop in mobility, at 2.62 versus 3.83 trips per day. Closer to home, in their 1992 survey of Kingsport, Tennessee's rider response to the city's coupon subsidized taxicab rides program, Wegmann, Chatterjee and Volpe (1992) found $57.3 \%$ of their sampled users took more trips as a result of the service. Over $38 \%$ indicated that they could make more trips, trips that could not otherwise be made before the service. These differences may be important not only because of the lost benefits from foregone travel discussed above, but also because of the potential for a linkage between adverse health costs and social isolation. While such a linkage has been documented (Olds, Schwartz and Webster, 1996; US DOT, 1997) it remains to be quantified. Given the large numbers of elderly riding Tennessee's transit vehicles this may be an uncounted dollar benefit within our analysis.

Travel/Non-Travel Benefit Trade-Offs. Using the spreadsheets developed for valuing transit benefits within this study, the analyst has the option of considering a mixture of the above types of benefit, i.e., either compare the costs of transit to the costs of auto or some other means of travel, or consider the costs of not being able to make the trip at all, or of relocating. In all cases we estimate the benefits that accrue to the public transit service being offered as the difference between the current transit costs and the costs associated with the most likely chosen (and by implication "least-cost") alternative. In experimenting with this approach it becomes clear that a benefit accruing to a foregone trip (or a need to relocate) is generally much higher than one accruing to a trip that results in a mode shift. In carrying out these sensitivity analyses, the benefits assigned to transit as a result of lost trips are no longer assigned trip cost savings (i.e., to alternative mode cost savings). They also lose any safety and environmental cost savings that would otherwise accrue from increased vehicle mileage (unless a substitute trip, such as a visit by medical personnel is involved). Examples of the sensitivity of benefit estimates to these tradeoffs are presented in Chapters 4 and 5.

\subsubsection{Non-Transit User Trip Benefits.}

Impacts on Daily Traffic Congestion. Well patronized transit vehicles keep automobiles off the highways. Where this occurs in significant number, during congested travel periods, additional benefits from public transit result from the savings in travel time that accrue to all those travelers already on the road. There can also be savings in fuel consumption and mobile source emissions where these lower traffic volumes result in smoother traffic flow.

Ideally, we would like to know the number of transit-removed automobile trips that are present on each of a region's highway corridors. From this we could then estimate the travel speed change, as a function of the before and after traffic volume to roadway capacity (v/c) ratio. 


\section{Public Transit in Tennessee}

When multiplied by the average distance traveled, this change in speed then gives at least a rough estimate of travel time savings due to transit service along that route. To do this properly requires route and time of day specific transit ridership data. It also requires a traffic simulation model, such as a traffic route assignment model, typically linked to a travel mode choice model that computes the speed on each transit-supported route as a function of the route's multimodal traffic carrying capacity (see Southworth, 1995).

For the purposes of this Statewide study an approximate value was placed on these congestion cost savings, based on the data reported by Litman (1999). This approach is based on assigning a passenger car equivalent or "pce" to a transit bus or van and then computing its relative contribution to traffic delays under different road conditions. Under this approach a transit bus may be equal to anywhere from 1.6 pce's under light congestion to as much as 4.4 pce's in congested conditions with regular stops (Litman, 1999). Hilly terrain can also increase the delay times associated with frequently stopping transit buses. These additional pce contributions to travel time increases then need to be translated into a dollar figure based on an assumed value of time. Applying this approach to congested driving conditions, Litman suggests the following range of costs, in cents per vehicle mile associated an average automobile and by an average transit bus in urban conditions (inflated here from 1996 to 1998 costs):

$\begin{array}{lcc} & \text { Automobile: } & \text { Bus: } \\ \text { Low: } & 1.71 \text { cents/mile } & 3.52 \text { cents } / \text { mile } \\ \text { Medium: } & 6.46 \text { cents/mile } & 13.29 \text { cents } / \text { mile } \\ \text { High: } & 19.00 \text { cents/mile } & 39.09 \text { cents } / \text { mile }\end{array}$

Litman also provides estimates that differentiate peak period from off-peak period operations. Translated into 1998 costs he suggests the following costs in cents/mile:

$\begin{array}{lll} & \text { Automobile: } & \text { Diesel Bus and Trolley/Shuttle } \\ \text { Off-Peak: } & 2 \text { cents/mile } & 4 \text { cents/mile } \\ \text { Peak: } & 17 \text { cents/mile } & 34 \text { cents/mile }\end{array}$

That is, a transit bus or transit trolley/shuttle is estimated to contribute about twice the congestion per vehicle mile as a typical automobile. Again, then, transit vehicle occupancy will be the primary determinant of any net savings in congestion costs accruing to these public transit services. For this present study different percentages of peak and off-peak congestion costs were applied to data from each of the State's urban transit systems, with values ranging from 100\% off-peak for the demand-responsive service offered by Oak Ridge to 50\% peak period operational costs applied to the four largest Tennessee cities. More definitive, up to date information for these larger cities would improve this estimation process. While none of the metropolitan transit agencies interviewed considered traffic congestion reductions to be a major benefit of public transit at the present time, the recent rapid and projected growth in the traveling populations in the regions surrounding and including Nashville, Memphis, Knoxville and 


\section{Public Transit in Tennessee}

Chattanooga warrant more serious consideration of this issue in the near future. With this in mind, some allowance for increased congestion reduction benefits from transit was introduced into the study's urban transit benefits forecasting scenarios (see Chapter 4).

Transit Service Support For Special Events. Some of the worst traffic congestion people experience occurs in conjunction with large public events, such as football games and other major sporting and recreational venues. Within Tennessee these include the six or so University of Tennessee, Vanderbilt University and University of Memphis college football games played each year in Knoxville, Nashville and Memphis respectively, the approximately bi-weekly Tennessee Titans' Fall season of National Football League (NFL)games at the Adelphia Coliseum in Nashville, the bi-annual NASCAR race in Bristol, and other quite large sporting, musical and cultural events in Memphis, Nashville, Knoxville and Chattanooga in particular. For example, the Bristol NASCAR venue relies on approximately 7,000 public transit trips to get visitors to and from the race-track during each week-long meeting, while parking in downtown Knoxville during a Tennessee Volunteers football game is notoriously problematic. Transit shuttles currently offer an excellent means of reducing the burden on limited capacity local roads and parking lots during such events. In Nashville the MTA currently provides shuttle service to Tennessee Titans NFL games from a number of remote park and ride lots, while KAT in Knoxville offers a shuttle service from three park and ride lots to Volunteers football games. These special event congestion reducing benefits of public transit were not computed in this study.

\subsection{Environmental Impacts From Transit Use.}

This section of the benefits tree covers what economists often refer to as environmental externality costs associated with transportation operations: costs in air, groundwater, and noise pollution, as well as the loss of land to highways in both urban and rural areas (see Figure 2.3 below). Of these externalities the most studied are air pollutants. These are also the only pollutants for which extensive analysis of transit vehicle operations currently exists, and our quantitative analysis focused primarily on these.

Air Quality Impacts - Mobile Source Emissions. As with mobility and accessibility impacts, air quality impacts were computed in this study on the assumption that loss of public transit service would lead to the use of alternative forms of transportation. For the most part these alternative modes are found to be more polluting forms of transportation per person mile of travel when transit buses and vans achieve a specific rider occupancy level. Today such air quality analyses include the impacts of so-called criterion pollutants currently regulated under the 1970 Federal Clean Air Act and its numerous Amendments. Increasingly also these air quality analyses have begun to include the impacts of carbon dioxide and other "greenhouse gas" emissions.

Figure 2.3 Potential Environmental Benefits. 


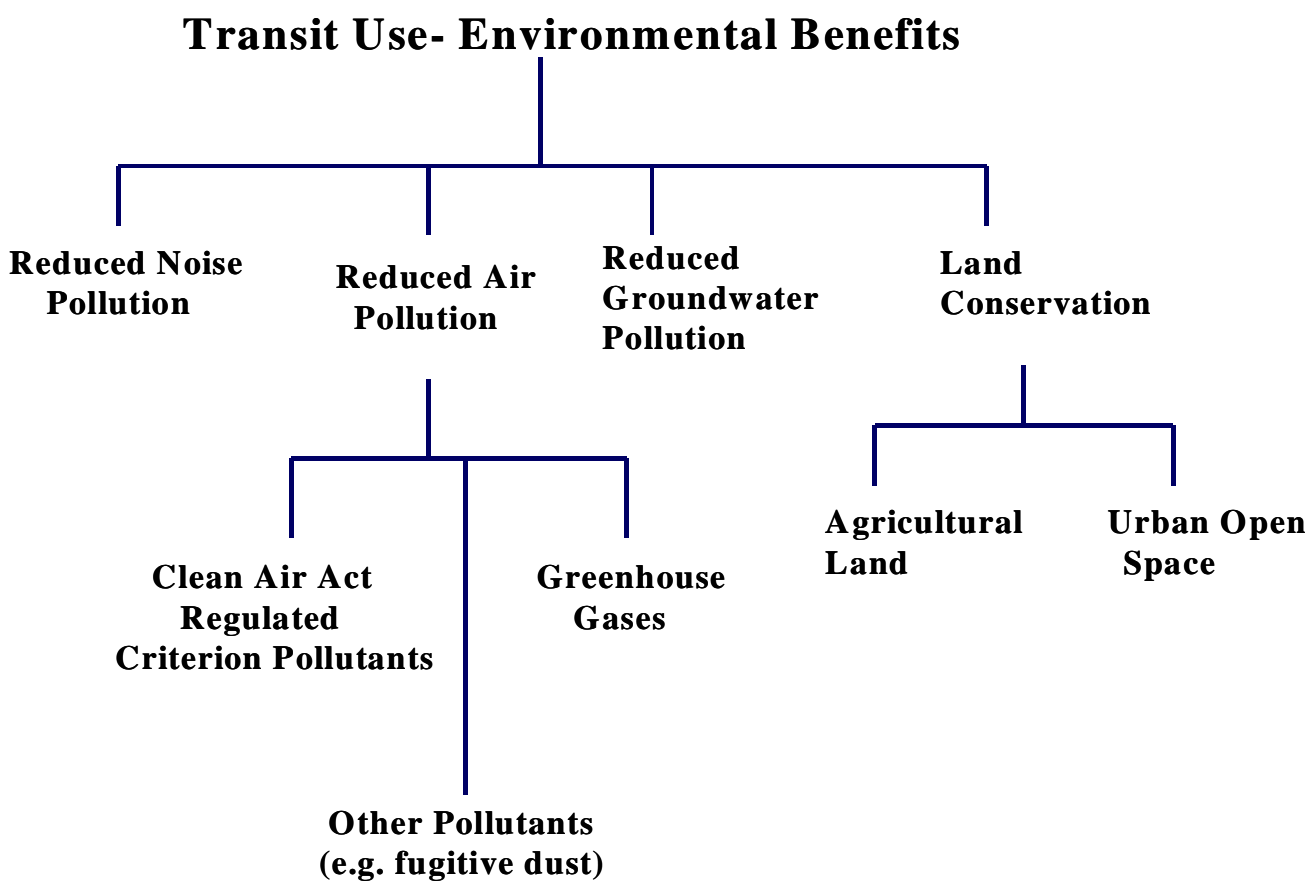

The main reason for putting an economic cost on air pollution is its effects on human health, which are attributed with about $90 \%$ of damage estimates. Other deleterious impacts include damage to crops, forests and materials, while loss of visibility has become an issue in highly polluted urban areas as well as in areas of ecological risk. One such at risk area within East Tennessee is the Great Smoky Mountains National Park. Both ecology and visibility have suffered significantly from anthropogenic emissions sources in recent years. In 1999 the Park attracted almost 10.3 million visitors ${ }^{22}$, many of these day visitors hoping to see scenic views by driving to the higher elevations of this mountain range.

A review of the literature found that a number of issues are currently unresolved, calling into question any one set of pollution damage estimates (see the various papers in Greene et al, 1997, for example). These issues can be grouped under three headings: 1) how much pollutants are being emitted by different modes of travel under different driving, geographic and climatic conditions, 2) which pollutants are causing the greatest human health and other damages, and 3) how many dollars to assign to specific types of damage, notably to human health costs.

Given the above uncertainties, two options were considered for estimating the air quality impacts of removing public transit services from a region: 1) generate or adopt a set of "averaged" mode

\footnotetext{
${ }^{22}$ http://www2.nature.nps.gov/stats/
} 


\section{Public Transit in Tennessee}

and emission specific pollutant impacts (i.e. estimates of average grams of pollutant per vehicle mile or per passenger mile of travel) and translate these into dollar damage costs, using estimates of dollar damages per gram of pollutant, or 2) take representative valuations of damage costs (\$/vehicle mile or \$/passenger mile) directly from this recent literature. Using the first of these two approaches the environmental (air quality) cost of losing transit services can be computed as:

environmental cost $=\Sigma_{\mathrm{TM}}(\$$ damages/gram of pollutant $*$ grams/vehicle mile $*$ annual vehicle miles of travel) $)_{\mathrm{TM}}$ - $\Sigma_{\mathrm{AM}}(\$ \text { damages/gram pollutant } * \text { grams/vehicle mile } * \text { annual vehicle miles of travel })_{\mathrm{A} \mathrm{M}}$

where $\mathrm{TM}=$ Transit Mode (bus, van, rail,...) and $\mathrm{AM}=$ Alternative Mode (Auto, taxi, walk/ cycle,...)

Emissions rates for the pollutants shown in Figure 2.3 can be obtained from US EPA's Mobile Source web site ${ }^{23}$. However, where pollutants such as hydrocarbons (HC), carbon monoxide (CO), nitrogen oxides (NOX) and carbon dioxide (CO2) are concerned, for example, estimates of grams/vehicle mile are highly dependent on vehicle speed, as well as acceleration and the stop-go nature of the driving cycle. Altitude and ambient air temperature also play a role. Experiments with average emissions rates for both automobiles and diesel buses suggested caution with little clear guide as to how to average rates appropriately across different types of transit operations and transit districts.

The recent literature offers a very broad range of air pollutant damage values. This includes the studies reviewed by Gomez-Ibanez (1997), by Krupnick, Rowe and Lang (1997), and by Litman, (1999) for selected highway modes, including the work of Small and Kazimi (1995), Rowe, et al (1996), Krupnick, Rowe and Lang (1997), Delucchi and McDubbin (1996), McCubbin and Delucchi, 1999, and Delucchi (2000). Translated into approximate 1998 costs these estimates span a range from 1 to 16 cents per vehicle mile for light duty automobiles versus a range of approximately 5 cents to a $\$ 1.50$ per diesel bus vehicle mile of travel. While there is good consensus that these are legitimate costs to society, there is currently little consensus on the values to place on specific levels of pollutant reductions. European studies have produced a similar range of results.

Only a limited number of U.S. studies provide data on transit vans and buses (Miller and Moffet, 1993; Apogee Inc.,1994; Litman, 1994; Rowe et al, 1996). In these studies buses are found to be from as much as three times to more than ten times more damaging as automobiles on a per gallon of fuel basis, largely because of their low fuel economy in typical operations. Being diesel fueled they are also likely to have higher pollution costs than gasoline vehicles of the same or lesser size because of high direct particulate emissions and typically higher NOX emissions per gallon. On a per passenger mile basis, however, buses are often more fuel efficient than autos

\footnotetext{
${ }^{23}$ http://www.epa.gov
} 


\section{Public Transit in Tennessee}

because of their occupancy ratios, especially in the peak commuting periods of the day. In trying to narrow the range of these environmental costs, comparisons across studies are hampered not only by differences in geographic location and timing but also because different studies place quite different weights on the relative health dis-benefits of different pollutants. Some of these estimates contain the dollar costs of manufacturing the fuel consumed as well as other so-called "upstream" emissions costs, in addition to the tail-pipe pollutants normally associated with mobile source emissions.

Finally, some of these estimates also contain damage costs attributed to greenhouse gas emissions (carbon dioxide, also methane and nitrous oxide), which have been variously estimated at costs from less than $\$ 1$ per ton to $\$ 30$ or more per ton of carbon. Recent estimates of these greenhouse gas costs for the US, reported by Delucchi (2000), puts them in a similarly large range, from $\$ 0.3$ to $\$ 4.2$ per metric ton of carbon dioxide equivalent emissions. This puts them at $7.6 \%$ to $17.1 \%$ of all human health impacting mobile source emissions costs from motor vehicles. This variability is further compounded because it is also a complex task to ascertain how human health is being affected by exposure to specific pollutants. In particular, assumptions about the effects of pollution on mortality rates, when multiplied by different "value of life" estimates play a big role in these cost calculations. Small and Kazimi (1995), for example, concluded that mortality from particulate matter is the dominant component of pollution damage costs associated with VOC (volatile organic compounds: notably non-methane HC), nitrogen oxides (NOX) and sulphur oxides (SOX), as well as from direct particulate matter creation (PM10: particulate matter less than 10 microns in diameter). ${ }^{24}$ Some recent studies raise the possibility that the dust kicked up by passing traffic (termed "fugitive dust") may also be a significant health hazard (Krupnick, Rowe and Lange, 1997; McCubbin and Delucchi, 1999, for example). The US EPA is also looking into the potential impacts of smaller particulates with diameters of less than 2.5 microns.

Given these considerable uncertainties, the second approach listed above was adopted. By this approach air quality benefits (or dis-benefits) resulting from the presence of public transit service are more simply estimated as follows, based on experiments with the (quite considerable) range of dollar valued air pollutant estimates reported in the recent literature:

$\Sigma_{\mathrm{TM}}\{\$ \mathrm{E}(\mathrm{TM}) * \mathrm{VMT}(\mathrm{TM})\}-\Sigma_{\mathrm{AM}}\{\$ \mathrm{E}(\mathrm{AM}) * \mathrm{VMT}(\mathrm{AM})\}$

where: $\$ \mathrm{E}(\mathrm{TM})=$ dollar environmental cost per vehicle mile of transit mode $(\mathrm{TM}=$ bus, van, rail) service; $\$ E(A M)=$ dollar environmental cost per vehicle mile of alternative mode AM $(\mathrm{AM}=$ auto, taxi, walk/cycle...)

\footnotetext{
${ }^{24}$ VOC's also react with NOX in the atmosphere to form damaging oxidants such as ozone, meaning that pollution damage estimates must also consider how different pollutants work in combination under different atmospheric conditions.
} 
Public Transit in Tennessee

VMT $(\mathrm{TM})=$ annual vehicle miles of travel by transit mode TM

$\operatorname{VMT}(\mathrm{AM})=$ annual vehicle miles of travel by alternative mode AM

Table 2.6 Baseline Per Mile Air Quality Damage Costs by Mode (in 1998 \$).

\begin{tabular}{lr} 
Mode of Transportation & \$/Vehicle Mile \\
\hline Private Automobile & 0.057 \\
Taxicab & 0.057 \\
Gasoline Powered Vanpool & 0.094 \\
Diesel Powered Vanpool & 0.094 \\
Diesel Bus & 0.173 \\
Electric Bus & 0 \\
Commuter Rail & 0.041 \\
Light Rail & 0.028 \\
Walk/Ride & 0 \\
\hline
\end{tabular}

This approach was applied using a set of aggregate (i.e. all inclusive) high and low air pollutant damage estimates, taking mid-range values from the literature. These estimates are listed in Table 2.6 above. In addition to the human health impacts of mobile source emissions there exists also the potential for such emission to damage crops, materials and forests, as well as impair visibility. Delucchi (2000, Table 6) assigns between just under $8 \%$ to as much as $21 \%$ of the total costs of motor vehicle emissions collectively to these four effects. None of these potential impacts could be computed with any reasonable level of precision within the present study. They are noted, however, as a possible source of additional environmental benefits (or disbenefits) associated with transit operations.

Given this current range of uncertainty, a further difficulty exists with projecting air quality benefits from public transit into the future: since both automobile and transit bus and van technologies are expected to change significantly for the better over the next two decades in response to US EPA regulations and compensating somewhat for the expected growth in traffic. To estimate these changes the latest Mobile 6 model spreadsheets were obtained from the US Environmental Protection Agency (US EPA) and the results adapted to reflect Tennessee transit vehicle average fuel consumption rates. For the most part these rates indicate improved air quality benefits from the use of transit over automobile travel if the latest heavy duty diesel engine technologies are adopted over the next decade, largely because of the projected reductions in tailpipe emitted particulate matter from diesel engines, currently thought to be a leading contributor to human health damages from motor vehicle emissions (see McCubbin and DeLucchi, 1999; Delucchi, 2000). These assumptions and their implications are detailed in Chapter 4 of this report. 


\section{Public Transit in Tennessee}

Groundwater Runoff Impacts: Methods for estimating the effects of different types of vehicle operations on groundwater runoff can be found in the literature (see US EPA, 1996, for example). However, computation of anything but relatively cursory estimates of groundwater pollution benefits were considered difficult to substantiate in this present study. According to Crain and Associates, Inc. (1999) a 1997 study by Litman estimates water pollution savings due to fewer highway miles driven at about 1 cent per vehicle mile. For comparison, the same study estimated air pollution savings at 4.2 cents per vehicle mile. Delucchi (1999) has recently estimated the total external environmental costs of US motor vehicle use. His analysis shows air pollution dominating the impacts, with water pollution costs estimated to contribute less than $1 \%$ of total costs. Given this comparatively small contribution to overall environmental benefits and the difficulties of establishing just where and how much groundwater runoff is taking pace (and in what ambient contexts) these impacts were not quantified in the present study.

Noise Pollution Impacts: Methods for estimating noise pollution have also been developed (see US EPA, 1996; Litman, 1999). Noise is measured in decibels and high noise levels can not only be deleterious to human health but can also impact land values. Transportation is often cited as one of today's major sources of "noise pollution". Difficulties in assigning damage costs to specific traffic streams result from the need to put the noise generated into the current ambient or surrounding noise context. Marginal increases in decibels over background or other source noise is one approach to measurement. Therefore knowledge of the effects of reaching different noise thresholds is an important consideration. A study by Haling and Cohen (1997) provides a range of damage estimates depending on urban versus rural location. A study by DeLucchi and ShiLing Hsu (1998) also provides a range of impact estimates based on roadway type (e.g freeway noise verus local roads noise). Litman's (1999) review summarizes these and several studies as putting automobile noise costs in the range 0.2 to 6 cents per vehicle mile. On this basis he suggests using a range of 1 to 2 cents per mile for an average automobile on urban roads, and around 0.05 cents per mile on rural roads. These same studies value diesel bus noise at about five times this level: at 5 cents per vehicle mile in urban areas and 2.5 cents per vehicle mile in rural situations. Electric Buses and Trolleys are estimated to have impacts on the order of 3 cents per urban mile and 1.5 cents per rural mile, while vans are valued similarly to automobiles. These values were adopted as the default or urban transit baseline noise costs in this present study. Rural transit noise impacts from demand responsive transit vans were considered marginal and not computed.

Land Conservation Impacts. The effect of the private automobile on urban development patterns has received a good deal of analysis over the past two decades, much of it within the context of the "urban sprawl" debate. Most of this literature (see "The Costs of Sprawl Revisited" by Burchell et al, 1998; Southworth and Jones, 1996) has focused on the nation's largest metropolitan areas and, of most relevance to this present study, on the potential benefits of mass transit as an adjunct to denser, more concentrated and more travel efficient urban development. Much of this discussion focuses on the use of higher density development as a means of increasing ridership. Greater density of development supports more cost-effective public transit 


\section{Public Transit in Tennessee}

services, which are otherwise faced with higher per passenger operating costs, due to longer rides between or within low density suburbs. "Density and compactness of employment and population is the single most important (attribute of urban form) associated with transit use." (Parsons, Brinkerhoff, Quade and Douglas Inc., 1996: italics added). Significant levels of public transit ridership can, in return, compensate for the need to build additional lane miles of highway, resulting in significant cost savings through reduced highway infrastructure building. As a result, less agricultural or otherwise developable land needs to be devoted to a city's transportation network.

In the urban transit ridership models reported in Chapter 3 of this study a positive if rather mild relationship between number of trips and urban population density is reported in a crosssectional analysis of some 125 urban areas across the United States. Recent statewide legislation, in the form of the Tennessee Growth Boundary Policy Act of July $1998{ }^{25}$ requires every county in the state to develop a comprehensive land use plan by July 2001. Where possible, such plans should re-use already developed land, revitalize urban centers, and encourage more mixed-use developments. Each Urban Growth Boundary should demarcate a reasonably compact region capable of accommodating 20 years worth of residential, commercial and industrial growth, while considering the effects of such boundaries on surrounding agricultural land and other jurisdictions. Ideally, such legislation will encourage the joint consideration of growth by adjacent communities in place of previous unilateral, uncoordinated annexations of land from one jurisdiction to another. Public transit may offer a long term option for helping to control such urban sprawl without having to devote excessive amounts of land to additional highway lane miles. Putting a dollar value on the benefits of such growth, however, was considered beyond the scope of this study's resources. Such benefits would depend a great deal on the speed at which the cities of Memphis and Nashville in particular continue to grow, and on the details of how adjacent jurisdictions had agreed to cooperate with each other to constrain growth along existing or proposed highway corridors.

\subsection{Safety and Security Impacts From Transit Use.}

Safety Benefits - Accident Avoidance : Figure 2.4 below shows the two main branches of this benefits sub-tree. Safety is usually measured in transportation systems as the number of accidents per vehicle mile of travel that occur on a particular mode, within a given geographic area, and over a specified time period (usually a year). Accident statistics are by nature difficult to deal with since they usually require long time periods within which to accumulate significant numbers of incidents. The number of accidents involving public transit vehicles in the state as a whole tends to be small on an annual basis (for example, in 1995 only 2 fatal bus involvements were reported in the federal government's Fatal Accident Reporting System for the entire state: FHWA, 1997). As a result, accident causality is a challenging field of statistical analysis and any

\footnotetext{
${ }^{25}$ http://www.legislature.state.tn.us/bills/100gahtm/100_BILL/SB3278.HTM
} 


\section{Public Transit in Tennessee}

attempt to assign safety benefits or dis-benefits to transit versus other modes of travel must recognize this uncertainty. Most accident statistics are based on number of crashes or incidents per vehicle mile, in an effort among other things, to allow comparisons across different modes. While this approach has been criticized, in favor of per capita rates in some cases (see Davis, 1992),both approaches rely on time series data in order to derive robust safety performance measures. Where local transit systems report few or no accidents it is questionable whether it its appropriate to apply averaged accident rates, except as a measure of expectation over a number of years.

Figure 2.4 Potential Safety and Security Benefits.

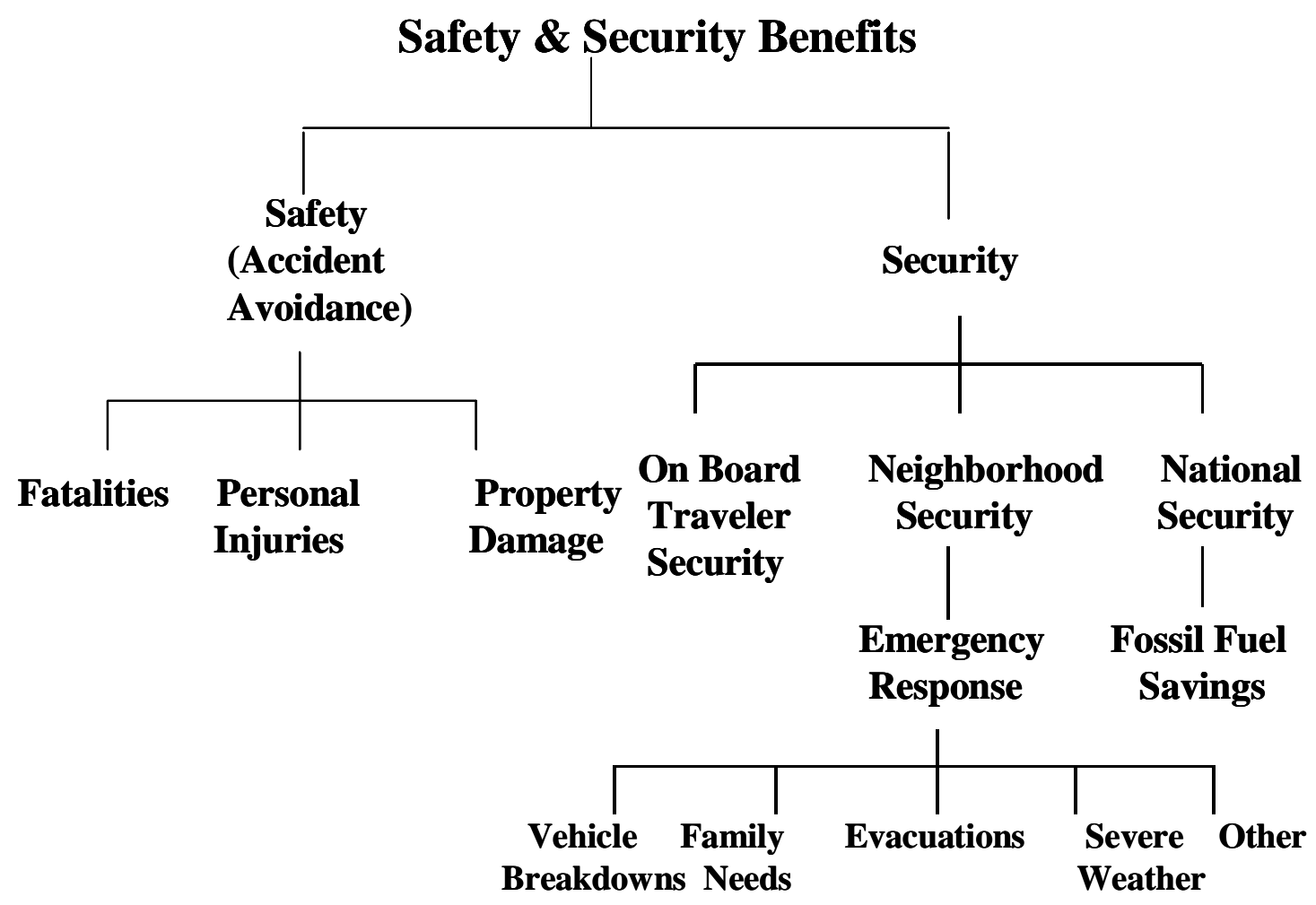

Speed of travel, functional class and geometry of highways, weather conditions, time of day, and driver characteristics can all play a role in causing accidents. The major reason for expecting transit to be a safer mode of travel over the automobile, per passenger mile of travel, is the reduction in aggregate vehicle miles of travel, resulting in fewer opportunities for exposure to traffic in general. Additional reasons include the better maintenance often carried out on public transit vehicles. A third factor is the benefit of having older people, whose reaction times have slowed, use transit as a means of travel. More data on this last topic is warranted. Using average accident costs for the population as a whole probably undervalues these safety risks. This is an 


\section{Public Transit in Tennessee}

area that warrants further investigation in any follow-on development of the data in the transit benefits spreadsheets developed by this study.

Offsetting these effects can be the cost of an accident involving a bus or van carrying a large number of people. Rural crashes, it is worth noting, are often more costly than urban ones, possibly due to the higher speeds involved (Tessmer, 1996). For the purpose of this present study recourse was made to the recent literature on accident rates and their associated costs. As with emissions modeling, there is an extensive literature on how to place a monetary value on different sorts of traffic-related accidents, but with limited consensus on the best method or numbers to use in doing so. Costs include not only medical costs resulting from any injuries (to drivers, passengers, others) and value of life estimates in the case of fatalities, but also lost wages, employer costs, ${ }^{26}$ property damage, the value of public services (e.g. emergency response), and incident induced travel delays (see UC-Berkeley, 1993; Miller, 1997).

Miller (1997) presents estimates of 13.6 cents per vehicle mile in safety costs for automobiles compared with 37 cents per mile for buses. These values are in 1993 dollars. Translating them into 1998 dollars yields approximate auto safety costs of 15.3 cents per vehicle mile, and an approximate bus safety costs of 41.7 cents per vehicle mile. These values are somewhat higher than those obtained for automobile travel by some other U.S. studies carried out during the 1990's (see Gomez-Ibanez, 1997; Berk and Associates, et al, 1998), which tend to fall in the range of 4 to 7 cents per passenger mile, or approximately 5 to 10 cents per vehicle mile depending on average vehicle occupancy (of 1.1 up to 1.5). A problem with passenger mile based numbers is that bus accident cost statistics depend on the number of occupants, since a single major accident may impact more people on average if a higher occupancy vehicle is involved (while the heavier bus may also generate more damage than an automobile in a collision, other things being equal).

Litman (1999) uses past study findings to develop separate estimates of the internal versus external costs associated with motor vehicle accidents. In total these costs include "deaths, injuries, pain, disabilities, lost productivity, grief, material damage, and accident prevention". These estimates are given net of insurance premiums (which fall under vehicle operating costs and are included in mobility-related accessibility benefits in our present study). Internal costs refer here to the damages done to occupants of the vehicles involved, while external costs are those costs imposed on others. This distinction is useful here because internal accident costs are given in dollars per passenger mile, allowing for some recognition of the number of passengers in

${ }^{26}$ Costs to employers from motor vehicle crashes include 1) employee health fringe benefits paid because of illness or injury, contributions to Workmen's Compensation medical and disability insurance, private insurance and its administration; 2) non-fringe costs including vehicle property damage and liability insurance, crash-related legal expenses and the costs of un-reimbursed vehicle damage and replacement; and 3) wage premiums paid to workers for accepting risky jobs (see NHTSA, 1996). 


\section{Public Transit in Tennessee}

the vehicle. External costs, in contrast, are given in dollars per vehicle mile. ${ }^{27}$ In the recent accident cost literature such estimates each have a wide range associated with them. For example, Litman's review of past studies puts automobile internal plus external accident costs in the range 5 to 20 cents per vehicle mile. Litman's automobile, van and diesel bus estimates were used in this report to compute a set of baseline accident rates by vehicle type. Miller's estimates for automobile and bus transit were also added to the transit benefits spreadsheets for comparison purposes, net of insurance costs (which, based on data also presented by Miller, were estimated to be approximately $17.8 \%$ of total accident costs).

Representative rail transit accident costs are harder to come by. Translating 1990 dollars into 1998 dollars by using the Consumer Price Index, Miller and Moffat (1993) put urban rail transit costs at 0.75 cents per passenger mile of travel (pmt), compared to 4.1 cents pmt for automobiles and just under 0.88 cents pmt for urban bus transit. In contrast, Apogee Inc. (1994) put rail transit accident costs at about half this figure, or 0.38 cents pmt, compared to 0.75 cents pmt for single occupancy autos on the expressway (in Boston, MA), and 1.37 cents pmt for urban transit bus, in 1998 dollars. With an estimated 4 passenger miles for every light rail mile operated in Memphis (based on Memphis operating and ridership data for 1998), a value of 0.75 cents pmt yields a value of 3 cents per vehicle mile, while a value of 0.38 cents pmt yields a value of 1.52 cents per vehicle mile. The mid-point of these values is 0.57 cents per pmt or 2.26 cents per vehicle mile. This midpoint valuation was adopted as the combined internal plus external baseline safety cost for the urban rail transit accident rate in this study. On the basis of this and related literature, the values shown in Table 2.7 were adopted as the baseline travel safety costs in this present study.

Table 2.7 Baseline Safety Costs by Mode of Transportation.

A. Based on results presented by Litman, 1999

\section{Internal Costs External Costs}

Mode of Travel: (cents/pmt) (cents/vmt)

\begin{tabular}{lrl}
\hline Auto & 5.2 & 3.64 \\
Van & 5.2 & 3.64 \\
Diesel Bus & 0.32 & 2.08 \\
\hline
\end{tabular}

B. Based on results presented by Gomex-Ibanez, 1997

\begin{tabular}{|c|c|c|}
\hline & $\begin{array}{l}\text { Combined Inter } \\
\text { (in cents/pmt) }\end{array}$ & $\begin{array}{r}\text { External Costs } \\
\text { (in cents/vmt) }\end{array}$ \\
\hline Rail Transit & 0.565 & 2.26 \\
\hline
\end{tabular}

* numbers converted to from A) 1996 and B) 1990 dollars to 1998 dollars using Consumer Price Index inflator.

\footnotetext{
${ }^{27}$ As Litman (Page 3.3-10 footnote) notes “. A vehicle carrying only one driver imposes only about $10 \%$ of the internal accident risk as a vehicle carrying ten people, but the external accident risk is considered the same for both."
} 


\section{Public Transit in Tennessee}

Security benefits or dis-benefits associated with transit refer to the positive and negative aspects of riding public transit through different neighborhoods during different times of the day. The literature on this is for the most part qualitative in nature and difficult to assign numerical benefits or costs to. On the negative side, urban transit systems operated in the nation's largest cities have often been labeled as sites where the crime rate may be higher than usual. Litman (1999, Section 3.3), argues that this sort of risk tends to be exaggerated by the news media, and that there is some evidence that the risk of public assault may decline as transit use increases, due to more "eyes on the street" (see Jacobs, 1992). Where a current transit patron shifts to walking or cycling as an alternative mode of travel, this too may result in higher injury costs per mile: although, as Litman also reports, the current literature on this topic offers widely different estimates from higher to lower net health risks from walking/cycling than from riding in vehicles.

Also on the positive side, public transit may offer the best, and sometimes only, source of mobility to sections of the public during bad weather or emergencies. A recent example of this in Tennessee was the use of public transit for evacuation and assistance during the ice storm of 1994 (RM Plan Group, 1994). Urban transit buses are often operated on at least a limited basis during bad weather winter "snow days". At such times much of the automobile traffic is kept off the road due to neighborhood access problems, fear of driving in poor conditions, vehicle breakdowns, etc. Transit buses can also be a useful backup fleet in times of crisis, such as during large emergency evacuations, notably where large numbers of people need to be moved quickly away from a fire or other danger site. This option can be especially important when trying to evacuate large institutional populations, such as hospitals and schools.

Transit systems can also provide an important back-up in terms of fossil fuel shortages, such as occurred during the energy crises of the late 1970's. Much of the nation's fossil fuel is imported from abroad and any significant contribution to fuel savings helps the State and the nation reduce its dependency on imported oil. The gallons of oil that are saved by public transit keeping the equivalent number of private vehicles off the road can be significant, and transit may be the only means in such crises for getting many employees to their place of work.

In this study comparisons against different average mpg values for automobile travel were used to estimate annual fuel savings or losses for each type of transit service. In the case of Chattanooga the use of electric-powered buses makes for an interesting fossil fuel and emissions impact analysis. So does the Memphis Light Rail Transit service, since energy consumption by both of these modes is reported in Kilowatt Hours. Note that all fuel cost savings, in monetary terms, are already included under the heading of "travel cost savings", as part of the MobilityBased Accessibility and Benefits sub-tree. When counting dollar equivalent savings, fuel consumption benefits or losses are only counted once. 


\section{Public Transit in Tennessee}

Both economic and social benefits are often attributed to expenditures on public transit systems. While the former are readily translated into dollar valued benefits, the latter, social benefits, are typically stated, and as a result measured, using less tangible metrics. Both types of benefits are addressed below, with the bulk of the effort in this present study focused on the more readily quantified economic benefits. This present study follows the approach used recently by Leigh, Scott and Cleary Inc, et al (1999) to estimate regional and statewide economic benefits in Colorado. Figure 2.5 below shows this approach, represented here as part of the overall benefits tree. The left branch of the tree contains economic benefits associated with the money that comes into a region in support of public transit. The right branch of the tree contains the generative economic growth benefits resulting from a transit system's impacts on the efficiency of the multi-modal regional transportation system within which it operates.

Figure 2.5 Potential Economic Benefits.

\section{Economic and Regional Development Benefits}

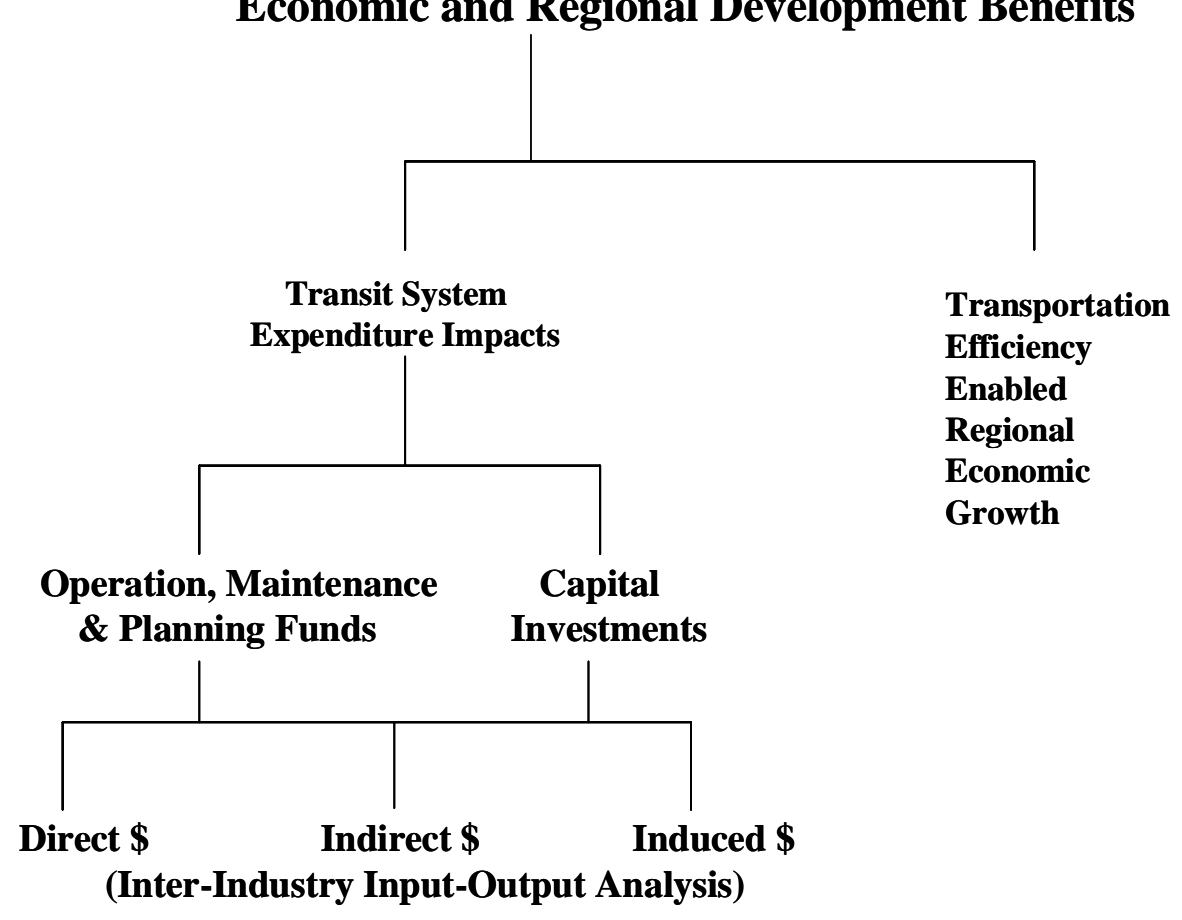

A recent review by Cambridge Systematics, et al (1996) presents evidence from a number of studies that expenditures on public transit systems have consistently yielded positive and significant net economic benefits over expenditures. While the majority of past transit (service expansion or reduction) impact studies have been focused on the nation's larger metropolitan systems, this generally positive finding was found to hold across mid-size as well as small urban and also rural transit systems. Two recent studies, one methodological (Cambridge Systematics Inc, et al, 1996), the other applied (Leigh, Scott and Cleary, Inc, 1999) analyze the economic 


\section{Public Transit in Tennessee}

benefits from regional transit systems from two different but complimentary perspectives. First, infusion of dollars to support transit capital and operating expenditures produces demands for goods and services that translate into jobs and business sales. These expenditures in turn stimulate not only direct employment in transit operations but also spending (and more employment) both within and outside the region.

Second, the greater locational accessibility, travel time and other cost savings resulting from efficient and well placed transit services (including the cost savings associated with safer and less polluting transportation services) have also been found to encourage additional economic activity. While such travel cost reductions are the direct effects of more efficient transportation on the economy, their effects, if sufficiently large, can also promote longer term structural changes in regional economic development and growth. These so-called "generative" impacts usually take time to manifest themselves, but in doing so they add net growth to a local or regional economy.

\subsubsection{Economic Benefits From Transit System Expenditures.}

In the course of annual operations, public transit adds to the local economic spending stream by purchasing local services and supplies, and through the subsequent consumer spending of its workers and those companies who also get contracts to supply parts and services to the transit operators. A 1994 study by the RM Plan Group, for example, cites successes in minority and woman-owned business ventures that were supported by capital and operating funds from local transit providers. Public transit also draws from the local spending stream by the fares it collects and from any local government matching funds used. Though public transit subtracts as well as adds to the local spending stream, our research indicates net impacts that are positive and often quite significant.

A regional input-output (I-O) modeling approach was used to capture these economic impacts of transit expenditures on each of the State's rural transit districts and metropolitan areas. This approach has been used in a number of previous transit benefit studies (for example, Strathman and Dueker, 1987), including recent statewide transit benefit studies in Colorado (Lee, Scott and Cleary, Inc. et al, 1999) and in Georgia (Meyer, Nelson and Peng, 1999). ${ }^{28}$

Input-output analysis is used to track the interrelationships between different industrial sectors within an economy. It does so by analyzing the relationship between a sector's inputs and its outputs --which sectors supply a particular sector with its inputs and which sectors use its outputs, the latter including final household consumption. Transit systems are allocated to specific industrial sectors within these accounts. As such they have "direct effects" on local or regional economies in terms of the jobs created and income spent in public transit itself. They

\footnotetext{
${ }^{28} \mathrm{~A}$ useful description of the basic I-O approach, with numerical examples, can be found in Beimborn et al (1993).
} 


\section{Public Transit in Tennessee}

also have "indirect effects" through the jobs and income spent in those industries that supply inputs to public transit. Finally, transit supply can have "induced effects" when it stimulates household spending with income generated through both of these direct and indirect effects. The total economic effect of transit expenditures within a region is given as the sum of these direct, indirect and induced effects, which are assumed to ripple through the economic system. Inputoutput analysis uses indirect and induced effect "multipliers" to capture these impacts ${ }^{29}$. Hence a dollar invested in transit supply may generate significantly more than a dollar in direct plus indirect and induced income within a region. It may also contribute to income and employment in other regions if businesses in those regions also supply inputs to the transit system or provide services to the transit system's users.

In this project the widely used IMPLAN ${ }^{30}$ input-output model was selected for the task of developing a set of transit district-specific economic multipliers. This requires the collection of a variety of data, including:

- detailed data on transit system expenditures in terms of capital outlays, operation and maintenance, and planning costs, including wages. This data was obtained from each of the State's public transit providers via the Tennessee Department of Transportation.

- transit district-specific levels of economic activity by industrial sector, plus associated interregional input-output coefficients and their resulting multipliers. 1997 data for all 95 Tennessee counties was acquired from the Minnesota IMPLAN Group in support of this analysis.

Separate economic multipliers were computed for a) annual transit system operation and maintenance expenses, including any funds spent on planning activities, and for b)annual capital expenditures (on vehicles, also some on structures). Operating, maintenance and planning expenditure multipliers were based on IMPLAN multipliers for the industrial sector "Local InterUrban Passenger Transportation”. Capital expenditure multipliers were based on IMPLAN multipliers for the industrial sector "Automotive Dealers and Service Stations". For each of these two expenditure classes, and for each urban and rural transit district in the state, the following four types of economic multiplier were computed:

- an employment multiplier, which estimates the number of jobs created in the region as a result of spending one million dollars in the public transportation sector.

${ }^{29}$ Three different approaches to generating such multipliers are commonly used for predictive modeling: (1) the Type I multiplier, which measures the direct and the indirect effects of a change in economic activity, and captures only the inter-industry effects; (2) the Type II multiplier, which takes into account not only the interindustry effects, but also income and expenditures of households, i.e., includes the induced effects; and (3) the SAM multiplier, which use all social accounting matrix information to generate a model that captures the interinstitutional transfers. In this project Type II multipliers were used.

${ }^{30} \mathrm{http} / / \mathrm{implan} . \mathrm{com}$ 


\section{Public Transit in Tennessee}

- a value added multiplier, which measures the amount of income generated in the region as a result of one dollar expenditure in the public transportation sector.

- an indirect business tax multiplier, which measures the increase in indirect business tax resulted from spending one dollar in the public transportation sector, and

- an output multiplier, which estimates the increase in output in the region as a result of spending one dollar on public transportation.

The majority of local economic impacts come through operating, maintenance and planning expenditures. In contrast, a high percentage of the capital expenditures, notably for vehicle purchases, are spent out of the region and also out of the state. Exceptions exist where money is spent on local construction and in special cases, such as the expenditure of about $50 \%$ of the costs of acquiring new electric buses within Hamilton County, Chattanooga.

Both gross and net economic benefits measures were computed for each of the four multipliers in each of the State's transit districts. A gross benefit refers here to the total impact of all transit system expenditures in a district. A net benefit subtracts from these gross benefits the effects of those expenditures, mainly in the form of transit fares and contracts plus any local district matching funds, since these represent net costs to the local district. This leaves the net effect of monies brought into the local district from outside the area: i.e. from state and federal funding sources. From the State's perspective only funds brought in from federal sources are considered in this study to constitute net benefits.

In computing the economic benefits of transit expenditures to add to the Transit Use benefits discussed above we use Value Added dollars. This is the value of production generated by economic activity net of the input materials (in contrast to Output, which we also computed, and which is the total value of this economic activity, including value added and materials costs). In IMPLAN these Value Added dollars are composed of wages, proprietors income, indirect business taxes and other property income. ${ }^{31}$

\subsubsection{Transit System Impacts on Economic Growth.}

Without an extensive, safe and well maintained transportation system, trade as we now know it would not be possible and economic growth would be limited at best. Many of the economic growth and development benefits of transportation supply are these days attributed to the nation's extensive highway system and to its influence on population, income and employment growth, land development, and investments in other forms of urban infrastructure. Investments in public transit systems have also been found to be very supportive of economic growth, in both

\footnotetext{
${ }^{31}$ The term "value added" is used because some activity (i.e. labor or owner service) is applied to a base input to transform it to a more desirable state -- i.e. the value added. In a market context the added value at the margin is equal to society's willingness to pay productive factors to generate the new product -- i.e the value of wages and capital.
} 


\section{Public Transit in Tennessee}

the short- and long-term. The longer-term benefits reflect the value of more cost-effective transportation supply in generating greater access to customers on the one hand and greater access to markets on the other. In so doing, these travel cost savings may also encourage economies of scale in business enterprises. In practice these generative growth impacts are very difficult to measure, however, since they require a dynamic model of a region's economy and its growth potentials.

To do so in a comprehensive manner, even for a single transit system, requires involved econometric and/or simulation modeling in which the demand for and supply of different goods and services is equilibrated over time as a function (among other things) of transit and other transportation costs (see Cambridge Systematics et al , 1996 for a review of available approaches). A posited benefit of mass transit in larger cities is its ability to encourage as well as support higher density residential and employment development, which in turn leads to shorter average travel distances, and hence shorter travel times and other costs between places, notably between different types of land use. Ultimately these effects, if borne out, could have significant economic impacts. Measuring them is another matter. To do so effectively requires a detailed land use-transportation planning model capable of simulating the impacts of different multimodal and multi-year land use plans (see Southworth, 1995 for a review of methods).

The approach taken in this present study had to be much less ambitious. It mirrors that used recently by Leigh, Scott and Cleary, Inc. et al (1999). As such it is based on the recent work of Nadiri and Mamuneas $(1996,1998)$ who have developed the most rigorous econometric approach to date for analyzing the economic impacts of US national transportation infrastructure investment (specifically, highway infrastructure investments) on economic growth. Based on this work, Leigh, Scott and Cleary, Inc. et al (1999, pages K-8 through K-12) adopt a figure of 4\% as being the annual averaged increment in economic growth attributable to transportation efficiencies. Hence if economic growth in a particular year is 5\%, then transportation efficiency accounts for $4 \% * 5 \%=0.2 \%$ of that annual growth. In this present study we treat this $4 \%$ figure as a default value.

Using this approach annual employment data was collected for each Tennessee county for the years 1980 through 1998. This data was grouped into the appropriate urban and rural transit operating districts and the net increase in employment computed for each year for each district. This done, a second time series of district employment was computed that simply deducts $4 \%$ from each yearly district employment total. Finally, the differences in these two time series were computed and the average difference in employment computed based on the past 10 years of data. These district specific employment differences are assumed attributable to transportation efficiencies introduced into each region. Public transit's contribution to these efficiencies is then computed on the assumption that its contribution matches its average share of overall highwayplus-transit ground transportation expenditures by the state for that ten year period. This is necessarily a guess but possible a conservative one. (Aschauer 1991, page 9, for example, found that "transit spending carries over twice the potential to impact productivity as does highway 


\section{Public Transit in Tennessee}

spending"). Finally, public transit's contribution to output and value added are obtained by taking the ratios of employment to output and employment to value added at the district level from the I-O analysis and applying them directly to the economic growth analysis.

The result of this exercise is meant to be approximate only: an attempt to get at least a reasonable order of magnitude impact out of available data on a regional and statewide level. Given the nature of the approach a sensitivity analysis was carried out by varying the assumed $4 \%$ annualized average increment in economic growth.

\subsection{Societal and Community Benefits.}

Equity and Community Values. General support for public transit services is quite common in response to surveys of the general public. There is convincing evidence from a number of attitudinal surveys that even citizens who don't use transit much, if at all, find it a worthwhile community service. For example, such a survey of some 424 Tennessee residents in the spring of 1994, posing questions about the state's public transportation services, found a good degree of knowledge about existing public transit options and almost $97 \%$ of respondents identifying public transportation as either "essential", "very important" or "important" to the quality of life in their communities (RM Plan group, 1994). These same respondents identified, in rank order, the elderly, persons with disabilities, the poor, the young, and commuters as the main beneficiaries of such systems. These sentiments echo concerns over equity in access and the mobility gap described in section 2.5.1 above. Similarly, a randomly generated sample of some 600 residents in Chattanooga in 1997 (Brodsky, 1997) found that substantial majorities of the sample agreed (i.e. "strongly agree" or "agree") that the City of Chattanooga should spend tax dollars on helping to further develop electric buses ( 62.1\%), continue to offer free shuttle service downtown (83.6\%), and continue to provide van service to riders with disabilities, regardless of cost $(89.9 \%)$. Sizeable majorities also agreed that a good transportation system helps create jobs $(79.8 \%)$ and was needed for the city's economy to grow $(87.3 \%)$.

More Liveable Communities. Also difficult to quantify are the benefits of "civic pride" and the feelings of being part of a progressive region or community that offers travel options without the effects of traffic congestion to both residents and visitors (tourists, business men and women). One of the more noticeable forms of urban development begun within Tennessee during the 1990's has been the efforts of the state's four largest cities to revitalize their downtown areas. All four of these efforts are associated with improvements and innovations in urban public transit services (see Chapter 4). A good deal has been written in recent years about the need to reduce our society's dependence on the private automobile, and in particular to create urban spaces where people can move about easily without fear of traffic incidents, noise or air pollution. Much of this literature deals with the often positive impacts of rail transit on neighborhoods, using 


\section{Public Transit in Tennessee}

either hedonic pricing or (most recently) stated preference approaches to putting value on the dollar benefits of improved land values or greater proximity to transit stations (see Lewis and Williams, 1999, Chapter 5). These sort of benefits warrant further study as the state considers the adoption of new forms of public transit, notably light rail and commuter rail systems in Memphis and Nashville, respectively.

Table 2.8 Quantitative Treatment of Transit Benefits.

\begin{tabular}{|l|c|c|}
\hline Type of Benefit & $\begin{array}{c}\text { Quantitative } \\
\text { (dollar valued) }\end{array}$ & $\begin{array}{c}\text { Qualitative } \\
\text { Measures }\end{array}$ \\
\hline 1. Mobility/Accessibility Impacts & & \\
1.A Trip Cost Savings & $\$ \$$ & \\
1.B Foregone Travel Avoidance & $\$ \$$ & \\
1.C Relocation Costs & $\$ *$ & \\
1.D Congestion Impacts & $\$$ & \\
$\quad$ Daily Congestion & & \\
$\quad$ Special Events & & $\mathrm{X}$ \\
\hline 2. Environmental Impacts & $\$ *$ & \\
2.A. Air Quality & & $\mathrm{X}$ \\
$\quad$ Health Hazards & & \\
$\quad$ Misibility & $\$ \$$, Gallons & $\mathrm{X}$ \\
2.B Energy Consumption & $\$ *$ & $\mathrm{X}$ \\
2.C Noise & & $\mathrm{X}$ \\
2.D Groundwater & & \\
2.E Land Conservation & & \\
\hline 3. Safety \& Security Impacts & & \\
3.A Safety (Accident Avoidance) & & \\
3.B Personal Security & & \\
3.C Oil Dependence (National & & \\
$\quad$ Security) & & \\
\hline 4. Economic Impacts & & \\
4.A Transit Expenditures & & \\
4.B Economic Growth & & \\
4.C Land Use/Land Development & & \\
\hline 5. Social \& Community Impacts & \\
5A Equity and Community Values & & \\
5B Liveable Community Initiatives & & \\
\hline
\end{tabular}




\section{Public Transit in Tennessee}

\subsection{Summary of Benefits Estimated.}

Table 2.8 above identifies the major types of transit benefits analyzed in this study, and whether they are quantified in dollar terms $(=\$ \$$, or $\$ *)$, or not $(=X)$. Where a $\$ \$$ or $\$ *$ sign is placed against a category of benefit in Table 2.8 , all sub-classes of that benefit are also quantified at the level shown. A $\$ *$ sign indicates that the computation of benefits is subject to a good degree of uncertainty in the resulting estimates due to data limitations or to outstanding issues with the current state of practice (or both). The major efforts in benefits computation in this present study are associated with the $\$ \$$ sign in Table 2.8 . 
Public Transit in Tennessee

\section{Transit Ridership Forecasting Models.}

\subsection{Introduction.}

This chapter provides a description of the various urban and rural transit ridership forecasting models developed by the study team. Section 3.2 below describes the urban ridership models and section 3.3 describes the rural ridership model.

A forecast of transit ridership may be needed for different purposes related to transit planning and management, and the level of detail for the forecast ridership is closely related to its use or application. The forecasting procedure or model to be used, therefore, should be tailored to the specific need or application of the output of the model. The availability of data also influences the structure of the model to be used. For example, for developing the future network of an existing transit system in a specific urban area, transit ridership estimates may be needed for each existing and proposed route. For this type of an application, a mode-choice model may be needed that will incorporate route-level service characteristics in the model structure as well as costs of using alternative modes including parking costs for automobile use. On the other hand, a detailed route-level model may not be needed for the purpose of developing future budgets or estimating future equipment needs of a transit system. In the latter case a simple aggregate trend analysis of ridership may be adequate.

This study's focus is on a statewide basis, and it was clear that a route-level mode choice model was not needed and that the data needs for such a detailed approach would be too much to deal with. However, the researchers did not want to go to the other extreme of using a very aggregate approach based on trend analysis. It was considered desirable to develop a crosssectional mathematical model and incorporate in it certain variables that can be influenced by policy decisions. Additionally it was considered desirable that the identity and characteristics of individual urban areas in the state be recognized. Another distinction among urban transit services that also was considered important involves the two types of transit service provided in most urban areas: 1) fixed-route, fixed-schedule service (FR), and 2) demand-responsive service (DR) that is primarily meant for persons with disabilities. Therefore, it was decided to develop two cross-sectional models, one for each of these two categories of transit service. These models emphasize potential rider populations and their socio-economic characteristics. Models involving transit fares were not developed and were not thought appropriate for this level of data aggregation. However transit level of service is found to be an important variable in both urban and rural ridership forecasts. 
Public Transit in Tennessee

\subsection{Forecasting Urban Transit Ridership.}

\subsubsection{Introduction.}

Under urban ridership modeling four separate approaches were required in order to handle the significant differences in size of operations, as well as in types of transit services provided, across the state's twelve urban transit districts. The majority of rides in the state were modeled using regression analysis to forecast fixed route transit services in seven of these urban areas. These were the services offered in the metropolitan areas of Chattanooga, Clarksville, Jackson, Johnson City, Knoxville, Memphis and Nashville. A second regression analysis was developed to handle demand responsive van services in these same seven urbanized areas. A separate, and simpler trend analysis was used to forecast rides on the small fixed route bus systems operated by the cities of Bristol and Kingsport, and on the small demand responsive system operated in Oak Ridge. Finally, a different form of trend analysis was used to estimate future ridership for the largely tourist oriented fixed route bus/trolley systems servicing the adjacent cities of Pigeon Forge and Gatlinburg.

\subsubsection{Fixed Route Transit Service Models.}

Model Variables and Data Sources. It was decided after considerable discussion that a regression model with multiple variables would be developed for forecasting transit ridership in the state's medium and large sized urban areas. The "dependent" or response variable of the ridership model is the number of annual transit trips for an individual urban area. Since only twelve urban areas in Tennessee provide transit service, data for Tennessee alone were not sufficient for the statistical analysis needed for developing a cross-sectional model. A search for data from other urban areas outside Tennessee led to the National Transit Database (NTD), which contains data supplied by most of the transit systems in the United States on an annual basis. One of the advantages of this database is that all transit systems report data in the same format and they are also supposed to use the same definition/ specification for each data item. The data items selected from the NTD to represent transit ridership were Annual Unlinked Trips, and the year for which these data were extracted from NTD was 1997.

"Independent" or explanatory variables for a ridership model should represent information of two types. First, the size and characteristics of the customer base for transit in each urban area must be represented, and variables such as population, income, and car availability are appropriate for this purpose. The NTD includes data on population and area (square miles) for each urbanized area as well as service area population and area. Considering the need for obtaining information on population characteristics and developing reliable forecasts of population, the urbanized area population was preferred to the service area population. The data on population and area were combined to create data on population density.

For information on population characteristics a search of census data was made. 


\section{Public Transit in Tennessee}

A variety of information for urbanized areas was found on a compact dist (CD90-3C-2), which was purchased from the US Bureau of Census. The characteristics that were extracted from the CD for each urbanized area are listed below.

1. Households with no vehicles, and total households. These were combined to express households with no vehicles as a percentage of total households.

2. Population of age 65 or more, and total population. These were combined to express elderly population as a percentage of total population.

3. Median income, and income per capita.

4. Persons with mobility limitations.

\section{Table 3.1 Urban Transit Related Data and Sources.}

\begin{tabular}{ll}
\hline Data Item & Source \\
Urbanized Area Population & 1990 Bureau of the Census Summary, CD90-3C-2 \\
Urbanized Area (square .miles) & 1990 Bureau of the Census Summary, CD90-3C-2 \\
Urbanized Density (Pop./ sq.mi) & Calculated \\
Annual Revenue Miles of Service & 1997 National Transit Database (NTD) \\
Annual Unlinked Trips & 1997 National Transit Database (NTD) \\
Annual Revenue Hours & 1997 National Transit Database (NTD) \\
Urbanized Revenue Miles / Person & Calculated \\
Urbanized Annual Trips / Person & Calculated \\
Local Operating Funds & 1997 National Transit Database (NTD) \\
State Operating Funds & \multicolumn{1}{c}{ 1997 National Transit Database (NTD) } \\
Total Operating Funds & Calculated \\
Expenditure per Capita & Calculated \\
No(Zero) Vehicle HHs*/Total HHs & 1990 Bureau of the Census Summary, CD90-3C-2 \\
65 or Over Pop./Total Population. & 1990 Bureau of the Census Summary, CD90-3C-2 \\
Mean Income & 1990 Bureau of the Census Summary, CD90-3C-2 \\
Income per Capita & 1990 Bureau of the Census Summary, CD90-3C-2 \\
DRS Annual Revenue Miles & 1997 National Transit Database (NTD) \\
DRS Annual Unlinked Trips & 1997 National Transit Database (NTD) \\
Persons with Mobility Limitation & 1990 Bureau of the Census Summary, CD90-3C-2
\end{tabular}

* $\mathrm{HH}=$ households

The second category of independent variables involved information on transit supply related characteristics. The NTD includes a variety of information on the magnitude of transit service provided in each urbanized area. The variable that was selected to represent the level of service is 'annual revenue miles', which reflects the combined effect of route miles of service and the operating funds expended for transit by local and state governments. The sum of local and state funds expended on each transit system was divided by the urban area's total population to develop data on 'operating funds expended per capita'. This variable was used to represent the 


\section{Public Transit in Tennessee}

amount of investment made in transit services within an urban area, allowing this investment level to be varied in subsequent analyses according to local and state policies. A list of items (variables) for which data were assembled for the ridership forecasting model is presented in Table 3.1 above. The source for each data item is shown in the table.

Data for each of the items listed in Table 3.1 were obtained for 125 urbanized areas. Not included in this group were the largest urbanized areas with heavy rail rapid transit systems such as the New York metropolitan area, Philadelphia, Chicago, San Francisco, and Atlanta. The reason for excluding these areas from the analysis is that no Tennessee cities are expected to have heavy rail rapid transit systems by the year 2020. However, urbanized areas with light rail transit systems such as Portland, Sacramento, and Pittsburgh were included.

A series of multiple regressions were developed and tested in order to identify a statistically significant and robust relation of the dependent variable, Annual Unlinked Trips, with a large number of candidate independent variables, individually as well as in different combinations. Additionally, the relationships among the independent variables themselves were examined carefully. After many trials and iterations, a two-step model consisting of two equations was developed to forecast Annual Unlinked Trips on fixed-route systems.

Initial analyses showed that the amount of transit service provided in an urban area is an important variable for predicting transit ridership. It also was recognized that the amount of transit service, which is measured in terms of revenue miles of service, is related not only to the population size of an urban area but also to the investment made in terms of funding for transit service within a community. Some urban areas such as Madison (Wisconsin), Spokane (Washington), and Austin (Texas) spend significantly more money for their transit systems than other comparable areas. So it was decided to develop a separate model for estimating revenue miles of service, and this was the first of the two equations to be used in a sequence. The best equation/model found for estimating Annual Revenue Miles of Service is presented below. A natural logarithmic transformation of some of the variables was used to improve the strength of correlation.

$\log ($ Revenue Miles $)=1.753+0.967[\log ($ Population $)]+0.025($ Expenditure per Capita $)(1)$

The R-Squared for this model is 0.91. Both independent variables are statistically significant. The assumptions for regression are also very good for this model. The Coefficient of Variation is 0.0235 .

The second equation is for predicting transit ridership based on revenue miles of service and other characteristics of an urban area. This equation is presented below, and once again a natural logarithmic transformation of some of the variables was used to improve the strength of the correlation. 


\section{Public Transit in Tennessee}

$\log ($ Annual Unlinked Trips) $=-3.396+0.276[\log ($ Population) $]+0.000177$ (Population Density) + 0.974 [Log (Annual Revenue Miles) +4.091 (Proportion of Households with No Vehicles)

The R-Squared for this model is 0.92 , which means that 92 percent of the variation in the dependent variable is explained by the variations in the independent variables. All of the independent variables are statistically significant. The assumptions for regression are also very good for this model. The Coefficient of Variation is 0.0283.

This set of two equations was used to estimate the 1997 ridership for seven of the eleven fixed route transit systems in Tennessee. When the actual and estimated ridership for individual urban areas were summed and compared, it was found that the statewide totals differed by only $0.6 \%$. However, this fit was gained in part from a noticeable overestimate of Knoxville ridership that would need to be compensated for in future applications of the model.

The small fixed route transit systems of Bristol and Kingsport were both found to be unsuited to this process. The Bristol urbanized area is split between two states, Tennessee and Virginia, and there is a separate and very small transit service in each state. The models also overestimated the 1997 transit ridership for the small Kingsport bus transit system by a substantial amount: largely due to the fact that Kingsport has a very small transit system compared to other areas of similar size. The future fixed route transit ridership for the urbanized areas of Bristol and Kingsport Tennessee was therefore estimated using a simple trend analysis, taking the trip rate per resident in the base year and incrementing trips at this same rate on the basis of population growth.

Sensitivity of Parameters in theFixed-Route Model. The independent variables of the model for forecasting ridership on fixed-route transit service are listed in Table 3.2 below, along with the trend of their future growth. The resulting impact on future ridership is indicated.

In order to determine the magnitude of the impact of changes in individual variables on transit ridership, a sensitivity analysis was performed with a few selected variables. The basic approach for this sensitivity analysis was to change one variable while holding the others at constant levels, and determine based on the mathematical model the changes in ridership caused by each level of change in the selected independent variable. The sensitivity analysis was performed for two independent variables - population, and transit expenditure per capita. The results are presented in this section. The sensitivity analysis was performed for one urban area Chattanooga. 
Public Transit in Tennessee

Table 3.2 Factors Affecting Fixed Route Ridership Forecasts.

\begin{tabular}{|c|c|c|}
\hline Factors & Growth Trend & Impact on Ridership \\
\hline 1. Population & Increasing & Positive \\
\hline $\begin{array}{l}\text { 2. Proportion of Households with } \\
\text { No Cars }\end{array}$ & Decreasing & Negative \\
\hline 3.Population Density & Increasing & Positive \\
\hline 4. Revenue Miles of Service & Increasing & Positive \\
\hline $\begin{array}{l}\text { 5. Expenditures per Capita } \\
\text { (\$/Capita) }\end{array}$ & Unknown & $\begin{array}{l}\text { Positive if } \$ / \text { Capita Increasing } \\
\text { Negative Otherwise }\end{array}$ \\
\hline
\end{tabular}

Table 3.3 Sensitivity of Fixed Route Ridership Model to Population- Chattanooga .

\begin{tabular}{c|c|c|c|c} 
Case & Population & $\begin{array}{c}\text { Change in } \\
\text { Population }\end{array}$ & Unlinked Trips & $\begin{array}{c}\text { Change in } \\
\text { Trips }\end{array}$ \\
\hline Base & 296,955 & $0.00 \%$ & $2,271,837$ & $0.00 \%$ \\
\hline 1 & 326,651 & $+10.00 \%$ & $2,526,265$ & $+11.20 \%$ \\
\hline 2 & 356,346 & $+20.00 \%$ & $2,795,082$ & $+23.03 \%$ \\
\hline 3 & 386,042 & $+30.00 \%$ & $3,078,360$ & $+35.50 \%$ \\
\hline
\end{tabular}

Table 3.4 Sensitivity of Fixed Route Ridership Model to Transit Investment - Chattanooga.

\begin{tabular}{c|c|c|c|c} 
Case & $\begin{array}{c}\text { Investment } \\
(\$ / \text { Capita })\end{array}$ & $\begin{array}{c}\text { Change in } \\
\$ / \text { Capita }\end{array}$ & Unlinked Trips & Change in Trips \\
\hline Base & $\$ 13.68$ & $0.00 \%$ & $2,271,837$ & $0.00 \%$ \\
\hline 1 & $\$ 15.73$ & $+15.00 \%$ & $2,387,199$ & $+5.08 \%$ \\
\hline 2 & $\$ 17.10$ & $+25.00 \%$ & $2,469,078$ & $+8.68 \%$ \\
\hline 3 & $\$ 20.52$ & $+50.00 \%$ & $2,686,117$ & $+18.24 \%$ \\
\hline
\end{tabular}




\section{Public Transit in Tennessee}

Sensitivity with Respect to Population. A base case was selected for Chattanooga with the following values of independent variables of the model:

o $\quad$ Population $=296,955$

o Proportion of households with no vehicles $=10.86 \%$

o $\quad$ Transit Expenditure per Capita $=\$ 13.68$

The population was then changed to reflect increases of $10 \%, 20 \%$, and $30 \%$ respectively. The other independent variables were held constant at the base level. The model was solved with the new population values, and the numbers of unlinked trips were calculated. The results are presented in Table 3.3. These results show that transit trips increase at a slightly greater rate than the increase in population.

Sensitivity with Respect to Expenditure per Capita. The variable "expenditure per capita" is included in the model for estimating "revenue miles of service", which is used as a variable in the model for estimating "annual unlinked trips". An analysis was performed to determine how much impact with increases in "expenditure per capita" would have on transit ridership measured in terms of "annual unlinked trips" using the same approach as that used for population increases. The base case value of "expenditure per capita" for Chattanooga was $\$ 13.68$ and this was changed to three higher values of $\$ 15.73, \$ 17.10$, and $\$ 20.50$, representing increases of $15 \%$, $25 \%$, and $50 \%$ respectively. The values of all other independent variables were held constant at the base case levels. The results of the analysis are presented in Table 3.4. These results show that transit trips increase with an increase in investment per capita; however, the growth rate in transit trips is lower than that in investment. For example, an increase of $25 \%$ in investment would result in an increase of about 9 percent in transit use.

\subsubsection{Demand-Responsive Service Model.}

The data for demand responsive (DR) transit service were obtained for the same urbanized areas as used for developing the model for fixed-route service. DR Annual Vehicle Revenue Miles and Annual Unlinked Trips representing supply and use respectively were obtained from NTD, and these were added to the data set already developed for the fixed-route service. An additional item of information, which was not used for the fixed-route service, was needed for the DRS model. Since DR in most of the urbanized areas is meant for persons with disabilities, the number of persons with mobility limitation was also obtained from the Bureau of Census compact disk (CD90-3C-2). After examining several different combinations and transformations of variables, two alternative equations were identified to be of nearly equal strength or reliability, the main difference being one independent variable. These equations are presented below:

Log $($ DR Annual Unlinked Trips $)=9.781+0.0287($ Expenditure per Capita $)+0.000116$ (Persons with Mobility Limitation) 


\section{Public Transit in Tennessee}

R-Squared for the above model is 0.5008 . Both independent variables are statistically significant. However, this model has a slight wedge shape in the residuals. The Coefficient of Variation is 0.0795. An alternative model formulation had the form:

$\log ($ DR Annual Unlinked Trips $)=1.504+0.726 \log ($ Population $)+0.026$ (Expenditure per Capita)

R-Squared for the above model is 0.5279 . Both independent variables are statistically significant, and all regression assumptions are met. The Coefficient of Variation is 0.0795.

In forecasting 1997 ridership in Tennessee the two models produced very similar results. However, the results were slightly better when using equation (4), which also includes the generally easier to obtain variable 'population' instead of 'persons with mobility limitation'. This equation was therefore used to generate the DR ridership forecasts reported in Chapter 4 of this report.

\subsubsection{Tourist-Oriented Transit Model.}

Both Gatlinburg and Pigeon Forge are small urban areas (populations approximately 3,500 and 4,500 respectively) that provide public transportation services to support the local tourism industry by transporting large numbers of tourists in a highly congested environment. Both cities have extreme variations in travel demand during the year. With a limited roadway network, the influx of tourists during the "peak season" results in extensive vehicular and pedestrian congestion. In 1980 Gatlinburg implemented a public transportation system to address the mobility needs of tourists and local citizens (Stoner, 1994). Pigeon Forge followed with an independent public transit service in 1986. Both systems consist of a fleet of vehicles with a trolley frame attached to a wheeled bus chassis. Pigeon Forge and Gatlinburg each currently operate 16 trolleys/buses.

Ridership for both systems grew rapidly. Pigeon Forge's annual ridership has grown to the mid 600,000 range (Figure 3.1). Gatlinburg's annual ridership reached over a million riders in 1982. Ridership is currently in the mid to upper 600,000s (see Figure 3.2). An onboard survey conducted in Gatlinburg in 1994 indicated that 98 percent of the riders were out of town guests, with 69 percent spending the night and 31 percent making day trips. Interestingly, 80 percent reported using the trolley to "just look around" with no specific trip purpose (just sight seeing). The survey included 217 weekday and 350 weekend riders (Stoner, 1994). Given the high utilization of these systems by tourists it was decided that future ridership will be 
Public Transit in Tennessee

Figure 3.1 Historic Trolley Ridership for Pigeon Forge, Tennessee

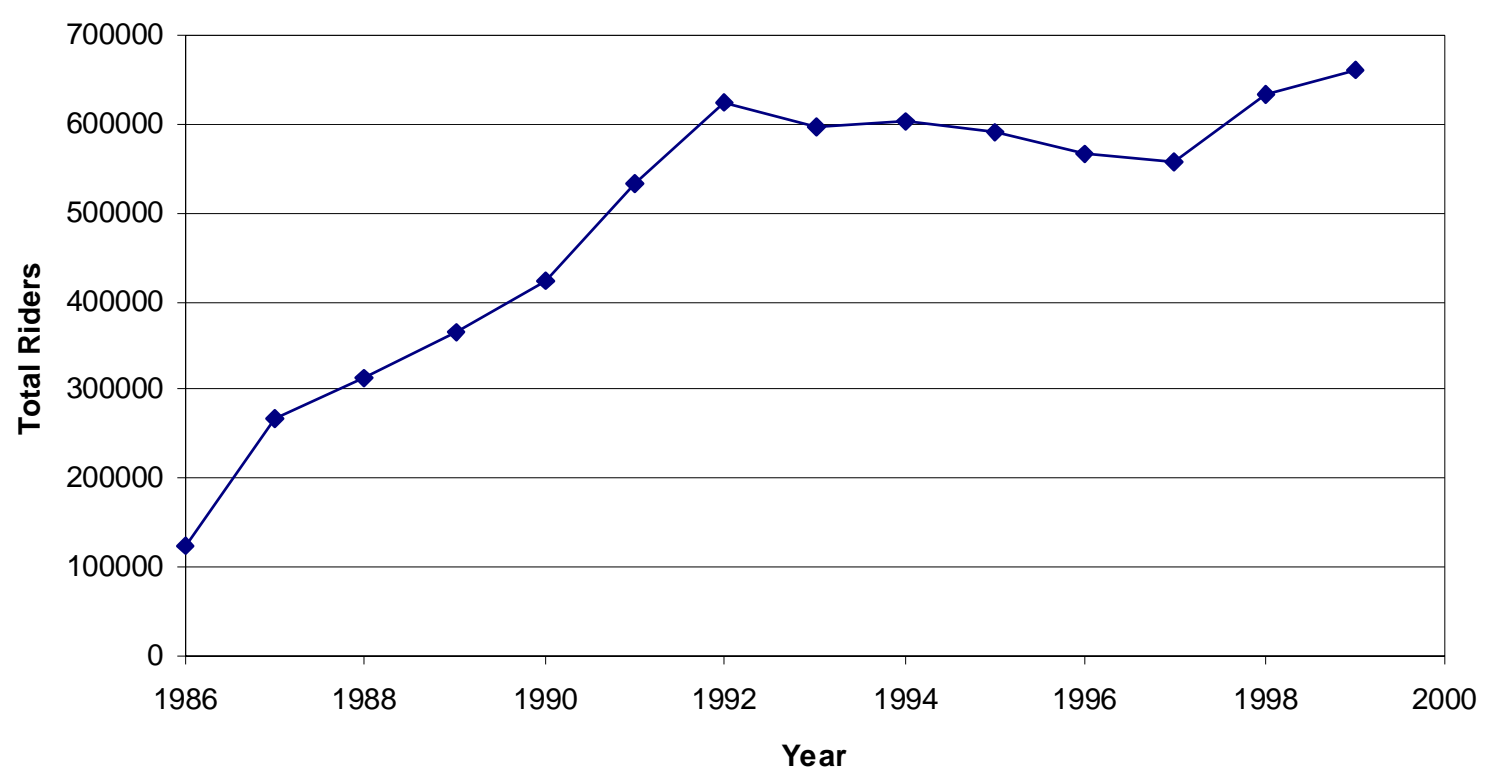

Figure 3.2 Historical Trolley Ridership for Gatlinburg, Tennessee

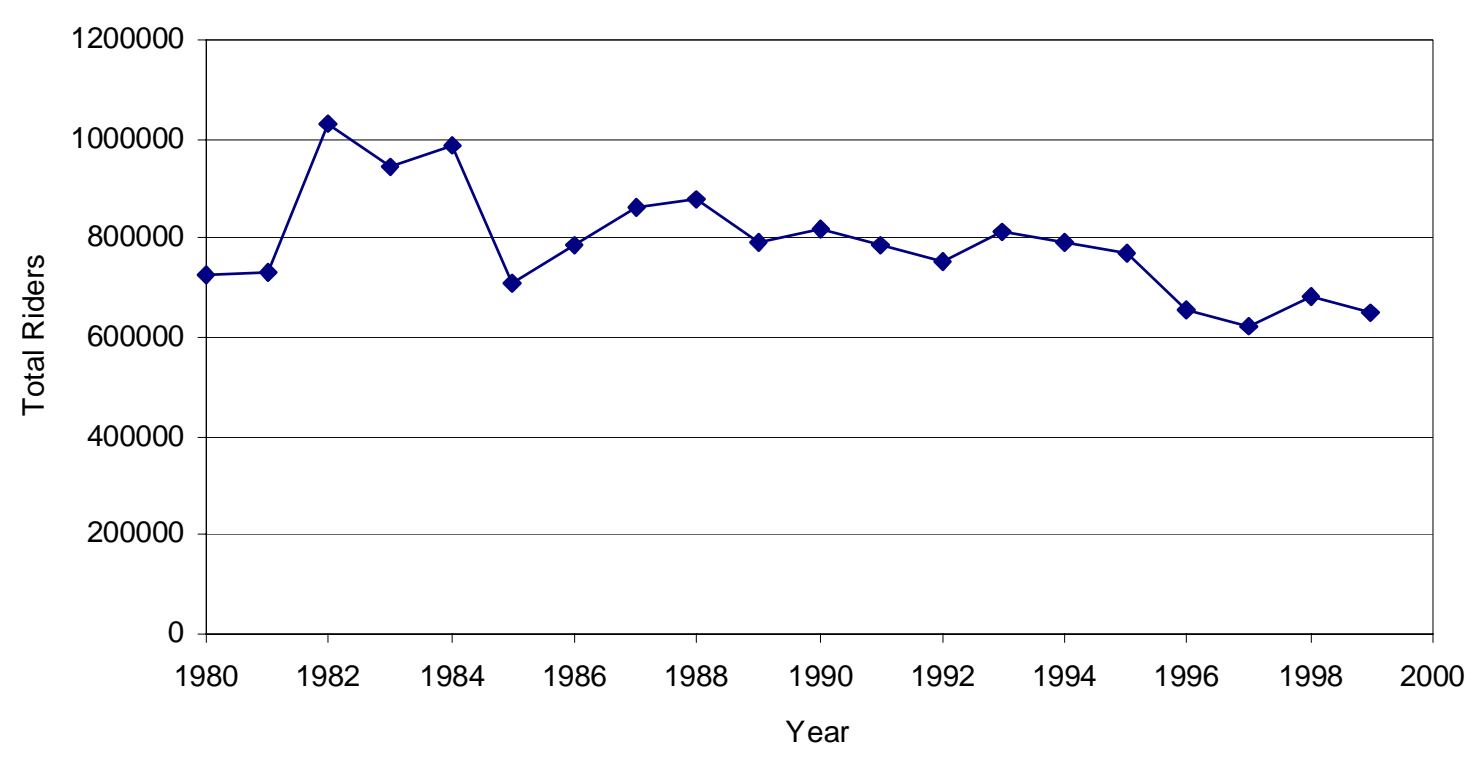


Public Transit in Tennessee

Figure 3.3 Gatlinburg vs Pigeon Forge, TN Annual Gross Business Receipts

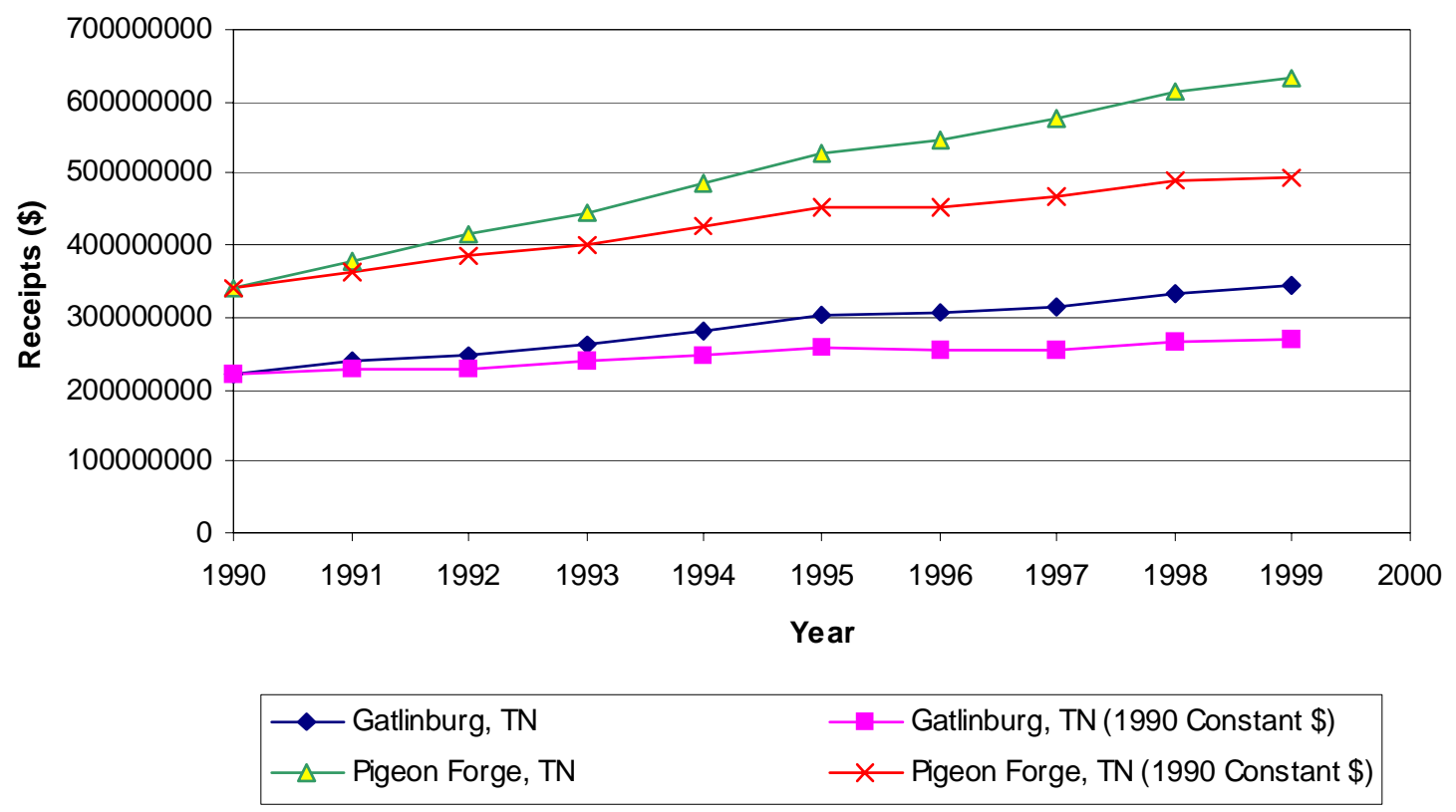

dependent on variables that reflect the growth in tourism and not variables that reflect the characteristics of the Gatlinburg and Pigeon Forge resident population. After reviewing a series of variables it was decided to select "annual business receipts", which reflect tourist activities for lodging, entertainment, meals, shopping, and other activities (Pigeon Forge Department of Tourism, 1990). Raw data for annual business receipts and data corrected to constant 1990 dollars are presented in Figure 3.3. In recent years the growth in Pigeon Forge resulted in a steady increase in business receipts, while Gatlinburg demonstrated a relatively stable trend.

Annual trolley ridership was found to be correlated with annual business receipts. The resulting equation for Pigeon Forge is noted in Figure 3.4. Selected for forecasting was the relationship:

$$
\mathrm{TR}=.0016 \text { (Annual Business Receipts in } 1990 \text { Dollars) - 107,743 }
$$

where:

$$
\text { TR }=\text { Total Annual Ridership }
$$

Gatlinburg's ridership data demonstrated no consistent connection with business receipts. Two clusters of observations were identified (Figure 3.5), one for 1990-1995 and the second 
Public Transit in Tennessee

Figure 3.4 Constant 1990 Dollars Gross Business Receipts vs. Trolley Ridership for Pigeon Forge, Tennessee (1986-1999)

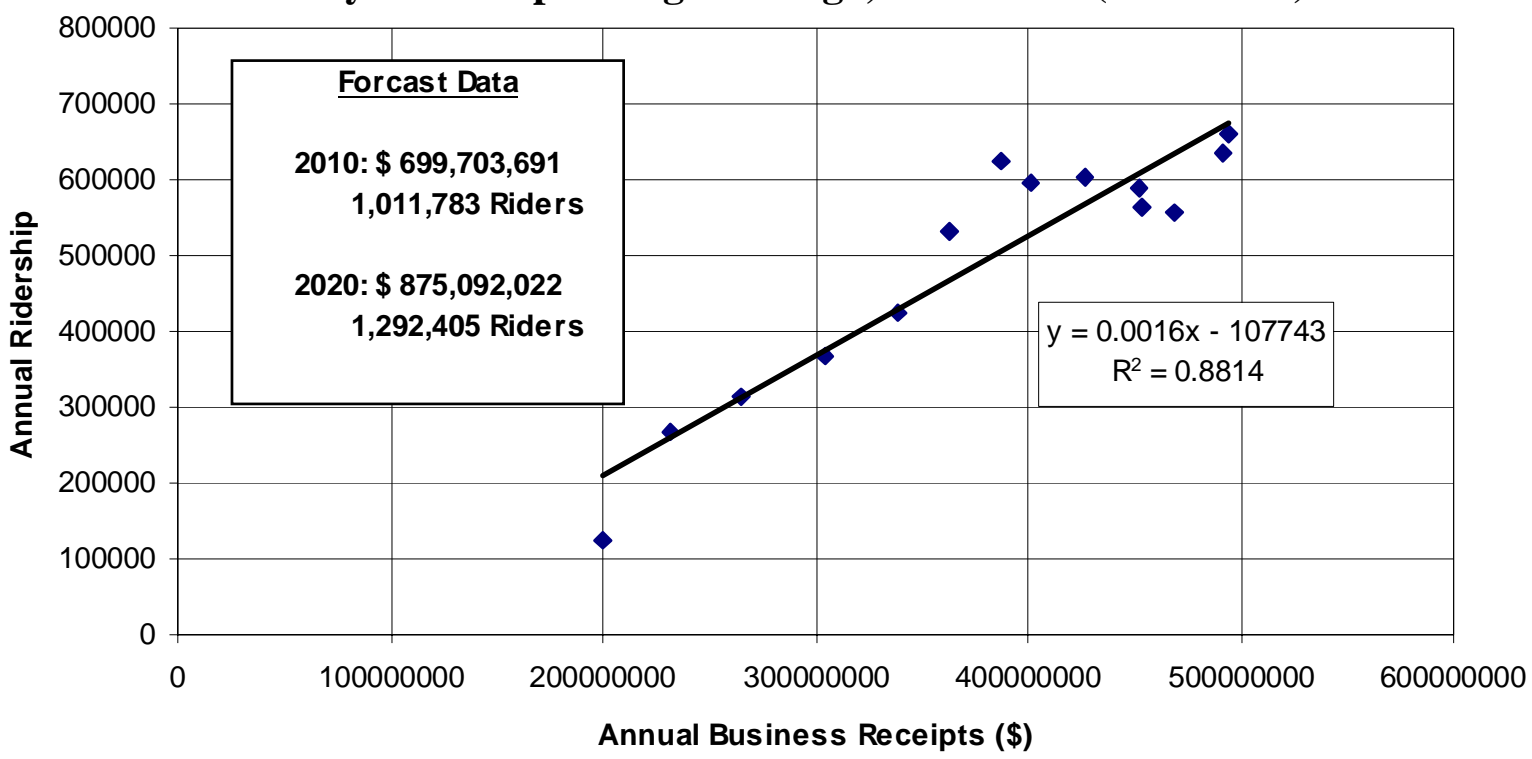

Figure 3.5 Constant 1990 Dollars Gross Business Receipts vs. Trolley Ridership for Gatlinburg, Tennessee (1990-1999) (Linear Relationship)

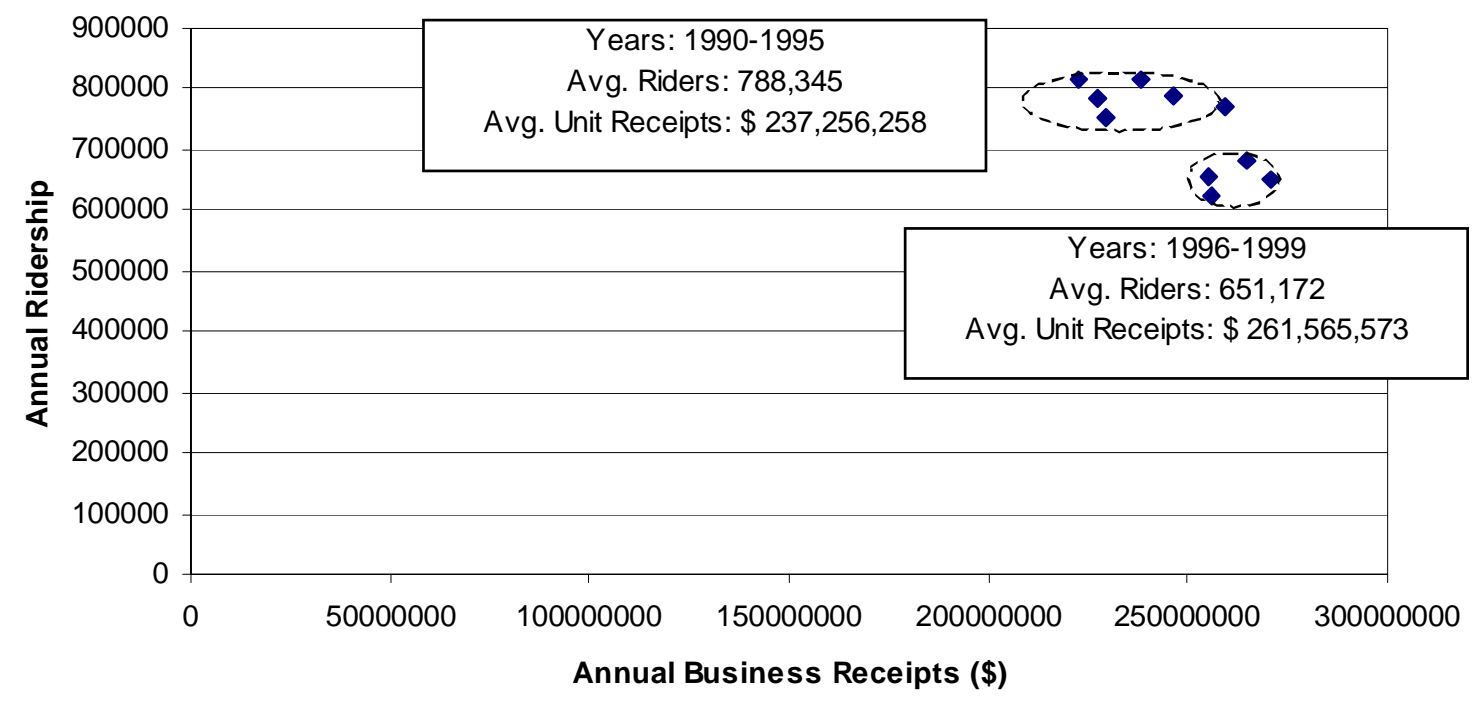


Public Transit in Tennessee

for 1996-1999. It is proposed that an average rate be used representing the 1990-1999 period of 2.5 rides for $\$ 1,000$ in annual business receipts (in 1990 dollars). If extending the Gatlinburg season to 12 months is successful a higher ridership rate reflecting the 1990-1995 period can be reflected as 3.3 rides per $\$ 1,000$ in annual business receipts (in 1990 dollars).

\section{Figure 3.6 Forecast Unit Annual Gross Business Receipts for Gatlinburg, TN (1990 \$)}

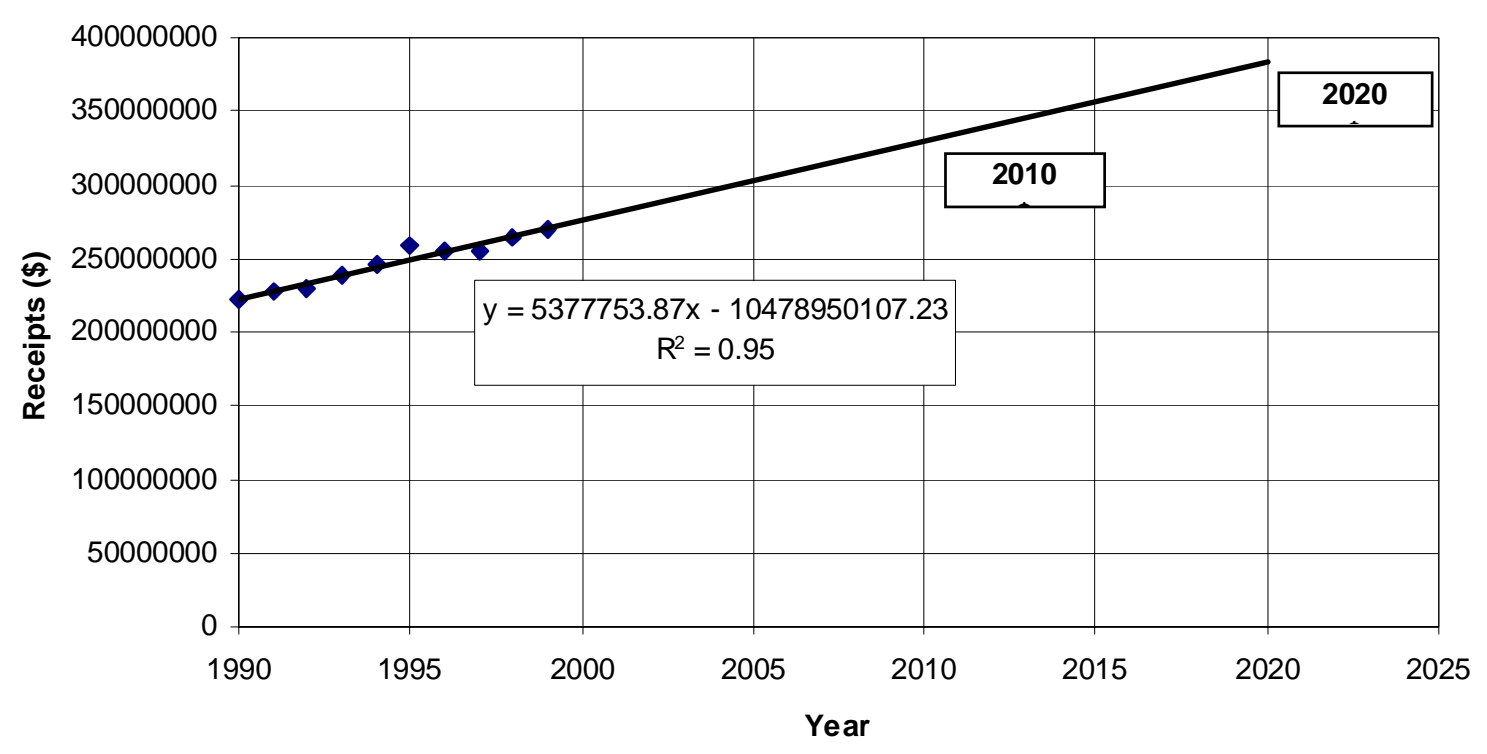

A forecast of future transit ridership in Gatlinburg was performed by trend extrapolation of annual business receipts to the years 2010 and 2020 (see Figure 3.6). Applying the ridership factor previously discussed, the high estimates of ridership are of 1.02 million riders in 2010 and 1.19 million riders in 2020. If current trends in trolley utilization prevail, the lower estimates of ridership are 826,000 riders in 2010 and 960,000 riders in 2020. A similar analysis was conducted for Pigeon Forge (see Figure 3.7 below), resulting in estimates of 1.01 million riders in 2010 and 1.29 million riders in 2020.

\subsection{Forecasting Rural Transit Ridership.}

\subsubsection{Introduction.}

Tennessee has an extensive rural public transportation system that serves all of the state's 95 counties. Eleven rural transportation services provide over 1.1 million trips per year with a fleet of over 500 vans. Over 53 percent of the rides are made by individuals over the age of 60 . For 
Public Transit in Tennessee

Figure 3.7 Forecast Unit Annual Gross Business Receipts for Pigeon Forge, TN (1990 \$)

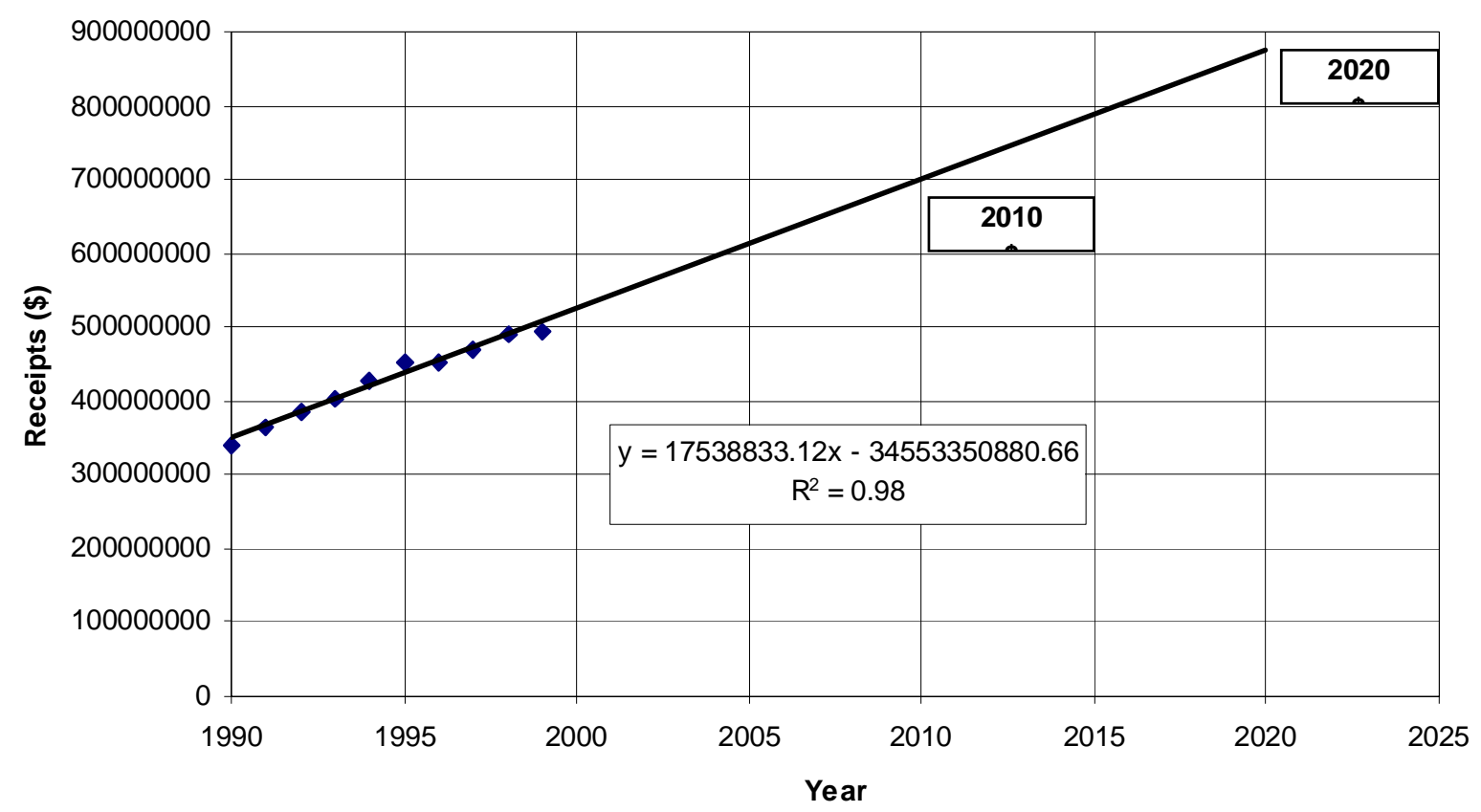

many of these individuals the rural transit system provides a lifeline to medical care, nutritional sites, schooling and training, jobs, and social-recreational opportunities (SG Associates Inc., 1995). As a background to forecasting, Tables 3.5 and 3.6 provide a historical time profile of Tennessee's rural transit systems. While statewide ridership levels remain stable, a growing amount of service is required to support contemporary mobility issues associated with programs such as Welfare-to-Work, Job Access and Reverse Commuting, Tennessee Family First, and TennCare. Over 50 percent of the 1998/1999 rural public transit trips were operated for a specific contract. From an historical perspective this is not uncommon. While the nature of the service contracts negotiated between rural operators and specific social service programs have changed, all the contracts continue to address the mobility needs of the same rural population. Rather than forecast the characteristics of specific service contracts, generalized rural ridership models were pursued.

\subsubsection{The Rural Transit Forecasting Model.}

Attempts were made to develop a generalized ridership forecasting model by calibrating regression equations for the 11 Tennessee rural transit systems for 1998-1999. Independent variables such as population, elderly population (over age 60), mobility limited population, 
Public Transit in Tennessee

Table 3.5. Rural Transportation Operations in Tennessee (1986-1998)— Annual Trips and Annual Vehicle-Miles.

\begin{tabular}{|c|c|c|c|c|c|c|c|c|}
\hline \multirow[t]{2}{*}{ Agency } & \multicolumn{4}{|c|}{$\begin{array}{c}\text { Annual Trips } \\
\text { Difference }\end{array}$} & \multicolumn{3}{|c|}{ Annual Vehicle-Miles } & \multirow[t]{2}{*}{ Difference } \\
\hline & 1986 & 1993 & 1998 & $1998-1986$ & 1986 & 1993 & 1998 & \\
\hline $\begin{array}{lcc}\text { East Tennessee } & \text { Human } & \text { Resource } \\
\text { Agency (ETHRA) } & & \\
\end{array}$ & 13131,758 & 12127,900 & 13135,067 & 3,309 & 850,837 & 6886,155 & $1,769,064$ & 918,227 \\
\hline $\begin{array}{lcc}\text { First Tennessee } & \text { Human } & \text { Resource } \\
\text { Agency (FTHRA) } & & \end{array}$ & 184,636 & 158,645 & 138,931 & $-45,705$ & 712,463 & 939,246 & $1,785,098$ & $1,072,635$ \\
\hline $\begin{array}{l}\text { Hamilton County Rural Transportation } \\
\text { System }\end{array}$ & 22,370 & 6,509 & 22,182 & -188 & 178,144 & 108,821 & 203,566 & 25,422 \\
\hline $\begin{array}{l}\text { Hancock County Rural Transportation } \\
\text { System (HCRTS) }\end{array}$ & $7,7,602$ & 24,227 & 3,537 & $2-4,065$ & 343,289 & 202,904 & 33,566 & $-309,723$ \\
\hline $\begin{array}{l}\text { Metropolitan } \\
\text { (MIFA)* }\end{array}$ & 67,171 & 48,215 & 36,319 & $-30,852$ & 242,047 & 400,118 & 594,259 & 352,212 \\
\hline $\begin{array}{l}\text { Mid-Cumberland Human Resource } \\
\text { Agency (MCHRA) }\end{array}$ & 141,627 & 127,711 & 122,065 & $-19,562$ & 749,988 & 566,327 & $1,087,441$ & 337,453 \\
\hline $\begin{array}{l}\text { Northwest Tennessee Human Resource } \\
\text { Agency ((NWTHRA) }\end{array}$ & 120,199 & 130,166 & 136,404 & 16,205 & 450,259 & 686,469 & $1,464,840$ & $1,014,581$ \\
\hline $\begin{array}{l}\text { South Central Tennessee Development } \\
\text { District SCTDD) }\end{array}$ & 138,620 & 163,056 & 120,795 & $-17,825$ & 530,376 & 6,775 & 808,164 & 277,788 \\
\hline $\begin{array}{l}\text { Southeast Tennessee Human Resource } \\
\text { Agency (SETHRA) }\end{array}$ & 118,767 & 120,334 & 98,114 & $-20,653$ & 749,936 & 824,434 & $1,131,761$ & 381,825 \\
\hline $\begin{array}{l}\text { Southwest Human Resource Agency } \\
\text { (SWHRA) }\end{array}$ & 130,693 & 203,905 & 180,459 & 4049,766 & 506,960 & 515,644 & 608,969 & 10102,009 \\
\hline $\begin{array}{l}\text { Upper Cumberland Human Resource } \\
\text { Agency (UCHRA) }\end{array}$ & 165,009 & 181,162 & 150,821 & $-14,188$ & 907,498 & $1,053,651$ & $1,763,888$ & 856,390 \\
\hline Totals & $1,228,452$ & $1,291,780$ & $1,144,694$ & $-83,758$ & $6,221,797$ & $5,990,544$ & $11,250,616$ & $5,028,819$ \\
\hline
\end{tabular}


Public Transit in Tennessee

* Now Delta Human Resource Agency.

Table 3.6. Rural Transportation Operations in Tennessee (1986-1998) - Vehicle-Miles per Trip, Use by Elderly, and Fleet Size .

\begin{tabular}{|c|c|c|c|c|c|c|c|c|c|c|}
\hline \multirow[t]{2}{*}{ Agency } & \multicolumn{4}{|c|}{ Vehicle-Miles per Trip } & \multicolumn{3}{|c|}{$\begin{array}{c}\text { \% Trips Made by Riders } \\
\text { Over } 60 \text { Years of Age } \\
\end{array}$} & \multicolumn{3}{|c|}{ Fleet Size } \\
\hline & 1986 & 1993 & 1998 & Difference & 1986 & 1998 & Difference & 1986 & 1998 & $\begin{array}{c}\text { Differenc } \\
\mathrm{e} \\
\end{array}$ \\
\hline $\begin{array}{lcc}\text { East Tennessee Human } & \text { Resource } \\
\text { Agency (ETHRA) } & & \\
\end{array}$ & 6.46 & 5.36 & 13.10 & 6.64 & 28 & 45.9 & 17.9 & 40 & 51 & 11 \\
\hline $\begin{array}{lcc}\text { First Tennessee } & \text { Human } & \text { Resource } \\
\text { Agency (FTHRA) } & & \\
\end{array}$ & 3.86 & 5.92 & 12.85 & 8.99 & 74.1 & 60.0 & -14.1 & 44 & 62 & 18 \\
\hline $\begin{array}{l}\text { Hamilton County Rural Transportation } \\
\text { System }\end{array}$ & 7.96 & 16.72 & 9.18 & 1.21 & 82.0 & 79.1 & -2.9 & 8 & 9 & 1 \\
\hline $\begin{array}{l}\text { Hancock County Rural Transportation } \\
\text { System (HCRTS) }\end{array}$ & 45.16 & 8.38 & 9.49 & -35.67 & 50 & 68.6 & 18.6 & 11 & 4 & -7 \\
\hline $\begin{array}{l}\text { Metropolitan } \text { Inter-Faith Association } \\
\text { (MIFA)* }\end{array}$ & 3.60 & 8.30 & 16.36 & 12.76 & 94 & 50.4 & -43.6 & 18 & 29 & 11 \\
\hline $\begin{array}{l}\text { Mid-Cumberland Human Resource } \\
\text { Agency (MCHRA) }\end{array}$ & 5.30 & 4.43 & 8.91 & 3.61 & 58.7 & 60.9 & 2.2 & 32 & 50 & 18 \\
\hline $\begin{array}{l}\text { Northwest Tennessee Human Resource } \\
\text { Agency ((NWTHRA) }\end{array}$ & 3.75 & 5.28 & 10.74 & 6.99 & 96 & 54.6 & -41.4 & 30 & 74 & 44 \\
\hline $\begin{array}{l}\text { South Central Tennessee Development } \\
\text { District SCTDD) }\end{array}$ & 3.83 & 0.04 & 6.69 & 2.86 & 67.4 & 69.1 & 1.7 & 42 & 52 & 10 \\
\hline $\begin{array}{l}\text { Southeast Tennessee Human Resource } \\
\text { Agency (SETHRA) }\end{array}$ & 6.31 & 6.85 & 11.54 & 5.22 & 68 & 58.7 & -9.3 & 47 & 52 & 5 \\
\hline $\begin{array}{l}\text { Southwest Human Resource Agency } \\
\text { (SWHRA) }\end{array}$ & 3.88 & 2.53 & 3.37 & -0.50 & 53 & 27.4 & -25.6 & 38 & 70 & 32 \\
\hline $\begin{array}{l}\text { Upper Cumberland Human Resource } \\
\text { Agency (UCHRA) }\end{array}$ & 5.50 & 5.82 & 11.70 & 6.20 & 51 & 61.4 & -19.6 & 52 & 76 & 24 \\
\hline Average/Total & 5.06 & 4.64 & 9.83 & 4.76 & 67.9 & 53.8 & -14.2 & 362 & 529 & 167 \\
\hline
\end{tabular}

*Now Delta Human Resource Agency. 
Public Transit in Tennessee

population below poverty, service area, and vehicle-miles of service were considered. Consistent statistical relationships could not be identified within acceptable levels of accuracy. Some regression equations developed were:

$$
\begin{array}{ll}
\text { 1. } & \mathrm{TR}=27502.3+0.21 \mathrm{Eld}+18.4 \mathrm{SA} \\
& \mathrm{R} 2=.62 \\
\text { 2. } & \mathrm{TR}=22911.1+2.89 \mathrm{Eld}-13.7 \mathrm{ML}+16.2 \mathrm{SA} \\
& \mathrm{R} 2=.67 \\
\text { 3. } & \mathrm{TR}=16803.8+1.8 \mathrm{Eld}-3.4 \mathrm{ML}+16.9 \mathrm{SA}+.03 \mathrm{VM} \\
& \mathrm{R} 2=.71 \\
\text { 4. } & \mathrm{NCR}=7267.2-.003 \mathrm{Eld}+14.2 \mathrm{SA} \\
& \mathrm{R} 2=.54 \\
\text { 5. } & \mathrm{NCR}=3006.2+6.76 \mathrm{Eld}-16.7 \mathrm{ML}+9.4 \mathrm{SA} \\
& \mathrm{R} 2=.76
\end{array}
$$

Where:

$$
\text { TR }=\text { Total Annual Ridership }
$$

NCR = Total Annual Ridership that is Non-Contractor General Population

Eld = Elderly Population (Individuals Over the Age of 60)

$\mathrm{SA}=$ Service Area (County Service Area in Square Miles)

$\mathrm{ML}=$ Mobility Limited Population (Age 16-64)

$\mathrm{VM}=$ Annual Vehicle-Miles of Service

Attempts were made to apply ridership forecasting equations and relationships developed by the sates of Washington, Oregon, and California (Painter and Casavont, 1998; Reid, 2000; TRB Conference, 2000). However, the specific service delivery elements used in these states were sufficiently different to make these equations of limited use in Tennessee. Rather, reliance was placed on a national demand forecasting methodology developed for rural passenger transportation and presented in Transit Cooperative Research Program (TRCP) Report 3: Workbook for Estimating Demand for Rural Passenger Transportation (SG Associates, Inc., 1995). The TCRP Report 3 model was calibrated for low density rural areas located outside a Metropolitan Statistical Area. The procedures determine "demand as the number of passenger trips that will be taken when a given level of passenger transportation service is available" and are one-way trips. While specific trip rates are provided for programs such as Head Start and nursing homes, correlations could not be developed between the trip rates reported and the ridership levels carried by Tennessee rural operators. A critical measure in applying a trip rate is the number of clients (unduplicated individuals), which is a difficult variable to track. The average statewide annual contract trip rate was 14.5 trips per client with a high of 26.1 trips/year and a low of 6.1 trips/year. Clearly the estimate depends on specific contract, the activity level of different clients, and reporting accuracy. Without an ability to define consistent relationships among the 11 systems, the TCRP Report 3 generalized public transportation was utilized.

The demand forecasting model considered the following variables: 


\section{Public Transit in Tennessee}

1. Persons aged 60 and over;

2. Persons aged 16 to 64, with mobility limitations; and

3. Persons aged 64 or less, residing in households having incomes below the poverty level.

Separate demand estimates are developed for each population group, although there are group overlaps. These three groups make up the majority of riders on rural passenger transportation services. To the extent individuals not belonging to one of these population segments made trips on services analyzed in developing these methodologies, the trip rates used for these market segments are slightly higher than they would be otherwise. As a result, the non-program estimates include "general public" demand.

A verification process was conducted, which indicated good agreement with statewide ridership totals, but differences with individual systems. The verification included:

1. Obtaining ridership data for 11 transit agencies operated in Tennessee.

2. Determining size of the service area. For those systems which operate in donut rural areas, the area of the donut hole, which is the actual urban area, has been subtracted out.

3. Determining the size of the following population groups:

o Number of persons aged 60 and over - elderly;

o Number of persons aged 16 to 64 who are mobility limited - mobility limited;

o Number of persons under age 65 residing in households with incomes below the poverty level - poverty.

Obviously a person could be over 60 , with mobility limitations, and living in poverty at the same time. There are overlaps between these three groups. In this case study, the modification for these overlaps was not conducted to the population, but on vehicle-miles of service provided.

4. Determining vehicle-miles of service:

o Annual vehicle-miles of service available to poverty group:

o Annual vehicle-miles of service available to mobility limited group; and

o Annual vehicle-miles of service available to poverty group.

As mentioned earlier, due to the overlaps between these three population groups, certain modifications are required. In this case study, 65 percent of the total vehicle-miles are considered available to the elderly group and 17.5 percent are available to each of the other two groups. This assumption yielded acceptable results. All demographic and ridership data were for 1998-99.

The TCRP Report 3 non-contract model was used to generate forecasts of riders for 11 geographic areas, which relate to the 11 rural transit systems. The equation used in forecasting was: 


\section{Public Transit in Tennessee}

$$
\begin{aligned}
\mathrm{TR}=\quad(1200 & (\text { Eld } \times \text { VMEld } \times 2.682+376) \\
& + \text { ML }(\text { VMML } \times 1.57+1010) \\
& + \text { POV }(\text { VMPOV x } 2,450+525)) / 1,000,000
\end{aligned}
$$

where:

TR $=$ Total Annual Ridership

Eld $=$ Elderly Population (Individuals Over the Age of 60)

POV $=$ Population under 65 Years of Age and Living in Poverty

$\mathrm{SA}=$ Service Area (County Service Area in Square Miles)

ML = Mobility Limited Population (Age 16-64)

$\mathrm{VM}=$ Vehicle-Miles of Service per Square Mile

VMEld $=$ Vehicle-Miles per Square Mile Available to the Elderly Population

VMML = Vehicle-Miles per Square Mile Available to the Mobility Limited Population

VMPOV = Vehicle-Miles per Square Mile Available to the Living in Poverty Population

The results of the forecasts were compared to the transit ridership data for these 11 rural systems. The ridership forecast results for most of the areas are acceptable, though some of them have a relatively high difference between the forecast and the real number of riders. However, the difference for the state as a whole is 6 percent, which was considered acceptable (see Table 3.7 below).

Other models were adapted with no success, using different weights of vehicle-miles of service and applying contract and non-contract demand relationships.

\subsubsection{Rural Ridership Forecasts.}

Demographic forecasts for Tennessee's 95 counties were provided for the years 2005, 2010, 2015 and 2020. The demographic data were aggregated to the eleven rural public transportation systems (see Table 3.8 below). The independent variables were used to predict rural public transportation ridership under two different scenarios: 1) a Baseline Scenario, in which a constant level of vehicle-miles of service is assumed between years 2000 and 2020, and 2) an alternative scenario, in which an increase in transit vehicle miles of service takes place roughly in proportion to the predicted growth of the elderly population in each Rural Transit District. Under the Baseline Scenario, with no changes in service levels, rural public transportation ridership is predicted to increase $3 \%$ by 2010 and $20 \%$ by 2020 . Alternatively, if vehicle miles of service are expanded in proportion to the growth in the elderly population, the resulting growth in passenger ridership is forecast to be almost $53 \%$ by 2015 , rising to over $82 \%$ by 2020 . These results are summarized in Table 3.9 below. Tables 3.10 and 3.11 show the Rural Transit District specific details for each of these two scenarios. 
Public Transit in Tennessee

Table 3.7. Calibrated TCRP3 Rural Public Transportation Ridership Model.

\begin{tabular}{|l|c|c|}
\hline Agency & $\begin{array}{c}1998 / 1999 \\
\text { Actual Ridership }\end{array}$ & $\begin{array}{c}1998 / 1999 \\
\text { Predicted Ridership }\end{array}$ \\
\hline East Tennessee Human Resource Agency (ETHRA) & 135,067 & 224,152 \\
\hline First Tennessee Human Resource Agency (FTHRA) & 138.931 & 228,772 \\
\hline Hamilton County Rural Transportation System & 22,182 & 69,110 \\
\hline $\begin{array}{l}\text { Hancock County Rural Transportation System } \\
\text { (HCRTS) }\end{array}$ & 3,537 & 3,270 \\
\hline $\begin{array}{l}\text { Metropolitan Inter-Faith Association } \\
\text { (MIFA)* }\end{array}$ & 36,319 & 169,135 \\
\hline $\begin{array}{l}\text { Mid-Cumberland Human Resource Agency } \\
\text { (MCHRA) }\end{array}$ & 122,065 & 98,116 \\
\hline $\begin{array}{l}\text { Northwest Tennessee Human Resource Agency } \\
\text { ((NWTHRA) }\end{array}$ & 136,404 & 99,844 \\
\hline $\begin{array}{l}\text { South Central Tennessee Development District } \\
\text { SCTDD) }\end{array}$ & 120,795 & 90,050 \\
\hline $\begin{array}{l}\text { Southeast Tennessee Human Resource Agency } \\
\text { (SETHRA) }\end{array}$ & 98,114 & 71,416 \\
\hline $\begin{array}{l}\text { Southwest Human Resource Agency } \\
\text { (SWHRA) }\end{array}$ & 180,459 & $1,207,696$ \\
\hline \hline $\begin{array}{l}\text { Upper Cumberland Human Resource Agency } \\
\text { (UCHRA) }\end{array}$ & 150,821 & \\
\hline $\begin{array}{l}\text { Totals } \\
\text { SW }\end{array}$ & $1,144,694$ & \\
\hline
\end{tabular}

*Now Delta Human Resource Agency. 
Public Transit in Tennessee

Table 3.8. Rural Public Transportation District Demographic Forecasts.

\begin{tabular}{|c|c|c|c|c|c|c|c|c|c|c|c|c|c|c|c|c|}
\hline \multirow[t]{2}{*}{ Agency } & \multicolumn{4}{|c|}{2000} & \multicolumn{4}{|c|}{2010} & \multicolumn{4}{|c|}{2015} & \multicolumn{4}{|c|}{2020} \\
\hline & ELD & $\mathrm{ML}$ & POV & Total & ELD & ML & POV & Total & ELD & ML & POV & Total & ELD & ML & POV & Total \\
\hline DHRA & 12,973 & 1,641 & 14,682 & 29,296 & 19,218 & 1,484 & 11,134 & 31,836 & 23,657 & 1,370 & 9,733 & 34,761 & 28,378 & 1,249 & 8,515 & 38,143 \\
\hline ETHRA & 124,693 & 16,142 & 89,082 & 229,917 & 175,111 & 14,312 & 68,625 & 258,048 & 202,227 & 13,173 & 60,455 & 275,856 & 229,509 & 12,030 & 53,290 & 294,831 \\
\hline FTHRA & 71,406 & 9,025 & 49,039 & 129,470 & 93,283 & 7,789 & 37,476 & 138,548 & 103,655 & 7,109 & 32,872 & 143,636 & 113,790 & 6,456 & 28,790 & 149,037 \\
\hline Hamilton Co & 21,271 & 1,914 & 9,711 & 32,896 & 26,177 & 1,583 & 6,743 & 34,503 & 29,410 & 1,422 & 5,747 & 36,579 & 32,387 & 1,273 & 4,933 & 38,593 \\
\hline Hancock Co & 1,091 & 249 & 1,797 & 3,137 & 1,350 & 225 & 1,382 & 2,957 & 1,527 & 202 & 1,204 & 2,933 & 1,727 & 178 & 1,055 & 2,961 \\
\hline MCHRA & 84,831 & 9,471 & 50,952 & 145,254 & 132,266 & 9,113 & 41,908 & 183,288 & 163,368 & 8,777 & 38,442 & 210,588 & 198,174 & 8,394 & 35,344 & 241,913 \\
\hline NWTHRA & 42,355 & 4,017 & 26,104 & 72,476 & 51,882 & 3,397 & 19,886 & 75,165 & 57,116 & 3,054 & 17,266 & 77,436 & 61,944 & 2,732 & 14,932 & 79,608 \\
\hline SCTDD & 57,069 & 6,635 & 37,717 & 101,421 & 78,702 & 6,093 & 30,282 & 115,077 & 90,115 & 5,667 & 27,057 & 122,840 & 102,055 & 5,221 & 24,235 & 131,512 \\
\hline SETHRA & 34,180 & 5,203 & 30,843 & 70,226 & 46,369 & 4,573 & 23,744 & 74,686 & 52,241 & 4,185 & 20,890 & 77,316 & 57,610 & 3,819 & 18,360 & 79,790 \\
\hline SWHRA & 34,992 & 3,884 & 25,437 & 64,313 & 44,940 & 3,364 & 19,232 & 67,536 & 51,904 & 3,069 & 16,866 & 71,840 & 58,927 & 2,783 & 14,755 & 76,466 \\
\hline UCHRA & 46,571 & 5,308 & 35,246 & 87,125 & 59,928 & 4,612 & 26,221 & 90,761 & 66,413 & 4,195 & 22,769 & 93,377 & 72,803 & 3,789 & 19,816 & 96,409 \\
\hline Total & 531,432 & 63,489 & 370,610 & 965,531 & 729,225 & 56,545 & 286,633 & $1,072,407$ & 841,633 & 52,223 & 253,301 & $1,147,163$ & 957,304 & 47,924 & 224,025 & $1,229,262$ \\
\hline
\end{tabular}


Public Transit in Tennessee

Table 3.9 Changes in Rural Ridership for Changes in Service Levels.

\begin{tabular}{l|l|r|r} 
& \multicolumn{3}{c}{ Ridership Increase (\%) } \\
\multicolumn{1}{c|}{ Scenario } & $\mathbf{2 0 1 0}$ & $\mathbf{2 0 1 5}$ & $\mathbf{2 0 2 0}$ \\
\hline $\begin{array}{l}\text { Current level of vehicle miles of service - - 1999 } \\
\begin{array}{l}\text { Increase of vehicle-mile of service in proportion to increase } \\
\text { of rural population* }\end{array}\end{array}$ & 3 & 11.7 & 20.8 \\
\hline
\end{tabular}

*VMT for elderly increased by 1.45 in 2010, 1.70 in 2015, and 1.90 in 2020.

Table 3.10 Rural Transportation Forecasting — 1999 Vehicle Miles of Service.

\begin{tabular}{|l|c|c|c|c|}
\hline \multicolumn{1}{|c|}{ Agency } & $\begin{array}{c}\text { Actual } \\
(1998-1999)\end{array}$ & $\begin{array}{c}2010 \\
\text { Estimated Trips }\end{array}$ & $\begin{array}{c}2015 \\
\text { Estimated Trips }\end{array}$ & $\begin{array}{c}2020 \\
\text { Estimated Trips }\end{array}$ \\
\hline DHRA & 36,319 & 37,397 & 40.560 & 43,888 \\
\hline ETHRA & 135,067 & 139,078 & 150,838 & 163,214 \\
\hline FTHRA & 138,931 & 143,056 & 155,153 & 167,883 \\
\hline HCRTS & 22,182 & 22,841 & 24,772 & 26,805 \\
\hline HCRTSK & 3,537 & 3,642 & 3,950 & 4,274 \\
\hline MCHRA & 122,065 & 125,690 & 136,317 & 147,502 \\
\hline NWTHRA & 136,404 & 140,454 & 152,331 & 164,829 \\
\hline SCTDD & 120,795 & 124,382 & 134,899 & 145,968 \\
\hline SETHRA & 98,114 & 101,027 & 109,570 & 118,560 \\
\hline SWHRA & 180,459 & 185,817 & 201,530 & 218,065 \\
\hline UCHRA & 150,821 & 155,299 & 168,431 & 182,251 \\
\hline TOTAL & $1,144,694$ & $1,178,684$ & $1,278,349$ & $1,383,239$ \\
\hline \% Increase & & $2.97 \%$ & $11.68 \%$ & $20.84 \%$ \\
\hline
\end{tabular}


Public Transit in Tennessee

Table 3.11 Rural Transportation Forecasting -- Vehicle Miles Change in Proportion to Growth of Elderly Population.*

\begin{tabular}{|l|c|c|c|c|}
\hline \multicolumn{1}{|c|}{ Agency } & $\begin{array}{c}\text { Actual } \\
(1998-1999)\end{array}$ & $\begin{array}{c}2010 \\
\text { Estimated Trips }\end{array}$ & $\begin{array}{c}2015 \\
\text { Estimated Trips }\end{array}$ & $\begin{array}{c}2020 \\
\text { Estimated Trips }\end{array}$ \\
\hline DHRA & 36,319 & 46,284 & 55,515 & 66,247 \\
\hline ETHRA & 135,067 & 172,125 & 206,454 & 246,366 \\
\hline FTHRA & 138,931 & 177,049 & 212,360 & 253,414 \\
\hline HCRTS & 22,182 & 28,268 & 33,906 & 40,461 \\
\hline HCRTSK & 3,537 & 4,507 & 5,406 & 6,452 \\
\hline MCHRA & 122,065 & 155,555 & 186,580 & 222,650 \\
\hline NWTHRA & 136,404 & 173,828 & 208,498 & 248,805 \\
\hline SCTDD & 120,795 & 153,937 & 184,639 & 220,334 \\
\hline SETHRA & 98,114 & 125,033 & 149,970 & 178,963 \\
\hline SWHRA & 180,459 & 229,971 & 275,837 & 329,163 \\
\hline UCHRA & 150,821 & 192,201 & 230,535 & 275,102 \\
\hline TOTAL & $1,144,694$ & $1,458,758$ & $1,749,700$ & $2,087,956$ \\
\hline$\%$ Increase & & $27.44 \%$ & $52.85 \%$ & $82.40 \%$ \\
\hline
\end{tabular}

*VMT for elderly increased by 1.45 in 2010, 1.70 in 2015 and 1.90 in 2020 . 
Public Transit in Tennessee

\section{Urban Transit Systems}

\subsection{Introduction.}

This chapter is divided into four major sections. Section 4.2 describes in quantitative terms the types of urban transit services offered by each of the State's twelve urban transit operating districts. Section 4.3 presents the results of this study's base year public transit benefits analysis. This analysis was carried out on data collected for calendar year 1998. The results of this analysis were then used to develop a set of expected benefits per transit trip. These "Baseline Benefits " are presented in Section 4.4 below. These per trip benefits, broken down by urban transit system and type of transit service, are then applied to the set of ridership forecasts described in Chapter 3 of this report for the forecast years of 2005, 2010 and 2020. These forecast trips and benefits are presented in Section 4.5. A number of additional urban public transit scenarios are investigated in this section, notably by making use of the urban ridership forecasting models described in Chapter 3 to carry out a "what if" analysis based on changes in the level of investment in the State's public transit services. All monetary values reported in tables and figures in this chapter are in 1998 dollars.

\subsection{Urban Transit Services in the State.}

There are twelve urban transit systems in Tennessee. Services are provided in each of the state's nine metropolitan areas of Bristol, Chattanooga, Clarksville, Jackson, Johnson City, Kingsport, Knoxville, Memphis and Nashville. Services are also provided in the cities of Oak Ridge, Gatlinburg and Pigeon Forge. Table 4.1 shows the types of public transit service provided in each city over the past two or more years. Figure 4.1 shows the geographic location of each of these systems within the State. Figures 4.2 through 4.6 show recent representations (mid- or late1990 's) of the fixed bus transit routes operated by each system. These fixed route bus services dominate ridership, accounting for almost $95 \%$ of all trips in 1998. Significant ridership also occurs on the various demand responsive van systems provided in support of Americans with Disabilities Act (ADA) qualified patrons. Table 4.1 is divided into two distinct urban system groupings, based on the urban area size. Group 1 represents the State's four largest metropolitan areas. The fixed route bus systems in these four cities account for approximately $75 \%$ of the State's total urban transit ridership in 1998: with the much larger cities of Memphis and Nashville accounting for approximately $41 \%$ and 23\%, respectively. Group 2 contains the State's five smaller metropolitan areas plus the heavily tourism oriented towns of Gatlinburg and Pigeon Forge, and the small town of Oak Ridge, which in recent years has operated only 2 or 3 demand responsive vans with no fixed route bus or commuter vanpool system in place.

Table 4.2 summarizes the key transit demand and supply variables, based on Tennessee DOT reported data for calendar year 1998. Figures in the table are summed over all types of transit service. In total, over 20.5 million miles of urban transit service was provided in order to satisfy some 121.3 million passenger miles of travel. In addition to the trips shown in Table 4.2, the 


\section{Public Transit in Tennessee}

Chattanooga Incline railway also carried 429,900 passengers up and down Lookout Mountain in 1998 , nearly all of them tourists. We treat these incline trips separately below and do not include these trips in subsequent tables unless specifically stated.

Table 4.1 Types of Urban Transit Service in Tennessee.

\begin{tabular}{|c|c|c|c|c|c|c|}
\hline \multirow[b]{2}{*}{ Urban Transit Systems } & \multicolumn{6}{|c|}{ Service Types* } \\
\hline & FB & DS & $\mathrm{CV}$ & DR & LR & IP \\
\hline \multicolumn{7}{|l|}{ Group 1: Large Urban } \\
\hline Chattanooga & $\mathbf{X}$ & $\mathbf{X}$ & & $\mathbf{X}$ & & $\mathbf{X}$ \\
\hline Knoxville & $\mathbf{X}$ & $\mathbf{X}$ & & $\mathbf{X}$ & & \\
\hline Memphis & $\mathbf{X}$ & & & $\mathbf{X}$ & $\mathbf{X}$ & \\
\hline Nashville & $\mathbf{X}$ & & $\mathbf{X}$ & $\mathbf{X}$ & & \\
\hline \multicolumn{7}{|l|}{ Group 2: Small Urban } \\
\hline Bristol & $\mathbf{X}$ & & & $\mathbf{X}$ & & \\
\hline Clarksville & $\mathbf{X}$ & & & $\mathbf{X}$ & & \\
\hline Gatlinburg & $\mathbf{X}$ & & & $\mathbf{X}$ & & \\
\hline Jackson & $\mathbf{X}$ & & & $\mathbf{X}$ & & \\
\hline Johnson City & $\mathbf{X}$ & & & $\mathbf{X}$ & & \\
\hline Kingsport & $\mathbf{X}$ & & & $\mathbf{X}$ & & \\
\hline Oak Ridge & & & & $\mathbf{X}$ & & \\
\hline Pigeon Forge & & & & $\mathbf{X}$ & & \\
\hline
\end{tabular}

Figure 4.1. Location of Urban Transit Systems in Tennessee.

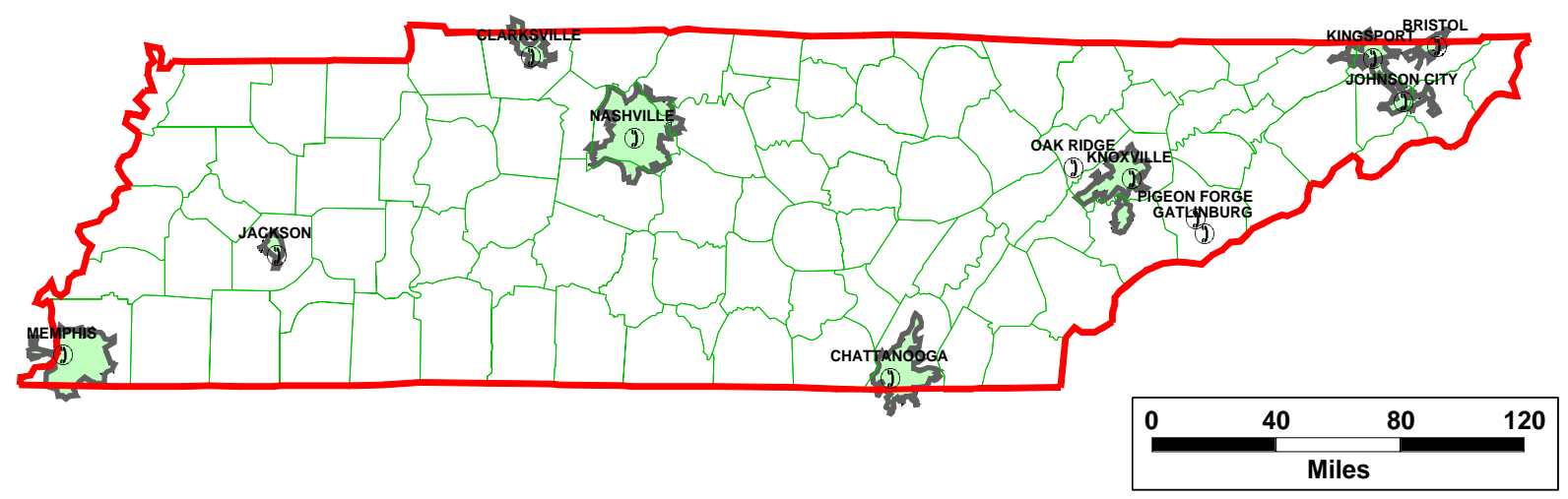


Public Transit in Tennessee

Knoxville Fixed Route Bus System

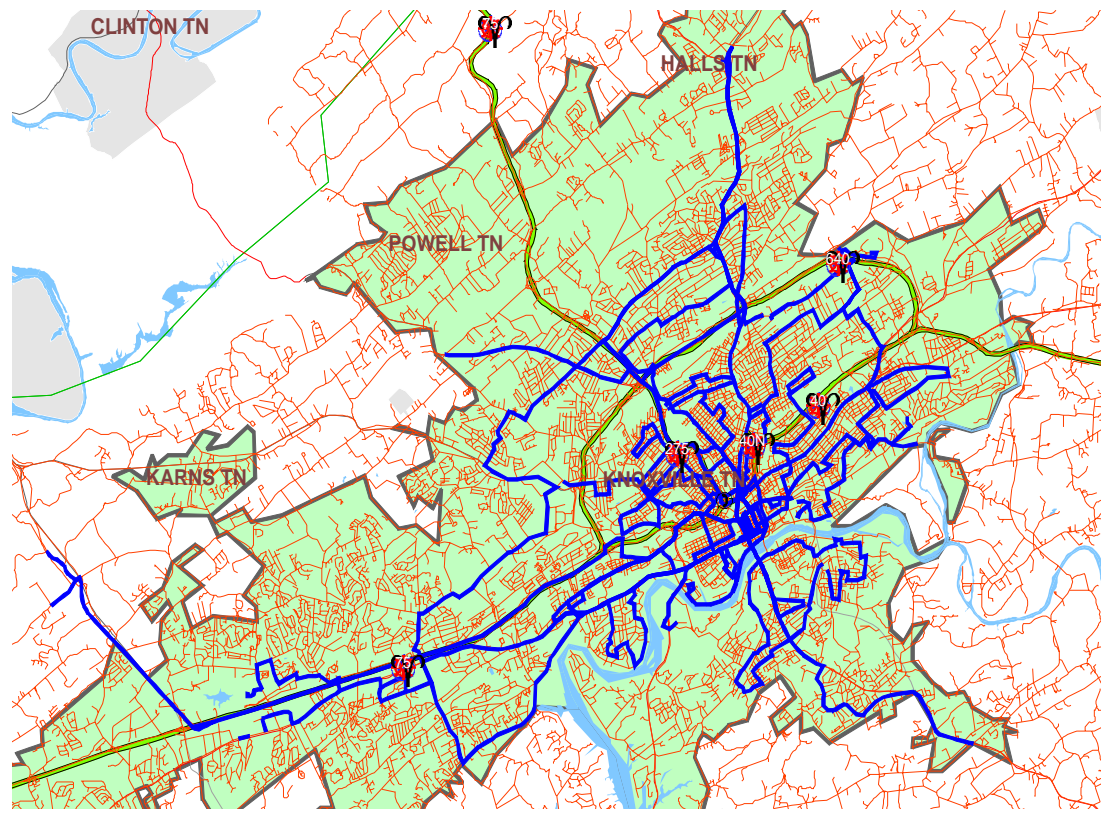

Gatlinburg Bus Routes
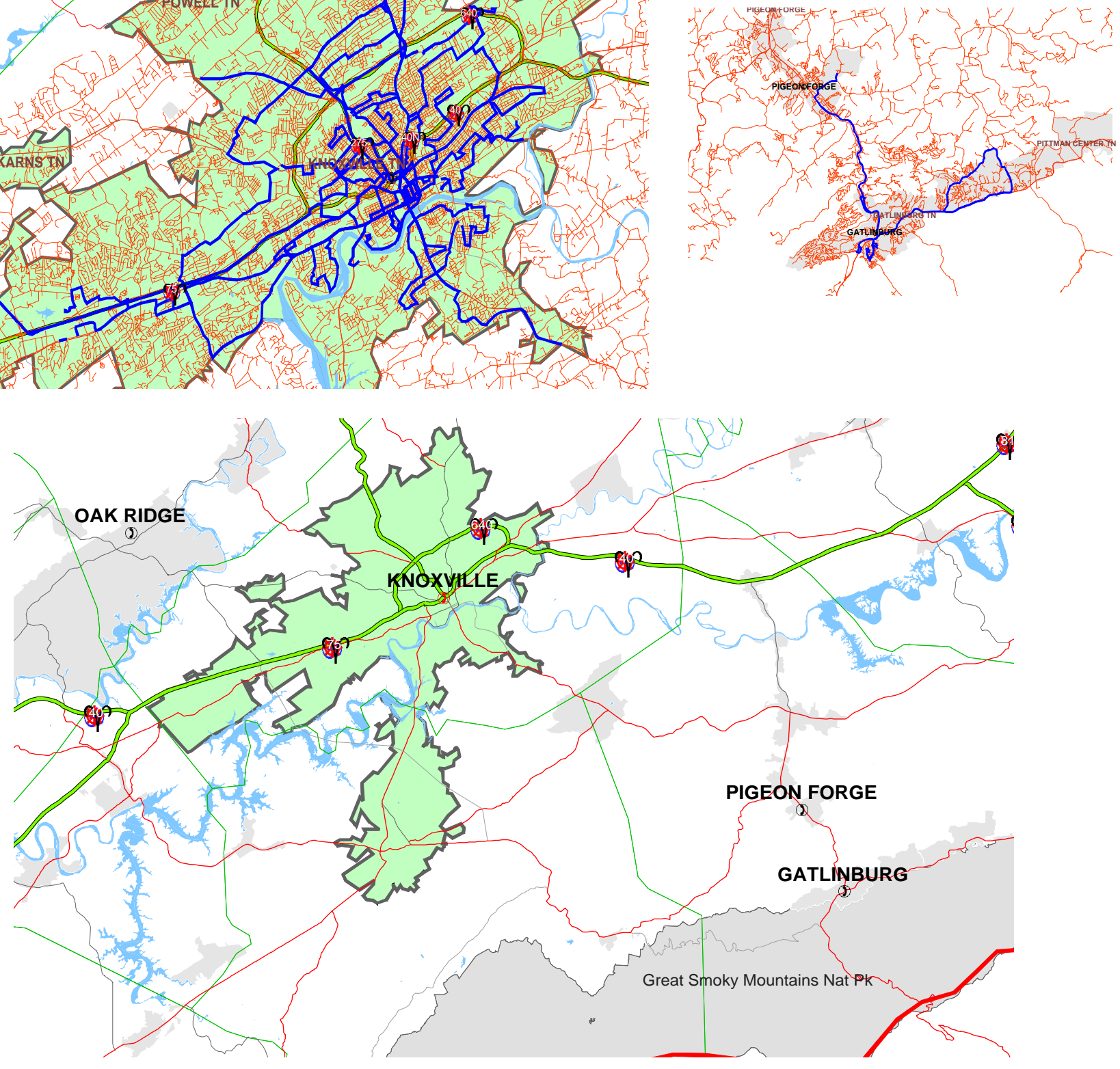

Regional Context

Figure 4.2. Knoxville-Oak Ridge-Gatlinburg-Pigeon Forge Region of East Tennessee. 
Public Transit in Tennessee

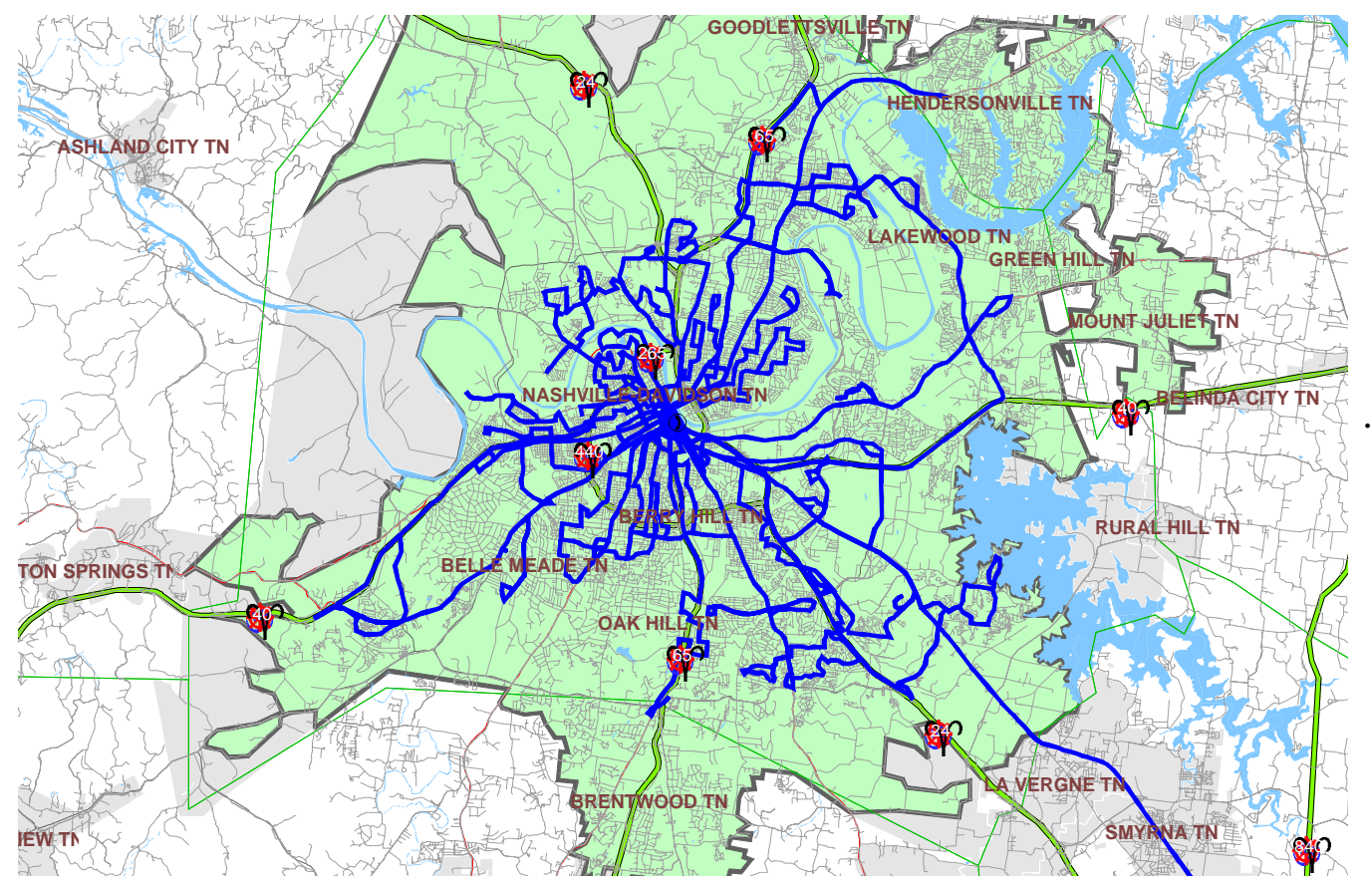

Nashville Fixed Route Bus System

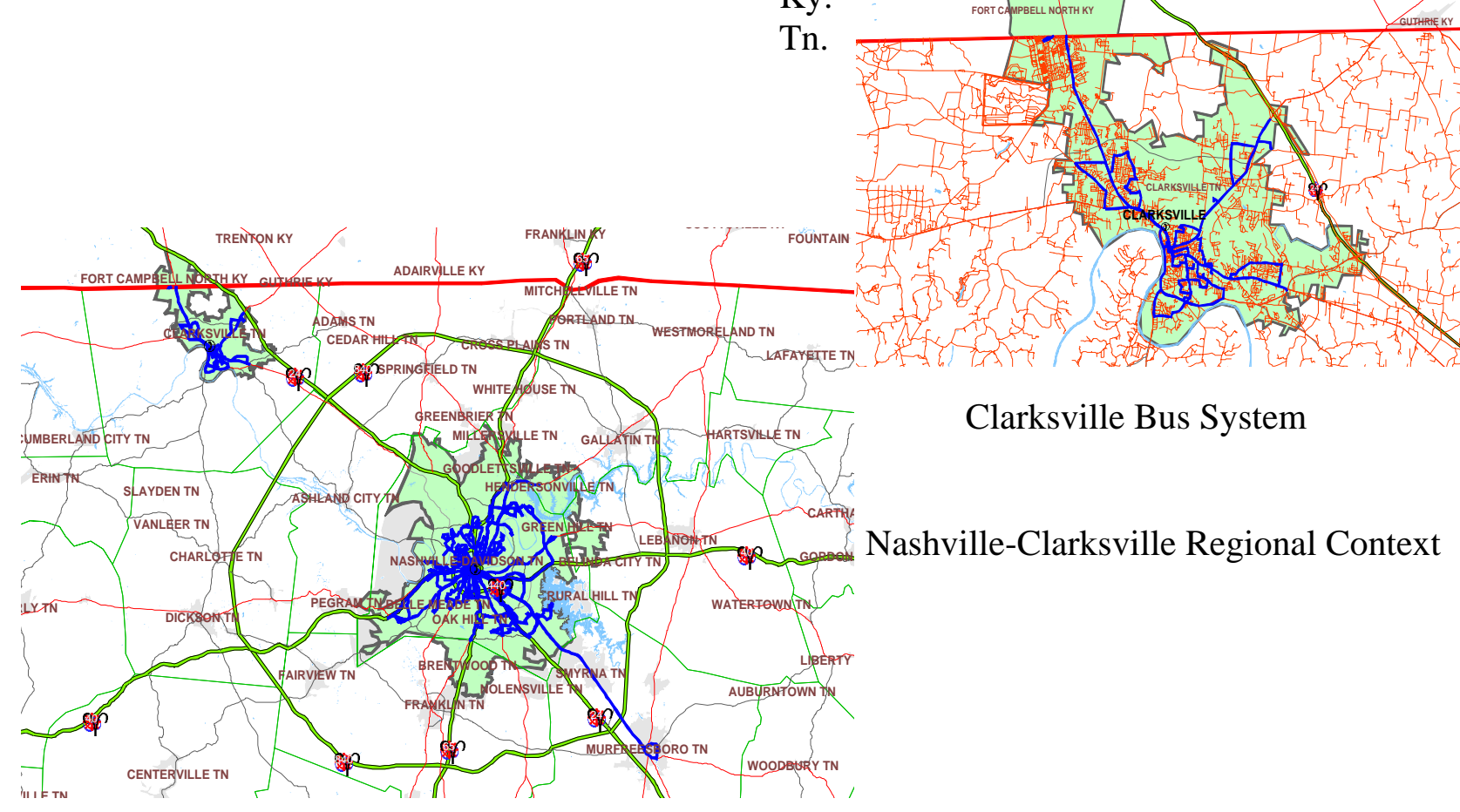

Figure 4.3 Nashville \& Clarksville Bus Systems and Regional Context. 
Public Transit in Tennessee

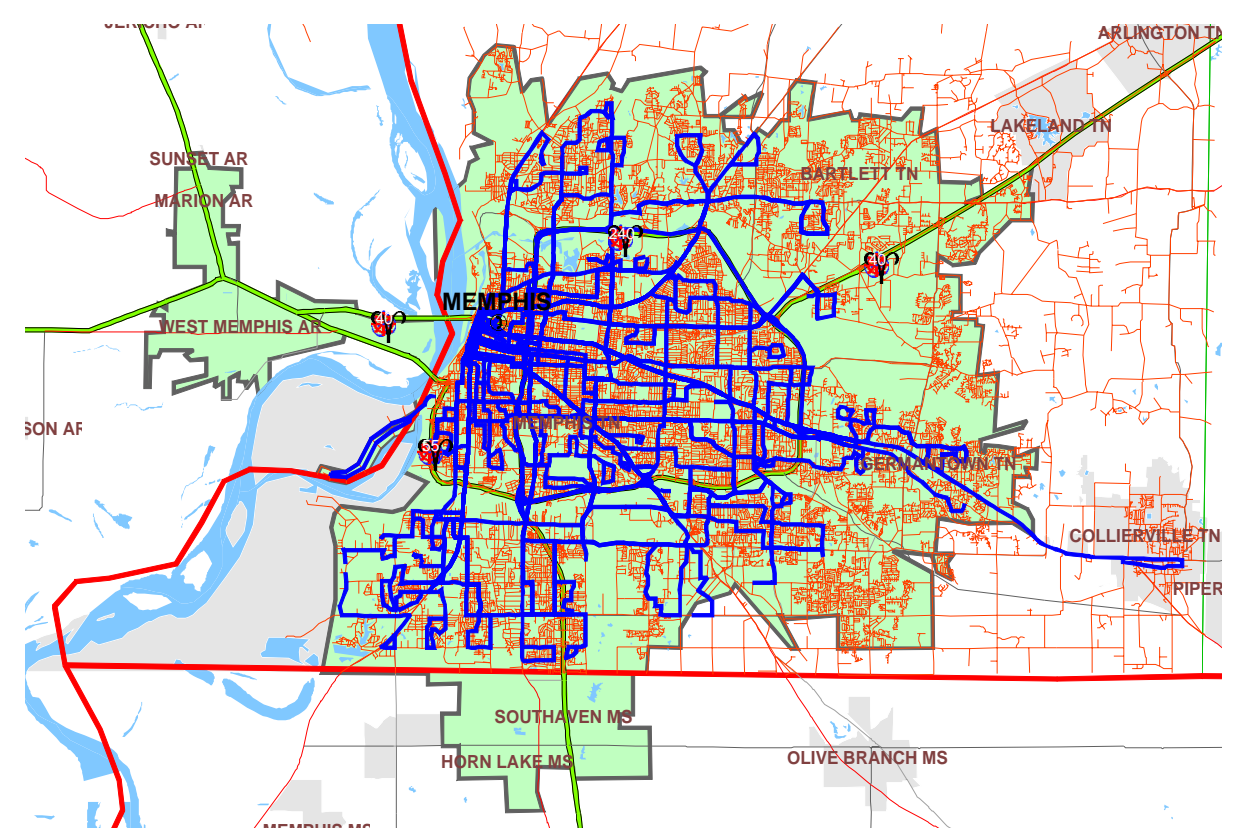

Memphis Fixed Route Bus System

Ar. / Tn.

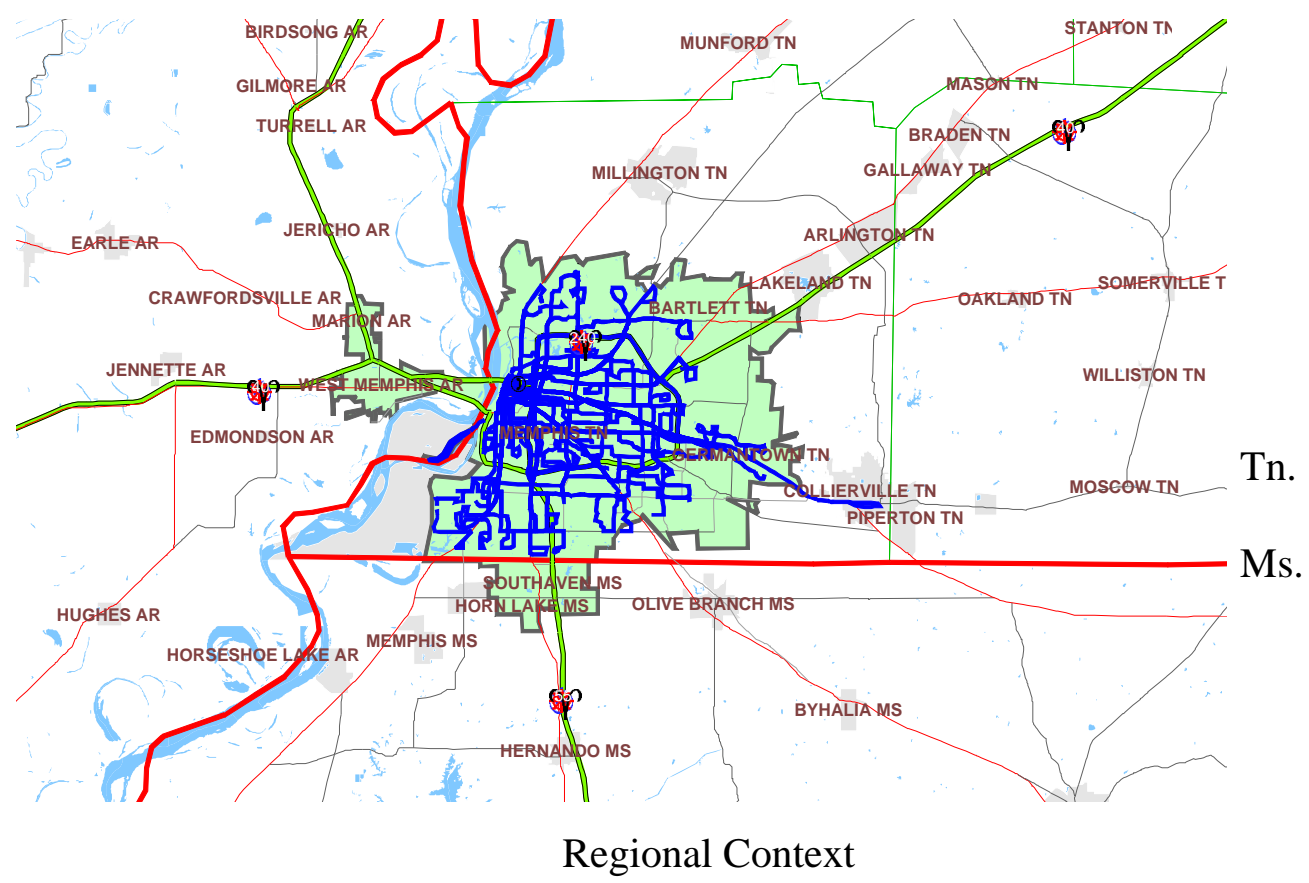

Figure 4.4 Memphis Bus System and Regional Context 
Public Transit in Tennessee

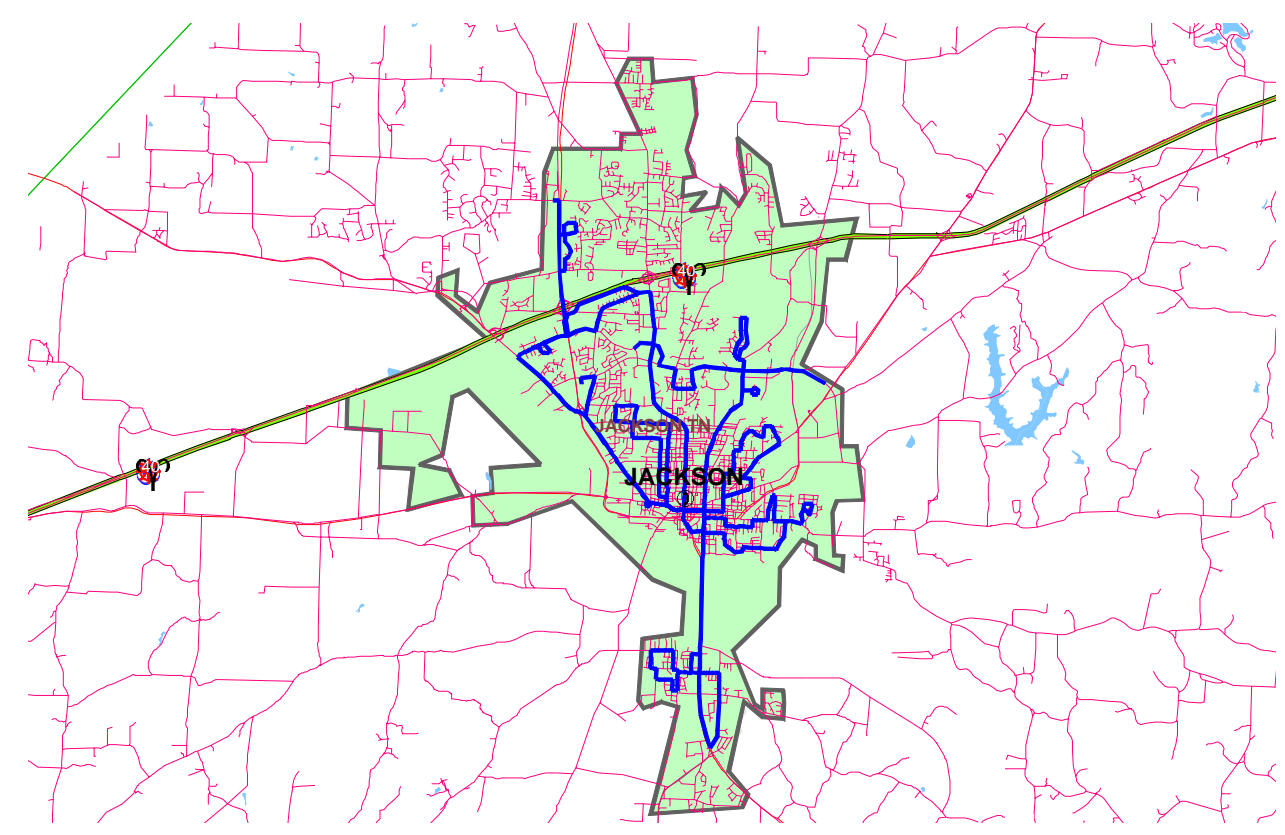

\section{Jackson Fixed Route Bus System}

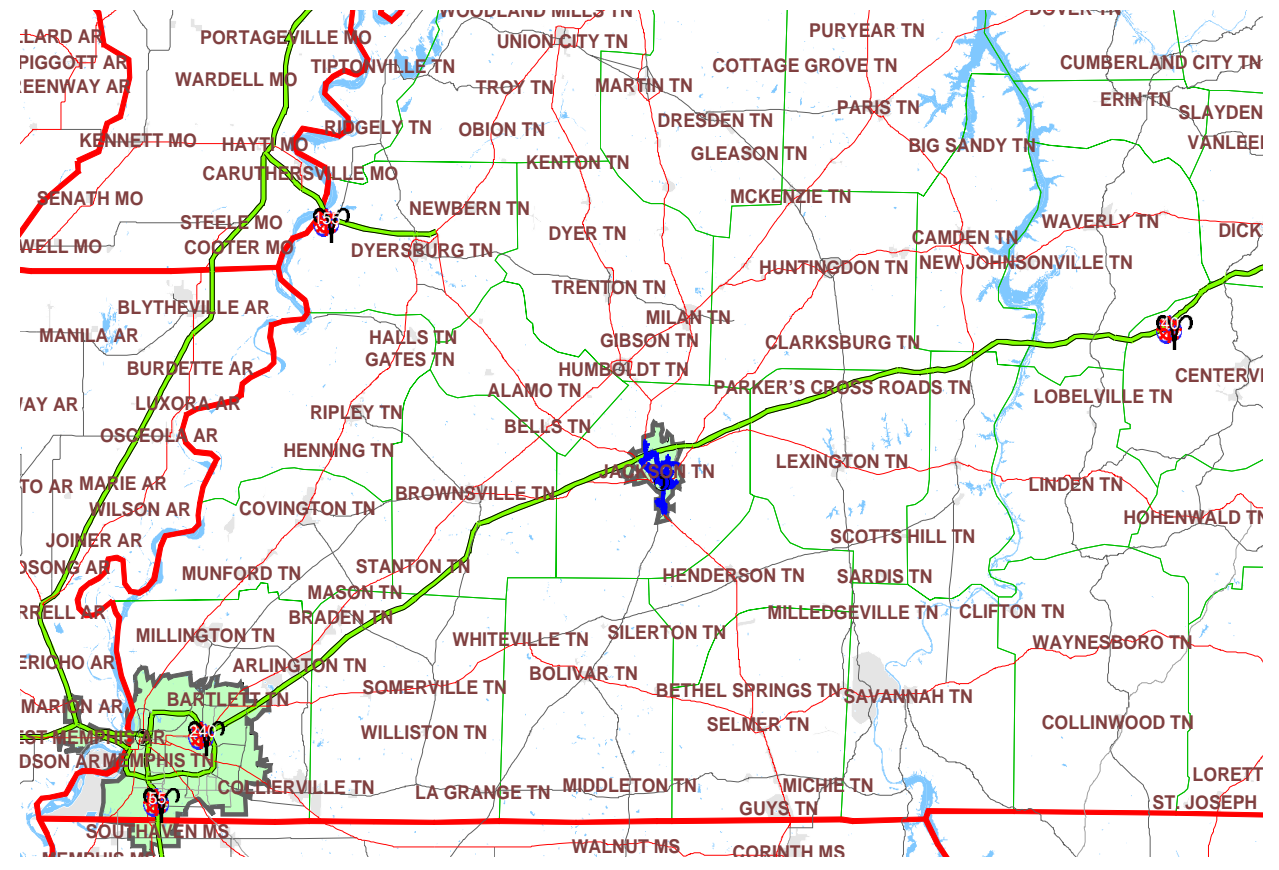

\section{Context}

Figure 4.5 Jackson Bus Transit System and Regional Context. 
Public Transit in Tennessee
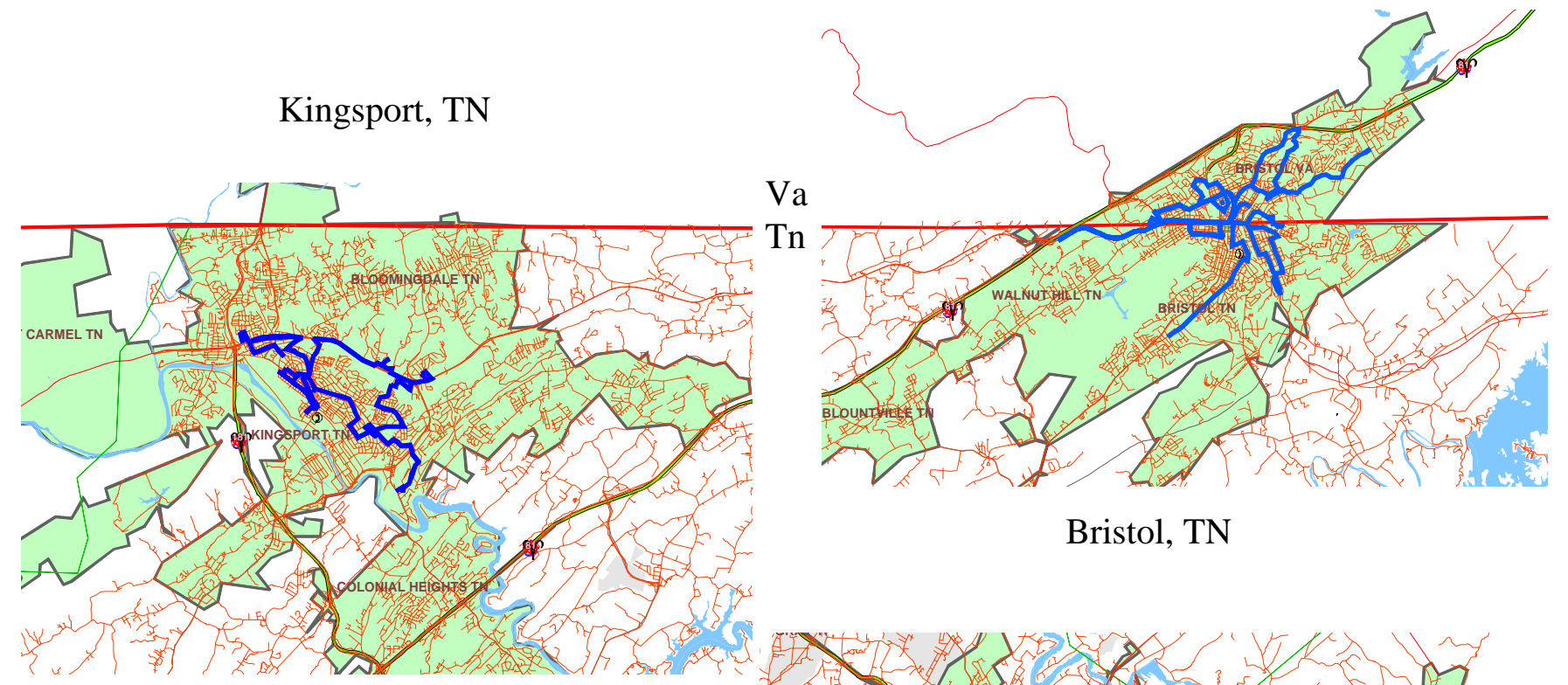

Johnson City, TN
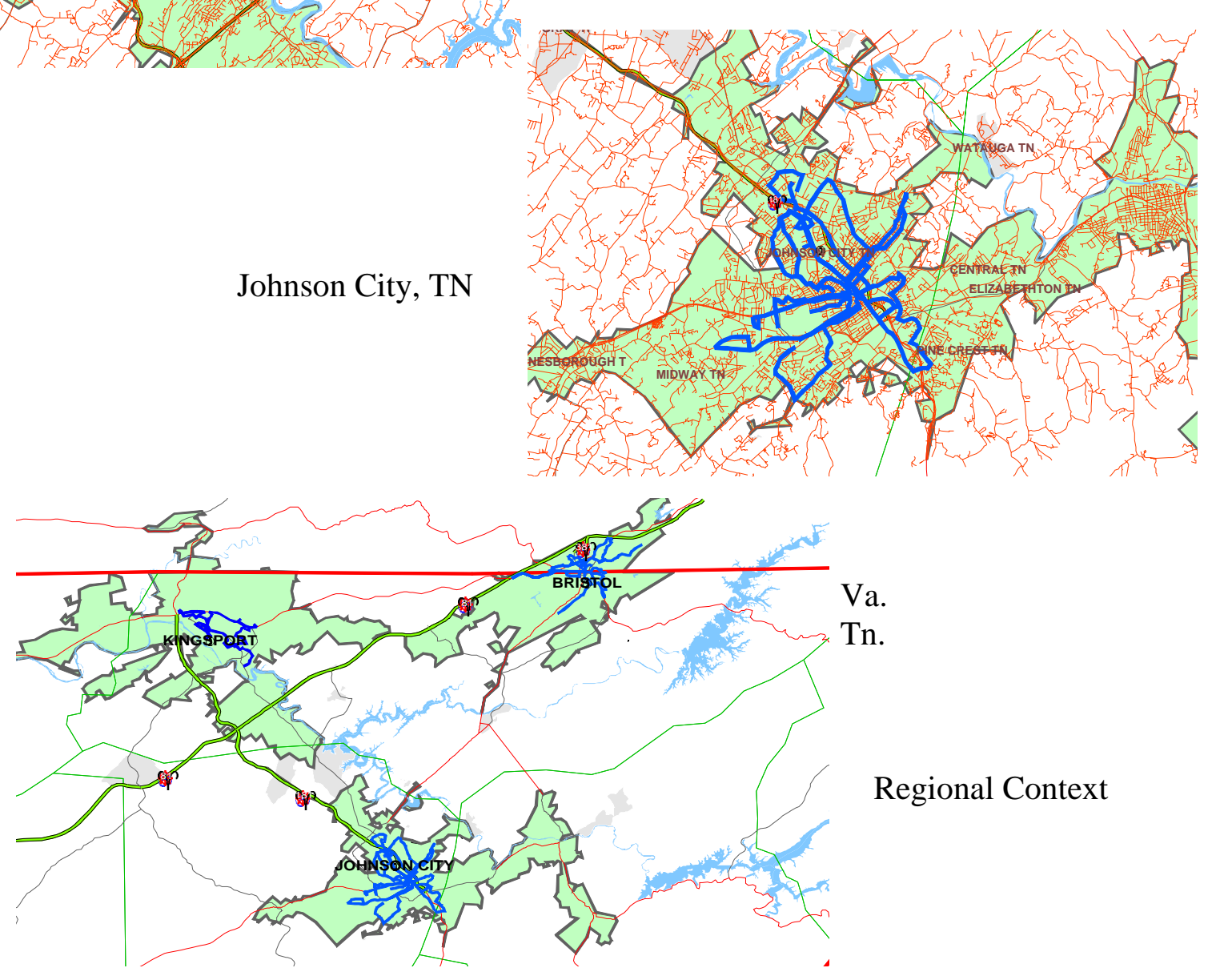

Regional Context

Figure 4.6 Fixed Bus Routes: Tri-Cities Region, North-East Tennessee 
Public Transit in Tennessee

Table 4.2 Urban Transit Demand and Supply Variables, Calendar Year 1998. (All Services).

\begin{tabular}{l|rrr} 
& $\begin{array}{r}\text { (A) Transit Demand Variables } \\
\text { Urban Area } \\
\text { Population }\end{array}$ & $\begin{array}{c}\text { Transit } \\
\text { Trips }\end{array}$ & $\begin{array}{c}\text { Passenger } \\
\text { Miles }\end{array}$ \\
\hline Urban Area & 155,276 & $2,464,363$ & $11,189,102$ \\
Chattanooga & 332,666 & $1,660,785$ & $5,643,395$ \\
Knoxville & 867,630 & $12,078,922$ & $64,858,300$ \\
Memphis & 599,314 & $6,414,751$ & $32,122,400$ \\
Nashville & 25,124 & 47,358 & 170,935 \\
Bristol & 121,988 & 430,831 & $2,683,000$ \\
Clarksville & 5,463 & 680,628 & 417,205 \\
Gatlinburg & 58,520 & 540,867 & $2,546,400$ \\
Jackson & 91,213 & 365,421 & 919,500 \\
Johnson City & 43,439 & 59,690 & 154,716 \\
Kingsport & 28,907 & 43,530 & 165,199 \\
Oak Ridge & 5,039 & 631,434 & 467,106 \\
Pigeon Forge & $\mathbf{2 , 3 3 4 , 5 7 9}$ & $\mathbf{2 5 , 4 1 8 , 5 8 0}$ & $\mathbf{1 2 1 , 3 3 7 , 2 5 7}$ \\
\hline Total & &
\end{tabular}

(B) Transit Supply Variables

\begin{tabular}{lrrr} 
Urban Area & \multicolumn{1}{c}{$\begin{array}{c}\text { Fleet } \\
\text { Size }\end{array}$} & $\begin{array}{c}\text { Vehicle Hours } \\
\text { of Service }\end{array}$ & $\begin{array}{c}\text { Vehicle Miles } \\
\text { of Service }\end{array}$ \\
\hline Chattanooga & 88 & 160,929 & $2,214,818$ \\
Knoxville & 97 & 165,212 & $2,300,849$ \\
Memphis & 258 & 502,091 & $7,379,563$ \\
Nashville & 158 & 379,870 & $6,072,615$ \\
Bristol & 8 & 9,601 & 118,304 \\
Clarksville & 20 & 40,329 & 655,554 \\
Gatlinburg & 21 & 36,806 & 371,425 \\
Jackson & 16 & 37,256 & 490,985 \\
Johnson City & 23 & 31,235 & 395,070 \\
Kingsport & 8 & 8,382 & 130,810 \\
Oak Ridge & 2 & 4,216 & 133,225 \\
Pigeon Forge & 16 & 91,873 & 311,404 \\
\hline Total & $\mathbf{7 1 5}$ & $\mathbf{1 , 4 6 7 , 8 0 0}$ & $\mathbf{2 0 , 5 7 4 , 6 2 2}$
\end{tabular}

Notes: (1) Populations estimated, based on Census data and 1998 Urbanized Area Boundary; (2) Number of One Way Revenue Trips; (3) Number of Revenue Passenger Miles - Based on rider survey derived estimates provided by each Transit District; (4) Number of all Transit Vehicles in Fleet; (5) Revenue Transit Vehicle Hours of Operation; (6) Revenue Transit Vehicle Miles of Operation 


\section{Public Transit in Tennessee}

Based on the data in Table 4.2, Table 4.3 lists the annual number of transit trips and transit miles driven per vehicle in each of the State's 12 urban transit districts in 1998. It also lists an estimate of the passenger miles supplied per vehicle in that same year. Looked at statewide, these urban transit systems provided just under 6 passenger miles of service for every transit vehicle mile operated in calendar year 1998. Among the Small Urban systems the cities of Clarksville, Jackson and Johnson City operate far more passenger miles than the other smaller cities. The fourth column in Table 4.3 is of particular interest since it provides an estimate of the passenger miles per trip taken. The larger this number the larger the user travel cost savings benefits, as well as the more safety and environmental benefits estimated per transit trip. Here data quality is an issue, with trip length estimates for a number of the smallest systems (Bristol, Kingsport, Pigeon Forge, Oak Ridge and Gatlinburg) difficult to verify. Given this problem with obtaining average miles per passenger trip, as well as comprehensive trip purpose data for some of the smaller cities, most results in this report are summed over all eight small urban systems.

Table 4.3 Urban Transit District Specific Service Characteristics.

\begin{tabular}{l|rrrr} 
& $\begin{array}{r}\text { Trips Per } \\
\text { Vehicle }\end{array}$ & $\begin{array}{c}\text { Transit Miles } \\
\text { Per Vehicle }\end{array}$ & $\begin{array}{l}\text { Pass. Miles } \\
\text { Per Vehicle }\end{array}$ & $\begin{array}{c}\text { Pass. Miles } \\
\text { Per Trip }\end{array}$ \\
\hline Chattanooga & 28,004 & 25,168 & 127,149 & 4.54 \\
Knoxville & 17,121 & 23,720 & 58,179 & 3.40 \\
Memphis & 46,818 & 28,603 & 251,389 & 5.37 \\
Nashville & 40,600 & 38,434 & 203,306 & 5.01 \\
Bristol & 5,920 & 14,788 & 21,367 & 3.61 \\
Clarksville & 21,542 & 32,778 & 134,150 & 6.23 \\
Gatlinburg & 32,411 & 17,687 & 19,867 & 0.61 \\
Jackson & 33,804 & 30,687 & 159,150 & 4.71 \\
Johnson City & 15,888 & 17,177 & 39,978 & 2.52 \\
Kingsport & 7,461 & 16,351 & 19,340 & 2.59 \\
Oak Ridge & 21,765 & 66,613 & 82,600 & 3.80 \\
Pigeon Forge & 39,465 & 19,463 & 29,194 & 0.74 \\
\hline Total & $\mathbf{3 5 , 5 5 0}$ & $\mathbf{2 8 , 7 7 6}$ & $\mathbf{1 6 9 , 7 0 2}$ & $\mathbf{4 . 7 7}$
\end{tabular}

\subsection{Base Year Urban Transit Benefits Estimation.}

As described in previous chapters of this report, there are considerable differences in the size and nature of these twelve urban transit systems. In applying a single benefits estimation framework to all systems allowance had to be made for these differences in terms of data reporting as well the sort of benefits to expect from each system and type of transit service. Using the methods described in Chapter 2 of this report, the following benefits of public transit service in Tennessee 


\section{Public Transit in Tennessee}

were estimated for each system:

1. Mobility-Based Accessibility Benefits From Transit Use.

2. Environmental Benefits From Transit Use.

3. Safety and Security Benefits From Transit Use; and,

4. Economic Benefits From Transit System Supply.

\subsubsection{Mobility-Based Accessibility Benefits.}

As described in Chapter 2 (cf Figure 2.2), mobility benefits were computed on a one way trip basis, as the sum of:

i) trip cost savings -- the monetary cost savings (in terms of vehicle operating, alternative fare and parking costs) to transit users when compared to the costs of making the same trip by an alternative mode;

ii) foregone travel savings -- the net cost to current transit riders of trips not taken due to loss of transit service, and

iii) congestion mitigation --- the net reduction in traffic congestion costs due to transit patronage.

As also described in Chapter 2 of this report, a default value of 44.5 cents per vehicle mile was assumed to be the average cost of a current transit patron switching to the private automobile, with the same cost assigned to friend or relative supplied private vehicle trips. Taxi trips, if assumed taken, were assigned a value of $\$ 1.50$ per mile. Parking costs were also assigned a value of $\$ 1.50$ per trip (or $\$ 3.00$ per two way, round trip) in those metropolitan areas where free parking was considered to be difficult to find on an average day.

Foregone trips are trips that would be lost (i.e. not taken) because current transit riders have no good, cost-effective option to riding public transit available to them. For the most part these are persons without access to or a license to drive a private automobile, or who for other reasons, such as health reasons, cannot or prefer not to drive. The value (or cost) of a foregone trip is tied to its trip purpose. From the limited trip purpose data available to the study (cf Chapter 2) three types of urban transit trip were defined: "Work-Based", "Medical", and "Other". Table 4.4 below shows the data obtained for specific fixed route bus and demand responsive systems, and the system defaults that were used to compute the baseline numbers reported below where no data was available. Data obtained included the results of a telephone poll of urban transit district operators for their best estimates of work versus non-work trip purpose shares.

For base year computations work-based foregone trips were evaluated at a default, or Baseline, value of $\$ 41.76$, based on 240 working days per year and a salary of $\$ 20,000$. Without definitive data on the average incomes of urban transit riders this baseline was based on reported average personal incomes for 1997 of between approximately \$19,000 in Montgomery County (Clarksville) and \$31,000 in Davidson County (Nashville), with average personal income in 


\section{Public Transit in Tennessee}

Shelby County (Memphis) close to $\$ 27,300^{1}$. “Other" trips, including shopping and personal business trips, were assigned a default, and probably conservative, value of $\$ 25$ per trip.

Table 4.4 Estimated Percentage of Urban Transit Trips by Trip Purpose

A) Data From Specific Systems:

Urban Area

A1. Fixed Route Bus Riders:

Chattanooga ${ }^{1}$

Memphis $^{2}$

Jackson $^{3}$

Johnson City ${ }^{4}$

Nashville ${ }^{5}$

Clarksville $^{6}$

38.1

55.0

58.1

27.0

47.0

70.0
Trip Destination Purpose (\%s):

\section{Work Medical Shop School Business Other \\ Personal}

21.3

13.2

21.0

10.38 .3

21.0

33.0

14.0

13.0 (Grocery)
6.9

1.6

2.3

40.0

25.0 (15.0 Entertain.) 30.0

\section{A2. Demand Responsive Riders:}

\begin{tabular}{|c|c|c|c|c|c|c|}
\hline Chattanooga $^{6}$ & 29.0 & & & & & 71.0 \\
\hline Memphis & 25.0 & & & & & 75.0 \\
\hline Nashville & 25.0 & & & & & 75.0 \\
\hline Knoxville (LIFT) ${ }^{7}$ & 31.9 & 56.7 & 7.1 & $1.8 *$ & 0 & 3.0 (Social Service) \\
\hline Jackson $^{8}$ & 22.8 & 73.0 & $1.6^{* *}$ & $2.1 *$ & 0 & 0.6 \\
\hline Johnson City ${ }^{6}$ & 20.0 & & & & & 80.0 \\
\hline Kingsport $^{9}$ & 6.4 & 17.3 & 44.1 & & $18.8 * * *$ & $\{* * *$ \\
\hline
\end{tabular}

Notes: $*=$ 'Education' ${ }^{* *}=$ shop/recreation, $* * *=$ personal business/other, $* * * *=$ social $/$ recreational

\section{B) System Averages: Service Type}

Fixed Route Bus

Demand Responsive
Trip Destination Purpose $(\% s)$

\section{Employment Medical}

50.1

7.8

62.0

\section{Other}

42.1

$29.0 \quad 62.0 \quad 9.0$

Data Sources: 1. Brodsky, D.M. and Swansbrough, R.H. "Market Survey of Residents in Chattanooga and Hamilton County": Frequent bus riders survey, based on random sampling. January 1992. 2. Weslin Consulting Services and WRI. MATA 1996 OnBoard Passenger Survey. Final Report. May 1997 3.Based on April 1998 Bus Rider Survey for Jackson Transit Authority by Union University, May, 1998. 4.Estimated from Johnson City Transit fixed route passenger survey data, February 12, 2000.

5. Nashville MTA. 1999 Passenger Survey. (Various months by route, non-random). 6. Telephone poll of urban transit operator. 7. Based on Knoxville Area Transit LIFT Data for Calendar Year 1998 8. Jackson Transit Authority FY 1992-2000 Spreadsheet: Demand 9. February 1990 telephone survey of coupon subsidized taxicab service. Wegmann, Chatterjee and Volpe, 1992. 1999.

\footnotetext{
${ }^{1}$ US Census Bureau, Bureau of Economic Analysis, Regional Economic Measurement Division, May
} 


\section{Public Transit in Tennessee}

Medical trips were handled as follows. If a person cannot or will not travel due to loss of transit service, and assuming that medical services need to be provided, two options were considered for fulfilling the need that originated the transit trip. One is to have that person visited by a qualified medical professional. The other is for the patient to move into, or near to, a health care facility. Both options can be costly. Data was obtained from the Tennessee State Department of Health in order to compute representative costs per visit for both at home visits and for visits to health care facilities. $^{2}$

\section{Table 4.5 Representative Costs Per Medical Visit by Urban Transit District.}

\begin{tabular}{l|rr} 
Urban Area & $\begin{array}{r}\text { Av. Nursing Home } \\
\text { Costs/Day (\$)* }\end{array}$ & $\begin{array}{c}\text { Average At Home } \\
\text { Visit Costs }\end{array}$ \\
\hline Chattanooga & 164 & 65 \\
Knoxville & 148 & 71 \\
Memphis & 151 & 188 \\
Nashville & 210 & 82 \\
Bristol & 205 & 81 \\
Clarksville Area & 130 & 91 \\
Gatlinburg Area & 113 & 118 \\
Jackson Area & 181 & 70 \\
Johnson City Area & 135 & 51 \\
Kingsport Area & 205 & 81 \\
Oak Ridge Area & 133 & 47 \\
Pigeon Forge Area & 113 & 118
\end{tabular}

*in 1998 \$, to nearest dollar.

Table 4.5 above provides the values used in this study. For at-home visits Home Health Agency Data for fiscal year 1998-99 (Tennessee Department of Health, 2000) were used to compute average at home visit costs in each urban and rural transit district, data that had to be aggregated from the individual health care agency level, as well as averaged across a number of different visit categories. ${ }^{3}$ In computing estimated savings per one way transit trip the costs shown in

\footnotetext{
${ }^{2}$ For the case of visits to facilities these costs may not be exactly the ones we want if we are trying to reproduce relocation costs on a cost per trip basis. However, they would appear to be of the right order of magnitude.

${ }^{3}$ The available categories of care are skilled nursing, home health aids, speech therapy, occ. therapy, physical therapy, medical social service, home-maker and other. Averaging was based on annual number of visits by each type.
} 


\section{Public Transit in Tennessee}

Table 4.5 are divided by 2 to capture the need for a return trip. It is also assumed that the costs of providing the at-home medical service includes the cost (and also the mileage involved) in a round trip visit by the medical staff persons involved. In most urban districts the average cost of an at home medical visit (by a nurse practitioner, for example) is higher than the daily cost of a nursing home stay. Without reliable data on the percentage of transit patrons who, in foregoing medical trips, would need to visit the nursing home, an exact estimate of either client based or trip based benefits cannot be made. As a default, 1 in 5 trips was assigned the cost of an average nursing home visit (divided by 2), while the other $80 \%$ are assumed to require at-home care. This produced a statewide average medical one way trip cost of $\$ 61.44$. Sensitivity to such an assumption is discussed below.

Empirical Results and Sensitivity Analysis. Mobility based accessibility benefits, as defined in this report, dominate the public transit benefits for all of the State's urban public transit systems, and this dominance increases as the percentage of foregone trips grows. While foregone medical trip costs are by far the highest for most cases, they represent only a relatively small percentage of fixed route bus trips. Across all trip purposes, foregone cost savings from having public transit available are on the order of $\$ 25$ to as much as $\$ 102$ per trip, depending on trip purpose, versus mode switching cost savings on the order of $\$ 1$ to $\$ 3.50$ per trip. Therefore the results of the benefits estimation process are very sensitive to the percent of trips foregone in each category. This sensitivity to the foregone travel assumption is demonstrated in two alternative base year travel mobility scenarios shown in Tables 4.6 and 4.7, and further in Figure 4.7.

Taking what may be a conservative estimate of $10 \%$ foregone trips across all trip purpose categories (i.e work, medical and other trips) produced the results shown in Table 4.6. ${ }^{4}$ The total transit mobility benefits from this scenario total $\$ 145.6$ million. This contrasts with the assumption of no foregone trips, as shown in Table 4.7, where benefits are less than half this total, at $\$ 65.6$ million. In contrast (see Figure 4.7), increasing the foregone trip percentage from $10 \%$ to $15 \%$ produced estimated net transit mobility benefits of $\$ 175.7$ million dollars. Finally, increasing the foregone trips percentage to $20 \%$ yielded estimated net benefits of $\$ 213.3$ million dollars. A poll of urban transit operators in 2000 indicated that $80 \%$ to $90 \%$ of their current riders had no short term alternative to existing transit services. This is consistent with the $85.5 \%$ transit dependency estimated by Wegmann, Chatterjee and Volpe (1993) for Johnson City's fixed route bus transit riders, and the $92.3 \%$ transit dependency they estimated for Kingsport's subsidized taxicab service in 1992. With so many of the State's current public transit ridership believed to be dependent on public transit services, at least in the near term, the true size of this foregone trip share needs to be determined with greater accuracy.

Further sensitivity testing was also carried out to determine how specific trip cost savings assumptions were impacting these benefits results. Both work trip and "Other", non-work trip

\footnotetext{
4"Small Urban" in this and subsequent tables refers to the summed benefits of the State's eight small urban systems listed in Table 4.1 above.
} 
Public Transit in Tennessee

cost savings from foregone trips were examined. Table 4.8 Part A shows the impacts on net transit mobility benefits of changing the Baseline assumption on costs incurred due to foregone work trips. This was done by changing the Baseline assumption of annual transit rider income from $\$ 20,000$ per year, to $\$ 18,000, \$ 22,000$ and $\$ 24,000$ per year respectively. For every additional $\$ 2,000$ per year increase or decrease in annual income, net mobility benefits rise or fall by some $\$ 4.8$ million dollars.

Figure 4.7 Urban Mobility Benefits: Sensitivity to Foregone Trip Percentages.

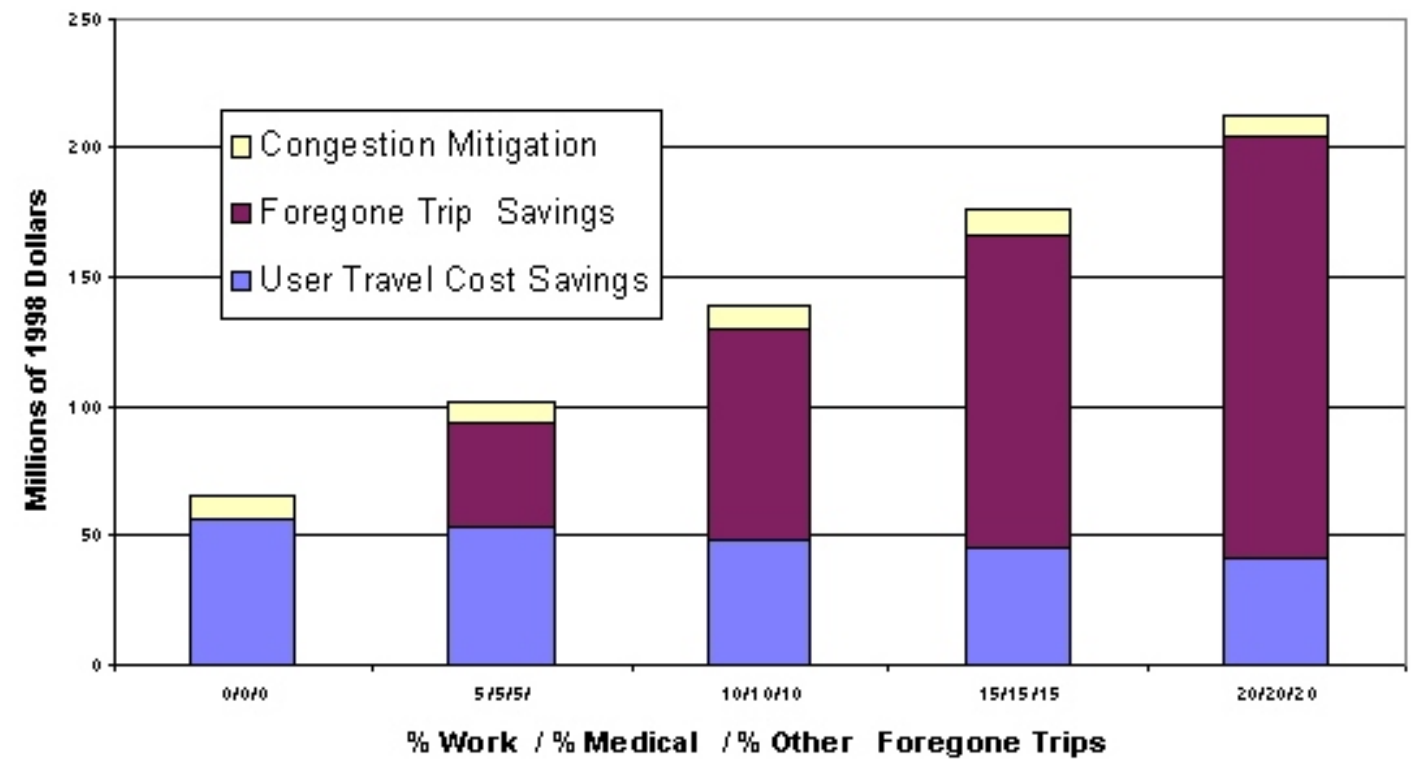

Table 4.6 Urban Mobility-Based Accessibility Benefits: 10\% Foregone Trips Scenario.

\begin{tabular}{l|rrrr}
$\begin{array}{l}\text { Benefits in 000's \$ } \\
\text { Urban System }\end{array}$ & $\begin{array}{r}\text { User Cost } \\
\text { Savings }\end{array}$ & $\begin{array}{r}\text { Foregone } \\
\text { Trip Savings }\end{array}$ & $\begin{array}{r}\text { Congestion } \\
\text { Mitigation }\end{array}$ & $\begin{array}{r}\text { Total Mobility } \\
\text { Benefits }\end{array}$ \\
\hline Chattanooga & 4,244 & 6,994 & 716 & 11,954 \\
Knoxville & 2,584 & 5,963 & 15 & 8,562 \\
Memphis & 26,590 & 44,519 & 5,505 & 76,614 \\
Nashville & 11,369 & 24,752 & 2,077 & 38,198 \\
Small Urban Systems & 4,338 & 5,501 & 445 & 10,283 \\
\hline Total & $\mathbf{4 9 , 1 2 5}$ & $\mathbf{8 7 , 7 3 0}$ & $\mathbf{8 , 7 5 7}$ & $\mathbf{1 4 5 , 6 1 1}$
\end{tabular}


Public Transit in Tennessee

Table 4.7 Urban Mobility-Based Accessibility Benefits: Zero Percent Foregone Trips Scenario.

\begin{tabular}{l|rrrr}
$\begin{array}{c}\text { Benefits in 000's \$ } \\
\text { Urban System }\end{array}$ & $\begin{array}{c}\text { User Cost } \\
\text { Savings }\end{array}$ & $\begin{array}{r}\text { Foregone } \\
\text { Trip Savings }\end{array}$ & $\begin{array}{c}\text { Congestion } \\
\text { Mitigation }\end{array}$ & $\begin{array}{c}\text { Total Mobility } \\
\text { Benefits }\end{array}$ \\
\hline Chattanooga & 4,915 & 0 & 744 & 5,660 \\
Knoxville & 2,980 & 0 & 24 & 3,004 \\
Memphis & 30,549 & 0 & 5,646 & 36,195 \\
Nashville & 13,333 & 0 & 2,148 & 15,481 \\
Small Urban Systems & 4,763 & 0 & 460 & 5,223 \\
\hline Total & $\mathbf{5 6 , 5 4 0 . 7}$ & $\mathbf{0 . 0}$ & $\mathbf{9 , 0 2 1 . 6}$ & $\mathbf{6 5 , 5 6 2 . 3}$
\end{tabular}

Table 4.8 Part B shows the effects of varying the average costs of "Other" non-work trips on net mobility benefits. Benefits estimates vary from $\$ 140.5$ million to $\$ 160.7$ million as these costs change from $\$ 20$ to $\$ 40$ per one-way transit trip. Part $\mathrm{C}$ of this table shows the results of varying the cost per mile of substituted automobile (including friend/relative) trips around the Baseline value of 44.5 cents/mile: from $\$ 32.5$ cents/mile to $\$ 53.1$ cents $/$ mile (see Chapter 2 ). The resulting mobility benefits vary from $\$ 136.2$ million to $\$ 152.3$ million. As with Parts $A$ and $B$ of Table 4.8, these estimates are derived for the Baseline 10\% Foregone Trips Scenario. Part D of Table 4.8 shows the effects of varying these automobile operating costs under the zero foregone trips scenario. This results in benefits ranging from $\$ 55.2$ million to $\$ 73$ million.

This sensitivity analysis shows the importance of knowing more about both the number and value of foregone travel as it impacts mobility costs. This is especially important since these mobility cost savings were found to be by far the largest class of benefits associated with urban public transit in the State. A more accurate representation of these benefits might also be obtained by knowing exactly how many transit patrons are taking different types as well as numbers of trips. Not all riders travel the system every day, although weekly work trip frequencies are likely to be higher than other types of trip. Collection of better data on urban transit trip purpose, and on daily, weekly or monthly trip frequency by trip purpose, is therefore warranted. A second important data requirement is better data on what current transit patrons would choose to do if they no longer had access to buses, downtown shuttles, or to demand responsive vanpools. This is an often neglected aspect of urban travel studies, which have tended to focus on what it takes to get current automobile riders to move over to public transit. Given the high level of transit dependence among current public transit patrons within the State, more attention is warranted to the potential for this transit dependent market segment to impose non-transportation costs, such as health care and employment subsidy costs, on public services. 
Public Transit in Tennessee

Table 4.8 Sensitivity of Transit Mobility Benefits to Various Parameter Values.

A) Effects of Annual Income (Work Trip Cost) Assumption (10\% Foregone Trips):

\begin{tabular}{l|rrrr} 
Scenarios & $\begin{array}{c}\text { User Cost } \\
\text { Savings }\end{array}$ & $\begin{array}{c}\text { Foregone } \\
\text { Trip Savings }\end{array}$ & $\begin{array}{c}\text { Congestion } \\
\text { Mitigation }\end{array}$ & $\begin{array}{c}\text { Total Mobility } \\
\text { Benefits }\end{array}$ \\
\hline \$18,000/Year & 49,125 & 82,937 & 8,757 & 140,818 \\
$\mathbf{\$ 2 0 , 0 0 0 / Y e a r}$ & $\mathbf{4 9 , 1 2 5}$ & $\mathbf{8 7 , 7 3 0}$ & $\mathbf{8 , 7 5 7}$ & $\mathbf{1 4 5 , 6 1 1}$ \\
\$22,000/Year & 49,125 & 92,523 & 8,757 & 150,404 \\
\$24,000/Year & 49,125 & 97,316 & 8,757 & 155,197
\end{tabular}

B) Effects of "Other" Non-Work Trip Cost Assumption (10\% Foregone Trips):

\begin{tabular}{l|rrrr}
\multicolumn{1}{c|}{ Scenarios } & $\begin{array}{c}\text { User Cost } \\
\text { Savings }\end{array}$ & $\begin{array}{r}\text { Foregone } \\
\text { Trip Savings }\end{array}$ & $\begin{array}{c}\text { Congestion } \\
\text { Mitigation }\end{array}$ & $\begin{array}{c}\text { Total Mobility } \\
\text { Benefits }\end{array}$ \\
\hline \$20/One-Way Trip & 49,125 & 82,708 & 8,757 & 140,589 \\
\$25/One-Way Trip & $\mathbf{4 9 , 1 2 5}$ & $\mathbf{8 7 , 7 3 0}$ & $\mathbf{8 , 7 5 7}$ & $\mathbf{1 4 5 , 6 1 1}$ \\
\$30/One-Way Trip & 49,125 & 92,752 & 8,757 & 150,633 \\
\$40/One-Way Trip & 49,125 & 102,796 & 8,757 & 160,677
\end{tabular}

C) Effects of Changes in Automobile Operating Cost Assumption (10\% Foregone Trips):

\begin{tabular}{l|rrrr}
\multicolumn{1}{c|}{ Scenarios } & $\begin{array}{r}\text { User Cost } \\
\text { Savings }\end{array}$ & $\begin{array}{r}\text { Foregone } \\
\text { Trip Savings }\end{array}$ & $\begin{array}{r}\text { Congestion } \\
\text { Mitigation }\end{array}$ & $\begin{array}{c}\text { Total Mobility } \\
\text { Benefits }\end{array}$ \\
\hline $32.5 \mathrm{c} /$ mile Auto Costs & 39,796 & 87,730 & 8,757 & 136,282 \\
$\mathbf{4 4 . 5 c / m i l e ~ A u t o ~ C o s t s ~}$ & $\mathbf{4 9 , 1 2 5}$ & $\mathbf{8 7 , 7 3 0}$ & $\mathbf{8 , 7 5 7}$ & $\mathbf{1 4 5 , 6 1 1}$ \\
$53.1 \mathrm{c} /$ mile Auto Costs & 55,810 & 87,730 & 8,757 & 152,297
\end{tabular}

D) Effects of Changes in Automobile Operating Cost Assumption ( $0 \%$ Foregone Trips):

\begin{tabular}{l|rrrr} 
Scenarios & $\begin{array}{c}\text { User Cost } \\
\text { Savings }\end{array}$ & $\begin{array}{c}\text { Foregone } \\
\text { Trip Savings }\end{array}$ & $\begin{array}{c}\text { Congestion } \\
\text { Mitigation }\end{array}$ & $\begin{array}{c}\text { Total Mobility } \\
\text { Benefits }\end{array}$ \\
\hline $32.5 \mathrm{c} /$ mile Auto Costs & 46,192 & 0 & 9,022 & 55,214 \\
$44.5 \mathrm{c} /$ mile Auto Costs & 56,541 & 0 & 9,022 & 65,562 \\
$53.1 \mathrm{c} /$ mile Auto Costs & 63,957 & 0 & 9,022 & 72,979
\end{tabular}




\section{Public Transit in Tennessee}

\subsubsection{Environmental and Energy Consumption Impacts.}

Mobile Source Emissions. The environmental benefits most commonly associated with the use of public transit systems are air quality benefits. Today these air pollutants include hydrocarbons (HC), carbon monoxide (CO), nitrogen oxides (NOx) and oxides of sulphur ( $\mathrm{SOx}$ ), as well as particulate matter (PM) of various sizes. This also includes a growing if as yet poorly developed science devoted to the effects of global warming and the transportation sector's contribution to it through the release of greenhouse gases, notably the effects of increased carbon dioxide $(\mathrm{CO} 2)$ in the atmosphere. Resulting damages take the form of increased health costs plus, (and to a much more limited extent) crop damage, ozone depletion and reduced visibility. As discussed in Chapter 2 of this report, the science of measuring these health and related impacts is still evolving, and despite extensive research into both the generation and subsequent health effects of each of the above named pollutants, estimates of health risk from specific pollutants can vary widely. One problem with using past research in the transportation area is that much of it reports per passenger mile benefits that are based on location specific vehicle occupancies, while per vehicle mile emission costs show a very wide range of possible impacts (cf Chapter 2). Exacerbating the problem of evaluation, recent US EPA developed software programs, as well as other recent studies (see Delucchi, 2000, for example), suggest that significant revisions in the estimates of past tail-pipe emissions rates may be on the way.

Using alternative results from recent studies, the impacts of lost transit services presented in the tables below can easily double, while positive benefits can become negative in a number of cases. This is noticeably the case where demand responsive (DR) transit van services are concerned. Given that uncertainty also exists in the true ratio of actual transit miles driven to the miles that would be required by a private vehicle to fulfill specific DR supported origin-todestination trips, added caution in accepting any single result is warranted here. In particular, low occupancy demand responsive vanpool services may currently result in negative emission benefits in a number of cases within the State.

A good deal of experimentation was made with these and other emissions rates and damage cost estimates, including computations based on valuing specific pollutants (HC, CO, PM, etc.). The range of possible results that could be obtained from this literature suggests considerable caution in accepting any single valuation at this time. The values chosen fall within the range of values reported by Litman (1999), based on his extensive survey of this literature. As such they are assumed here to represent the combined effects of each of the major criterion pollutants monitored by the US EPA (HC, CO, NOx, SOx, PM), as well as the more global impacts of pollutants such as $\mathrm{CO} 2$ which contribute to climate change, ozone depletion and acid rain. They are also assumed to incorporate the emissions produced during petroleum production. Roughly speaking, Litman suggests that these latter contribute about 1.2 cents per mile of driving costs for an average automobile out of total in the range 5.2 cents/mile (urban off-peak) to 6.2 cents per mile (urban peak). For diesel transit buses, both the values and the ratio of each pollutant's contribution to full environmental damage costs are assumed to be somewhat different. 


\section{Public Transit in Tennessee}

Relatively high per mile pollution costs are caused by high oxides of nitrogen and particulates production, notably in older buses. These emissions are estimated to cause buses to produce on the order of 2.5 to 3 times the criterion pollution, and as much as 5 times the greenhouse gas pollution per mile as the average private automobile. More recent estimates, which put much higher damage costs on particulate matter in both the 10 and 2.5 microns ranges, suggest even higher per mileage pollution costs from large diesel vehicles such as transit buses (see Delucchi, 2000; US EPA Mobile 6 preliminary spreadsheet). Surrounded by all of this uncertainty, the per vehicle mile air quality damage costs listed in Table 4.9 were used as the baseline in this study.

\section{Table 4.9 Baseline Per Mile Air Quality Damage Costs by Mode (in 1998 \$).}

\begin{tabular}{l|r} 
Mode of Transportation & \$/Vehicle Mile \\
\hline Private Automobile & 0.057 \\
Taxicab & 0.057 \\
Gasoline Powered Vanpool & 0.094 \\
Diesel Powered Vanpool & 0.094 \\
Diesel Bus & 0.173 \\
Electric Bus. & 0.073 \\
Commuter Rail & 0.041 \\
Light Rail & 0.028 \\
Walk/Ride & 0
\end{tabular}

Using the emissions rates shown in Table 4.9 produces the results reported in column two of Table 4.10 below. This table also shows three additional scenarios. All four scenarios show the effects of shifting all current public transit ridership to private automobiles, private van pools or taxis (ratios vary by urban transit district, but are dominated by auto travel), i.e. the results of a zero percentage foregone trips scenario.

Table 4.10 Alternative Air Quality Impact Estimates (in 1998 \$).

\begin{tabular}{l|r|r|r|r} 
Urban Area & \multicolumn{1}{|l}{ Baseline } & Low Emissions & High Emissions & \multicolumn{1}{l}{ High Diesel } \\
\hline Chattanooga & 106,303 & 60,799 & 117,403 & $-359,921$ \\
Knoxville & $-108,990$ & $-60,016$ & $-114,590$ & $-592,100$ \\
Memphis & $1,928,081$ & $1,050,288$ & $2,107,752$ & $-18,961$ \\
Nashville & 558,759 & 309,268 & 614,108 & $-812,490$ \\
Small Urban Systems & $-31,194$ & 14,707 & $-37,742$ & $-518,220$ \\
\hline Total & $\mathbf{2 , 4 5 2 , 9 5 8}$ & $\mathbf{1 , 3 7 5 , 0 4 6}$ & $\mathbf{2 , 6 8 6 , 9 3 2}$ & $\mathbf{- 2 , 3 0 1 , 6 9 2}$
\end{tabular}

The "Low Emissions" rates scenario shows the results of using a 0.031 cents/mile emissions damage rate for private automobiles versus, a rate of 0.097 cents per vehicle mile for diesel bus 


\section{Public Transit in Tennessee}

emission damages. The "High Emissions" rates scenario shows the result of using a value of 0.062 cents per mile for automobiles and a rate of 0.187 cents per mile for diesel buses. Finally, the "High Diesel" emissions scenario shows the result of using recent estimates by DeLucchi (2000) that put automobile emission damage costs at close to 0.045 cents per mile (in 1998 dollars) and diesel buses at 0.387 cents per mile (and both of which are on the lower end of Delucchi's scenarios). These much higher bus emissions damage costs are due to significantly higher particulate matter health costs than reported in most previous studies, which also appear to be expected, to some degree, from the next round of US EPA (Mobile 6 model) results. The "baseline" scenario, based on the emissions damage costs shown in Table 4.9, is used in the rest of this report.

With foregone trips assumed to result from lost transit service, air quality benefits are necessarily reduced, but at much greater increases in mobility benefits, as discussed earlier in this chapter.

With 10\% foregone trips, for example, the Baseline Air Quality benefits shown in Table 4.11 fall from $\$ 2.45$ million dollars to $\$ 1.93$ million dollars.

Fuel Consumption Impacts. Given the current uncertainties in the rates at which each vehicle type studied is emitting pollutants, it was also decided to look at the problem from the angle of gallons of fossil fuel consumed in a calendar year, as reported by each urban transit agency. Tables 4.11 and 4.12 show this information. While non-greenhouse gas emissions resulting from a gallon of fuel can vary a great deal (depending on speed, acceleration, ambient conditions, engine conditions, etc.) it was found instructive to compare the reported gallons of fuel (and megawatt hours of electricity) consumed by transit in the State (see Table 4.11) with an estimate of the fuel that would need to be consumed in supplying the automobile-induced passenger travel miles these transit miles currently replace (see Table 4.12). To make the comparison we began with the annual number of passenger miles estimated to be served by each transit district and service type. This number was then converted to a set of automobile equivalent vehicle miles of travel. Based on district developed estimates, an average auto occupancy of 1.2 persons was assumed in converting passenger miles to the auto vmt figures shown in Table 4.12. This left the average urban automobile mpg to be set. According to data reported in the Federal Highway Administration's 1998 Highway Statistics publication, the average fuel efficiency for highway vehicles (urban plus rural) in Tennessee in 1998 was 22.6 mpg. In Table 4.13 we use a lower figure of $18 \mathrm{mpg}$, to recognize the lower fuel efficiencies of the urban peak hour traffic for whioch bus transit is currently substituting in the State's larger metropolitan areas.

Converting both diesel fuel and Kilowatt hours (kWhrs) of electricity to gallons of gasoline, on a btu basis, produces an estimate of some 4,991,300 gallons of gasoline equivalent fuel consumed directly by the State's transit system in 1998. What this implies is that the State's current transit systems offer only limited energy savings benefits. Given the nature of the different modal operations, however, these differences, where marginally positive, imply countable emissions benefits. This is especially true for the fixed bus routes system in Memphis (with an estimated 


\section{Public Transit in Tennessee}

1998 savings of about 853,000 gallons of gasoline), Nashville (a savings of about 120,000 gallons), and Chattanooga (about 119,000 gallons), as well as the demand responsive van pooling program run by the Nashville RTA (105,000 gallons). The fixed bus route system in Clarksville also appears to have been energy efficient in 1998, saving an estimated 36,000 gallons of fuel in 1998. This last system recorded the highest average passenger miles per trip in 1998, at 6.23 miles (compared to an urban statewide average of 4.33 passenger miles per trip).

Table 4.11 Urban Transit Fuel Use Statistics by District, Fuel and Service Types, 1998.

\begin{tabular}{|c|c|c|c|c|c|c|}
\hline Urban Area & $\begin{array}{l}\text { Vehicle } \\
\text { Type* }\end{array}$ & $\begin{array}{l}\text { Diesel } \\
\text { (Gals.) }\end{array}$ & $\begin{array}{c}\text { Gasoline } \\
\text { (Gals.) }\end{array}$ & $\begin{array}{l}\text { Electric } \\
\text { (KWhs) }\end{array}$ & $\begin{array}{c}\text { Transit } \\
\text { VMT }\end{array}$ & $\begin{array}{l}\text { Transit } \\
\text { MPG }\end{array}$ \\
\hline \multirow[t]{3}{*}{ Chattanooga } & DR & 45,800 & 0 & 0 & 410,234 & 8.96 \\
\hline & FB & 400,500 & 0 & 306,700 & $1,804,584$ & $4.63^{* *}$ \\
\hline & IP & 0 & 0 & 137,800 & 19,070 & \\
\hline \multirow[t]{2}{*}{ Clarksville } & DR & 6,400 & 6,700 & 0 & 123,082 & 9.40 \\
\hline & FB & 92,500 & 0 & 0 & 532,472 & 5.76 \\
\hline \multirow[t]{2}{*}{ Jackson } & DR & 12,400 & 0 & 0 & 94,185 & 7.60 \\
\hline & FB & 106,600 & 0 & 0 & 396,800 & 3.72 \\
\hline \multirow[t]{2}{*}{ Johnson City } & DR & 9,400 & 5,100 & 0 & 104,254 & 7.19 \\
\hline & FB & 83,200 & 0 & 0 & 290,816 & 3.50 \\
\hline \multirow[t]{2}{*}{ Kingsport } & DR & 0 & 4,000 & 0 & 43,942 & 10.99 \\
\hline & FB & 12,700 & 0 & 0 & 86,868 & 6.84 \\
\hline \multirow[t]{2}{*}{ Knoxville } & DR & 43,700 & 0 & 0 & 258,744 & 5.92 \\
\hline & FB & 556,100 & 0 & 0 & $2,042,105$ & 3.67 \\
\hline \multirow[t]{3}{*}{ Memphis } & DR & 148,000 & 0 & 0 & 983,833 & 6.65 \\
\hline & FB & $2,018,700$ & 0 & 0 & $6,156,937$ & 3.05 \\
\hline & LR & 0 & 0 & $1,430,800$ & 238,793 & \\
\hline \multirow[t]{2}{*}{ Nashville } & DR & 19,500 & 158,000 & 0 & $1,001,379$ & 5.64 \\
\hline & FB & $1,091,700$ & 102,400 & 0 & $5,071,236$ & 4.25 \\
\hline Bristol & $\mathrm{FB}+\mathrm{DR}$ & & & 0 & & \\
\hline Gatlinburg & $\mathrm{FB}+\mathrm{DR}$ & 42,263 & 2,728 & 0 & 371,425 & 8.26 \\
\hline Pigeon Forge & FB & 37,735 & 1,037 & 0 & 311,404 & 8.03 \\
\hline Oak Ridge & DR & & & 0 & & \\
\hline Total & & $4,727,197$ & 279,964 & $1,875,300$ & $20,342,163$ & 3.92 \\
\hline
\end{tabular}

Notes: $* \mathrm{FB}=$ Fixed Route Bus, DR = Demand Responsive Van, LR = Light Rail, IP = Incline Plain. Fuel consumption data based on either FTA National Transit Database or Tennessee Transit District specific Monthly state operating reports. VMT data is from annual district operating summaries submitted to Tennessee DOT. **Includes a conversion from kilowatt hours (kWhr) to diesel gallons, using btu equivalency. 
Public Transit in Tennessee

Table 4.12 Estimated Automobile Equivalent VMT and Fuel Consumption, 1998.

\begin{tabular}{|c|c|c|c|}
\hline Urban Area & $\begin{array}{l}* \text { Estd. } \\
\text { Auto } \\
\text { VMT }\end{array}$ & $\begin{array}{c}* * \text { Estd. Auto } \\
\text { Fuel Use } \\
\text { (Gals.) } \\
\end{array}$ & $\begin{array}{c}* * * \text { Transit VMT } \\
\text { as } \% \text { of } \\
\text { Auto VMT }\end{array}$ \\
\hline \multirow[t]{3}{*}{ Chattanooga } & 169,917 & 9,440 & 201.19 \\
\hline & $9,154,335$ & 508,574 & 16.43 \\
\hline & 358,250 & 19,903 & 4.44 \\
\hline \multirow[t]{2}{*}{ Clarksville } & 84,500 & 4,694 & 121.38 \\
\hline & $2,151,333$ & 119,519 & 20.63 \\
\hline \multirow[t]{2}{*}{ Jackson } & 151,333 & 8,407 & 51.86 \\
\hline & $1,970,667$ & 109,481 & 16.78 \\
\hline \multirow[t]{2}{*}{ Johnson City } & 64,167 & 3,565 & 135.39 \\
\hline & 702,083 & 39,005 & 34.52 \\
\hline \multirow[t]{2}{*}{ Kingsport } & 39,167 & 2,176 & 93.49 \\
\hline & 89,764 & 4,987 & 80.65 \\
\hline \multirow[t]{2}{*}{ Knoxville } & 180,333 & 10,019 & 119.57 \\
\hline & $4,702,829$ & 261,268 & 36.19 \\
\hline \multirow[t]{3}{*}{ Memphis } & $1,561,500$ & 86,750 & 52.50 \\
\hline & $51,689,250$ & $2,871,625$ & 9.93 \\
\hline & 797,833 & 44,324 & 24.94 \\
\hline \multirow[t]{2}{*}{ Nashville } & $5,063,083$ & 281,282 & 16.48 \\
\hline & $21,705,583$ & $1,205,866$ & 19.47 \\
\hline Bristol & - & - & - \\
\hline Gatlinburg & 347,671 & 34,767 & 89.03 \\
\hline Pigeon Forge & 389,255 & 38,926 & 66.67 \\
\hline Oak Ridge & - & - & \\
\hline Total & $101,372,853$ & $5,664,577$ & 16.72 \\
\hline
\end{tabular}

As a final step in this fuel consumption analysis, the modal (transit bus, DR van, light rail transit and automobile) energy consumption figures shown in Tables 4.11 and 4.12 were translated into mobile source emission costs, for comparison with the empirical results reported in Table 4.10. This resulted in an estimated automobile pollution cost of $\$ 5,811,856$ versus a total urban transit pollution cost of $\$ 3,192,703$ : resulting in an estimated net air quality damage savings of $\$ 2$, 619,154 . This is very close to the Baseline damage savings figure of $\$ 2,452,958$ reported in Table 4.10, suggesting that the method used is reasonable, at least for the assumptions made. 


\section{Public Transit in Tennessee}

In summary, the air quality benefits from urban public transit appear to be quite small at the present time. However, this situation may change a good deal over the next decade or two. If traffic continues to grow in the State's largest metropolitan areas, and if recent US EPA promulgated regulations on diesel engines in particular come to fruition, a generally brighter picture for urban transit's contribution to the State's environment emerges. This topic is taken up again, in Section 4.5 below, where ridership forecasts are combined with significantly adjusted per trip emissions rates.

Noise Pollution. Recalling the discussion in Chapter 2 of this report, Table 4.13, Part A below shows the ( very approximate) urban noise pollution costs used to estimate baseline noise benefits or dis-benefits of public transit in the study. Part B of this same table shows the results. As with the other externality analyses (i.e. air quality and safety) these results are based on a zero foregone trips scenario.

Table 4.13. Estimated Noise Impacts.

A) Noise Damage Rates

\begin{tabular}{lrrrr} 
& Average Auto. & Van & Diesel Bus & Electric Bus/Trolley \\
\hline Urban & 0.0104 & 0.0104 & 0.052 & 0.0312 \\
Rural & 0.0052 & 0.0052 & 0.026 & 0.0156 \\
\hline
\end{tabular}

B) Estimated Noise Damage Costs

\begin{tabular}{l|c}
\begin{tabular}{l||} 
Benefits in $\mathbf{1 9 9 8}$ \$'s \\
Urban System
\end{tabular} & $\begin{array}{c}\text { Noise } \\
\text { Costs }\end{array}$ \\
\hline Chattanooga & $-11,164$ \\
Knoxville & $-53,695$ \\
Memphis & 233,834 \\
Nashville & 20,666 \\
& $-45,318$ \\
\hline Total & $\mathbf{1 4 4 , 3 2 3}$
\end{tabular}

Given the comparatively small impact these results suggest, and the range of uncertainty in the recent literature about computing such estimates at this level of analysis further sensitivity testing was considered unnecessary.

\subsubsection{Travel Safety Benefits.}

Based on a review of the recent travel safety literature, as reported in Chapter 2 of this report, 


\section{Public Transit in Tennessee}

Table 4.14 shows the baseline, mode specific travel safety costs used in this study. Both internal to external costs are shown. Internal costs(see Section 2.6) refer here to the costs of damage and injury, and possibly death, to people riding in a vehicle that takes part in an accident. External costs refer to the injury and damage to pedestrians and to others impacted by such crashes. Separating these two types of cost allows for internal costs, reported in cents per passenger mile (cents/pmt) to reflect typical vehicle occupancies. External costs, in contrast, are given in cents/vehicle mile (cents/vmt)(cf discussion in Section 2.6 of this report). As discussed in Chapter 2, the current literature on accident costs offers a wide range of values, even within a specific mode of travel. And as with other estimates of transportation externalities (such as emissions, noise) the more recent the literature the higher these costs tend to be.

\section{Table 4.14 Baseline Safety Costs by Mode of Transportation.}

A. Based on results presented by Litman, 1999

\begin{tabular}{lcc} 
Mode of Travel: & $\begin{array}{c}\text { Internal Costs } \\
\text { (cents/pmt) }\end{array}$ & $\begin{array}{c}\text { External Costs } \\
\text { (cents/vmt) }\end{array}$ \\
\hline Auto & 5.20 & 3.64 \\
Van & 5.20 & 3.64 \\
Diesel Bus & 0.32 & 2.08 \\
\hline
\end{tabular}

B. Based on results presented by Gomez-Ibanez, 1997

\section{Internal + External Costs (cents/pmt)} (cents/vmt)

Rail Transit $0.565 \quad 2.26$

* numbers converted to 1998 dollars from A) 1996 and B) 1990 dollars, using Consumer Price Index inflator.

Taxi trips are treated as auto trips throughout this study as far as safety cost rates are involved.

Table 4.15 shows a range of empirical results. As with the air quality and noise analyses, each of the scenarios shown is run on the assumption of zero foregone trips. The Baseline scenario shown is the one used in the rest of this report. It is based on applying the accident cost rates shown in Table 4.14 to each urban district spreadsheet. Scenario 2 is a variant on this, using the same automobile rates for transit buses and vanpools and therefore basing safety on vmt alone. Note that the estimated benefits go down because of the higher rate of per passenger risk associated with automobiles in Table 4.14.

Scenario 3 uses an alternative set of modal accident rates, based on the work of Miller (see Miller, 1997). In this Scenario it is assumed that private vehicle costs (i.e. auto, also taxi trips) are costed at 15.3 cents per vehicle mile, and bus transit at 41.7 cents per vehicle mile. Van pools are assumed to have the same accident costs per mile as automobiles. These rates yield 
Public Transit in Tennessee

statewide safety benefits $33 \%$ higher than the baseline value.

Table 4.15 Estimated Urban Transit Safety Benefits.

\begin{tabular}{l|r|r|r|r} 
Urban Area & \multicolumn{1}{|c|}{ Baseline } & \multicolumn{1}{c}{ Scenario \#2 } & \multicolumn{1}{c}{ Scenario \#3 } & Scenario \#4 \\
\hline Chattanooga & 382,098 & 154,588 & 412,995 & 889,405 \\
Knoxville & 9,326 & 94,371 & $-170,123$ & 368,993 \\
Memphis & $3,810,163$ & $1,833,568$ & $5,576,708$ & $7,202,139$ \\
Nashville & $1,443,002$ & 793,438 & $1,839,495$ & $3,178,301$ \\
Small Urban Systems & 156,147 & 174,048 & 54,681 & 601,935 \\
\hline Total & $\mathbf{5 , 8 0 0 , 7 3 6}$ & $\mathbf{3 , 0 5 0 , 0 1 5}$ & $\mathbf{7 , 7 1 3 , 7 5 5}$ & $\mathbf{1 2 , 2 4 0 , 7 7 3}$
\end{tabular}

Scenario \# 4 uses these same estimates based on Miller et al's work, but as with Scenario \#2, all modal accident costs are set equal to those of the average automobile, i.e. the only impact on accident costs are modal differences in vmt. This produces positive safety benefits from urban transit systems in the State that are 2.11 times the baseline value.

Introducing foregone trips into the analysis leads to fewer safety benefits as a smaller number of trips are now assumed to take place. For example, assuming a 10\% foregone trip rate the baseline Statewide safety benefits reported in Table 4.15 reduce to just under $\$ 4,879,000$ (but with considerable increase in net overall transit benefits as a result of foregone trip costs).

In examining these and other scenarios generated by values from the recent literature it seems reasonable to assign significant positive safety benefits to the State's urban transit systems as a whole. In looking at some of the higher negative benefits associated with some of the State's smaller urban systems, however, this average rates-based approach seems unrealistic. The computation requires a reliable time series on annual accident counts from each transit district. This is likely to show these systems as being somewhat safer, relative to the average automobile, than is represented in the above statistics. An additional, and potentially significant factor not picked up in this approach is the problem of older and unhealthy drivers taking to the roads as a result of transit service losses or cutbacks. For this reason also, the Baseline estimates used in this study are likely to err on the conservative side.

\subsubsection{Economic Benefits From Transit Supply.}

As described in Chapter 2 of this report, economic benefits from the supply of public transit services are computed in this study in terms of the estimated number of jobs created and associated economic value added, in each urban transit district as a result of a) federal, state and local expenditures on urban transit in 1998 and b) the estimated benefits resulting from the transportation efficiencies which the presence of these urban transit systems encourages within each region. 


\section{Public Transit in Tennessee}

Transit System Expenditure-Induced Economic Benefits: The IMPLAN Input-Output model and county level economic activity database was used to compute separate economic multipliers for each urban transit district based on a) annual transit system operation and maintenance expenses, including any funds spent on planning activities, and b) annual capital expenditures (on vehicles, also some on structures). Operating, maintenance and planning expenditure multipliers were based on IMPLAN multipliers for the industrial sector "Local Inter-Urban Passenger Transportation". Capital expenditure multipliers were based on IMPLAN multipliers for the industrial sector "Automotive Dealers and Service Stations". For each of these two expenditure classes, and for each urban transit district in the state, the following four types of economic multiplier were computed:

- an employment multiplier, which estimates the number of jobs created in the region as a result of spending one million dollars in the public transportation sector.

- a value added multiplier, which measures the amount of income generated in the region as a result of one dollar expenditure in the public transportation sector.

- an indirect business tax multiplier, which measures the increase in indirect business tax that results from spending one dollar in the public transportation sector, and

- an output multiplier, which estimates the increase in output in the region as a result of spending one dollar on public transportation.

Results are presented below for the first two of these multipliers. In computing the economic benefits of transit expenditures to add to the Transit Use benefits discussed above, we use the Value Added dollars. This is the value of production generated by economic activity net of the input materials (in contrast to Output, which we also computed, and which is the total value of this economic activity, including value added and materials costs). These Value Added dollars are composed of wages, proprietors income, indirect business taxes and other property income. ${ }^{5}$ Table 4.16 shows the breakdown of planning, operating and capital funds expended by each urban transit district in calendar year $1998 .^{6}$

The majority of local economic impacts come through operating, maintenance and planning expenditures. In contrast, a high percentage of the capital expenditures, notably for vehicle purchases, are spent out of the region and also out of the state. A default value of $6.5 \%$ of capital funds being spent within an urban area was adopted as a default value, based on a study of

\footnotetext{
${ }^{5}$ The term "value added" is used because some activity (i.e. labor or owner service) is applied to a base input to transform it to a more desirable state -- i.e. the value added. In a market context the added value at the margin is equal to society's willingness to pay productive factors to generate the new product -- i.e the value of wages and capital.

${ }^{6}$ It is worth noting that a significant amount of funds originally reported to the State DOT under “ capital" are in fact used in operations within some urban transit districts, notably to pay mechanics wages. These adjustments have been made in Table 4.16 after discussions with specific transit systems. In some cases an approximate percentage of such cross-over funds was used.
} 


\section{Public Transit in Tennessee}

IMPLAN local expenditure multipliers in the relevant industrial sector for the State as a whole. A notable exception to this rule was the case of the Chattanooga Regional Transit Authority, where some $41 \%$ of the capital costs were reported to be spent locally in 1998: the money going towards the acquisition of new electric buses constructed within Hamilton County itself.

Table 4.16 Urban Public Transit System Expenditures in 1998.

\begin{tabular}{l|rrrr} 
Urban Area & Planning & Operating & Capital & Total \\
\hline Chattanooga & 2,880 & $4,515,515$ & $3,776,520$ & $8,294,915$ \\
Knoxville & 0 & $7,606,151$ & $1,853,745$ & $9,459,896$ \\
Memphis & 239,818 & $16,762,041$ & $24,480,274$ & $41,482,133$ \\
Nashville & 255,171 & $9,819,976$ & $1,312,148$ & $11,387,295$ \\
Bristol & 22,863 & 245,869 & 87,717 & 356,449 \\
Clarksville & 22,679 & $1,271,051$ & 555,921 & $1,849,651$ \\
Gatlinburg & 0 & 742,186 & 0 & 742,186 \\
Jackson & 25,299 & 556,536 & 522,516 & $1,104,351$ \\
Johnson City & 40,060 & $1,011,759$ & 544,684 & $1,596,503$ \\
Kingsport & 37,500 & 369,598 & 80,850 & 487,948 \\
Oak Ridge & 0 & 139,880 & 30,198 & 170,078 \\
Pigeon Forge & 0 & $\mathbf{7 1 , 8 5 0}$ & 505,000 & 576,850 \\
\hline Total & $\mathbf{6 4 6 , 2 7 0}$ & $\mathbf{4 3 , 1 1 2 , 4 1 2}$ & $\mathbf{3 3 , 7 4 9 , 5 7 3}$ & $\mathbf{7 7 , 5 0 8 , 2 5 5}$
\end{tabular}

Transportation Efficiency-Induced Benefits. A positive relationship between expenditures on transportation supply on the one hand and population, income and employment growth, land development, and investments in other forms of urban infrastructure on the other are often attributed to the building of the nation's highway system. Investments in public transit systems have also been found to be very supportive of economic growth, in both the short- and longterm. These benefits of more cost-effective, or more efficient, transportation supply result from greater access to customers on the one hand and greater access to markets on the other: with the added benefit that these travel cost savings may also encourage economies of scale in business enterprises.

In practice, these generative growth impacts are very difficult to measure, since they require a dynamic model of a region's economy and its growth potentials. Nevertheless, to ignore the likelihood of such impacts seemed inappropriate. While the approach taken in this present study had to be much less ambitious, an effort to estimate such economic growth inducing benefits did seem worthwhile. The approach adopted mirrors that used recently by Leigh, Scott and Cleary, Inc. et al (1999), based in turn on the recent work of Nadiri and Mamuneas (1996, 1998). Based on this work, Leigh, Scott and Cleary, Inc. et al (1999, pages K-8 through K-12) adopt a figure of $4 \%$ as being the annual averaged increment in economic growth attributable to transportation efficiencies. Hence if economic growth in a particular year is $5 \%$, then transportation efficiency 


\section{Public Transit in Tennessee}

accounts for $4 \% * 5 \%=0.2 \%$ of that annual growth. In all of the tables presented below this $4 \%$ figure is used as the default value for the benefits from transportation efficiency.

Empirical Results: Three Perspectives. Table 4.17 summarizes the main finding from the study's economic impacts analysis, measured in terms of a) jobs generated in the State, and b) in thousands of (1998) dollars of Value Added to the State's various regional economies.

\section{Table 4.17 1998 Employment and Economic Impacts of Urban Transit Supply .}

\begin{tabular}{l|rrr|r|r}
$\begin{array}{l}\text { A) Jobs Impact } \\
\text { of Transit System }\end{array}$ & \multicolumn{6}{|c|}{ Transit Expenditure Induced Jobs: } & \multicolumn{1}{|l|}{$\begin{array}{l}\text { Trans. Efficiency } \\
\text { Fed. Funds State Funds }\end{array}$} & Local Funds & \multicolumn{1}{l}{ Induced Jobs } & \multicolumn{1}{c}{ Total Jobs } \\
\hline Chattanooga & 55.7 & 37.8 & 163.5 & 14.5 & 271.4 \\
Knoxville & 32.0 & 38.8 & 264.9 & 14.4 & 350.0 \\
Memphis & 184.4 & 111.2 & 685.1 & 95.0 & $1,075.8$ \\
Nashville & 23.1 & 70.4 & 462.3 & 34.8 & 590.7 \\
Small Urban Systems & 66.6 & 33.3 & 163.6 & 16.9 & 280.4 \\
\hline Total & $\mathbf{3 6 1 . 8}$ & $\mathbf{2 9 1 . 7}$ & $\mathbf{1 , 7 3 9 . 4}$ & $\mathbf{1 7 5 . 6}$ & $\mathbf{2 , 5 6 8 . 4}$
\end{tabular}

\begin{tabular}{l|rrr|r|r|r}
$\begin{array}{l}\text { B) Economic Impact } \\
\text { of Transit System }\end{array}$ & \multicolumn{2}{|c|}{$\begin{array}{l}\text { Expenditure-Based Value Added: } \\
\text { Fed. Funds State Funds }\end{array}$} & $\begin{array}{l}\text { Trans. Efficiency } \\
\text { Local Funds }\end{array}$ & $\begin{array}{r}\text { Total Economic } \\
\text { Impacts (000's \$) }\end{array}$ & $\begin{array}{r}\text { Impact (000's \$) } \\
\text { Chattanooga }\end{array}$ \\
\hline Knoxville & $9,079.9$ & $1,293.6$ & $5,386.6$ & 504.3 & $9,264.5$ \\
Memphis & $6,462.4$ & $1,147.0$ & $7,791.8$ & 365.3 & $10,262.3$ \\
Nashville & 744.0 & $2,224.9$ & $14,570.5$ & $3,293.6$ & $35,991.2$ \\
Small Urban Systems & $1,418.6$ & 676.5 & $3,329.0$ & 859.6 & $18,399.0$ \\
\hline Total & $\mathbf{1 1 , 6 6 3 . 1}$ & $\mathbf{9 , 0 5 7 . 3}$ & $\mathbf{5 3 , 5 9 7 . 7}$ & 412.8 & $5,836.8$ \\
\hline
\end{tabular}

In total, expenditures on urban transit within the State are estimated to support almost 2,570 jobs, worth almost $\$ 79.8$ million in economic value to the State. What Table 4.17 also indicates is that, for calendar year 1998, almost $70 \%$ of the economic impacts accrue from locally provided transit support funds (including the effects of fares and other revenues taken in). An additional $11 \%$ of these economic impacts result from federal dollars spent on these transit systems, while $11.8 \%$ are attributable to State supplied transit support funds. The remaining $7.3 \%$ are estimated to come from transportation efficiency gains. These efficiency gains are most appropriately viewed as additional benefits resulting from the combination of federal, state and local dollars spent to operate the transit system within an urban area.

Tables 4.18 and 4.19 below provide two additional perspectives on the economic impacts of urban transit supply. Table 4.18 lists what we term the "local area benefits". These are benefits viewed from a specific urban transit district's perspective, to which the benefits accrue largely as 


\section{Public Transit in Tennessee}

a result of the federal and state funds brought into that district, plus the additional transportation efficiency gains induced by the transit operations made possible by the combined effects of all of these three expenditure sources combined. It is estimated that in total such investments support some \$26.1 (i.e. \$20.7 + \$5.4) million worth of local economic activity. It is these net economic statewide benefits, i.e. benefits less any obvious within-district or within-State transfer payments, that are used in the benefits forecasts presented later in this chapter.

Table 4.18 Local Area Impacts of Federal and State Urban Transit Expenditures in 1998.

\begin{tabular}{l|rr|rr|r} 
Transit System-Based & \multicolumn{2}{|c|}{$\begin{array}{l}\text { Expenditure-Based } \\
\text { Local Area Benefits }\end{array}$} & \multicolumn{2}{|l|}{ Trans. Efficiency-Based } & \multicolumn{2}{l}{ Local Ecoomic } \\
Value Added & \multicolumn{1}{l|}{ Jobs } & Benefits (000s \$) & Jobs & Benefits (000's\$) \\
\hline Chattanooga & $3,373.6$ & 93.5 & 504.3 & 14.5 & $3,877.9$ \\
Knoxville & $2,105.2$ & 70.8 & 365.3 & 14.4 & $2,470.5$ \\
Memphis & $10,177.7$ & 295.7 & $3,293.6$ & 95.0 & $13,471.4$ \\
Nashville & $2,968.9$ & 93.6 & 859.6 & 34.8 & $3,828.5$ \\
Small Urban Systems & $2,095.0$ & 66.6 & 412.8 & 16.9 & $2,507.9$ \\
\hline Total & $\mathbf{2 0 , 7 2 0 . 5}$ & $\mathbf{6 2 0 . 2}$ & $\mathbf{5 , 4 3 5 . 6}$ & $\mathbf{1 7 5 . 6}$ & $\mathbf{2 6 , 1 5 6 . 1}$
\end{tabular}

Table 4.19 Net Statewide Impacts of Federal and State Urban Transit Expenditures in 1998.

\begin{tabular}{l|rr|rr|r}
$\begin{array}{l}\text { Transit System-Based } \\
\text { Net State Benefits }\end{array}$ & \multicolumn{2}{|c|}{ Expenditure-Based } & \multicolumn{2}{|l}{ Trans. Efficiency-Based } & \multicolumn{2}{l}{$\begin{array}{l}\text { Statewide Economic } \\
\text { Value Added }\end{array}$} & \multicolumn{1}{c}{ Jobs } & Benefits (000s \$) & \multicolumn{1}{c}{ Jobs } & Benefits (000's\$) \\
\hline Chattanooga & $2,079.9$ & 55.7 & 504.3 & 14.5 & $2,584.2$ \\
Knoxville & 958.2 & 32.0 & 365.3 & 14.4 & $1,323.5$ \\
Memphis & $6,462.4$ & 184.4 & $3,293.6$ & 95.0 & $9,756.0$ \\
Nashville & 744.0 & 23.1 & 859.6 & 34.8 & $1,603.6$ \\
Small Urban Systems & $1,418.55$ & 66.58 & 412.8 & 16.9 & $1,831.4$ \\
\hline Total & $\mathbf{1 1 , 6 6 3 . 1}$ & $\mathbf{3 6 1 . 8}$ & $\mathbf{5 , 4 3 5 . 6}$ & $\mathbf{1 7 5 . 6}$ & $\mathbf{1 7 , 0 9 8 . 7}$
\end{tabular}

Table 4.19 provides a third, State support agency perspective. From the State's perspective it can be argued that only those expenditure-induced impacts resulting from federal funds coming into the State offer a net economic benefit, since any within-State generated funds represent a form of transfer payment from one pot of money to another. Table 4.19 shows the results of netting out only those economic activity gains derived from the federally provided urban transit funds. Together with the transportation efficiency induced gains this results in a total of \$17.1 million dollars of value added within the State. It is these net economic statewide benefits, i.e. benefits less any obvious within-district or within-State transfer payments, that are used in the benefits forecasts presented later in this chapter. 


\section{Public Transit in Tennessee}

As both a perspective and a check on the reasonableness of the input-output method used for generating employment and associated economic benefits from transit service expenditures, Table 4.20 was constructed. This table shows the number of direct full-time jobs reported for each urban transit district in the State, next to the total number of direct, indirect plus induced jobs estimated to have been supported in each district by these expenditures in 1998. Statewide the ratio of estimated total jobs to direct (i.e. transit agency) jobs is 1.924 (i.e. 2,392.8/1,243.4), close to one additional job created for every urban transit worker job in the state.

\section{Table 4.20 Estimated Direct Plus Indirect and Induced Employment Impacts Of Transit Expenditures in 1998.}

\begin{tabular}{l|r|r} 
Urban Area & $\begin{array}{c}\text { Full-Time Jobs } \\
\text { in Transit in 1998 }\end{array}$ & $\begin{array}{r}\text { Transit Expenditure } \\
\text { Created Jobs (Gross) }\end{array}$ \\
\hline Chattanooga & 138.0 & 257.0 \\
Knoxville & 169.0 & 335.7 \\
Memphis & 517.0 & 980.8 \\
Nashville & 322.0 & 555.9 \\
Bristol & $\mathrm{nd}$ & 8.6 \\
Clarksville & 25.0 & 69.6 \\
Gatlinburg & $\mathrm{nd}$ & 39.0 \\
Jackson & 28.0 & 45.9 \\
Johnson City & 30.4 & 43.8 \\
Kingsport Area & 14.0 & 19.3 \\
Oak Ridge & $\mathrm{nd}$ & 6.5 \\
Pigeon Forge & $\mathrm{nd}$ & 30.7 \\
\hline Total & $\mathbf{1 , 2 4 3 . 4}$ & $\mathbf{2 , 3 9 2 . 8}$
\end{tabular}

Notes: nd $=$ no data collected.

Sensitivity Analysis: Noting that these shares of federal, state and local transit investments change from year to year, a more robust estimate of the economic benefits of transit supply ought to use time series data going back a decade or so. To this end time series data on federal, state and local transit system expenditures was obtained for State fiscal years 1994-95 through 1999-2000 for each of the four large urbanized areas plus aggregated data for small urban systems. Taken over this six year reporting period, the average federal share of transit funding was approximately $28.5 \%$, the State share was $13.5 \%$, and the local share (including revenues) was $58 \%$, with a noticeable drop in the federal share from around 34\% through 1994-96 to the low- to mid-twenties range since that time. For the calendar year 1998, on which the detailed, district specific expenditures data used to generate Tables 4.17 - 4.19 was based, these shares were very comparable, with a $30.7 \%$ federal, $12.5 \%$ State, and $57 \%$ local funding breakdown. This reflects a slightly higher federal share, but also with a higher percentage of this allocation going to capital investments, notably in the Memphis system, which yield much lower local 


\section{Public Transit in Tennessee}

economic gains per dollar of funding than the largely locally spent operational and planning funds. With these figures in mind, it is concluded that the results shown in Tables 4.17 through 4.19 are reasonably representative of the total annual economic benefits these transit systems have produced for the State as a whole.

A second potential cause of change in the above transit expenditure impacts is the assumption that only a $6.5 \%$ share of capital expenses are spent locally (except the $41 \%$ used for the Chattanooga system). Doubling this local expenditure share, to $13 \%$, only increases the gross value added estimate for the State from the $\$ 79.8$ million shown in Table 4.17 to $\$ 81.3$ million. Local impacts (Table 4.18) increase from \$26.1 to \$27.5 and Statewide Net impacts (i.e. impacts from federally received dollars only, shown in Table 4.19) increase from $\$ 17.1$ to $\$ 18.2$ million.

A third assumption to which the above results are sensitive is the assumed $4 \%$ annualized average increment in economic growth associated with transportation efficiency induced benefits. A sensitivity analysis proves straight-forward in this case since increasing or decreasing this percentage results in a proportional change in the estimated transportation efficiency benefits, e.g. increasing the transportation efficiency induced growth rate from $4 \%$ to $6 \%$ increases the economic impacts reported in the tables below by $50 \%$.

\subsection{Summary of Base Year Benefits.}

Table 4.21 summarizes this study's computation of urban public transit base year (= Calendar Year 1998) benefits, estimated in 1998 dollars.

Table 4.21 Urban Public Transit Benefits Summary Table (10\% Foregone Trips Scenario) (in thousands of 1998 dollars).

\begin{tabular}{l|rrrrr} 
Urban Area & Mobility & \multicolumn{1}{c}{ Safety } & Air Quality & Economic & \multicolumn{1}{c}{ Total } \\
\hline Chattanooga & 12,484 & 307 & 86 & 2,584 & 15,461 \\
Knoxville & 8,215 & -34 & -134 & 1,323 & 9,372 \\
Memphis & 77,449 & 3,339 & 1,726 & 9,756 & 92,270 \\
Nashville & 37,885 & 1,215 & 448 & 1,604 & 41,152 \\
Small Urban Systems & 10,175 & 110 & -54 & 1,831 & 12,063 \\
\hline Total & $\mathbf{1 4 6 , 2 0 8}$ & $\mathbf{4 , 9 3 8}$ & $\mathbf{2 , 0 7 2}$ & $\mathbf{1 7 , 0 9 9}$ & $\mathbf{1 7 0 , 3 1 8}$
\end{tabular}

As expected, transit use-based mobility benefits dominate, with results very sensitive to the amount of foregone travel and to the values assigned to those trips (cf Table 4.8). Safety benefits may be undervalued by this methodology, while air quality benefits in this base year may be somewhat overvalued. Using the urban transit demand and supply data presented earlier in this chapter (cf. Tables 4.2 and 4.3), Table 4.22 presents the result of this Baseline benefits analysis scenario in terms of per trip, per transit vehicle mile and per transit passenger mile of service. The scenario results in a net urban public transit benefit of $\$ 6.70$ per one-way transit 


\section{Public Transit in Tennessee}

trip, of which $\$ 5.41$ comes from mobility based accessibility benefits alone. This translates into an $\$ 8.28$ net benefit per transit vehicle mile of service and a net benefit of $\$ 1.40$ per passenger mile of service.

\section{Table 4.22 Urban Transit Benefits Statistics for CY 1998.}

\begin{tabular}{l|l|r|r}
$\begin{array}{l}\text { Statewide Urban Public Transit } \\
\text { Systems Benefits: CY 1998 }\end{array}$ & $\begin{array}{c}\text { \$ Per Trip } \\
\text { Benefits }\end{array}$ & $\begin{array}{r}\text { \$ Per Vehicle } \\
\text { Mile Benefits }\end{array}$ & $\begin{array}{r}\text { \$ Per Passenger } \\
\text { Mile Benefits }\end{array}$ \\
\hline User Mobility Benefits & $\$ 5.41$ & $\$ 6.68$ & $\$ 1.13$ \\
Congestion Mitigation & $\$ 0.34$ & $\$ 0.43$ & $\$ 0.07$ \\
Safety Benefits & $\$ 0.19$ & $\$ 0.24$ & $\$ 0.04$ \\
Air Quality Benefits & $\$ 0.08$ & $\$ 0.10$ & $\$ 0.02$ \\
Expenditure Multiplier Benefits & $\$ 0.46$ & $\$ 0.57$ & $\$ 0.10$ \\
Transportation Efficiency Benefits & $\$ 0.21$ & $\$ 0.26$ & $\$ 0.04$ \\
& & & \\
\hline Total Estimated Benefits: & $\$ 6.70$ & $\$ 8.28$ & $\$ 1.40$
\end{tabular}

It is important to note that benefits can vary considerably within each benefits category depending on the specific urban transit system.

\subsection{Urban Transit Ridership and Benefits Forecasts.}

Recent Ridership Trends. Figures 4.8 through 4.13 show the history of urban transit ridership within the State, on an annual basis, during the 1990's (data compiled by Tennessee DOT). Figure 4.8 shows aggregate annual demand for all types of service for the State's four large urban areas plus an aggregate demand for the State's remaining 8 small urban area systems. Figure 4.9 shows this same ridership broken down by individual small urban area. Figures 4.10 and 4.11 repeat these tables for fixed route bus ridership only. Figure 4.12 and 4.13 do the same for demand responsive (largely ADA assisted) trips. Total ridership declined $10.1 \%$ statewide during the 1990 's, largely because fixed route bus trips were down by $15.5 \%$. However, there was a noticeable flattening off and some recovery of ridership in the second half of the decade: reflecting a similar trend in the national transit ridership picture. ${ }^{7}$ This recovery was also helped by steadily increasing demand responsive, largely ADA assisting, urban transit ridership (see Figures 4.12 and 4.13).

Projecting Potential Ridership Populations. Estimates were made of the number of future riders based on the number of people projected to have the necessary ridership characteristics in specific urban areas in future years. The Center for Business Economics (CBER) at the

\footnotetext{
${ }^{7}$ See the latest data reported at http://www.apta.com
} 
Public Transit in Tennessee

Figure 4.8 Total Urban Public Transit Ridership in the 1990's.

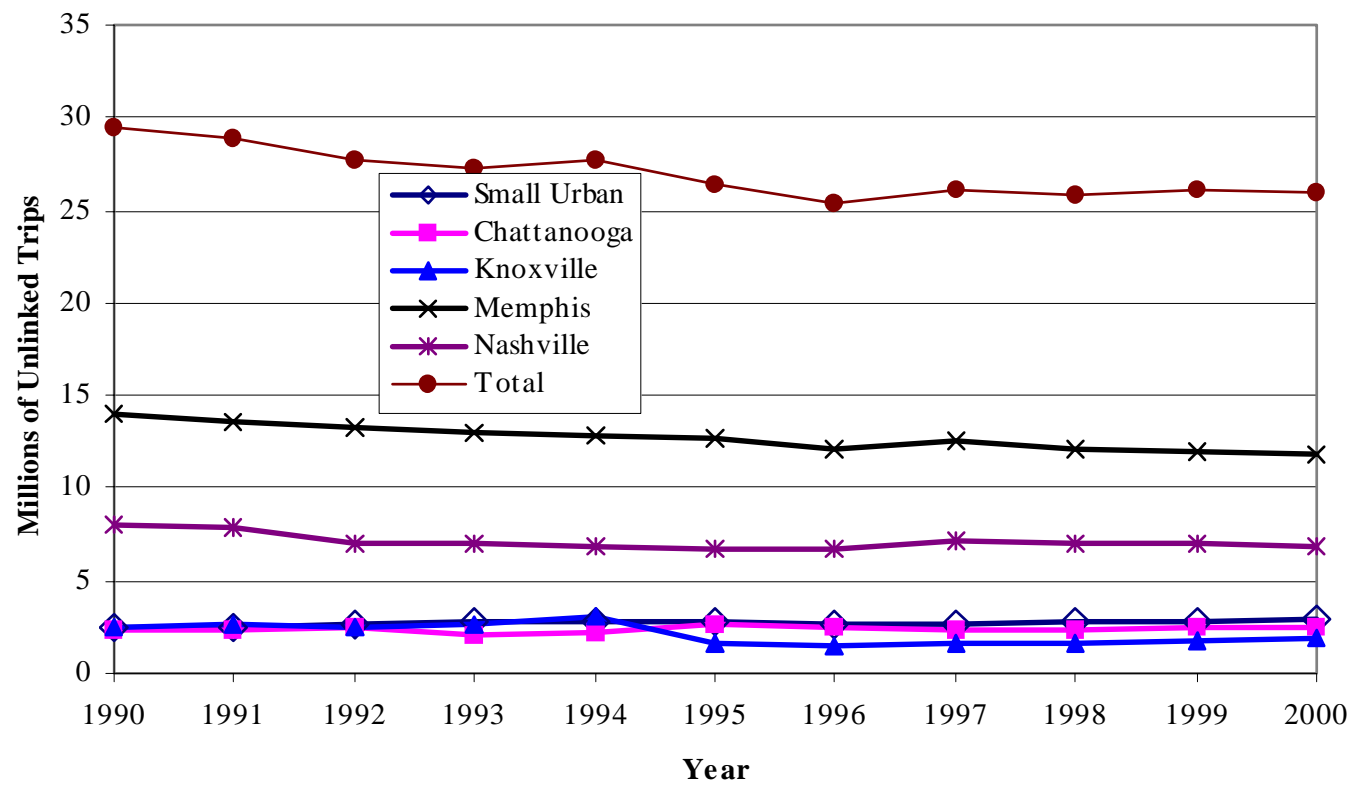

Figure 4.9 Urban Public Transit Ridership in Small Urban Areas in the 1990's.

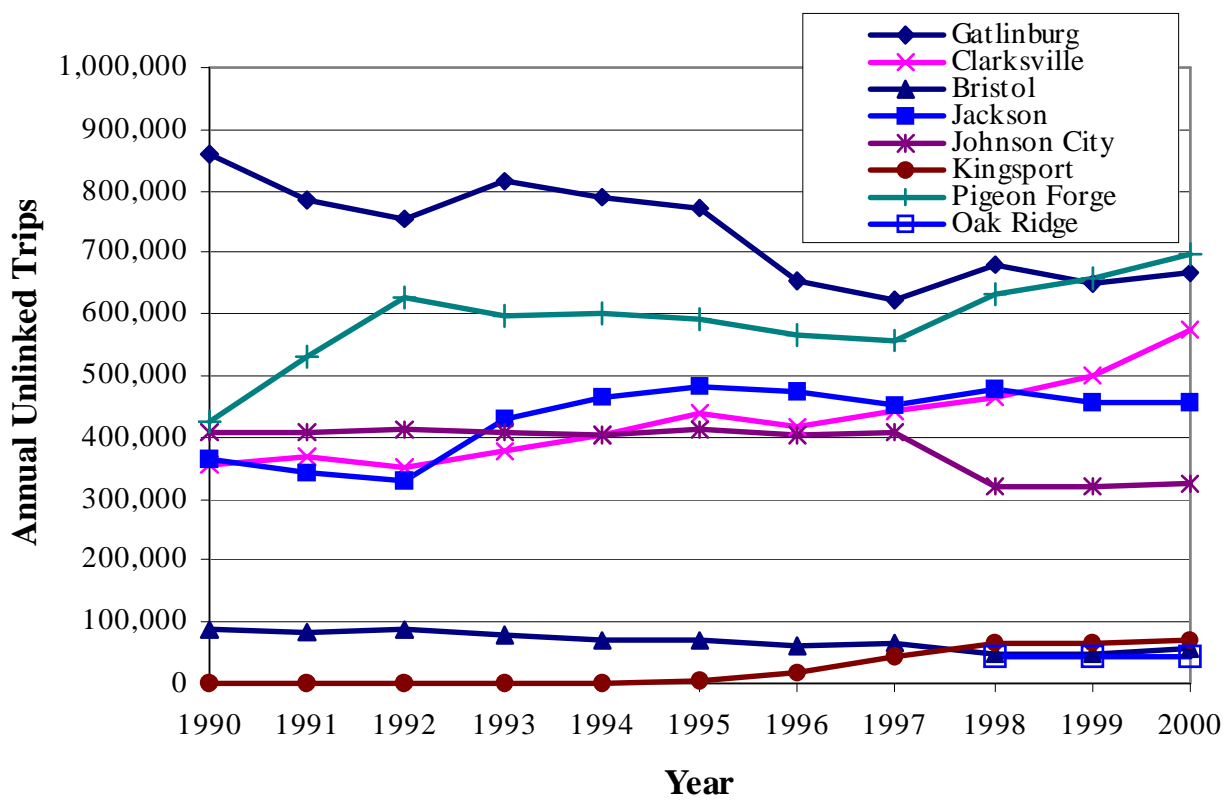


Public Transit in Tennessee

Figure 4.10. Fixed Route Bus Ridership in the 1990's.

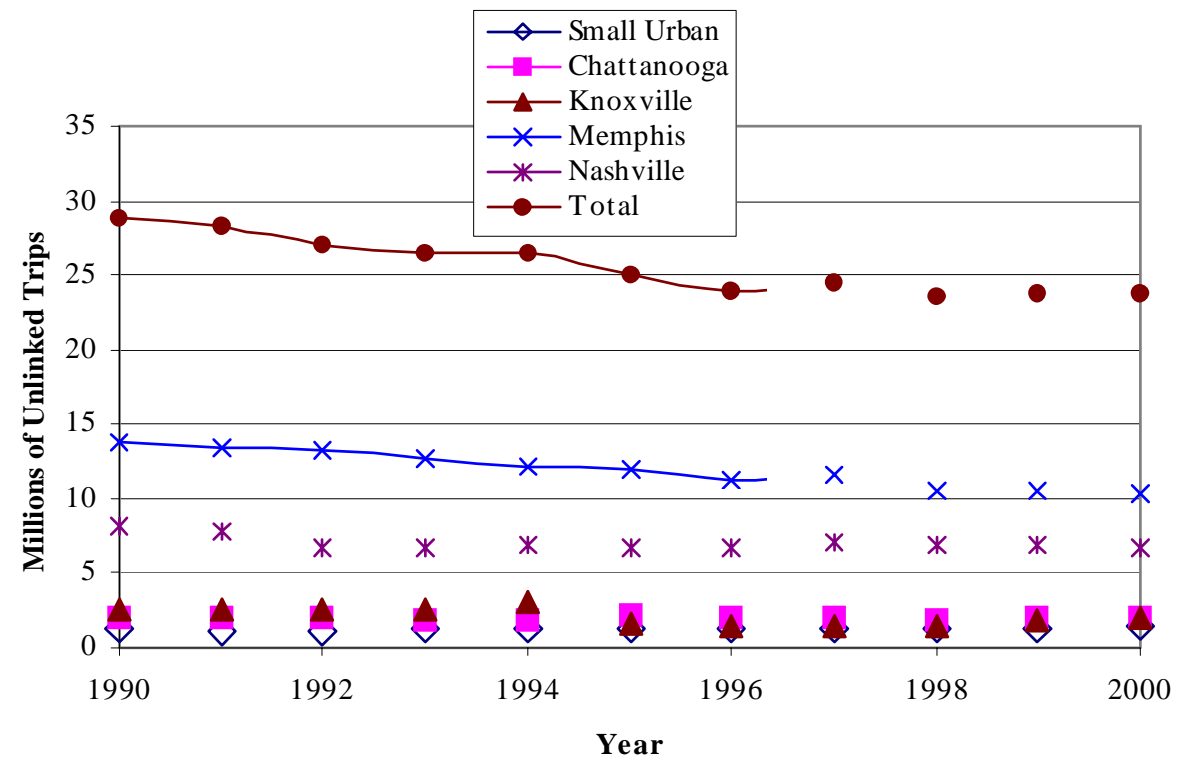

Figure 4.11. Fixed Route Bus Ridership in Small Urban Areas in the 1990's.

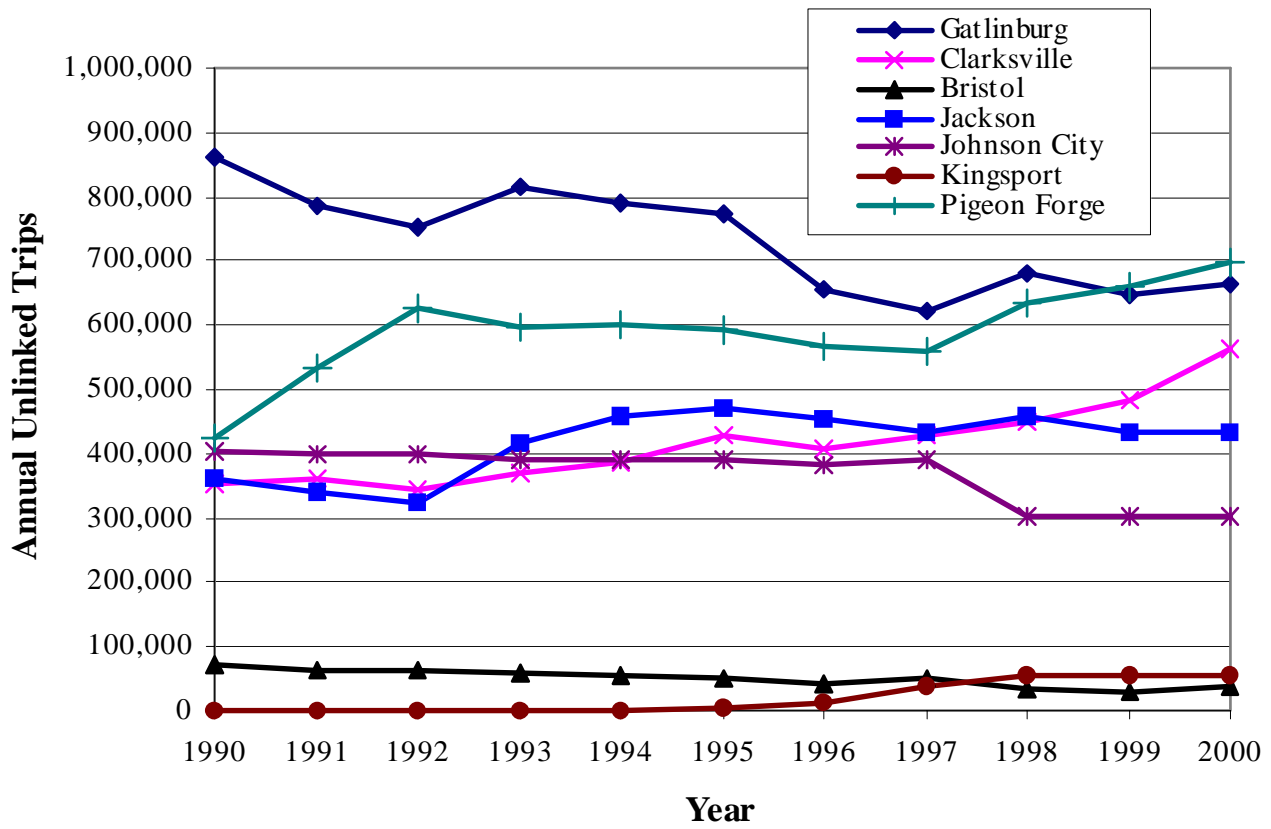


Public Transit in Tennessee

Figure 4.12. Demand Responsive Ridership in the 1990's.

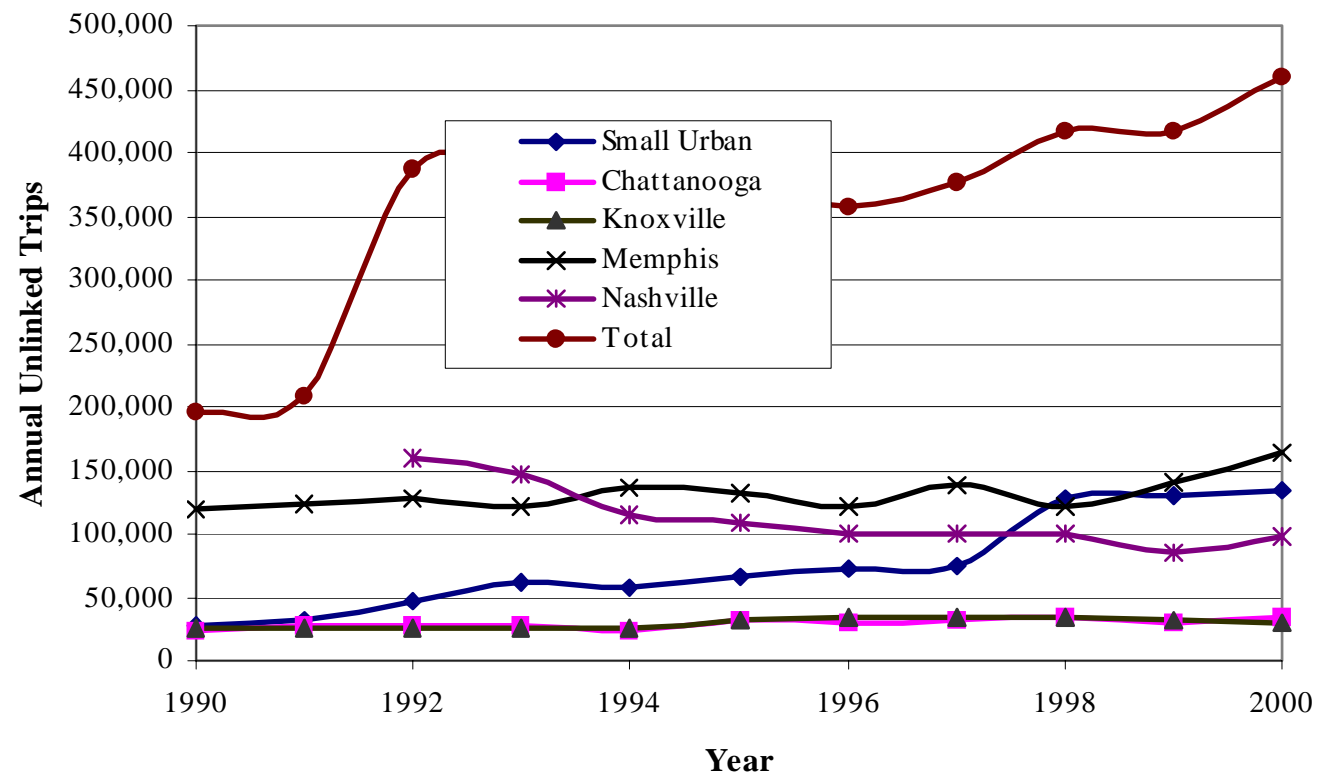

Figure 4.13. Demand Responsive Ridership in Small Urban Areas in the 1990's.

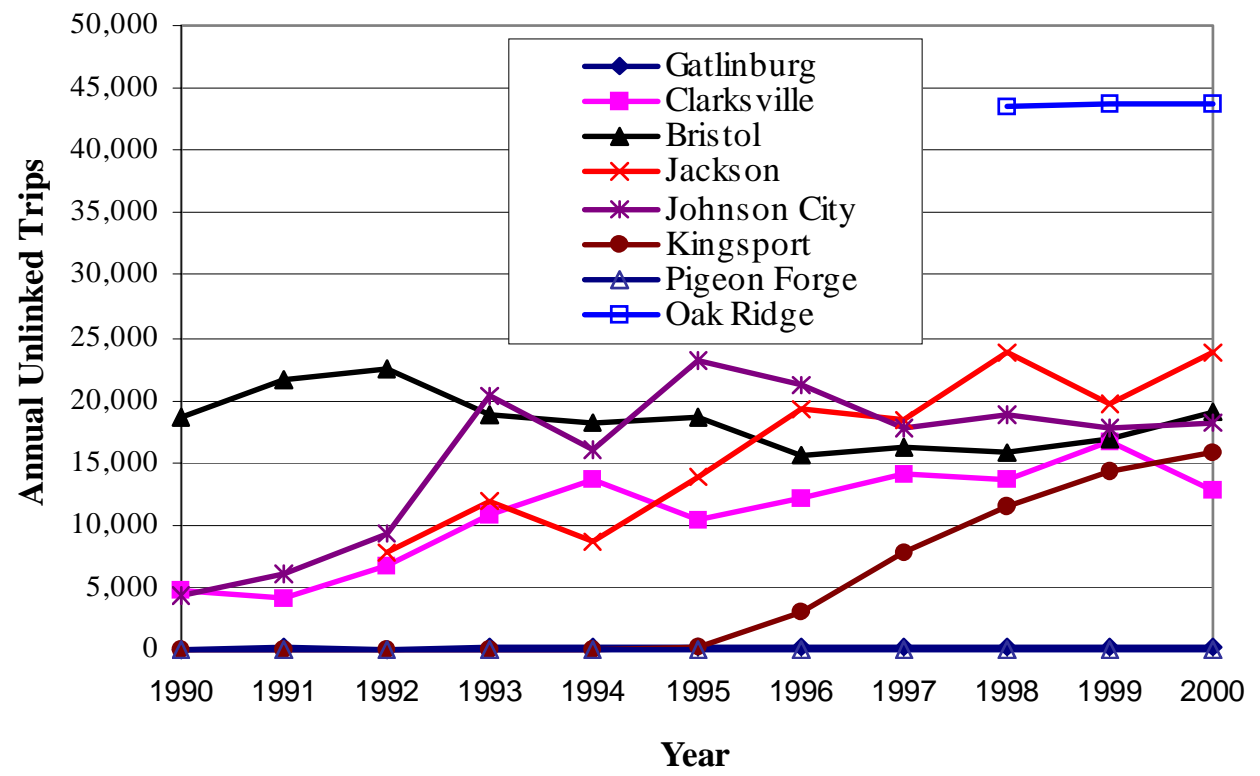




\section{Public Transit in Tennessee}

University of Tennessee had already prepared county projections of total population by five-year intervals, to 2020, prior to the start of the present study (Murray, 1999). These were adopted as the starting point and acted as the "official" control totals for the subsequent analysis. Baseline future population forecasts in each transit operator district were first generated by summing over the forecast populations in every county within that urban district (holding current district boundaries constant throughout the forecasts for this purpose). 1990 based Census defined Urbanized Area were used in the forecasting process. Where an urbanized area occupied parts of a county, recourse was made to zip code level population and socio-economic data to generate the urban district specific population forecasts. These populations were then disaggregated into transit-sensitive sub-populations at the county and urbanized area level.

To develop a set of potential transit market sub-populations, estimates of several population cohorts, or sub-groups, were developed using 1990 Census data. This included county level data from "Census Counts 98", 8 and also data from the Bureau of the Census's Internet site. Two proprietary population projection series were also used to develop alternative, cohort specific population projections -- the National Planning Association ${ }^{9}$ and Woods \& Poole ${ }^{10}$ data series. In doing so it was assumed that the county land area provided in the 1990 Census will remain static for the period of the projections. For forecasting purposes these projections were further broken down at the county and transit district level into a number of different age, income and mobility limited cohorts. As explained in Chapter 3 of this report, for fixed route urban transit the number of persons in each urbanized area, the population density, and the number of households without an automobile were eventually chosen as explanatory socio-economic variables. For demand responsive urban ridership forecasting the number of persons who are mobility limited (transportation handicapped) was also found to be a useful indicator variable.

The following ridership and benefit forecasts were based heavily on these cohort specific population projections. Total urban population and population density, as well as proportion of households without a car were all subsequently used in the urban ridership forecasting process, via the models described in Chapter 3 of this report. Other cohort specific population projections were generated and tested using this same population sharing and projection process.

Urban Ridership Forecasts. Table 4.23 shows the Baseline Forecast calculated and used in this study to project future year transit benefits (cf Chapter 3), summed over all transit services (i.e. over fixed route bus, trolley and commuter vanpool, fixed route rail, incline railroad, and demand responsive transit van services). Figure 4.14 graphs the trends implied by this data. (See

\footnotetext{
${ }^{8}$ Decisionmark Corp, CensusCounts98, Cedar Rapids, Iowa

${ }^{9}$ National Planning Association Data Services, Regional Economic Projection Series (REPS), February, 1999, Washington, D.C.

${ }^{10}$ Woods \& Poole Economics, Inc. CEEDS: State Profiles, Washington, D.C. 1998
} 
Public Transit in Tennessee

Chapter 3 for ridership forecasting model details).

Table 4.23 Urban Transit Baseline Ridership (Unlinked Trip) Forecasts: All Services Combined.

\begin{tabular}{r|rrrrrrrr} 
& Small Urban Chattanooga* & Knoxville & Memphis & Nashville & $\begin{array}{c}\text { Gatlinburg \& } \\
\text { Pigeon Forge }\end{array}$ & Total \\
\hline $\mathbf{1 9 9 0}$ & $1,214,189$ & $2,349,959$ & $2,543,833$ & $13,977,728$ & $8,076,944$ & $1,285,109$ & $29,447,762$ \\
$\mathbf{1 9 9 5}$ & $1,412,799$ & $2,606,734$ & $1,592,114$ & $12,669,232$ & $6,750,011$ & $1,362,768$ & $26,393,658$ \\
$\mathbf{2 0 0 0}$ & $1,523,467$ & $2,449,530$ & $1,942,179$ & $11,801,084$ & $6,815,898$ & $1,363,186$ & $25,895,344$ \\
$\mathbf{2 0 0 5}$ & $1,604,549$ & $2,422,487$ & $2,007,898$ & $11,891,862$ & $6,956,010$ & $1,600,589$ & $26,483,395$ \\
$\mathbf{2 0 1 0}$ & $1,732,532$ & $2,407,682$ & $2,071,580$ & $11,802,715$ & $7,175,908$ & $1,837,946$ & $27,028,362$ \\
$\mathbf{2 0 1 5}$ & $1,891,833$ & $2,402,804$ & $2,146,147$ & $12,085,548$ & $7,458,086$ & $2,045,266$ & $28,029,684$ \\
$\mathbf{2 0 2 0}$ & $2,084,018$ & $2,409,033$ & $2,223,242$ & $12,412,150$ & $7,780,318$ & $2,252,578$ & $29,161,338$ \\
* see text. & & & & & & &
\end{tabular}

Figure 4. 14. Urban Transit Ridership (Unlinked Trip) Forecasts: All Services Combined.

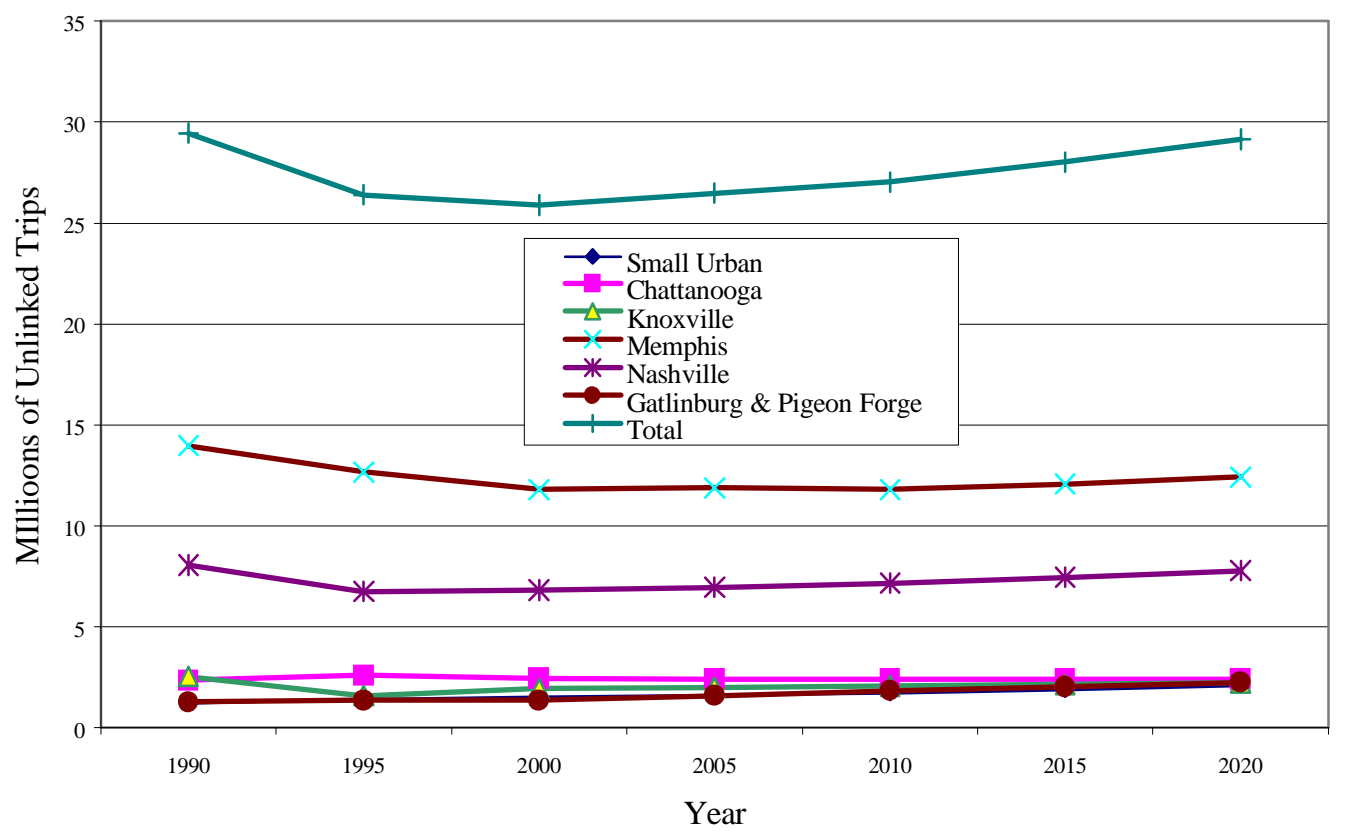

Dominated by fixed bus ridership, these transit ridership forecasts imply a gradual recovery of transit patronage across the State over the next two decades, getting back to the level experienced in 1990 and the late 1980's. A net increase of 3.27 million one way trips is projected 
Public Transit in Tennessee

between 2000 and 2020. This is equivalent to a $12.6 \%$ increase over the full two decades. This Baseline Ridership Forecast assumes a constant level of transit service (in terms of transit revenue vehicle miles operated) over the time period.

Table 4.24 and Figure 4.15 show this study's Baseline urban transit ridership forecasts for fixed route transit bus and trolley systems within the State. Table 4.25 and Figure 4.16 below show the same for demand responsive transit services. Each of these forecasts are based on the modeling procedures described in Chapter 3 of this report, and based on the population forecasts developed for the state by the Center for Business and Economic Research at the University of Tennessee (Murray, 1999).

Table 4.24 Baseline Urban Fixed Route Transit Ridership (Unlinked Trip) Forecasts.

\begin{tabular}{r|rrrrrrrr}
\multicolumn{1}{c|}{ Small Urban Chattanooga* Knoxville Memphis } & Nashville & \multicolumn{2}{c}{$\begin{array}{l}\text { Gatlinburg \& } \\
\text { Pigeon Forge }\end{array}$} & Total \\
\hline $\mathbf{1 9 9 0}$ & $1,186,545$ & $1,969,860$ & $2,517,738$ & $13,858,277$ & $8,076,944$ & $1,285,066$ & $28,894,430$ \\
$\mathbf{1 9 9 5}$ & $1,346,550$ & $2,086,493$ & $1,559,287$ & $12,024,311$ & $6,640,873$ & $1,362,567$ & $25,020,081$ \\
$\mathbf{2 0 0 0}$ & $1,390,208$ & $1,969,243$ & $1,911,695$ & $10,395,874$ & $6,718,082$ & $1,363,076$ & $23,748,178$ \\
$\mathbf{2 0 0 5}$ & $1,465,406$ & $1,933,706$ & $1,975,078$ & $10,468,196$ & $6,859,948$ & $1,600,430$ & $24,302,764$ \\
$\mathbf{2 0 1 0}$ & $1,589,944$ & $1,907,035$ & $2,037,824$ & $10,355,487$ & $7,072,281$ & $1,837,783$ & $24,800,353$ \\
$\mathbf{2 0 1 5}$ & $1,745,721$ & $1,894,363$ & $2,111,507$ & $10,598,248$ & $7,351,585$ & $2,045,094$ & $25,746,516$ \\
$\mathbf{2 0 2 0}$ & $1,934,277$ & $1,885,941$ & $2,187,769$ & $10,877,496$ & $7,670,941$ & $2,252,405$ & $26,808,830$ \\
$*$ see text below for discussion. & & & & & &
\end{tabular}

Figure 4.15 Baseline Urban Fixed Route Transit Ridership (Unlinked Trip)Forecasts.

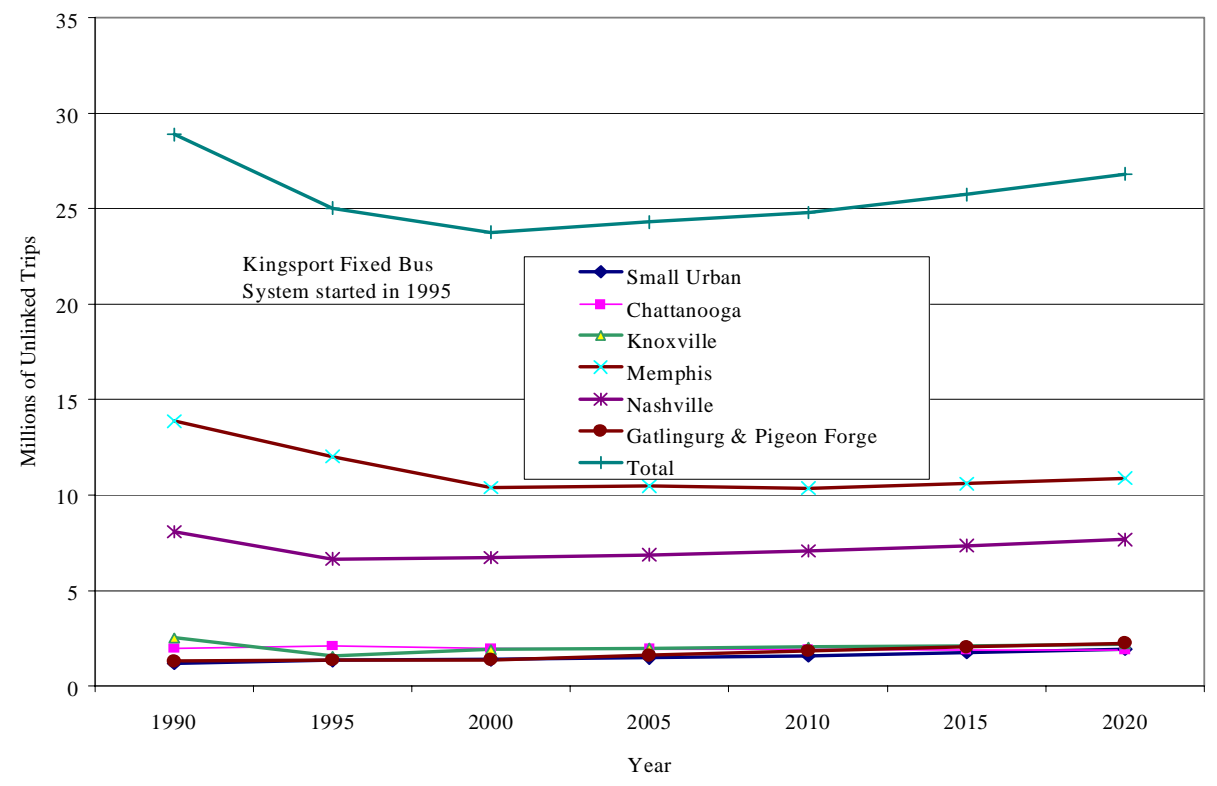


Public Transit in Tennessee

Table 4.25 Baseline Urban Demand Responsive Transit Ridership (Unlinked Trip) Forecasts.

\begin{tabular}{r|rrrrrr} 
& \multicolumn{1}{|c}{ Small Urban* } & \multicolumn{1}{l}{ Chattanooga Knoxville } & \multicolumn{1}{l}{ Memphis } & Nashville & \multicolumn{1}{l}{ Total } \\
\hline $\mathbf{1 9 9 0}$ & 27,687 & 22,445 & 26,095 & 119,451 & 0 & 195,678 \\
$\mathbf{1 9 9 5}$ & 66,450 & 31,100 & 32,827 & 132,698 & 109,138 & 372,213 \\
$\mathbf{2 0 0 0}$ & 133,369 & 61,764 & 64,949 & 147,749 & 106,060 & 458,741 \\
$\mathbf{2 0 0 5}$ & 139,303 & 62,421 & 69,926 & 151,186 & 104,158 & 469,422 \\
$\mathbf{2 0 1 0}$ & 142,751 & 62,990 & 71,921 & 154,675 & 112,360 & 485,551 \\
$\mathbf{2 0 1 5}$ & 146,284 & 63,476 & 73,806 & 158,126 & 115,477 & 496,933 \\
$\mathbf{2 0 2 0}$ & 149,914 & 63,882 & 75,579 & 161,558 & 118,595 & 508,298
\end{tabular}

* The small number of DR rides on the Gatlinburg system (typically less than 400 per year) are added into Small Urban.

Figure 4.16 Baseline Urban Demand Responsive Ridership (UnlinkedTrip)Forecasts.

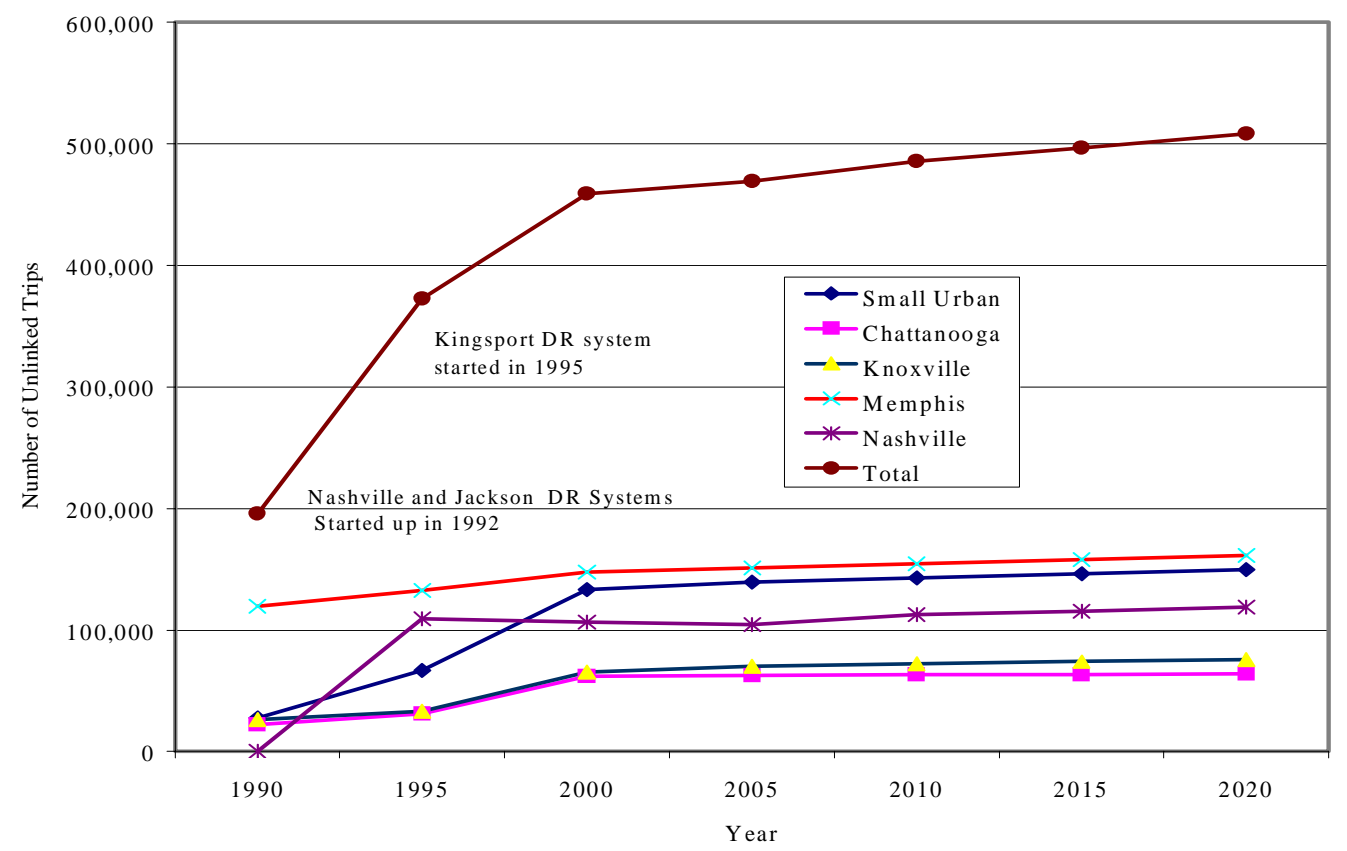

Small Urban transit district ridership shows a steady increase through year 2020. With the exception of Chattanooga, all of the larger urban transit systems also show gradual increases in ridership through the first two decades to the century. And the Chattanooga numbers were here subject to a limited population growth projection, including a city population taken to remain constant at 152,339 through the first two decades of the century (Murray, 1999). However, the 


\section{Public Transit in Tennessee}

Census 2000 estimate already puts the city's 2000 population at 155,554 , while other sources suggest that the region's urban population may indeed continue to grow. The ChattanoogaHamilton County Regional Planning Agency, for example, projected a population of 160,689 for the City of Chattanooga by 2020. This is for the population within the city's year 2000 boundary. Additional population growth has also been forecast for adjacent areas within the region's proposed new urban growth boundary (City of Chattanooga, December, 1999; see Chattanooga Urban Area Metropolitan Planning Organization, 2000). These recent projections suggest overall urbanized area population growth of around $2 \%$ per year through $2020-$ essentially mirroring the growth recorded for the city through the 1990's. If this is the case, then fixed route transit ridership in Chattanooga is also likely to see modest growth in line with this population increase (cf. Table 3.3). This also implies a conservative estimate in this report for the future year benefits recorded for this urban transit system.

Similarly, different population growth forecasts for each region will alter the results presented above. Among the Small Urban systems the tourist oriented transit systems of Pigeon Forge and Gatlinburg are expected to see the most significant growth on the assumption that their recent and quite rapid economic expansion continues. However, as Figure 4.16 shows, from a Statewide perspective the fastest growing sector of the urban transit market over the past decade has been its demand responsive (ADA assisting) ridership. This rate of growth is projected to slacken now that all of these systems have been operating within the State for a number of years, but to continue to grow as the size of each city's elderly urban population increases. While not large by comparison to fixed route patronage, these DR trips typically bear greater than average expenses in order to move needy riders longer than average distances.

Future Year Benefits Forecasts and Scenarios. Table 4.26 shows the results of translating and combining these fixed route and demand responsive ridership forecasts listed in Table 4.23 into 1998 dollar valued one-way transit trip benefits. This was done by taking the average district specific benefits per one-way trip for fixed route plus demand responsive systems and multiplying these per trip benefits by the forecast number of trips for each transit district. In doing so an adjustment was made to recognize the differences between linked trip benefits and unlinked trip benefits totals where these two trip totals differed within fixed route systems.

Table 4.26 Baseline Urban Transit Ridership Benefits Forecasts. (10\% foregone trips scenario, in 1998 dollars)

\begin{tabular}{r|rrrrrr} 
& Small Urban & Chattanooga* & Knoxville & Memphis & Nashville & \multicolumn{1}{c}{ Total } \\
\hline $\mathbf{2 0 0 0}$ & $12,729,037$ & $15,368,159$ & $10,959,525$ & $90,147,380$ & $43,725,590$ & $172,929,691$ \\
$\mathbf{2 0 0 5}$ & $13,636,442$ & $15,198,495$ & $11,330,372$ & $90,840,822$ & $44,624,439$ & $175,630,570$ \\
$\mathbf{2 0 1 0}$ & $14,948,258$ & $15,105,605$ & $11,689,722$ & $90,159,839$ & $46,035,138$ & $177,938,561$ \\
$\mathbf{2 0 1 5}$ & $16,488,716$ & $15,075,005$ & $12,110,498$ & $92,320,370$ & $47,845,378$ & $183,839,967$ \\
$\mathbf{2 0 2 0}$ & $18,311,779$ & $15,114,081$ & $12,545,534$ & $94,815,254$ & $49,912,569$ & $190,699,218$
\end{tabular}




\section{Public Transit in Tennessee}

Figure 4.17 shows this Baseline Benefits Forecast trend, along with three adjustments. The first adjustment (Scenario 2) was made in an effort to recognize the high probability of increased traffic congestion, notably within the State's four largest metropolitan areas. The second adjustment (Scenario 3) recognizes that significant reductions in the pollution costs associated with diesel fueled buses are expected to occur over the next two decades. Finally, Scenario 4 shows the results of combining both of these impacts within a single scenario. Table 4.27 contains these results.

Figure 4.17 Traffic Congestion and Air Quality Impacting Future Benefits Scenarios.

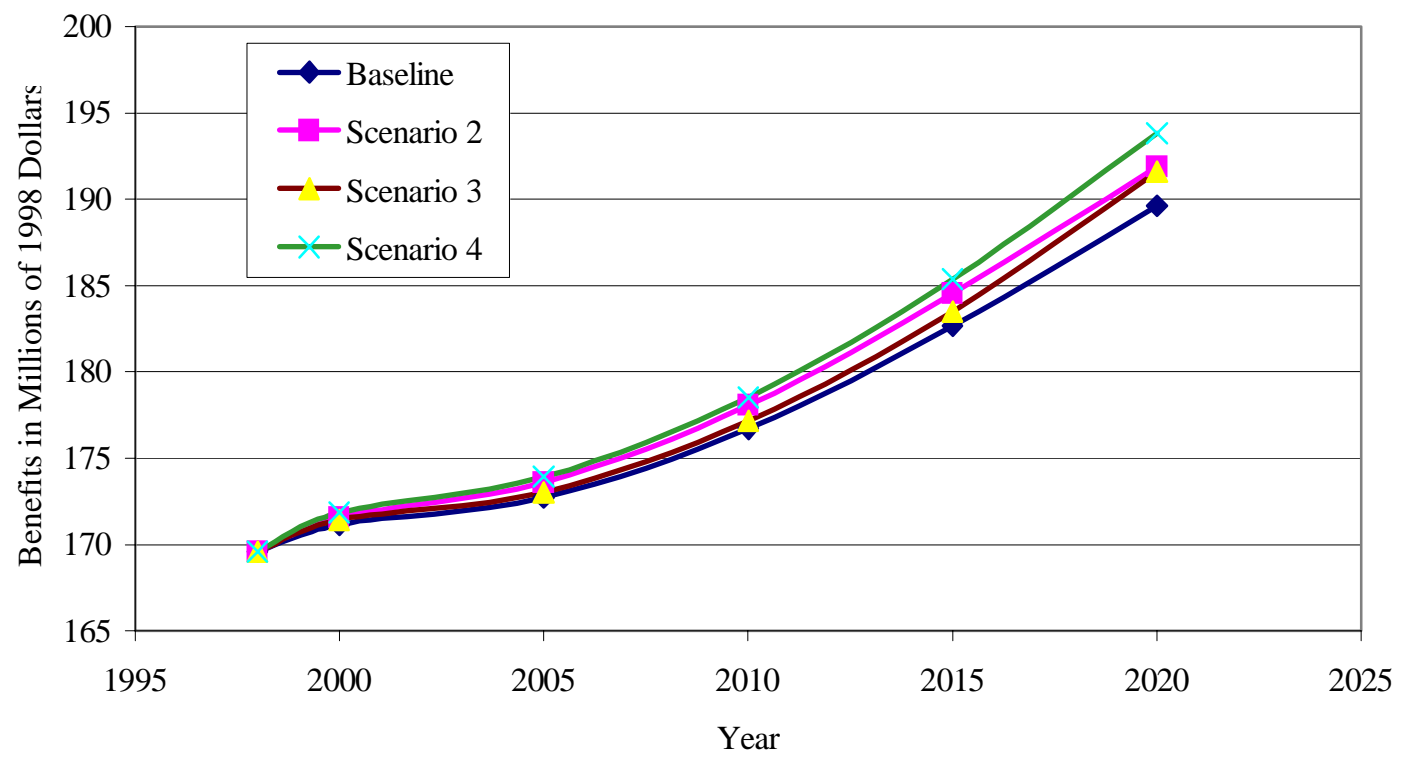

Table 4.27. Alternative Congestion Growth and Air Quality Improvement Scenarios.

\begin{tabular}{r|crrr} 
& Baseline & $\begin{array}{c}\text { Scenario 2 } \\
\text { Congestion Inc. }\end{array}$ & $\begin{array}{r}\text { Scenario 3 } \\
\text { Air Quality Imp. }\end{array}$ & $\begin{array}{r}\text { Scenario 4 } \\
\text { Combined 2\&3 }\end{array}$ \\
\hline $\mathbf{2 0 0 0}$ & $172,929,691$ & $173,376,247$ & $173,185,495$ & $173,632,050$ \\
$\mathbf{2 0 0 5}$ & $175,630,570$ & $176,537,630$ & $175,935,054$ & $176,842,114$ \\
$\mathbf{2 0 1 0}$ & $177,938,561$ & $179,317,032$ & $178,380,713$ & $179,759,183$ \\
$\mathbf{2 0 1 5}$ & $183,839,967$ & $185,738,884$ & $184,640,964$ & $186,539,882$ \\
$\mathbf{2 0 2 0}$ & $190,699,218$ & $192,964,451$ & $192,562,835$ & $194,828,069$
\end{tabular}

For Scenario 2 a simple congestion cost savings analysis was adopted. Congestion cost savings per unlinked transit trip were assumed to be $5 \%$ greater than under the Baseline scenario in 2005, and to increase by two additional 5\% per trip increments over the Baseline in 2010 and 2015 respectively. Finally, an additional 3\% savings per transit trip was assumed due to further 


\section{Public Transit in Tennessee}

congestion reduction in 2020. These values are arbitrary and meant to be illustrative. The result is a modest increase in net transit benefits from $\$ 6.70$ to $\$ 6.78$ per one-way trip, producing $\$ 2.26$ million in additional benefits of by 2020 .

Given also the tremendous uncertainty in the air quality impacts of transit on a statewide basis at this time, a similarly simple strategy was adopted for Scenario 3. Using recent evidence provided by the US EPA ${ }^{11}$, and recently published data on pollutant specific costs by DeLucchi (2000), an assumption was made that transit buses would significantly reduce their pollution costs over time, so that by 2020 they would be no more than $118 \%$ those of a typical gasoline powered automobile on a per vehicle mile basis. The results of this exercise are also shown in Figure 4.17. The result is again a modest per trip improvement in net overall benefits, from $\$ 6.70$ in 1998 to $\$ 6.74$ by 2020 . This results in an additional $\$ 1.9$ million in savings by 2020 , added to the just over \$2 million dollars estimated for the baseline scenario. Finally, Scenario 4 in Table 4.27 combines the above two results, to produce an estimated additional $\$ 4.1$ million in benefits per year by 2020. Given the considerable uncertainty inherent in both the study's congestion and air quality benefits, these numbers are viewed as useful largely as indicators of additional sensitivity in the Baseline forecasts made using the study's overall approach to benefits estimation.

11 The US EPA's (currently under development) Heavy Duty Diesel Emissions Model spreadsheet. 
Public Transit in Tennessee

\section{Rural Transit Systems.}

\subsection{Introduction.}

This chapter is divided into three major sections. Section 5.2 describes in quantitative terms the types of urban transit services offered by each of the State's eleven rural transit operating districts. Section 5.3 presents the results of this study's base year public transit benefits analysis. This analysis was carried out on data collected for fiscal year 1998-99, defined as the twelve month period from July 1, 1998 through June 30, 1999. The results of this analysis are used to develop a set of expected benefits per rural transit trip. These per trip benefits, broken down by rural transit system and type of transit service, were then applied to the set of rural ridership forecasts described in Chapter 3 of this report. These "baseline benefits forecasts" are presented in Section 5.4 below, for the forecast years of 2005, 2010 and 2020. All monetary values reported in tables and figures are in 1998 dollars.

\subsection{Rural Transit Services in the State.}

The State is broken up into eleven rural transit districts. Together these eleven districts cover all 95 Tennessee counties. All agencies provide some form of demand responsive transit, using 7 to 15 seat transit vans for the most part. Figure 5.1 shows the geographic location of each of these systems within the State.

\section{Figure 5.1 Tennessee Rural Public Transit District Service Areas.}

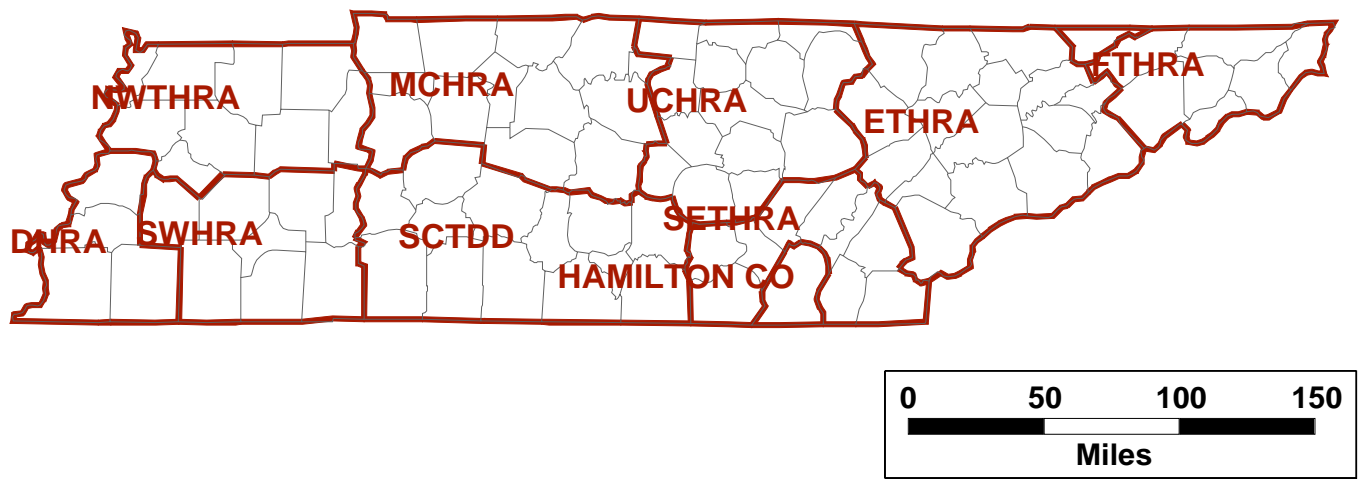

Key: Thick lines $=$ Rural Transit District Service Area Boundaries. Thin lines $=$ county boundaries. See Table 5.1 for District Names.

Table 5.1 summarizes the key transit demand and supply variables, based on Tennessee DOT reported data for FY 1998-99. 
Public Transit in Tennessee

Table 5.1 Rural Transit Demand and Supply Variables in FY 1998-99.

\begin{tabular}{l|rrr} 
& A) Transit Demand Variables & \\
\hline & \multicolumn{1}{|c}{ Rural Area } & Land Area & \multicolumn{1}{c}{ Transit } \\
Rural District* (Map Symbol) & Population & (Sq. Miles) & \multicolumn{1}{c}{ Trips ** } \\
\hline Delta HRA (DHRA) & 99,287 & 2,390 & 36,319 \\
Southwest HRA (SHRA) & 167,940 & 4,038 & 180,459 \\
Northwest Tennessee HRA (NTHRA) & 246,426 & 4,221 & 136,404 \\
Mid-Cumberland HRA (MCHRA) & 580,133 & 5,916 & 122,065 \\
South Central TN Devel. Dist.(SCTDD) & 367,294 & 6,415 & 120,795 \\
Southeast Tennessee HRA (SETHRA) & 239,537 & 3,238 & 98,114 \\
Hamilton County (Hamilton Co.) & 139,400 & 543 & 22,182 \\
Upper Cumberland HRA (UCHRA) & 282,550 & 4,998 & 150,821 \\
East Tennessee HRA (ETHRA) & 617,940 & 6,564 & 135,067 \\
Hancock County Transp. (Hancock Co.) & 6,805 & 222 & 3,537 \\
First Tennessee HRA (FTHRA) & 287,586 & 2,674 & 138,931 \\
\hline Total & $\mathbf{3 , 0 3 4 , 8 9 8}$ & $\mathbf{4 1 , 2 1 9}$ & $\mathbf{1 , 1 4 4 , 6 9 4}$
\end{tabular}

B) Transit Supply Variables

\begin{tabular}{l|rrr}
\hline Rural District & Fleet & Vehicle Miles & \# Counties \\
Size & *** & of Service & Served \\
\hline Delta HRA & 29 & 594,259 & 4 \\
Southwest HRA & 70 & 608,969 & 8 \\
Northwest Tennesse HRA & 74 & $1,464,840$ & 9 \\
Mid-Cumberland HRA & 50 & $1,087,441$ & 13 \\
South Central TN Devel. Dist. & 52 & 808,164 & 13 \\
Southeast Tennessee HRA & 52 & $1,131,761$ & 9 \\
Hamilton County & 9 & 203,556 & 1 \\
Upper Cumberland HRA & 76 & $1,763,888$ & 14 \\
East Tennessee HRA & 51 & $1,769,064$ & 16 \\
Hancock County Transp. & 4 & 33,566 & 1 \\
First Tennessee HRA & 62 & $1,785,098$ & 7 \\
Total & $\mathbf{5 2 9}$ & $\mathbf{1 1 , 2 5 0 , 6 0 6}$ & $\mathbf{9 5}$
\end{tabular}

* HRA $=$ Human Resources Agency. ** Transit trips refers here to one-way unlinked trips.*** Fleet Size refers here to average number of transit vehicles usually in service. 


\section{Public Transit in Tennessee}

In total, over 11.25 million miles of rural transit service was provided across the State's 42,219 square mile land area, in order to satisfy more than 1.14 million one way trips. The size of these rural transit districts varies a good deal, both in terms of rural populations, number of counties served, and geographic area of coverage. This variability is reflected in the size of the district specific transit fleets, which varied in size from 4 vehicles in the Hancock County operation, to 76 vehicles in the Upper Cumberland Human Resources Agency (HRA). In 1998, two of the eleven rural transit systems were county specific operations (Hamilton and Hancock Counties), eight of the eleven systems were operated by multi-county HRA's, and one system (South Central Tennessee) was operated by a multi-county Development District.

Based on the data in Table 5.1, Table 5.2 lists the annual number of transit trips and transit miles driven per vehicle in each of the State's 11 rural transit districts in fiscal year 1998-99.

Table 5.2 Rural Transit District Specific Service Characteristics. Fiscal Year 1998-99.

\begin{tabular}{l|rrr} 
Rural District & $\begin{array}{r}\text { Trips Per } \\
\text { Vehicle }\end{array}$ & $\begin{array}{c}\text { Transit Miles } \\
\text { Per Vehicle }\end{array}$ & $\begin{array}{c}\text { Average Miles } \\
\text { Per Trip }\end{array}$ \\
\hline Delta HRA & 1,252 & 20,492 & 16.36 \\
Southwest HRA & 2,578 & 8,700 & 3.37 \\
Northwest Tennessee HRA & 1,843 & 19,795 & 10.74 \\
Mid-Cumberland HRA & 2,441 & 21,749 & 8.91 \\
South Central TN Devel. Dist. & 2,323 & 15,542 & 6.69 \\
Southeast Tennessee HRA & 1,887 & 21,765 & 11.54 \\
Hamilton County & 2,465 & 22,617 & 9.18 \\
Upper Cumberland HRA & 1,984 & 23,209 & 11.70 \\
East Tennessee HRA & 2,648 & 34,688 & 13.10 \\
Hancock County Transp. & 884 & 8,392 & 9.49 \\
First Tennessee HRA & 2,241 & 28,792 & 12.85 \\
Total & $\mathbf{2 , 1 6 4}$ & $\mathbf{2 1 , 2 6 8}$ & $\mathbf{9 . 8 3}$
\end{tabular}

Given the difficulty of substituting some trips in rural areas if transit service is lost or reduced, a survey of current trip purposes and trip lengths was requested. Without the resources to carry out a ridership survey, a request was made by the Tennessee DOT in September of 1999 for each rural transit district operator's best estimates of why and how many trips were being taken in its vans. While a carefully sampled and collected survey would have been preferable, for the most part the drivers of these rural transit vans are very familiar with their patrons and the reasons for their riding transit. The results of this survey are summarized in Table 5.3. 
Public Transit in Tennessee

Table 5.3 Approximate Distribution of Trip Purposes by Rural Transit District.

\begin{tabular}{l|rrrrrrr} 
& \multicolumn{8}{|c}{ Families } \\
Rural Transit District & Medical & Nutrition & First & Work & DaycareGeneral & Other \\
\hline Delta HRA & 43.0 & 5.0 & 17.0 & 0.0 & 6.00 & 29.0 & 0.00 \\
Southwest HRA & 31.6 & 0.0 & 16.8 & 0.0 & 0.00 & 19.4 & 32.20 \\
Northwest Tennesse HRA & 49.0 & 8.0 & 12.0 & 3.0 & 8.00 & 19.0 & 1.00 \\
Mid-Cumberland HRA & 47.0 & 27.0 & 8.0 & 3.0 & 0.00 & 15.0 & 0.00 \\
SouthCentral TN Devel. Dist. & 15.0 & 10.0 & 15.0 & 0.0 & 0.00 & 60.0 & 0.00 \\
Southeast Tennessee HRA & 12.0 & 13.0 & 13.0 & 1.0 & 6.00 & 50.0 & 5.00 \\
Hamilton County & 18.0 & 15.0 & 0.0 & 4.0 & 46.00 & 17.0 & 0.00 \\
Upper Cumberland HRA & 60.0 & 2.0 & 10.0 & 2.0 & 0.00 & 26.0 & 0.00 \\
East Tennessee HRA & 48.0 & 5.0 & 20.0 & 2.0 & 3.00 & 19.0 & 3.00 \\
Hancock County Transp. & 50.0 & 0.0 & 10.0 & 0.0 & 0.00 & 40.0 & 0.00 \\
First Tennessee HRA & 15.7 & 22.3 & 4.1 & 2.9 & 2.57 & 7.0 & 45.39 \\
\hline \multicolumn{1}{c}{ Total } & $\mathbf{3 5 . 8}$ & $\mathbf{1 0 . 0}$ & $\mathbf{1 2 . 4}$ & $\mathbf{1 . 7}$ & $\mathbf{3 . 2 2}$ & $\mathbf{2 5 . 4}$ & $\mathbf{1 1 . 4 9}$
\end{tabular}

Notes:"Work" category requested as "Employment" trips in survey. "General" trips are mostly shopping trips. Southwest "Other" trips include 5.4\% Headstart and 2.0\% Foster Grandparent trips, both oriented towards child care/education.

The first three columns in Table 5.3 contain many of the State's public transit-supported, public service supplied "Program" trips. Many of these trips are public service, or "Program" supported rides, notably rides that fall under the State's TennCare medical assistance program ${ }^{1}$, as well as trips under its nutrition for the elderly program. Together these health related trips accounted for almost $46 \%$ of all trips taken in the State in 1998-99. Trips under the State's Families First Program ${ }^{2}$ accounted for another $12.4 \%$ of all trips taken over the course of the year. This Families First travel included rides to school, to job-training sites and a limited amount of daycare transportation. It also included a limited amount of subsidized direct rides to work sites, under the umbrella of the State's Welfare-to-Work services. After medical, the second largest trip purpose category is General Trips, which are "Non-Program" based, notably shopping trips.

\footnotetext{
${ }^{1}$ The State's TennCare program covers approximately 1.3 million Tennesseans, including those who are Medicaid eligible, along with uninsured and uninsurable populations. The program's website can be found at http://www.state.tn.us/tenncare/

2 In 1999 the State's Families First program was funded as part of the State's Temporary Assistance for Needy Families (TANF) federal welfare block grant. By October 1997 it had served approximately 44,000 clients. Statistics can be found at http://cber.bus.utk.edu/tdhs/ccs1997/Contents.htm
} 
Public Transit in Tennessee

What Table 5.3 also shows is the considerable variability in the trip purpose mix when viewed across different transit districts. Given their importance to transit patrons, the nature of current medical and job training program trips was explored further. Some key points that help to highlight the considerable value of these trips to the patrons involved are noted below.

Medical Trips. Figure 5.2 maps the distribution of medical trips by rural transit district in FY1998-99. The blue (darker) segments of each pie chart indicate the approximate percentage of rural transit trips being taken for medical purposes in each district in 1999. These services are typically billed on a per mile basis by the State's rural transit providers, and the growth in these trips during the late 1990's appears to have contributed to a significant increase in average rural transit trip lengths.

\section{Figure 5.2 Significance of Medical Trips by Rural Transit District.}

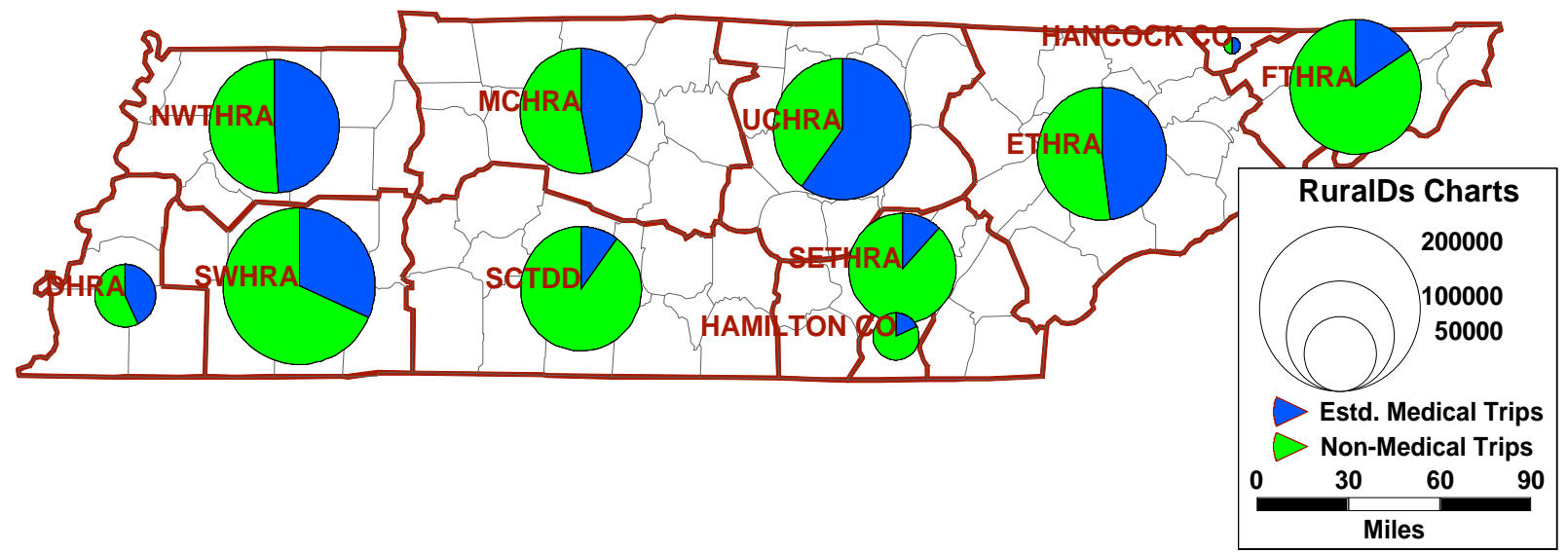

To accommodate these patrons many of the state's rural transit vehicles are fitted with wheelchair-lifts and other ADA-required characteristics for assisting disabled and elderly patrons. Table 5.4 shows the number and percentage of one way trips taken by patrons with disabilities, who require some assistance in traveling, including patrons using wheelchairs. Table 5.4 shows the number and percentage of trips requiring wheelchair assisted travel, and trips by patrons with disabilities who are not in wheelchairs. Some 8 percent of all trips require wheelchair assistance statewide, while wheelchair plus other disabled patrons' trips represented $31.6 \%$ of all rural transit trips in the state from July 1,1998 through June 30, 1999.

Table 5.5 adds a further important perspective - that of elderly patron travel in rural areas. Elderly patrons are defined here as transit riders over 60 years of age. Just over half of all rural transit trips in the state in 1998-99 were made by elderly patrons. These patrons accounted for $53.6 \%$ of all rides taken in fiscal year 1998-99: one of the reasons why there are so many medical trips being supported by the State's current rural transit services. 
Public Transit in Tennessee

Table 5.4 Wheelchair Trips and Riders with Disabilities Trips by Rural Transit District. Fiscal Year 1998-99.

\begin{tabular}{l|rrrrr} 
Rural Transit District & $\begin{array}{l}\text { Total Trips } \\
\text { on Transit }\end{array}$ & $\begin{array}{c}\text { Disabled } \\
\text { Client Trips* }\end{array}$ & $\begin{array}{r}\text { \% Trips by } \\
\text { Disabled }\end{array}$ & $\begin{array}{r}\text { Wheelchair } \\
\text { Trips }\end{array}$ & $\begin{array}{r}\text { \% Wheelchair } \\
\text { Trips }\end{array}$ \\
\hline Delta HRA & 36,319 & 17,864 & 49.2 & 11 & 0.3 \\
Southwest HRA & 180,459 & 23,198 & 12.9 & 14415 & 10.7 \\
Northwest Tennesse HRA & 136,404 & 21,471 & 15.7 & 7883 & 8.0 \\
Mid-Cumberland HRA & 122,065 & 56,227 & 46.1 & 16712 & 12.0 \\
South Central TN Devel. Dist. & 120,795 & 64,933 & 53.8 & 11245 & 8.2 \\
Southeast Tennessee HRA & 98,114 & 23,287 & 23.7 & 11171 & 7.4 \\
Hamilton County & 22,182 & 10,557 & 47.6 & 6780 & 3.8 \\
Upper Cumberland HRA & 150,821 & 51,756 & 34.3 & 13980 & 11.5 \\
East Tennessee HRA & 135,067 & 61,875 & 45.8 & 5139 & 14.1 \\
Hancock County Transp. & 3,537 & 11 & 0.3 & 630 & 2.8 \\
First Tennessee HRA & 138,931 & 30,871 & 22.2 & 2505 & 2.1 \\
\hline Total & $\mathbf{1 , 1 4 4 , 6 9 4}$ & $\mathbf{3 6 2 , 0 5 0}$ & $\mathbf{3 1 . 6}$ & $\mathbf{9 0 4 7 1}$ & $\mathbf{7 . 9}$ \\
*Disabled client trips include wheelchair client trips. & & & &
\end{tabular}

Table 5.5 Rural Transit Trips by Elderly Patrons. Fiscal Year 1998-99.

\begin{tabular}{l|rrrr}
\multicolumn{1}{c}{} & \multicolumn{2}{r}{ Trips by } & $\begin{array}{c}\text { \% } \\
\text { by }\end{array}$ & T i s s \\
Rural Transit District & $\begin{array}{l}\text { Total Trips } \\
\text { on Transit }\end{array}$ & $\begin{array}{c}\text { Elderly } \\
(>\mathbf{6 0})\end{array}$ & $\begin{array}{l}\text { Elderly } \\
(>\mathbf{6 0})\end{array}$ \\
\hline Delta HRA & 36,319 & 18,189 & 50.1 \\
Southwest HRA & 180,459 & 49,164 & 27.2 \\
Northwest Tennesse HRA & 136,404 & 74,046 & 54.3 \\
Mid-Cumberland HRA & 122,065 & 74,437 & 61.0 \\
South Central TN Devel. Dist. & 120,795 & 83,458 & 69.1 \\
Southeast Tennessee HRA & 98,114 & 57,451 & 58.6 \\
Hamilton County & 22,182 & 17,667 & 79.6 \\
Upper Cumberland HRA & 150,821 & 91,158 & 60.4 \\
East Tennessee HRA & 135,067 & 62,005 & 45.9 \\
Hancock County Transp. & 3,537 & 2,417 & 68.3 \\
First Tennessee HRA & 138,931 & 83,038 & 59.8 \\
\hline Total & $\mathbf{1 , 1 4 4 , 6 9 4}$ & $\mathbf{6 1 3 , 0 3 0}$ & $\mathbf{5 3 . 6}$
\end{tabular}


Public Transit in Tennessee

Job Training/Welfare to Work Trips: Figure 5.3 shows the result of aggregating and then mapping county level data compiled from the State's Families First Group Characteristics Survey of October 1997. At that time, Tennessee had 54,762 Families First cases, representing 142,674 people. Of 13,223 adults deemed eligible for assistance by the Tennessee Department of Health and Human Services under this same program, 6,200, or almost 47\% had received some form of transportation assistance (including subsidized taxi rides) by October 1997. Some $90 \%$ of those receiving assistance had income below the poverty threshold, with most program recipients receiving Food Stamps. Nearly all of the assistance group "caretakers" ${ }^{3}$ in the program at that time were female (95.8 percent), with a high percentage being young mothers.

Figure 5.23 shows the results of aggregating vehicle ownership data from the rural county to the Rural Transit District level.

Figure 5.3 Car Ownership in Families First Assistance Groups by Rural Transit District.

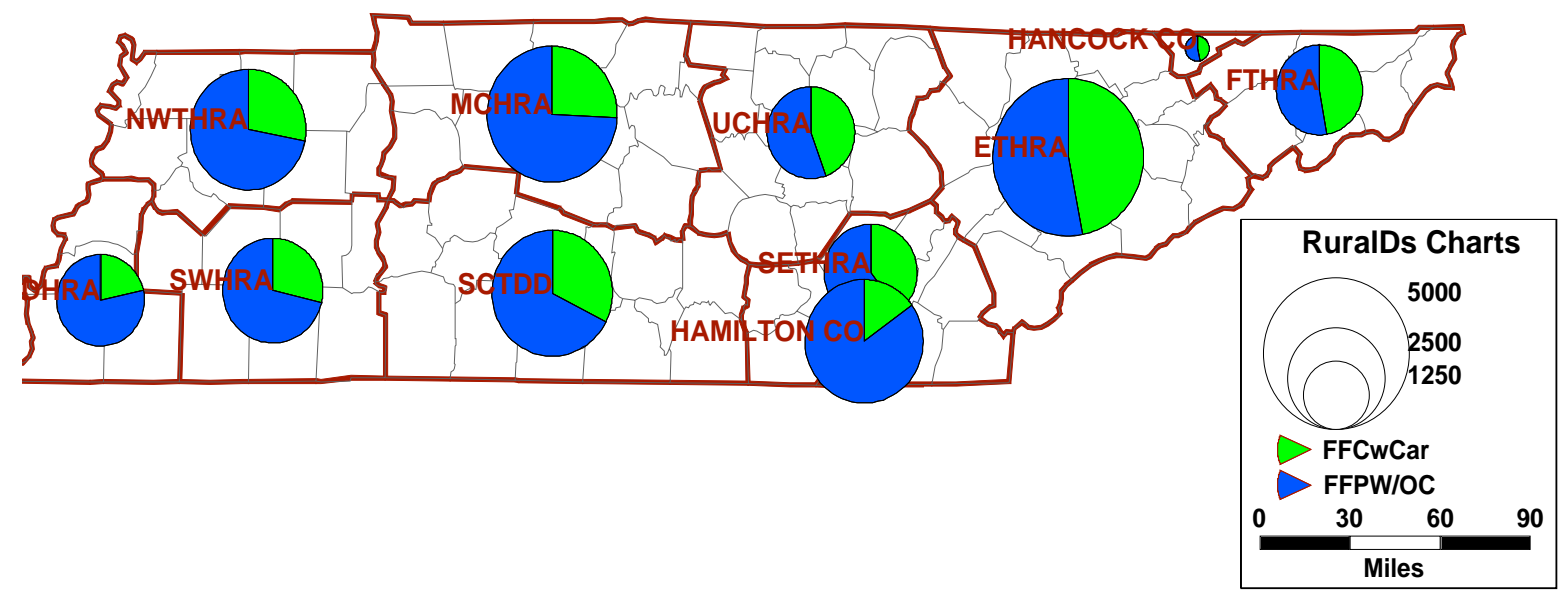

The blue (darker) colored wedge in each pie chart represents the percentage of assistance groups who did not own a car. Car ownership among this assistance group as a whole was estimated by the survey to be just under $46 \%$. This is roughly consistent with the data shown in Table 5.6, in which just over $45 \%$ of a sample survey of program recipients indicated that they did not drive themselves to their school/job training/job sites. Over one quarter of respondents were reliant on friend/relatives for a ride, while a small percentage of respondents $(3.4 \%)$ indicated no transportation options available.

${ }^{3}$ Caretakers are defined as those people who are the principle information provider to the State's Department of Health and Human Services (DHS): usually a parent. For more information see the following web site: http://cber.bus.utk.edu/tdhs/ccs1997/ExecSum.htm 
Public Transit in Tennessee

Table 5.6 Mode of Adult Transport to Work, School or Training in the Families First Program.

\begin{tabular}{l|rrrrrr}
\multirow{2}{*}{ Transportation } & \multicolumn{2}{|c}{ Total } & \multicolumn{3}{c}{ Urban } & Rural \\
\cline { 2 - 7 } & Adults & Percent & Adults & Percent & Adults & Percent \\
\hline Drive myself & & & & & & \\
Ride with friend/relative & 222 & 37.5 & 110 & 28.0 & 112 & 55.9 \\
Bus, 1 or fewer transfers & 140 & 23.6 & 87 & 22.3 & 53 & 26.3 \\
Bus, 2 or more transfers & 110 & 18.6 & 105 & 26.9 & 5 & 2.5 \\
Walk & 50 & 8.4 & 46 & 11.8 & 3 & 1.7 \\
Other & 30 & 5.1 & 25 & 6.4 & 5 & 2.5 \\
No transportation & 19 & 3.2 & 7 & 1.7 & 12 & 5.9 \\
Taxi & 15 & 2.5 & 8 & 2.0 & 7 & 3.4 \\
& 7 & 1.1 & 3 & 0.9 & 3 & 1.7 \\
\hline Total & & & & & & \\
\hline
\end{tabular}

(Source: October 1997 data reported by the Tennessee Department of Health and Human Services) ${ }^{4}$

Missing observations: 90 Total, 61 Urban, 29 Rural . Includes all eligible adults (some assistance groups have 2).

Excludes child-only assistance groups.

\subsection{Base Year Rural Transit Benefits Estimation.}

\subsubsection{Mobility-Based Accessibility Benefits.}

Mobility benefits resulting from the provision of existing rural transit services were computed on a one way trip basis, as the cost savings that would result from:

i) trip cost savings -- the monetary cost savings (in terms of vehicle operating, alternative fare and parking costs) to transit users when compared to the costs of making the same trip by an alternative mode;

ii) foregone travel savings -- the net cost to current transit riders of trips not taken due to loss of transit service

Rate structures for specific types of rural transit trip vary by transit district, with a variety of fares customized to match specific programs, and with travel usually billed on a per trip or on a mixed per trip and per mile basis. A large percentage of the revenue of each district comes from pre-determined contract rides, such as pick-up and delivery at hospitals and other public service facilities (see Table 5.7).

\footnotetext{
${ }^{4}$ These data tables can be can be found at http://cber.bus.utk.edu/tdhs/ ccs1997/ Contents.htm
} 
Public Transit in Tennessee

Table 5.7 Rural Transit Trips Operated on Contract in Fiscal Year 1998-99

\begin{tabular}{l|rrr} 
Rural Transit District & Total Trips & Contract Trips & \% Contract \\
\hline Delta HRA & 36,319 & 1,295 & 36.6 \\
Southwest HRA & 180,459 & 85,108 & 63.0 \\
Northwest Tennesse HRA & 136,404 & 35,228 & 35.9 \\
Mid-Cumberland HRA & 122,065 & 67,903 & 48.9 \\
South Central TN Devel. Dist. & 120,795 & 60,790 & 44.6 \\
Southeast Tennessee HRA & 98,114 & 47,102 & 31.2 \\
Hamilton County & 22,182 & 163,795 & 90.8 \\
Upper Cumberland HRA & 150,821 & 60,538 & 49.6 \\
East Tennessee HRA & 135,067 & 25,780 & 71.0 \\
Hancock County Transp. & 3,537 & 13,505 & 60.9 \\
First Tennessee HRA & 138,931 & 26,393 & 21.8 \\
\hline Total & $\mathbf{1 , 1 4 4 , 6 9 4}$ & $\mathbf{5 8 7 , 4 3 7}$ & $\mathbf{5 1 . 3}$
\end{tabular}

Table 5.8 shows that between contract fares and general purpose rider fares, the average revenue collected per one way rural transit trip in FY 1998-99 trip fell between \$2.79 in rural Hamilton county to $\$ 10.89$ in Hancock county, where $70 \%$ of trips were reported to be to destinations out of the county, and where half of the trips are quite long distance medical trips (cf Table 5.3).

Table 5.8 Average Revenue Dollars Per Transit Trip by Transit District.

\begin{tabular}{l|r} 
Rural Transit District & Revenue/Trip (\$) \\
\hline Delta HRA & 9.74 \\
Southwest HRA & 4.78 \\
Northwest Tennesse HRA & 5.32 \\
Mid-Cumberland HRA & 4.80 \\
South Central TN Devel. Dist. & 2.45 \\
Southeast Tennessee HRA & 7.29 \\
Hamilton County & 2.79 \\
Upper Cumberland HRA & 6.04 \\
East Tennessee HRA & 6.29 \\
Hancock County Transp. & 10.89 \\
First Tennessee HRA & 5.84
\end{tabular}

Trip Cost (Alternative Mode) Savings. A value of 44.5 cents per vehicle mile was assumed to be the average cost of a current transit patron using a private automobile, with the same cost assigned to friend or relative-supplied private vehicle trips. Taxi trips, if assumed taken, were 


\section{Public Transit in Tennessee}

assigned a value of $\$ 1.50$ per mile. Parking costs were assumed to be zero if substituted for rural transit trips. Congestion benefits were also assumed to be negligible for rural transit trips.

Foregone Travel Savings. Foregone trips are trips that would be lost (i.e. not taken) because current transit riders have no good, cost-effective alternative to public transit. For the most part these are persons without access to a private vehicle, without a license to drive, or who for other reasons, such as health reasons, cannot or prefer not to drive. The value (or cost) of a foregone trip is tied to its trip purpose. In computing base year benefits, work-based foregone trips were evaluated at a default value of $\$ 29.17$ based on 250 paid working days per year and a salary of $\$ 14,000$. Families First trips were valued at $\$ 25.46$, based on a wage rate of $\$ 6.12$ reported by a University of Memphis study of that program's job recipients. ${ }^{5}$ Nutrition trips were valued at a cost of $\$ 22.43$ per trip, which was the average cost of an at home medical visit for the State in 1998. "General" and "Other" trips, including shopping and personal business trips, were assigned a default, and probably conservative, value of \$25 per trip. Medical trips were handled as follows. If a person cannot or will not travel due to loss of transit service, and assuming that medical services need to be provided, two options were considered for fulfilling the need that originated the transit trip. One is to have that person visited by a qualified medical professional. The other is for the patient to move into, or near to, a health care facility. Both options can be costly. Data was obtained from the Tennessee State Department of Health in order to compute representative costs per visit for both at home visits and for visits to health care facilities. ${ }^{6}$

Table 5.9 provides the values used in this study. For at- home visits, Home Health Agency Data for fiscal year 1998-99 (Tennessee Department of Health, 2000) were used to compute average at home visit costs in each rural transit district. This data had to be aggregated from the individual health care agency level, as well as averaged across a number of different visit categories ${ }^{7}$. In computing estimated savings per one way transit trip, the costs shown in Table 5.9 are divided by 2 to capture the need for a return trip. It is also assumed that the costs of providing the at-home medical service includes the cost (and also the mileage involved) in a round trip visit by the medical staff persons involved. More significant is the proportion of medical trips that would involve at home versus nursing facility care. For Baseline benefits estimation it was assumed that with loss of public transit service $50 \%$ of these medical trips would be handled by home visits and $50 \%$ by trips (using taxi, friends/relatives, other means)to

${ }^{5}$ http://www.state.tn.us/humanserv/statisti.html

${ }^{6}$ For the case of visits to facilities, these costs may not be exactly the ones we want if we are trying to reproduce relocation costs on a cost per trip basis. However, they would appear to be of the right order of magnitude.

${ }^{7}$ The available categories of care are skilled nursing, home health aids, speech therapy, occ. therapy, physical therapy, medical social service, home-maker and other. Averaging was based on annual number of visits by each type. 


\section{Public Transit in Tennessee}

medical facilities. The average statewide cost of a lost (one way) transit trip for medical purposes was estimated under these assumptions to be just under $\$ 47$. With an assumed $80 \%$ at home visit rate, this average medical trip value falls to $\$ 32.25$, with an $80 \%$ nursing home visitation rate it rises to $\$ 61.73$. None of these scenarios capture some of the costs of permanent relocation that may be required for public transit patrons who cannot afford to live at home and also spend time in nursing care. For this reason the baseline medical cost savings used here are likely to be conservative.

Table 5.9 Representative Costs Per Medical Visit by Rural Transit District.

\begin{tabular}{l|rr} 
Rural Transit District & $\begin{array}{r}\text { Average } \\
\text { Nursing Home } \\
\text { Costs /Day }\end{array}$ & $\begin{array}{r}\text { Average } \\
\text { At Home } \\
\text { Visit Costs }\end{array}$ \\
\hline Delta HRA & 139.79 & 55.53 \\
Southwest HRA & 164.00 & 65.14 \\
Northwest Tennesse HRA & 135.77 & 74.07 \\
Mid-Cumberland HRA & 130.79 & 67.29 \\
South Central TN Devel. Dist. & 146.96 & 56.88 \\
Southeast Tennessee HRA & 112.77 & 76.27 \\
Hamilton County & 87.00 & 38.24 \\
Upper Cumberland HRA & 133.06 & 55.04 \\
East Tennessee HRA & 116.84 & 70.01 \\
Hancock County Transp. & 145.05 & 69.26 \\
First Tennessee HRA & 171.09 & 70.86 \\
\hline Statewide Average & $\mathbf{1 4 3 . 1 0}$ & $\mathbf{4 4 . 8 6}$
\end{tabular}

Empirical Results. Mobility based accessibility benefits, as defined in this report, dominate the State's rural public transit benefits, and this dominance increases as the percentage of foregone trips grows. The high percentage of medical and employment related trips, many of the former taken by elderly citizens, provide the rural public transit system's major benefits. Table 5.10 presents the base year Baseline rural transit mobility benefits used to forecast future year benefits in this present study. This table is based on a $25 \%$ foregone trip scenario, i.e. one in every four current rural transit trips would not be made if public transit service was no longer provided. Sensitivity of benefit estimates to both the number and valuation placed on foregone trips is clearly seen by comparing the figures in Table 5.10 with those in Table 5.11 below. Table 5.11 results are based on an assumption that all trips currently taken will be made by some other means (private automobile, friend/relative, taxi, walk/cycle). That is, there are no foregone trip benefits, only benefits resulting from differences in transit versus alternative mode travel costs. 
Public Transit in Tennessee

Table 5.10 Rural Mobility-Based Accessibility Benefits: 25\% Foregone Trips Scenario.

\begin{tabular}{l|rrr} 
& $\begin{array}{r}\text { User Cost } \\
\text { Savings }\end{array}$ & $\begin{array}{r}\text { Foregone } \\
\text { Trip Savings }\end{array}$ & $\begin{array}{r}\text { Total Mobility } \\
\text { Benefits }\end{array}$ \\
\hline Delta HRA & 94,615 & 336,853 & 431,468 \\
Southwest HRA & 325,579 & $1,434,987$ & $1,760,566$ \\
Northwest Tennessee HRA & 378,543 & $1,220,997$ & $1,599,540$ \\
Mid-Cumberland HRA & 343,803 & $1,253,256$ & $1,597,059$ \\
South Central TN Devel. Dist. & 191,458 & 869,244 & $1,060,702$ \\
Southeast Tennessee HRA & 141,219 & 324,580 & 465,799 \\
Hamilton County & 96,673 & 170,822 & 267,494 \\
Upper Cumberland HRA & 142,175 & $1,496,622$ & $1,638,797$ \\
East Tennessee HRA & 234,037 & $1,225,971$ & $1,460,008$ \\
Hancock County Transp. & 14,600 & 24,850 & 39,450 \\
First Tennessee HRA & 373,645 & 993,853 & $1,367,499$ \\
\hline Total & $\mathbf{2 , 3 3 6 , 3 4 7}$ & $\mathbf{9 , 3 5 2 , 0 3 4}$ & $\mathbf{1 1 , 6 8 8 , 3 8 2}$
\end{tabular}

Table 5.11 Rural Mobility-Based Accessibility Benefits: Zero \% Foregone Trips Scenario.

\begin{tabular}{l|rrr} 
& User Cost & Foregone & Total Mobility \\
Rural Area & Savings & Trip Savings & Benefits \\
\hline Delta HRA & 244,092 & 0 & 244,092 \\
Southwest HRA & 721,428 & 0 & 721,428 \\
Northwest Tennesse HRA & 746,583 & 0 & 746,583 \\
Mid-Cumberland HRA & 653,549 & 0 & 653,549 \\
South Central TNDevel. Dist. & 353,839 & 0 & 353,839 \\
Southeast Tennessee HRA & 426,579 & 0 & 426,579 \\
Hamilton County & 149,532 & 0 & 149,532 \\
Upper Cumberland HRA & 493,005 & 0 & 493,005 \\
East Tennessee HRA & 595,445 & 0 & 595,445 \\
Hancock County Transp. & 32,303 & 0 & 32,303 \\
First Tennessee HRA & 768,579 & 0 & 768,579 \\
\hline Total & $\mathbf{5 , 1 8 4 , 9 3 5}$ & $\mathbf{0}$ & $\mathbf{5 , 1 8 4 , 9 3 5}$
\end{tabular}




\section{Public Transit in Tennessee}

The difference in these two scenarios is a more than doubling of estimated mobility benefits in the $25 \%$ foregone trips case. Given the age, income levels, and also medical/disability problems faced by a significant percentage of the State's current rural ridership, the zero percentage foregone trips scenario represented in Table 5.11 appears to be an unrealistic one.

Table 5.12 shows the results of further sensitivity tests. In Part A of this table the statewide results from the $0 \%$ and $25 \%$ foregone trips scenarios are compared to a $50 \%$ and $100 \%$ foregone trips scenario. The mobility benefits are listed in the second column of the table. Parts B through E are based on the study's Baseline Scenario of $25 \%$ foregone rural trips. (In this and all other parts of the table the study's Baseline Scenario is highlighted for ease of reference). Part B shows the results of varying the percentage of foregone medical trips allocated to at home (versus at nursing facility) visits. Part $\mathrm{C}$ shows the effects of varying the lost employment trip benefits based on varying the average wage from a low of $\$ 12,000$ per year to a high of $\$ 18,000$ per year. Part D shows the results of varying the average cost of a foregone shopping or "other" (typically discretionary travel) trips, from a low of $\$ 20$ to a high of $\$ 40$ per one-way trip. Parts $\mathrm{E}$ and $\mathrm{F}$ show the results of varying the average automobile cost per mile savings, from the baseline assumption of 44.5 cents per mile, to a high of 53.1 cents per mile and a low of 32.5 cents per mile (see the discussion in Chapter 2). Eliminating the unrealistic 0\% and 100\% foregone trip scenarios, the total value of rural transit use benefits falls within the range $\$ 10.9$ million to $\$ 17.9$ million. The other principal finding from this sensitivity analysis is the importance of the foregone trips percentage in the determination of rural transit benefits when compared to other trip cost savings parameters.

\subsubsection{Air Quality and Safety Benefits.}

The air quality and safety benefits estimated for rural transit statewide are also presented in Table 5.12. These estimates were developed using the same methods as described in Chapters 2 and 4 of this report. As expected, both of these transportation externality benefits remain quite small for rural transit. Both noise and traffic congestion impacts from rural transit operations were judged to be negligible in either direction on a district-wide or statewide basis. Total Rural Transit Use benefits, equal to mobility plus externality benefits, are shown in the far right column for each scenario. Note that negative safety and air quality benefits shown for the $50 \%$ and $100 \%$ foregone trips scenarios result from significant loss of transit vmt relative to the current transit ridership baseline. That is, they are traded off against the much higher costs of lost mobility. In the case of the unrealistic $100 \%$ foregone trips scenario these negatives therefore equate to the baseline emissions and safety costs associated with current rural transit operations within the State. The dominance of mobility-induced accessibility benefits over these other transit use impacts within the rural areas of the State is clear. 
Public Transit in Tennessee

Table 5.12 Baseline and Alternative Transit Use Benefit Scenarios.

A) Four Foregone trip Percentage Scenarios:

\begin{tabular}{c|rrrr} 
Scenario & \multicolumn{1}{c}{ Mobility } & \multicolumn{1}{c}{ Safety } & \multicolumn{1}{c}{ Air Quality } & \multicolumn{1}{c}{ Total } \\
\hline 0\% Foregone Trips & $5,184,935$ & 853,035 & 208,476 & $6,246,446$ \\
25\% Foregone Trips & $\mathbf{1 1 , 6 8 8 , 3 8 2}$ & $\mathbf{3 3 9 , 4 0 3}$ & $\mathbf{6 9 , 1 6 5}$ & $\mathbf{1 2 , 0 9 6 , 9 4 9}$ \\
50\% Foregone Trips* & $18,191,828$ & $-174,230$ & $-70,147$ & $17,947,452$ \\
100\% Foregone Trips* & $31,198,720$ & $-1,201,494$ & $-348,769$ & $29,648,458$
\end{tabular}

B) Three Medical Cost Savings Scenarios (25\% Foregone Trips)

\begin{tabular}{l|ccrc}
\multicolumn{1}{c|}{ Scenario } & Mobility & Safety & Air Quality & Total \\
\hline 80\% At Home Medical & $10,648,314$ & 339,403 & 69,165 & $11,056,881$ \\
50\% At Home Medical & $\mathbf{1 1 , 6 8 8 , 3 8 2}$ & $\mathbf{3 3 9 , 4 0 3}$ & $\mathbf{6 9 , 1 6 5}$ & $\mathbf{1 2 , 0 9 6 , 9 4 9}$ \\
20\% At Home Medical & $12,728,449$ & 339,403 & 69,165 & $13,137,017$
\end{tabular}

C) Four Average Earnings Scenarios (25\% Foregone Trips)

\begin{tabular}{|c|c|c|c|c|}
\hline Scenario & Mobility & Safety & Air Quality & Total \\
\hline$\$ 12,000$ Average Wage & $11,668,191$ & 339,403 & 69,165 & $12,076,758$ \\
\hline$\$ 14,000$ Average Wage & $11,688,382$ & 339,403 & 69,165 & $12,096,949$ \\
\hline$\$ 16,000$ Average Wage & $11,708,572$ & 339,403 & 69,165 & $12,117,140$ \\
\hline$\$ 18,000$ Average Wage & $13,051,027$ & 339,403 & 69,165 & $13,459,594$ \\
\hline
\end{tabular}

D) Four Shopping and Other Trip Cost Saving Scenarios (25\% Foregone Trips)

\begin{tabular}{|c|c|c|c|c|}
\hline Scenario & Mobility & Safety & Air Quality & Total \\
\hline \$20/Shopping/Other Trip & $11,247,627$ & 339,403 & 69,165 & $11,656,194$ \\
\hline \$25/Shop/Other Trip & $11,688,382$ & 339,403 & 69,165 & $12,096,949$ \\
\hline \$30/Shop/Other Trip & $12,129,136$ & 339,403 & 69,165 & $12,537,703$ \\
\hline \$40/Shop/Other Trip & $13,010,645$ & 339,403 & 69,165 & $13,419,213$ \\
\hline
\end{tabular}

E) Three Alternative Automobile Cost Savings Scenarios (25\% Foregone Trips)

\begin{tabular}{l|ccrc}
\multicolumn{1}{c|}{ Scenario } & Mobility & Safety & Air Quality & Total \\
\hline 32.5c/mile auto costs & $10,515,238$ & 339,403 & 69,165 & $10,923,805$ \\
$\mathbf{4 4 . 5 c / m i l e ~ a u t o ~ c o s t s ~}$ & $\mathbf{1 1 , 6 8 8 , 3 8 2}$ & $\mathbf{3 3 9 , 4 0 3}$ & $\mathbf{6 9 , 1 6 5}$ & $\mathbf{1 2 , 0 9 6 , 9 4 9}$ \\
53.1c/mile auto costs & $12,529,135$ & 339,403 & 69,165 & $12,937,702$
\end{tabular}

F) Three Alternative Automobile Cost Savings Scenarios (0\% Foregone Trips)

\begin{tabular}{l|cccc}
\multicolumn{1}{c|}{ Scenario } & Mobility & Safety & Air Quality & Total \\
\hline 32.5c/mile auto costs & $3,620,744$ & 853,035 & 208,476 & $4,682,254$ \\
$\mathbf{4 4 . 5 c / m i l e ~ a u t o ~ c o s t s ~}$ & $\mathbf{5 , 1 8 4 , 9 3 5}$ & $\mathbf{8 5 3 , 0 3 5}$ & $\mathbf{2 0 8 , 4 7 6}$ & $\mathbf{6 , 2 4 6 , 4 4 6}$ \\
53.1c/mile auto costs & $6,305,939$ & 853,035 & 208,476 & $7,367,450$
\end{tabular}




\section{Public Transit in Tennessee}

\subsubsection{Economic Benefits From Transit Supply.}

As described in Chapter 2, and further discussed in Chapter 4 of this report, economic benefits from the supply of public transit services were computed in terms of the estimated number of jobs created and associated economic value added in each rural transit district as a result of a) federal, state and local expenditures on urban transit in 1998 and b) the estimated benefits resulting from the transportation efficiencies which the presence of these urban transit systems encourage within each region. As in the urban case, benefits were computed on a transit district by district basis then summed to obtain statewide benefits.

Table 5.13 shows how money was spent on rural public transit in the State in FY 1998-99, and where that money came from, summed across all eleven rural transit districts. The majority of economic impacts came through operating and administrative expenditures.

\begin{tabular}{c|c|c} 
\$Spent on: & & \\
\hline Administration & Operating & \multicolumn{1}{|c}{ Capital } \\
$2,393,217$ & $10,079,382$ & $2,012,853$ \\
& & \\
\hline \$ Spent by: & & \\
\hline Local & State & Federal \\
Expenditures & Expenditures & Expenditures \\
$7,431,017$ & $2,983,207$ & $4,071,229$
\end{tabular}

Table 5.13 Rural Public Transit Expenditures in FY 1998-99.

Tables 5.14 and 5.15 summarize the main finding from the study's economic impacts analysis, measured in terms of a) jobs generated in the State, and b) dollars of Value Added to the State's various regional economies. In total, expenditures on rural transit within the State are estimated to support some 529 jobs, worth over $\$ 11.6$ million in direct, indirect and induced economic value added to the State in FY 1998-99. This represents just over $86 \%$ of the economic impacts reported in Table 5.15, with just over $47 \%$ of such impacts attributed to local funding (including fares and other revenues taken in by the transit agency), $20.7 \%$ to federal funding and $18.3 \%$ to State supplied funds. Growth-supporting transportation efficiency impacts are estimated to have added a further $\$ 1.9$ million dollars in economic activity and to have supported some 70 additional jobs statewide in FY 1998-99, equivalent to $13.9 \%$ of the $\$ 13.5$ million in gross economic impact reported in Table 5.14 
Public Transit in Tennessee

Table 5.14 Economic and Employment Impacts of Rural Transit Supply.

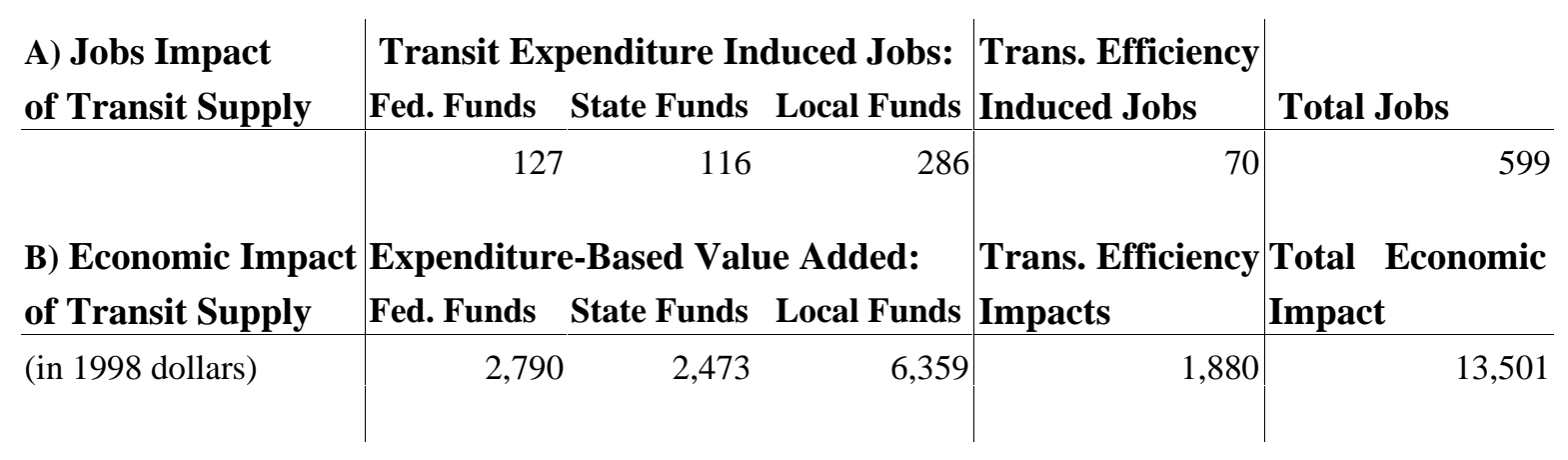

Table 5.15 Economic Impacts of Rural Transit: Three Perspectives.

\begin{tabular}{|c|c|c|c|c|c|}
\hline \multirow[b]{2}{*}{ Benefits Context } & \multicolumn{2}{|c|}{ Expenditure-Based } & \multicolumn{2}{|c|}{ Trans. Efficiency-Based } & \multirow{2}{*}{$\begin{array}{l}\text { Total Economic } \\
\text { Impacts (000’s\$) }\end{array}$} \\
\hline & $\begin{array}{l}\mathbf{V} \underset{\text { a }}{\mathbf{l}} \\
\text { Added }^{*}\end{array}$ & Jobs & Benefits (\$000’s) & Jobs & \\
\hline Gross Impacts & 11,621 & 529 & 1,880 & 70 & 13,501 \\
\hline Local Area Benefits & 5,263 & 243 & 1,880 & 70 & 7,143 \\
\hline Net State Benefits & 2,790 & 116 & 1,880 & 70 & 4,670 \\
\hline
\end{tabular}

*All \$ values reported in the table are in thousands of 1998 dollars .

The top row of data in Table 5.15 reproduces these gross economic benefit figures. The next two rows of this table provide two other perspectives. Row two lists what we term the "local area benefits". These are benefits viewed from a specific urban transit district's perspective, to which the benefits accrue largely as a result of the federal and state funds brought into that district, plus the additional transportation efficiency gains induced by the transit operations made possible by the combined effects of all of these three expenditure sources combined. It is estimated that in total such investments support some $\$ 7.1$ million worth of local economic activity, which translates into some 313 additional jobs statewide. Row three of Table 5.15 provides a third, State support agency perspective. From the State's perspective it can be argued that only those expenditure-induced impacts resulting from federal funds offer a net benefit, since within-State generated funds represent a form of transfer payment from one pot of money to another. Netting out only those economic activity gains derived from the federally provided funds only yields a value added total of $\$ 4.67$ million dollars to the State in FY 1998-99. In employment terms this was estimated to represent some 186 net jobs added statewide. It is these net economic statewide benefits, i.e. benefits less any obvious within-district or within-State transfer payments, that are used in the benefits forecasts presented later in this chapter.

As also noted in Chapter 4, the above results are most sensitive to the assumed $4 \%$ annualized average increment in economic growth associated with transportation efficiency induced benefits, since increasing or decreasing this percentage results in a proportional change in the 
Public Transit in Tennessee

estimated transportation efficiency benefits e.g. increasing the transportation efficiency induced growth rate from $4 \%$ to $6 \%$ increases the economic efficiency impacts reported in the tables below by $50 \%$ (from $\$ 1.88$ million to $\$ 2.82$ million).

\subsection{Summary of Base Year Benefits.}

Table 5.16 summarizes this study's estimates of base year (FY 1998-99) benefits, estimated in 1998 dollars. As expected, mobility benefits dominate the rural transit findings, with results very sensitive to the amount of foregone travel and to the values assigned to those trips. Safety benefits may be undervalued for this scenario, while air quality benefits in this base year may be a little overvalued. The highlighted 25\% Foregone Trips Scenario is used in section 5.5 below as the base year Baseline for forecasting future rural ridership benefits.

\section{Table 5.16 Rural Transit Benefits Summary Table.}

\begin{tabular}{|c|c|c|c|c|c|c|}
\hline \multirow[b]{2}{*}{ Scenario } & \multicolumn{2}{|c|}{ A) Transit Use Benefits } & \multicolumn{3}{|c|}{ B) Transit System Benefits } & \multirow[b]{2}{*}{ Total } \\
\hline & Mobility & Safety & $\begin{array}{c}\text { Air } \\
\text { Quality }\end{array}$ & $\begin{array}{c}\text { Expenditure } \\
\text { Based }\end{array}$ & $\begin{array}{c}\text { Efficiency } \\
\text { Based }\end{array}$ & \\
\hline $0 \%$ Foregone Trips & $5,184,935$ & 853,035 & 208,476 & $2,789,726$ & $1,879,861$ & $10,916,032$ \\
\hline $25 \%$ Foregone Trips & $11,688,382$ & 339,403 & 69,165 & $2,789,726$ & $1,879,861$ & $16,766,535$ \\
\hline $50 \%$ Foregone Trips* & $18,191,828$ & $-174,230$ & $-70,147$ & $2,789,726$ & $1,879,861$ & $22,617,038$ \\
\hline $100 \%$ Foregone Trips $*$ & $31,198,720$ & $-1,201,494$ & $-348,769$ & $2,789,726$ & $1,879,861$ & $34,318,044$ \\
\hline
\end{tabular}

* See text for explanation on negative safety and air quality benefits in these tables.

Table 5.17. Base Year, Baseline Rural Transit Benefits Statistics.

\begin{tabular}{l|rr|r|r}
$\begin{array}{l}\text { Net State Rural Public Transit } \\
\text { Benefits: }\end{array}$ & $\begin{array}{l}\text { \$ Per Trip } \\
\text { Benefits }\end{array}$ & & $\begin{array}{l}\text { \$ Per Vehicle } \\
\text { Mile Benefits }\end{array}$ & \multicolumn{2}{|l}{$\begin{array}{l}\text { P Per Passenger } \\
\text { Mile Benefits }\end{array}$} \\
\hline User Mobility Benefits & $\$ 10.21$ & $\$ 1.04$ & $\$ 0.86$ \\
Congestion Mitigation & $\$ 0.00$ & $\$ 0.00$ & $\$ 0.00$ \\
Safety Benefits & $\$ 0.30$ & $\$ 0.03$ & $\$ 0.03$ \\
Air Quality Benefits & $\$ 0.06$ & $\$ 0.01$ & $\$ 0.01$ \\
Expenditure Multiplier Benefits & $\$ 2.44$ & $\$ 0.25$ & $\$ 0.21$ \\
Transportation Efficiency Benefits & $\$ 1.64$ & $\$ 0.17$ & $\$ 0.14$ \\
\hline Total Estimated Benefits: & $\$ 14.65$ & $\$ 1.49$ & $\$ 1.24$
\end{tabular}

Using the transit demand and supply data presented earlier in this chapter (Tables 5.2 and 5.3), Table 5.17 shows a number of rural transit benefits statistics for this base year Baseline scenario. 
Public Transit in Tennessee

The scenario yielded a statewide averaged one-way net rural transit trip benefit of $\$ 14.65$. This is equated to a $\$ 1.49$ net benefit per transit vehicle mile of service and a $\$ 1.24$ net benefit per passenger mile of service. This $\$ 14.65$ figure is near the middle range of rural transit benefits that appear possible based on the methods and sensitivity analyses discussed above. Combining the sensitivities from both the Transit Use and Transit Supply branches of the benefits tree, this range is estimated to fall somewhere between $\$ 9.5$ and $\$ 20.6$ per one- way transit trip. Finally, this $\$ 14.65$ per trip figure compares favorably with estimated rural transit expenditures in FY $1998-99$ of $\$ 12.65$ per trip.

\subsection{Rural Transit Benefits Forecasts.}

Recent Ridership Trends. Figure 5.4 shows the recent history of rural ridership in the State, on an annual basis from fiscal year 1990-91 through fiscal year 1999-2000 (data compiled by Tennessee DOT).

Figure 5.4 Rural Transit Ridership in the 1990's.

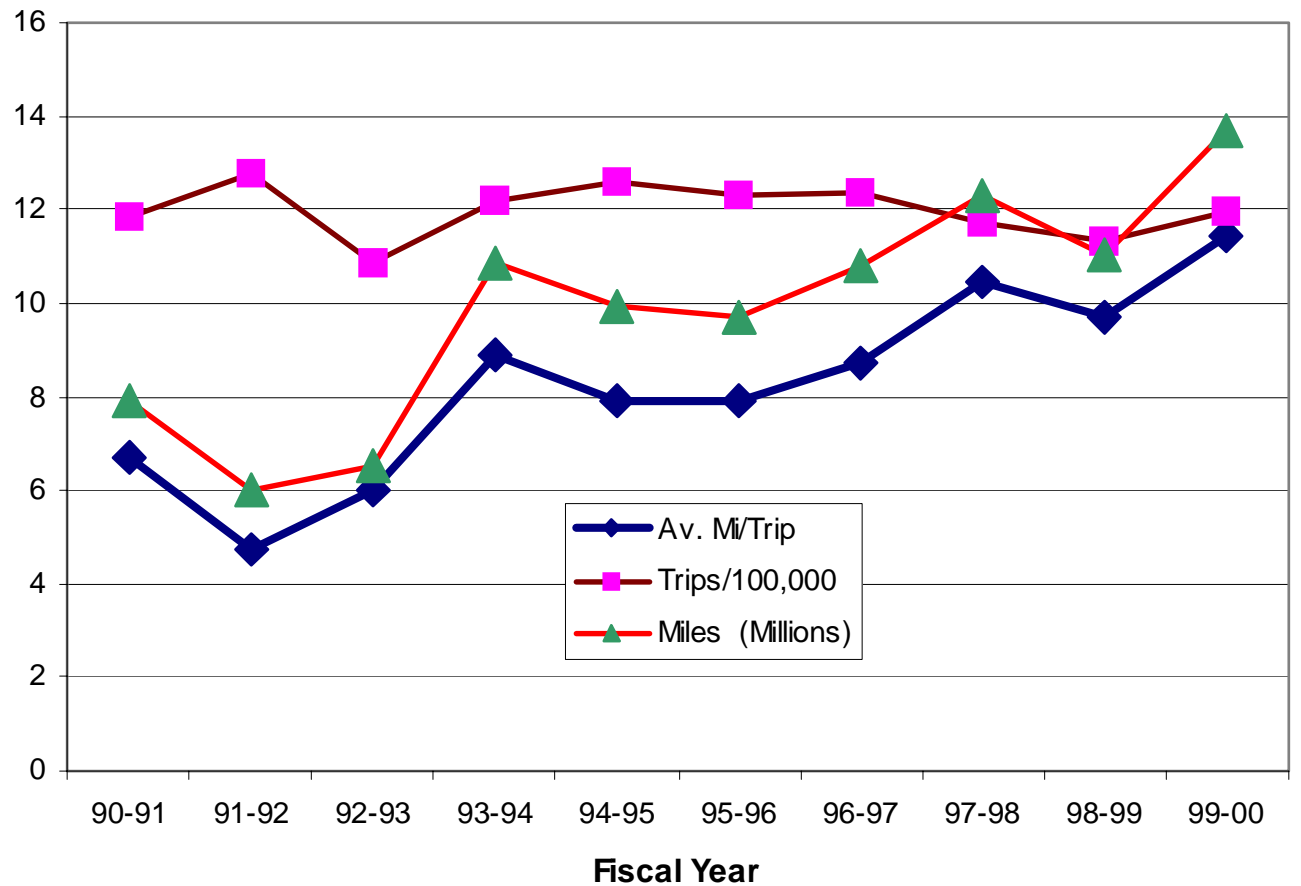

While ridership statewide remained very stable throughout the decade of the nineties, the number of transit vehicle service miles grew over this same period by more than $72.4 \%$ : from 7.9 million miles to almost 13.7 million miles. As a result, the average length of a rural transit trip increased from 6.7 miles to 11.5 miles over the course of the decade. An explanation for this 


\section{Public Transit in Tennessee}

includes an increase in the percentage of medical trips, as TennCare and other patients have become a more important part of the State's rural transit market. In doing so, given the relatively flat ridership trend, these trips seem to have replaced lost patrons who on average took shorter trips. In developing rural transit ridership and associated benefits forecasts special attention was therefore paid to the estimated $48.6 \%$ of trips made for medical or nutrition purposes, as well as to the $53.6 \%$ of trips made in fiscal year 1998-98 by elderly patrons.

Projecting Potential Ridership Populations. Estimates were made of the number of future riders based on the number of people projected to have the necessary ridership characteristics in specific rural districts in future years. County level projections by the Center for Business Economics at the University of Tennessee were adopted as the starting point and acted as the "official" control totals for the subsequent analysis (Murray, 1999). Baseline future population forecasts in each transit district were first generated by summing over the forecast populations in every county within that rural district and holding current district boundaries constant throughout the forecasts for this purpose. To develop a set of potential transit market subpopulations, estimates of several population cohorts, or sub-groups, were then developed (at the county level) using 1990 Census data. This included county level data from "CensusCounts $98 ", 8$ and also data from the Bureau of the Census's Internet site. Two proprietary population projection series were also used to develop alternative, cohort specific population projections -the National Planning Association ${ }^{9}$ and Woods \& Poole ${ }^{10}$ data series. In doing so it was assumed that the county land area provided in the 1990 Census will remain static for the period of the projections. For the rural transit ridership forecasts presented below, using the model described in Chapter 3 of this report, these projections were further broken down at the county and transit district level into 1) the number of people in the 16-64 and also over 60 age groups, 2) the number of people in different income groups, including the number of persons existing at or below the poverty level, and 3) the number of persons who are mobility limited.

Rural Ridership Forecasts. Table 5.18, Part A shows the results of applying the rural transit forecasting model described in Chapter 3 of this report to two different ridership scenarios. Each forecast was applied to the population projections developed for this study for each of the eleven individual rural transit districts. Given the difficulty experienced in forecasting individual rural transit district ridership more than a few years into the future, these forecasts were aggregated to the statewide level.

\footnotetext{
${ }^{8}$ Decisionmark Corp, CensusCounts98, Cedar Rapids, Iowa

${ }^{9}$ National Planning Association Data Services, Regional Economic Projection Series (REPS), February, 1999, Washington, D.C.

${ }^{10}$ Woods \& Poole Economics, Inc. CEEDS: State Profiles, Washington, D.C. 1998
} 
Public Transit in Tennessee

Table 5.18 Baseline and An Additional Rural Ridership \& Benefits Forecast.

A) Number of Unlinked One-way Passenger Trips:

\begin{tabular}{r|rr} 
Year & Baseline & Scenario 2 \\
\hline 1990 & $1,184,826$ & $1,184,826$ \\
1995 & $1,228,478$ & $1,228,478$ \\
1998 & $1,144,694$ & $1,144,694$ \\
2005 & $1,080,297$ & $1,205,107$ \\
2010 & $1,178,684$ & $1,458,758$ \\
2015 & $1,278,349$ & $1,749,700$ \\
2020 & $1,383,239$ & $2,087,956$
\end{tabular}

\section{B) Estimated Net Statewide Benefits in 1998 Dollars:}

\begin{tabular}{r|cr}
\multicolumn{1}{|l|}{ Year } & Baseline & Scenario 2 \\
\hline 1998 & $16,766,535$ & $16,766,535$ \\
2005 & $15,823,301$ & $17,651,415$ \\
2010 & $17,264,393$ & $21,366,686$ \\
2015 & $18,724,203$ & $25,628,165$ \\
2020 & $20,260,546$ & $30,582,660$
\end{tabular}

The Baseline forecast referred to in Table 5.18 assumes that there will be no change in the level of rural transit vehicle miles of service (VMS) offered during the forecast period. That is, the 1998-99 number of vehicle miles of public transit service will be maintained throughout the twenty year forecast period. Scenario 2, in contrast, offers a more aggressive scenario, a VMS increase proportional to the increases (at the five year intervals shown) in the forecast number of elderly rural residents in the State. Under the Baseline forecast, ridership is predicted to fall a little and remain roughly level until around 2005, when it is expected to increase at an average rate of around $1.7 \%$ per year, reaching 1.38 million one-way trips by 2020 . Under Scenario 2 rural ridership grows slowly, at around $0.75 \%$ per year, until 2005 . Then it increases more rapidly at around $4 \%$ per year, as the numbers of elderly patron grow, reaching 2.08 million trips by year 2020. Figure 5.5 plots these two forecasts along with State DOT supplied data on the number of unlinked rural transit trips from fiscal years 1990-91, 1995-96 and 1998-99.

Both of these statewide rural transit forecasts were applied to a set of average statewide benefit figures based on the above described benefits analysis. Part B of Table 5.18 shows the results of applying the Baseline benefits forecast of $\$ 14.65$ per rural transit trip to these forecast trip totals. Baseline benefits are estimated to increase from some \$16.7 million in 1998 to \$20.3 million, in constant 1998 dollars, over the next two decades. Scenario 2 benefits are forecast to grow to nearly $\$ 20.4$ million by 2010 , increasing to $\$ 30.6$ million by 2020 . 
Public Transit in Tennessee

Figure 5.5 Baseline and An Additional Rural Ridership Forecast.

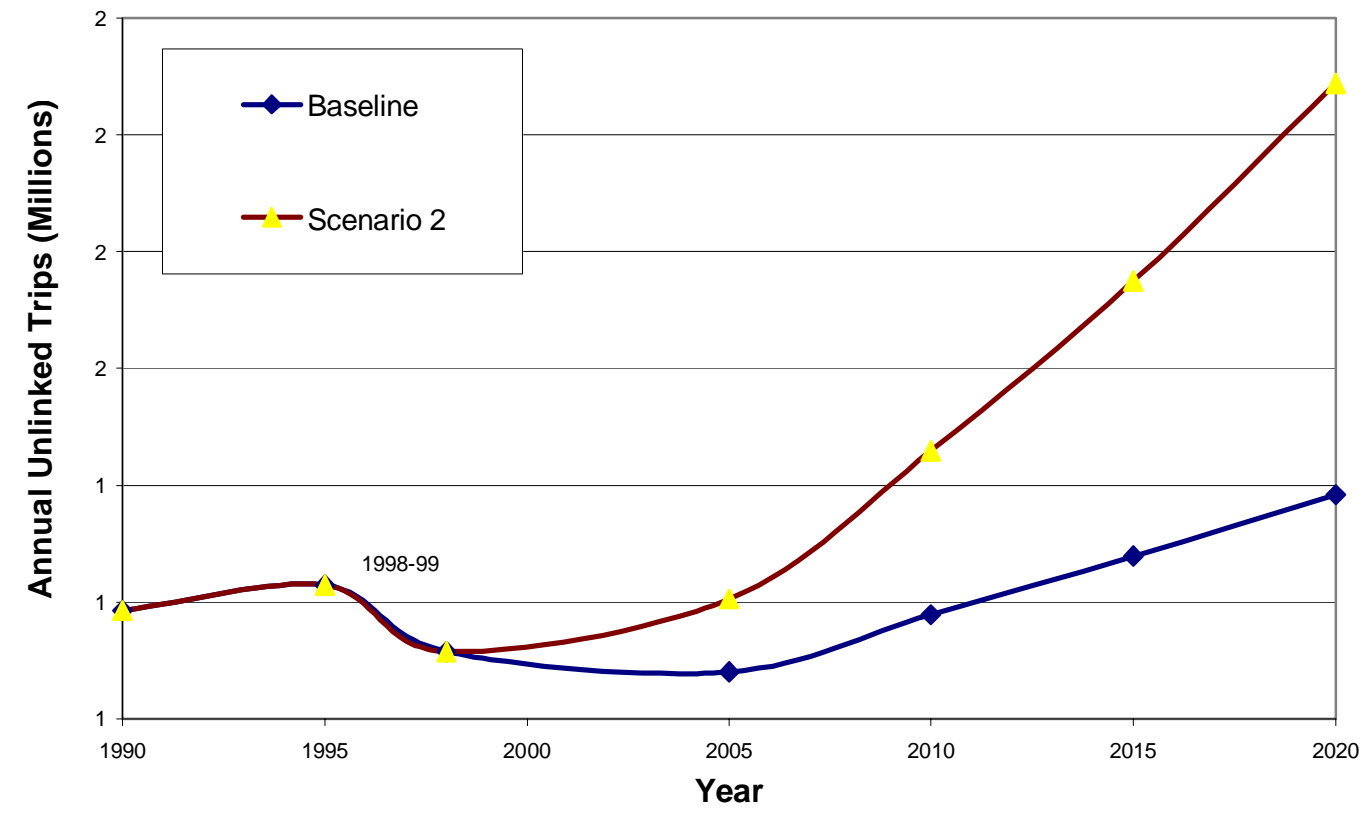


Public Transit in Tennessee

\section{Recommendations For Future Analysis.}

\subsection{Introduction.}

An important product from this study is the benefits analysis framework and spreadsheet software developed in support of it. The idea behind this framework was to create a process by which State transit planners could add to and improve on the results of this present study by adding to and improving the current database contained within it. Different assumptions will lead to different results as the sensitivity analyses described in Chapters 4 and 5 of this report clearly demonstrate. As such this project should be seen as a starting point from which to begin a gradual improvement in the data underlying future public transit benefits assessment studies. It is hoped that the approach taken will be able to support future data collection exercises that are reasonable in terms of their costs to collect, and subsequently to apply. In so doing the following section describes briefly where better data appears most likely to improve the estimation of current and future year transit benefits.

\subsection{Some Data Elements Needing Additional Attention.}

This study has found that both urban and rural public transit systems in Tennessee offer significant benefits to not only transit riders but also to the local economies where transit services are provided. This result was obtained despite a current inability, largely due to data limitations, to quantify a number of seemingly genuine but difficult to measure impacts. In order to estimate the benefits/impacts for which quantitative data was available, recourse was made to a large number of different data sources, not all local in nature and not all as reliable as would have been desired. Future work using the benefits analysis and ridership forecasting framework developed by this study should seek to improve on these current data sources. Most of this effort should be devoted to those data elements which impact the estimation of mobility-based accessibility benefits, since these produced the majority of benefits found in this study. In particular, the following data would be most useful, and most likely obtained from suitably derived and collected samples of urban and rural transit riders:

1.Origin-destination trip data and/or passenger trip length data (i.e. in addition to already collected transit vehicle trip length data) for rural and small urban transit systems.

2. Data on the number of patrons using the different transit services offered, by trip purpose (in addition to the current data on number of transit trips taken).

3. Data on the number of patrons who are currently "transit dependent"(i.e. have no short term alternative to public transit for the trips they wish to take).

4. Data on the options available to, and likely responses of, current riders to a loss or gain 


\section{Public Transit in Tennessee}

(reduction or increase) in the level of current transit services. Again, this data would be most useful if such responses could be differentiated by trip purpose. A "response" here should include not only the choice of alternative modes of transport, but also the possibility of not making a trip. A third response to consider here is the possibility that some elderly, disabled, unhealthy or remotely located patrons would need to relocate their residence in order to at least maintain their current quality of life.

In particular, combining the data obtained under bullets 2 through 4 above should allow a movement away from a trip-based evaluation approach per se, and produce a more reliable, patron based assessment, from which to apply the sort of "travel plus other societal impacts" approach at the root of this present study.

Given the high percentage of elderly riders using Tennessee public transit vehicles, notably in rural areas, additional effort is also warranted in the area of safety analysis. As the so-called "baby-boom" generation moves into its sixties and seventies, the number of older Tennesseans will increase both numerically and as a proportion of the total population of the State. These elderly members of society show no signs currently of slowing down their travel activity patterns. Alternatives to solo driving are likely to become more pressing for some of these elderly travelers in the future.

Finally, with the results of the 2000 Decennial Census soon to be available, updates to some of the transit district population forecasts generated by this study should prove useful. 
Public Transit in Tennessee

\section{Bibliography.}

\section{A. Transit Benefits References.}

Aschauer, D.A. (1991) Transportation Spending and Economic Growth. The Effects of Transit and Highway Expenditures. Report prepared for the American Public Transit Association. September 1991.

Beimborn, E., et al (1993) Measurement of Transit Benefits. Urban Mass Transit Administration. US Department of Transportation. Washington D.C. 20590.

Berk and Associates, et al (1998) Economic Analysis for ther Intercity Passenger Rail Program for Washington State. 1998-2020. Report prepared for the Public Transportation and Rail Office, Washington State Department of Transportation. September 1998.

Burchell, R., and Davis, J., Downs, A., Gall, M., Morre, T., Phillips, H., Seskin, S., and Shad, N. (1998) The Costs of Sprawl-Revisited. Transit Cooperative Research Program Report 3.Transportation Research Board, National Academy Press, Washington DC. 20418.

Brodsky, D.M. (1997) Survey of Public Opinion Regarding Transportation Issues. Chattanooga Area Regional Transportation Authority, Chatttanooga, Tennessee. October, 1997.

Burkhardt, J.E. et al (1998) Assessment of The Economic Impacts of Rural Public. Transit Cooperative Research Program Report 34. Transportation Research Board, National Academy Press, Washington D.C. 20418.

Cambridge Systematics, Inc..et al (1996) Measuring and Valuing Transit Benefits and Disbenefits. Summary. Transit Cooperative Research Program Report 20. Transportation Research Board, National Academy Press, Washington D.C. 20418.

Cambridge Systematics, Inc. et al (1998) Economic Impact Analysis of Transit Investments: Guidebook For Practitioners. Transit Cooperative Research Program Report 35. Transportation National Academy Press, Washington D.C. 20418.

Cambridge Systematics, Inc. et al (1999) Using Public transportation to Reduce the Economic, Social, and Human Costs of Personal Immobility. Transit Cooperative Research Program Report 49. Transportation National Academy Press, Washington D.C. 20418.

Cambridge Systematics, Inc. and Glen Weisbrod, Inc (199) Public Transportation and the Nation's Economy. American Public Transit Association Pul;bication, Washington D.C. 20005. 
Public Transit in Tennessee

Camph, D.H. (1997) Dollars and Sense. The Economic Case for Public transportation in America. Report by Aldaron Inc. for the Campaign for Efficient Passenger Transportation, c/o Citizen Action, Washington D.C.. 20036.

Cervero, R. (1999) Estimating Ridership and Economic Benefits of Coordinated Transit and Urban DevelopmentA Heuristic Approach. National Planning Conference, Seattle WA, 1999. http//www.asu.edu/caed/proceedings99/AVIN/PAPER2.HTM

Cervero, R. and Kockelman, K. (1996) Travel Demand and the 3Ds: Density, Diversity, and Design. Transportation Research Digest 2, 3199-219.

CGA Consulting Services, Inc. (1998) The Economic Impact of Public Transportation in the State of Tennessee. Draft Report submitted to the Tennessee Department of Transportation, Office of Public transportation. October, 1998.

Chatterjee, A. and Sinha, K..C. (1975) Distribution of Benefits of Public Transportation. Transportation Engineering Journal 101 :505-519.

Chatterjee, A. and Wegmann, F.J. (1983) New Fixed-Route Bus Service in A Small Urban Area. Transportation Research Record 931: 115-119.

Corrales, M., Grant, M., and Chan, E. (1996) Indicators of the Environmental Impacts of Transportation. Highway, Rail, Aviation and Marine Transport. Office of Policy, Planning and Evaluation, United States Environmental Protection Agency. EPA-230-R-96-009. Washington D.C. 20460.

Crain \& Associates, Inc., et al (1999) Using Public Transportation to Reduce the Economic, Social and Human Costs of Personal Mobility. Transit Cooperative Research Program Report 49.Transportation National Academy Press, Washington D.C. 20590.

Delucchi, M.A. (2000) Environmental Externalities of Motor-Vehicle Use in The US. Journal of Transport Economics and Policy, 34.2: 135-168.

FHWA (1997) Truck and Bus Crash Factbook 1995. Office of Motor Carriers, Federal Highway Administration, U.S. Department of Transportation, Washington D.C. 20590.

FTA (1997) Safety Management Information Statistics (SAMIS) 1995 Annual Report. Federal Transit Administration. Report No. FTA-MA-26-9033-91-1. U.S. Department of Transportation, Washington D.C. 20590. 


\section{Public Transit in Tennessee}

Gomez-Ibanez, J.A. (1997) Estimating Whether Transport Users pay Their Way: The State of The Art. In Greene, D.L., Jones D.W. and Delucchi, M.A. (Eds) (1997) The Full Costs and Benefits of Transportation. Springer-Verlag, New York.

Greene, D.L. , Jones D.W. and Delucchi, M.A. (Eds) (1997) The Full Costs and Benefits of Transportation. Springer-Verlag, New York.

Hearn, H.H. (1985) Impact analysis. A No-Transit Alternative. Jackson, Tennessee. Jackson Transit Authority, Jackson, TN 38301. March, 1985.

Horowitz, A.J. and Beimborn, E. (1995) Methods and Strategies For Transit Benefit Measurement. Transportation Research Record 1496 :9-16.

Jacobs, J (1992) The Death and Life of Great American Cities. Vintage Books, New York.

Leigh, Scott and Cleary, Inc. et al (1999) Transit Needs and Benefits Study. Final Report and Appendix to Final Report. Prepared for the Colorado Department of Transportation, Denver, CO 80222.

Leinbach, T.R., Watkins, J.F, and Stamatiadis, N. (1994) Transportation Services, Utilization and Needs of the Elderly in Non-Urban Kentucky. Report \# FTSA-KY-26-001. Federal Transit Administration, U.S. Department of Transportation, Washington D.C. 20590.

Lewis, D. and Williams, F.L. (1999) Policy and Planning as Public Choice. Mass transit in the United States. Ashgate, Brookfield, Vermont.

Litman, T. (1994) Transportation Cost Analysis: Techniques, Estimates and Implications. Victoria Transport Policy Institute, Victoria, British Columbia, Canada.(http://www.vtpi.org/)

Litman, T. (1999) Evaluating Public Transit Benefits and Costs. Victoria Transport Policy Institute, Victoria, British Columbia, Canada. (http://www.vtpi.org/)

Litman, T. (1999) Transportation Costs Analysis. Summary. Victoria Transport Policy Institute, Victoria, British Columbia, Canada. (http://www.vtpi.org/)

Louis Berger and Associates Inc (1998) Guidance for Estimating the Indirect Effects of Proposed Transportation Projects. National Cooperative Highway Research program Report 403. Transportation Research Board, National Academy Press, Washington D.C. 20418.

McCubbin, D.R. and Delucchi, M.A. (1999) The health costs of motor-vehicle-related air pollution. Journal of Transport Economics and Policy, 33.3: 253-286. 
Public Transit in Tennessee

Meyer, M. , Nelson, A.C. and Peng, Z-R (1999) Development of a Methodology to Evaluate the Economic Impacts of Rural Public Transportation on Georgia Counties. Report No. FHWAGA-99-930-9. Prepared for the Georgia Department of Transportation, Office of Materials and Research, Atlanta, GA 30334.

Miller, T.R. (1997) Societal Costs of Transportation Crashes. In The Full Costs and Benefits of Transportation. Greene, DL, Jones, D.W. and Delucchi, M. A. (Eds): 281-312.

Miller, T,R, and Moffet, J. (1993) The Price of Mobility. Natural Resources defense Council, Washington D.C.

Mohammedshah, Y.M. and Kohls, A.R. (1994) Accidents Rates Using HSIS. Public Roads, Summer 1994. (Available at http:/www.tfhrc.gov/pubrds/summer94/p94su44.htm)

Nadiri, M.I. and Mamuneas, T.P. (1996) Highway Capital and Productivity Growth, in Economic Returns from Transportation Investment. Eno Foundation, Inc., Landsdown, VA.

Nadiri, M.I. and Mamuneas, T.P. (1998)Contribution of Highway Capital to Output and Productivity Growth in the US Economy and Industries. August 1998. Report prepared for the Federal Highway Administration, U.S. Department of Transportation, Washington D.C. 20590. (Available at http://www.fhwa.dot.gov/policy/gro98cvr.htm)

NHTSA (1996) What Do Traffic Crashes Cost? Total Costs to Employers by State and Industry. National Highway Traffic Safety Administration, Report No. DOT-HS-808-478. U.S. Department of Transportation, Washington D.C. December, 1996.

Olds, J., Schwartz, R.S. and Webster, H. (1996) Overcoming Loneliness in Everyday Life. Carol Publishing Group, New York.

Parsons, Brinkerhoff, Quade and Douglas Inc. (1996) Transit and Urban Form. Transit Cooperative Research Program Report 16. Volume 2. Transportation Research Board, National Academy Press, Washington D.C. 20418.

Peng, Z-R and Nelson, A.C. (1998) Rural Transit Services. A Local Economic And Fiscal Impact Analysis. Transportation Research Record 1623: 57-62.

Smith, J.L. and Rieken, G. (1985) Ridership Survey and Analysis for the Johnson City Transit System. Report prepared by the East Tennessee State University for the Urban Mass Transit Administration and Tennessee Department of Transportation. 
Public Transit in Tennessee

Rowe, R.D., Bird, L., Epel, J. and Chestnut, L. (1996) Externality Benefits from Natural Gas Vehicles in New York. Report prepared for the New York Gas Group., by Hagler-Bailly Consulting Inc., New York.

SG Associates Inc., et al (1995) Workbook for Estimating Demand for Rural Passenger Transportation. Transit Cooperative Research Program Report 3. Transportation Research Board, National Academy Press, Washington D.C. 20418.

Skolnik, J. and Schreiner, R. (1998) Benefits of Transit In Small Urban Areas. A Case Study. Transportation Research Record 1623: 47-56.

Southworth, F. and Jones D.W. (1996) Travel Reduction Through Changes in Urban Spatial Structure: A Search for Policy Instruments in Support of Cleaner, More Energy Efficient Cities. Office of Policy, Planning and Program Evaluation. U.S. Department of Energy, Washington D.C. 20585.

Strathman, J. and Dueker, K. (1987) Regional Economic Impacts of Local Transit Financing Alternatives: Input-Output Results for Portland. Transportation Research Record 1116: 40-48.

Tessmer, J. .M. (1996) Rural and Urban Crashes - A Comparative Analysis. Report No. DOT HS-808 450. National Highway Traffic Safety Administration, U.S. Department of Transportation, Washington D.C. August 1996.

Wegmann, F.J., Chatterjee, A., Parnell, S., and Welch, G.L. (1979) Impact of the 1977 Transit Strike in Knoxville. Transportation Research Record 719: 6-13.

Wegmann, F.J., Chatterjee, A. and Vople, R. (1992) Cost-Effective Public Transportation for Small Urban Areas. Southeastern Transportation Center Document. Prepared by the University of Tennessee at Knoxville, August 1992.

US DOT (1997) Improving Transportation for a Maturing Society. Office of the Assistant Secretary for Transportation Policy. January, 1997. Report \# DOT-P10-97-01. US Department of Transportation, Washington D.C.. 20590.

\section{B. Ridership and Population Forecasting References.}

Chattanooga Urban Area Metropolitan Planning Organization (2000) Transplan25. Long-Range Transportation Plan 2025. Chattanooga Hamilton County Regional Planning Agency. Chattanooga, TN 37402. June 2000. 
Public Transit in Tennessee

Marshment, R. and Wedel, K. (1999) The Impacts of Welfare Reform on Rural Public Transportation. Mack-Blackwell Transportation Center, University of Arkansas, Fayetteville, December.

Murray, M. N. (1999) Population Projections for Tennessee Counties and Municipalities. 20002020. Center for Business and Economic Research, University of Tennessee, Knoxville, TN 37996. March 1999.

Painter, K.M. and Casavant, K.L. (1998) Demand forecasting for rural transit. Technical Report. Research Project T9902. Report prepared for the Washington State Transportation Commission, Washington Department of Transportation by Washington State University, Pullman, WA 99164.

Polzin, S.E., Rey, J.R. and Chu, X. (1998) Public Transit in America: Findings from the 1995 Nationwide Personal Transportation Survey. Center for Urban Transportation Research, University of South Florida, Tampa, Fl 33620.

Pratt, R.H. (2001) Traveler response to transportation changes. New insights from the revised handbook. Transportation Research News 212: 9-14.

Rosenbloom, S. and Fileding, G.J. (1998) Transit Markets of the Future. The Challenge of Change. Transit Cooperative Research Program Report 28.Transportation Research Board, National Research Council, Washington D.C. 20418.

TRB (1983) Planning Transportation Services For Handicapped Persons. User's Guide. National Cooperative Highway Research Report 262. Transportation Research Board. National Academy Press, Washington D.C. 20418.

TRB (1998) Travel Estimation Techniques for Urban Planning. National Cooperative Highway Research Report 365. Transportation Research Board. National Academy Press, Washington D.C. 20418.

TRB Conference (2000) "Interregional Transit Performance Analysis: A California Perspective." Paper presented at the 14th National Transportation Research Board Conference on Rural Public and Intercity Bus Transportation, Lake Tahoe, Nevada, November 13.

Pigeon Forge Department of Tourism (1990) "Totally Tourism." Pigeon Forge, Tennessee.

Reid, J. (2000) "Oregon's Mobility Needs Study: Three Surveys to Determine Transportation Needs and Resources." Paper prepared by the Oregon Department of Transportation Research Group, Salem Oregon, November. 


\section{Public Transit in Tennessee}

SG Associates, Inc. (1995). Workbook for Estimating Demand for Rural Passenger Transportation, Transit Cooperative Research Program Report 3. Transportation Research Board, National Academy Press, Washington, D.C.

Stoner, E. (1994) Evaluation of the Gatlinburg, Tennessee Trolley Service as It Impacts the Local Transportation System. Thesis, The University of Tennessee, Knoxville. 
Public Transit in Tennessee

Appendix.

Table A1. List of Tennessee Counties Within Each Rural Transit District.

\begin{tabular}{|c|c|c|c|}
\hline FIPS & County Name & \multicolumn{2}{|c|}{ Rural Transit District } \\
\hline 47097 & Lauderdale, TN & DHRA & Delta Human Resources Agency \\
\hline 47157 & Shelby, TN & DHRA & \\
\hline 47167 & Tipton, TN & DHRA & \\
\hline 47047 & Fayette, TN & DHRA & \\
\hline 47039 & Decatur, TN & SWHRA & Southwest Human Resources Agency \\
\hline 47071 & Hardin, TN & SWHRA & \\
\hline 47075 & Haywood, TN & SWHRA & \\
\hline 47077 & Henderson, TN & SWHRA & \\
\hline 47113 & Madison, TN & SWHRA & \\
\hline 47069 & Hardeman, TN & SWHRA & \\
\hline 47023 & Chester, TN & SWHRA & \\
\hline 47109 & McNairy, TN & SWHRA & \\
\hline 47005 & Benton, TN & NWTHRA & Northwest Tennessee Human Resources Agency \\
\hline 47079 & Henry, TN & NWTHRA & \\
\hline 47033 & Crockett, TN & NWTHRA & \\
\hline 47053 & Gibson, TN & NWTHRA & \\
\hline 47131 & Obion, TN & NWTHRA & \\
\hline 47045 & Dyer, TN & NWTHRA & \\
\hline 47095 & Lake, TN & NWTHRA & \\
\hline 47017 & Carroll, TN & NWTHRA & \\
\hline 47183 & Weakley, TN & NWTHRA & \\
\hline 47149 & Rutherford, TN & MCHRA & Mid-Cumberland Human Resources Agency \\
\hline 47021 & Cheatham, TN & MCHRA & \\
\hline 47037 & Davidson, TN & MCHRA & \\
\hline 47147 & Robertson, TN & MCHRA & \\
\hline 47187 & Williamson, TN & MCHRA & \\
\hline 47043 & Dickson, TN & MCHRA & \\
\hline 47083 & Houston, TN & MCHRA & \\
\hline 47085 & Humphreys, TN & MCHRA & \\
\hline 47125 & Montgomery, TN & MCHRA & \\
\hline 47161 & Stewart, TN & MCHRA & \\
\hline 47165 & Sumner, TN & MCHRA & \\
\hline 47189 & Wilson, TN & MCHRA & \\
\hline 47169 & Trousdale, TN & MCHRA & \\
\hline 47003 & Bedford, TN & SCTDD & South Central Tennessee Development District \\
\hline 47031 & Coffee, TN & SCTDD & \\
\hline 47051 & Franklin, TN & SCTDD & \\
\hline 47081 & Hickman, TN & SCTDD & \\
\hline 47101 & Lewis, TN & SCTDD & \\
\hline 47117 & Marshall, TN & SCTDD & \\
\hline 47119 & Maury, TN & SCTDD & \\
\hline 47135 & Perry, TN & SCTDD & \\
\hline 47055 & Giles, TN & SCTDD & \\
\hline 47099 & Lawrence, TN & SCTDD & \\
\hline 47181 & Wayne, TN & SCTDD & \\
\hline
\end{tabular}


Public Transit in Tennessee

Table 1 Continued...

47103 Lincoln, TN

47127 Moore, TN

47007 Bledsoe, TN

47107 McMinn, TN

47121 Meigs, TN

47143 Rhea, TN

47011 Bradley, TN

47115 Marion, TN

47153 Sequatchie, TN

47061 Grundy, TN

47139 Polk, TN

47065 Hamilton, TN

47015 Cannon, TN

47041 De Kalb, TN

47111 Macon, TN

47159 Smith, TN

47175 Van Buren, TN

47177 Warren, TN

47035 Cumberland, TN

SCTDD

SCTDD

SETHRA Southeast Tennessee Human Resources Agency

SETHRA

SETHRA

SETHRA

SETHRA

SETHRA

SETHRA

SETHRA

SETHRA

HAMILTON CO Hamilton County

UCHRA

Upper Cumberland Human Resources Agency

UCHRA

UCHRA

UCHRA

UCHRA

UCHRA

UCHRA

UCHRA

47137 Pickett, TN UCHRA

47027 Clay, TN UCHRA

47133 Overton, TN UCHRA

47141 Putnam, TN UCHRA

47185 White, TN UCHRA

47087 Jackson, TN UCHRA

47009 Blount, TN ETHRA

47025 Claiborne, TN

ETHRA

$\begin{array}{lll}47093 & \text { Knox, TN } & \text { ETHRA } \\ 47173 & \text { Union, TN } & \text { ETHRA }\end{array}$

47105 Loudon, TN ETHRA

47123 Monroe, TN ETHRA

47145 Roane, TN ETHRA

47001 Anderson, TN ETHRA

47129 Morgan, TN ETHRA

47151 Scott, TN ETHRA

47013 Campbell, TN ETHRA

47155 Sevier, TN ETHRA

47029 Cocke, TN ETHRA

47057 Grainger, TN ETHRA

47063 Hamblen, TN ETHRA

47089 Jefferson, TN ETHRA

47067 Hancock, TN

47091 Johnson, TN

47059 Greene, TN

47073 Hawkins, TN

HANCOCK CO Hancock County

FTHRA First Tennessee Human Resources Agency

FTHRA

FTHRA

FTHRA

FTHRA

$\begin{array}{lll}47171 & \text { Unicoi, TN } & \text { FTHRA } \\ 47179 & \text { Washington, TN } & \text { FTHRA }\end{array}$

East Tennessee Human Resources Agency

47019 Carter, TN 